\title{
Oxylipinstoffwechsel in Physcomitrella patens
}

\author{
Dissertation \\ zur Erlangung des Doktorgrades \\ der Mathematisch-Naturwissenschaftlichen Fakultäten \\ der Georg-August-Universität zu Göttingen
}

vorgelegt von

Kristin Sauer

aus Schwerin

Göttingen 2010 
D 7

Referent:

Prof. Dr. Ivo Feußner

Ko-Referent:

Prof. Dr. Ralf Ficner

Tag der mündlichen Prüfung: 
„, Geh nicht nur die glatten Straßen. Geh Wege, die noch niemand ging, damit du Spuren hinterlässt und nicht nur Staub. “

-Antoine de Saint-Exupéry- 


\section{INHALTSVERZEICHNIS}

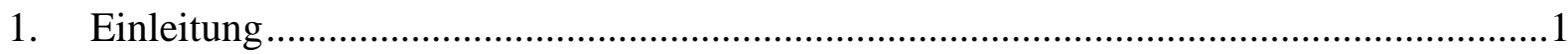

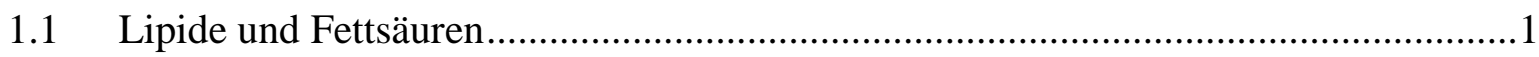

1.2 Oxylipine

1.2.1 Vorkommen, Biosynthese und Funktion von Oxylipinen in Säugetieren ............2

1.2.2 Vorkommen und Funktion von Oxylipinen in Blütenpflanzen ...........................3

1.2.3 Biosynthese von JA und Zyklopentenonen in Blütenpflanzen ...........................6

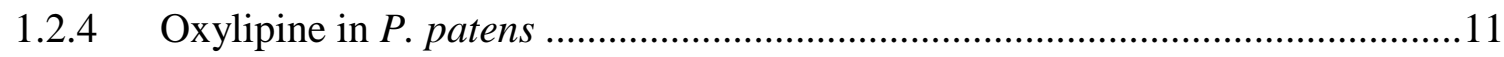

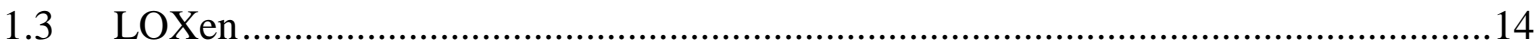

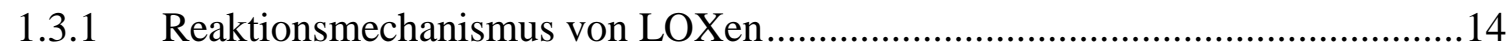

1.3.2 Mutagenesestudien zur Spezifität verschiedener LOXen ................................16

1.3.3 Theorien zur Positionsspezifiät verschiedener LOXen .................................... 18

1.3.4 Die Enzymfamilie in Blütenpflanzen und Säugetieren...................................18

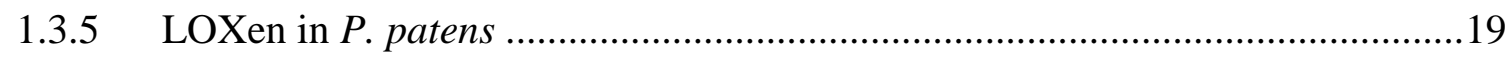

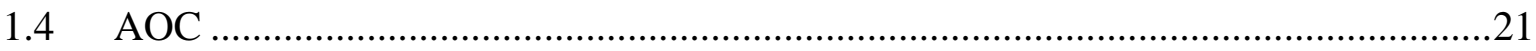

1.4.1 Struktur und Reaktionsmechanismus der AOC …........................................22

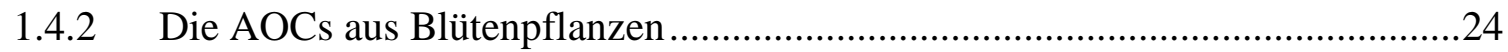

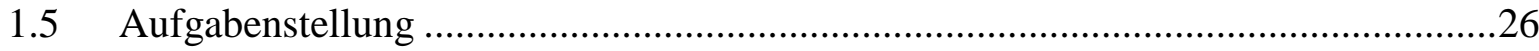

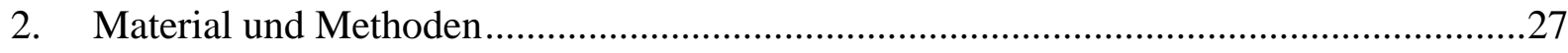

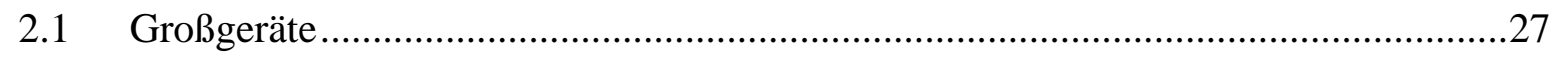

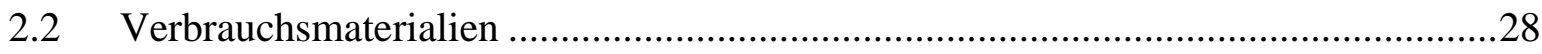

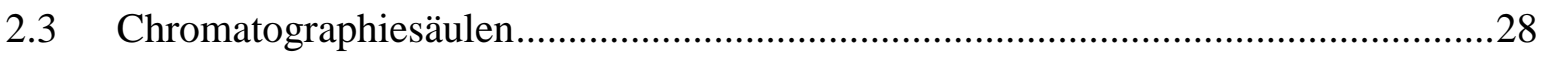

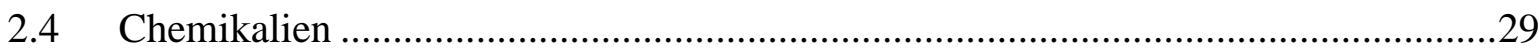

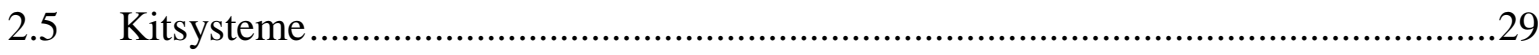

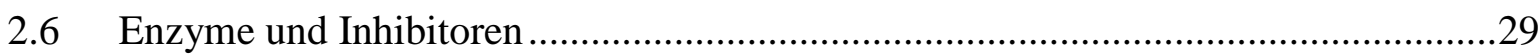

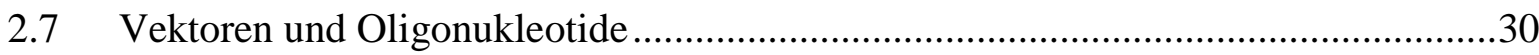

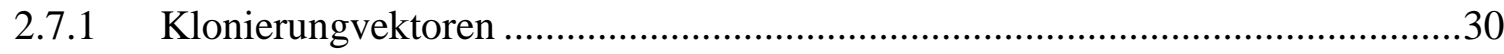




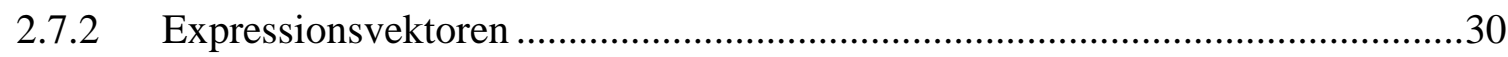

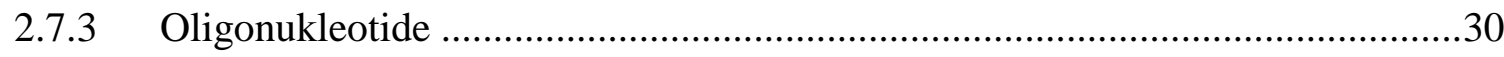

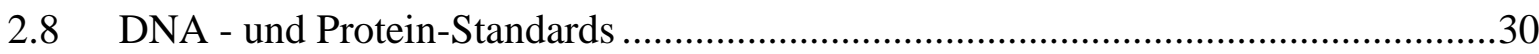

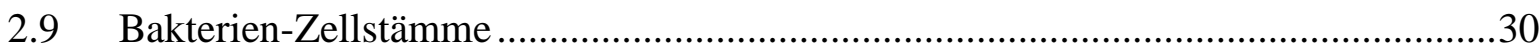

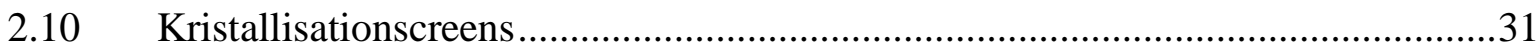

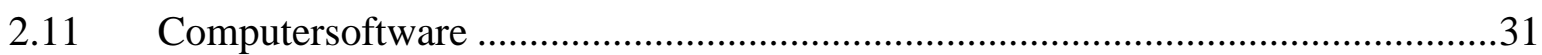

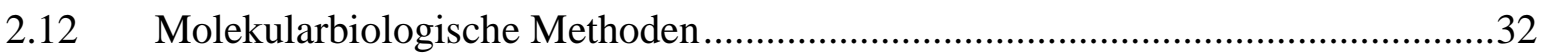

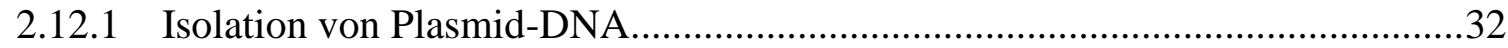

2.12.2 Amplifikation von DNA-Fragmenten durch Polymerase-Kettenreaktion (PCR)...

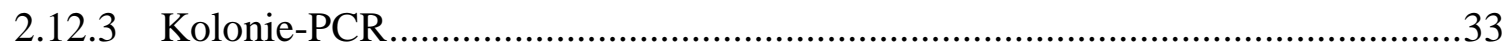

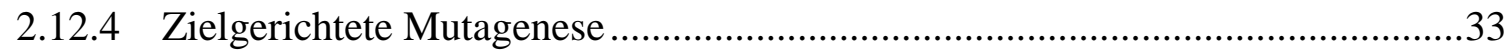

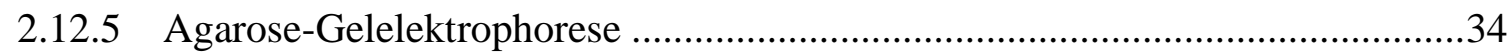

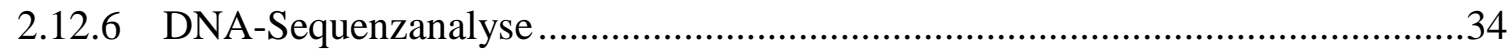

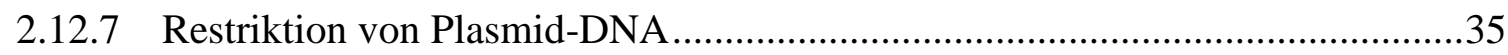

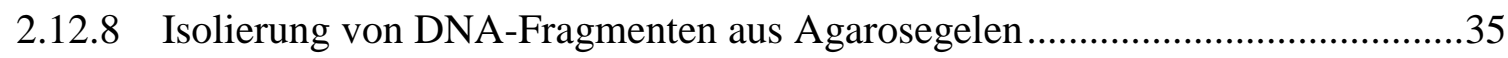

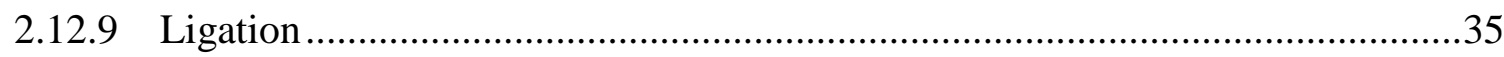

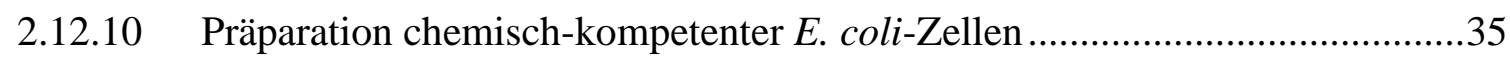

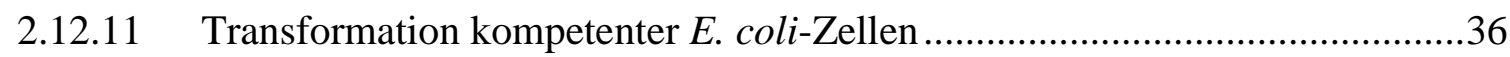

2.13 Strategien zur Klonierung rekombinanter Plasmide für die Expression ................36

2.13.1 Klonierung von PpAOC1 und PpAOC2 in den pGEX-6-P-1 Vektor .................36

2.13.2 Zielgerichtete Mutagenese von PpAOC1 und PpAOC2 ...................................37

2.13.3 Klonierung von $P p L O X 1$ in verschiedene Vektoren des pET-Systems..............38

2.13.4 Herstellung von $P p L O X 1$ ohne Signalpeptid ( $\triangle P p L O X 1)$...............................39

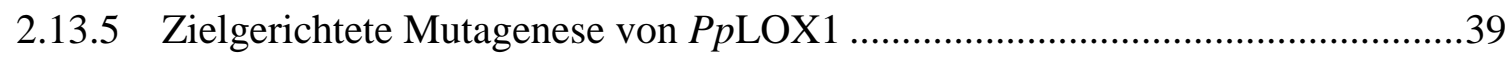

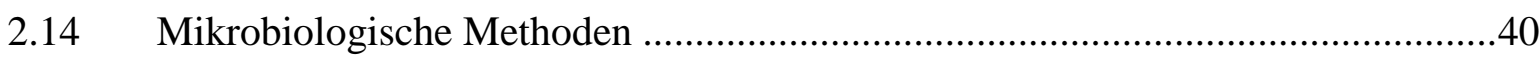

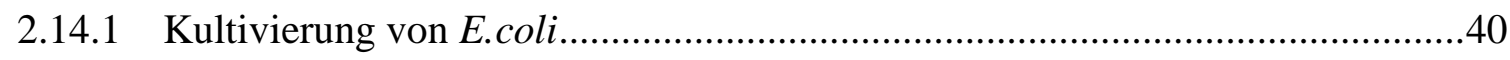

2.14.2 IPTG-induzierte Proteinexpresion in E.coli.......................................................4 


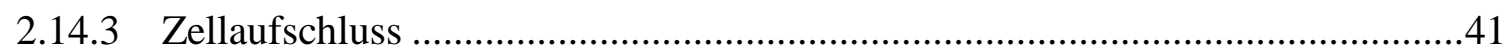

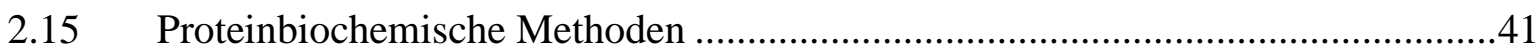

2.15.1 Affinitätschromatographie über Glutathion-Sepharose .................................41

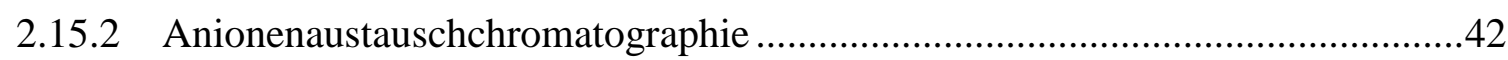

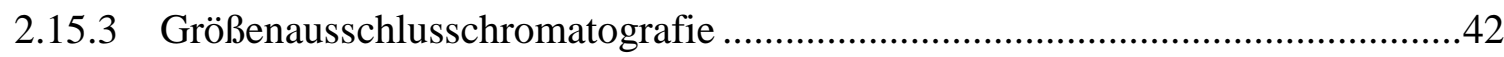

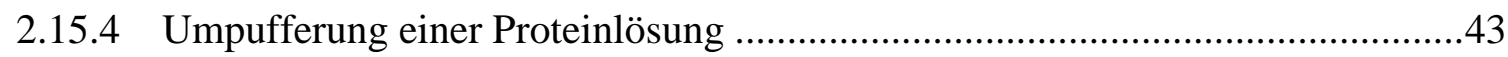

2.15.5 Diskontinuierliche SDS-PAGE, modifiziert nach Laemmli (Laemmli, 1970) ...43

2.15.6 Proteinbestimmung nach Bradford (1976) ......................................................44

2.15.7 Western-Blot Analyse und Immunodetektion ..............................................44

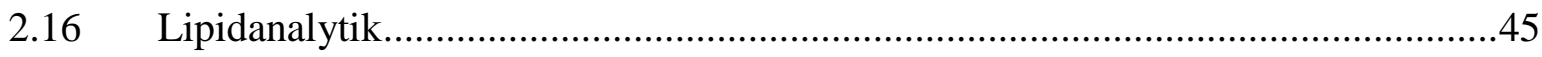

2.16.1 Herstellung von Hydroperoxy-Fettsäurederivaten........................................45

2.16.2 Gekoppelter PpAOS/PpAOC-Aktivitätstest..................................................46

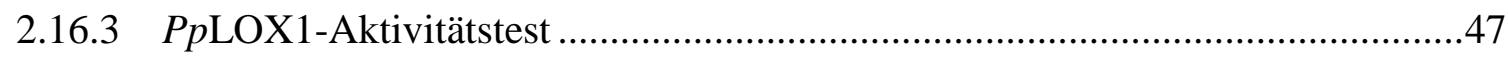

2.16.4 Hochleistungs-Flüssigkeitschromatographie (HPLC) ...................................47

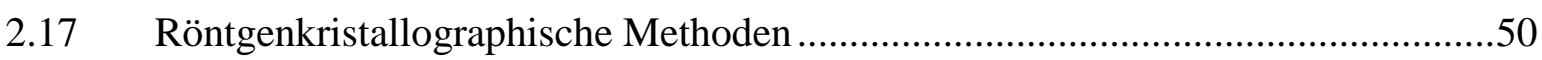

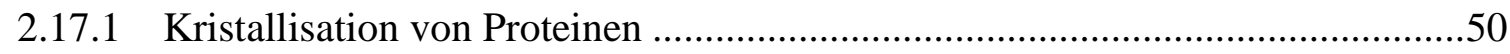

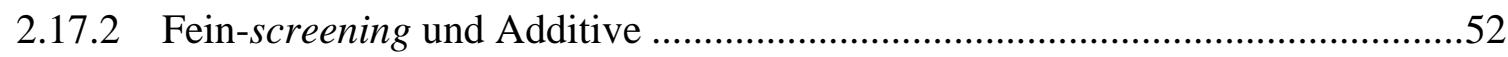

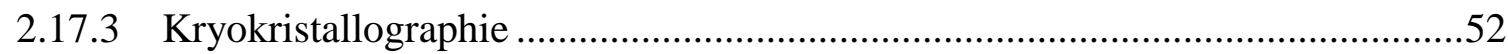

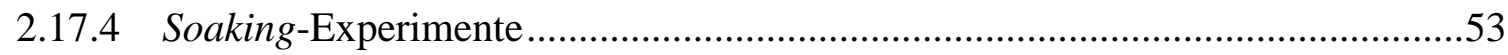

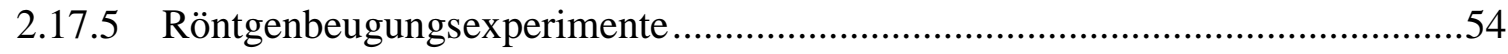

2.18 Testen von Kristallen und Strategie zur Aufnahme von Datensätzen .....................55

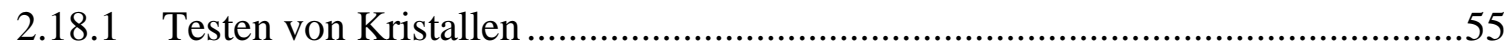

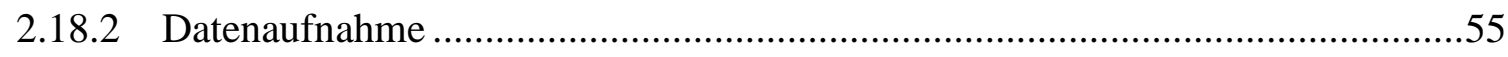

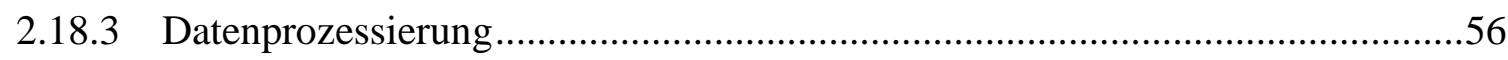

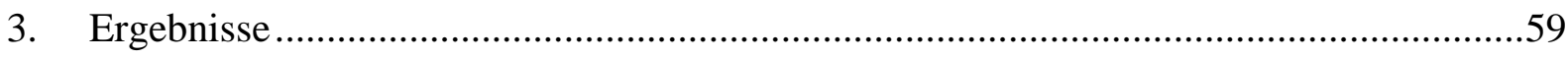

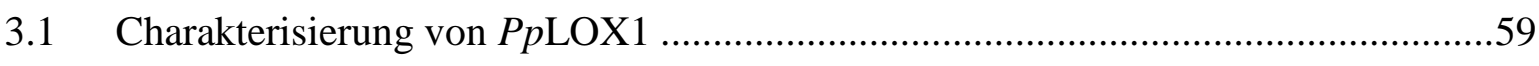

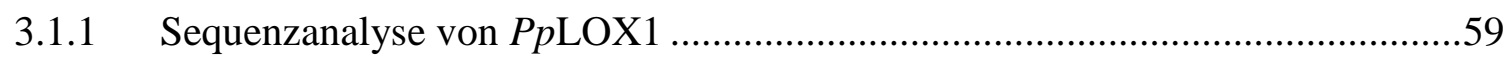


3.1.2 Untersuchung des Produktspektrums von $P p L O X 1$ und ihren Varianten durch

Umsetzung verschiedener Fettsäuresubstrate .63

3.2 Biochemische Charakterisierung von PpAOC1 und PpAOC2 ................................70

3.2.1 Klonierung und Expression von PpAOC1 und PpAOC2 .................................70

3.2.2 Reinigung von rekombinanter PpAOC1 und PpAOC2 ..................................70

3.2.3 Ko-Expression von PpAOC1 und PpAOC2 in E. coli .....................................75

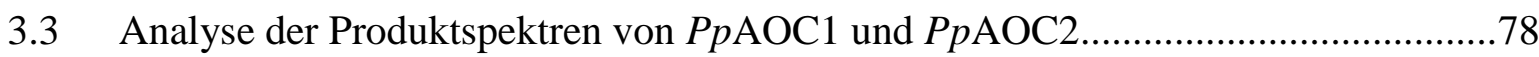

3.3.1 Die Umsetzung von 12-Hydroperoxy-Fettsäuren ............................................79

3.3.2 Die Umsetzung von 15-Hydroperoxy-Fettsäuren .........................................82

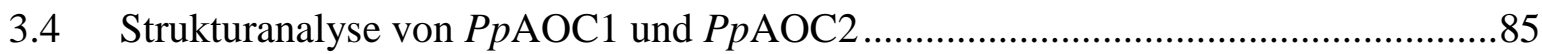

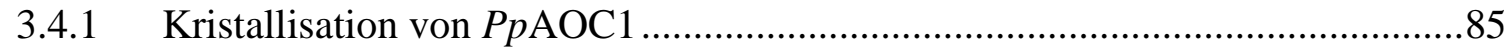

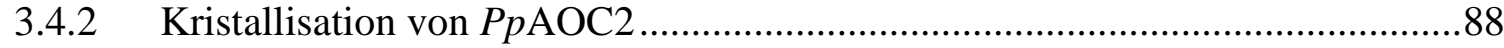

3.4.3 Datenaufnahme und Datenprozessierung von PpAOC1 und PpAOC2 2.............90

3.4.4 Phasenbestimmung durch molekularen Ersatz und Verfeinerung der Daten .....93

3.4.5 Die dreidimensionale Proteinstruktur von PpAOC1 und PpAOC2 .................100

3.4.6 Dreidimensionale Proteinstruktur von PpAOC1 mit 12,13-EOD ${ }^{9 \mathrm{Z} 15 \mathrm{Z}}$ im aktiven

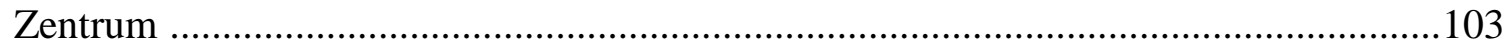

3.4.7 Dreidimensionale Proteinstruktur von PpAOC2 mit $12,13-\mathrm{EOD}^{\triangle 9 Z \Delta 15 Z} \mathrm{im}$

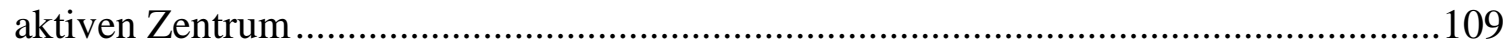

3.4.8 Vergleich der Proteinstrukturen von PpAOC1 und PpAOC2 ..........................119

3.4.9 Ortsgerichtete Mutagenese von PpAOC1 und PpAOC2 ...............................121

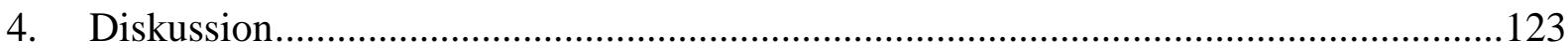

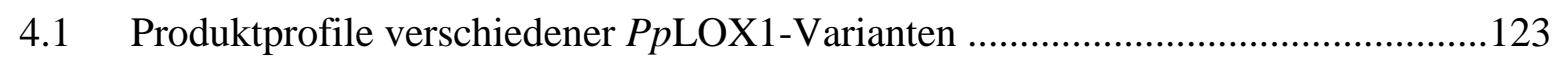

4.2 Umsetzung von verschiedenen Hydroperoxy-Fettsäuren durch PpAOC1 und

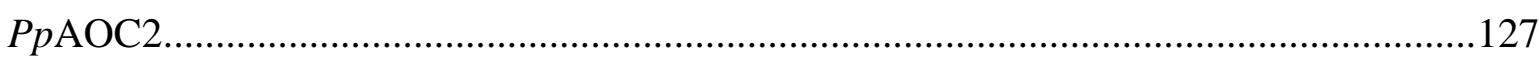

4.2.1 OPDA und Phytoprostane als Signalmolekül in P. patens? ...........................130

4.3 Die Kristallstrukturen von PpAOC1 und PpAOC2 ..........................................133

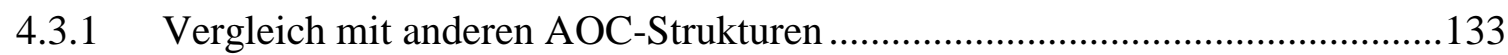

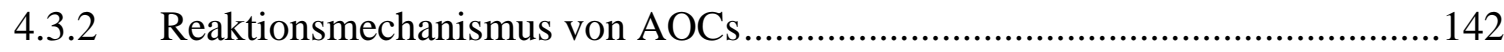




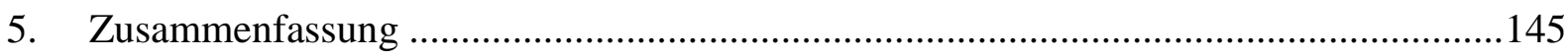

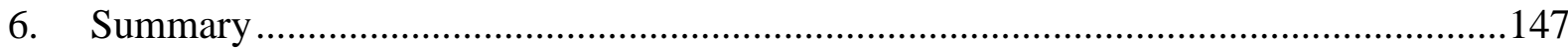

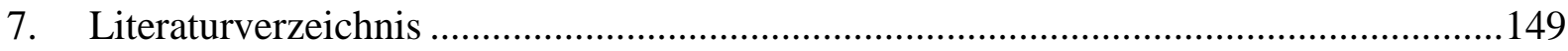

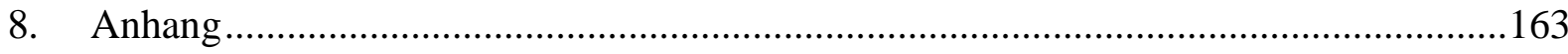

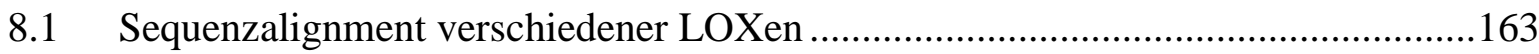

8.2 Datensammlung der PpAOC1- und PpAOC2-Strukturen .....................................165

8.3 Verfeinerungsstatistiken der PpAOC1- und PpAOC2-Strukturen ..........................166

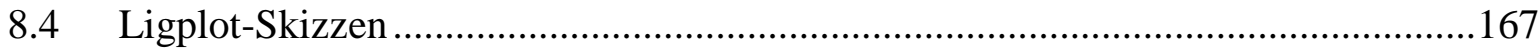

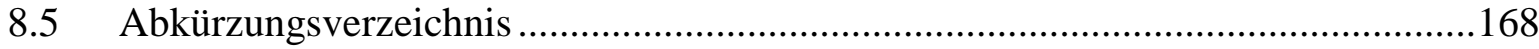

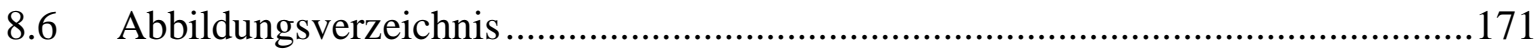

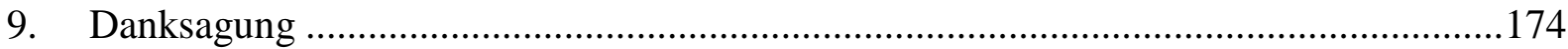




\section{EINLEITUNG}

Die vorliegende Dissertation beschäftigt sich mit der Charakterisierung von Enzymen des Oxylipinstoffwechsels im Laubmoos Physcomitrella patens. Moose gehören zu den Embryophyten (Landpflanzen), deren älteste gemeinsame Vorfahren sich im Zuge der Besiedlung des terrestrischen Lebensraum evolutiv von den Grünalgen getrennt haben (Rensing et al., 2008). Aus den gemeinsamen Vorläufern der heutigen Embryophyten entwickelten sich vor ca. 450 Millionen Jahren die heutigen Samenpflanzen, die Farne und die Moose. Die verschiedenen Moosklassen besetzen somit ideale phylogenetische Positionen um evolutionsbiologische Entwicklungen des Lipid- und Oxylipinstoffwechsels im Hinblick auf die Anpassung der Landpflanzen an ihren Lebensraum zu untersuchen. Im folgenden Abschnitt werden zunächst die Eigenschaften und Funktionen von Lipiden und Fettsäuren behandelt.

\subsection{Lipide und Fettsäuren}

Lipide sind hydrophobe Biomoleküle und ein wesentlicher Bestandteil aller lebenden Zellen. Die Hydrophobizität von Lipiden basiert auf dem Vorkommen aliphatischer Kohlenstoffketten in Form z. B. von Fettsäuren in Phospho- und Glykolipiden oder der Kohlenwasserstoffkette des Sphingosins in den Sphingolipiden. Zum Beispiel ist ein Phosphoglyzerid aus einem Glyzerinrückgrat, zwei Fettsäureketten und einem

phosphoryliertem Alkohol aufgebaut. Die langkettigen Fettsäuren in Phospho- und Glykolipiden enthalten hauptsächlich zwischen 14 und 24 Kohlenstoffatome und können gesättigt oder ungesättigt vorliegen. In tierischen Zellen liegen die Kohlenwasserstoffketten unverzweigt vor und haben meist eine Länge von $C_{16}$ bis $C_{20}$. Dabei haben die Zahl der Doppelbindungen und die Länge der Fettsäuren eine große Bedeutung für die Membranfluidität. Lipide dienen als hochangereicherte Kohlenstoff- und Energiespeicher und sind wichtige Strukturelemente der biologischen Membranen. Membranbildende Lipide haben ein wichtiges gemeinsames Strukturmerkmal, sie besitzen einen hydrophilen und einen hydrophoben Anteil und sind somit amphipathische Moleküle. Damit sind sie zur Ausbildung sogenannter Lipiddoppelschichten befähigt, der Hauptkomponente biologischer Membranen. Die Hauptgruppen der Membranlipide sind Phospholipide, Glykolipide und das nichtamphipathische Cholesterin. Phospholipide leiten sich entweder von Glyzerin (Phosphoglyzeride) oder Sphingosin (Sphingomyelin) ab. Biomembranen sind 
hochorganisierte Aggregate, die zum großen Teil aus Lipiden und Proteinen bestehen. Sie bilden hochselektive Permeabilitätsschranken und grenzen somit Zellen und Zellorganellen von ihrer Umgebung ab (Berg et al., 2004).

\subsection{Oxylipine}

Darüber hinaus kommt einigen Lipiden eine wichtige Bedeutung als Signalmoleküle (Wang et al., 2006, Xue et al., 2007) zu. In dieser Arbeit sollten vor allem die oxidierten Formen ungesättigter Fettsäuren behandelt werden, die Oxylipine genannt werden. Diese Fettsäurederivate spielen eine wichtige Rolle in Signal- und Abwehrprozessen von Säugetieren (Kühn \& Thiele, 1999) und Pflanzen (Schilmiller \& Howe, 2005, Wasternack, 2007).

Während Oxylipine in Säugetieren hauptsächlich Schlüsselaufgaben bei Entzündungsreaktionen, Fieber und bei der Antwort auf Allergien haben (Smith et al., 2000), spielen sie in Pflanzen eine bedeutende Rolle in verschiedenen Entwicklungsprozessen sowie bei Reaktionen auf biotischen und abiotischen Stress (Blée, 2002, Feussner \& Wasternack, 2002). Die Oxidation mehrfach ungesättigter Fettsäuren stellt also eine wichtige und häufige Reaktion in der Lipidumwandlung in Pflanzen dar (Müller, 2004). Die Lipidoxidation geschieht entweder durch nichtenzymatische Autooxidation oder durch enzymkatalysierte Reaktionen, an denen Lipoxygenasen (LOX) oder Dioxygenasen ( $\alpha$-DOXen) beteiligt sind (Brash, 1999).

Da zur Funktion und Biosynthese von Oxylipinen in Blütenpflanzen, Tieren und Pilzen umfassende Studien vorliegen, werden zunächst diese Prozesse separat vorgestellt damit sie miteinander verglichen werden können.

\subsubsection{Vorkommen, Biosynthese und Funktion von Oxylipinen in Säugetieren}

Die wichtigste Gruppe von Oxylipinen in Säugetieren stellen Eikosanoide $\left(\mathrm{C}_{20}\right.$-Lipide $)$ dar, zu denen die Leukotriene und die Prostaglandine (z. B. Prostazyklin und Thromboxan) zählen (Funk, 2001). Weil es sich um kurzlebige Verbindungen handelt, werden Eikosanoide auch als „lokale Hormone“ bezeichnet (Schneider et al., 2007b). In Säugetieren werden zusätzlich $\mathrm{zu}$ den $\mathrm{C}_{18}$-Fettsäuresubstraten Linolsäure $\left(18: 2^{\Delta 9 Z \Delta 12 Z}\right.$, LA) und $\alpha$-Linolensäure (18:3 $3^{\Delta 9 Z \Delta 12 Z \Delta 15 Z}$, ALA), die $C_{20}$ und $C_{22}$-Fettsäuren Arachidonsäure (20:4 ${ }^{\triangle 5 Z \Delta 8 Z \Delta 11 Z \Delta 14 Z}$, AA), Eikosapentensäure (20:5 $5^{\Delta 5 Z \Delta Z \Delta \Delta 11 Z \Delta 14 Z \Delta 17 Z}$, EPA) Eikosatriensäure $\left(20: 3^{\Delta 11 Z \Delta 14 Z \Delta 14 Z}\right.$, ETA) und Docosahexaensäure (22:6 $6^{\Delta 4 Z \Delta 7 Z \Delta 10 Z \Delta 13 Z \Delta 16 Z \Delta 19 Z}$, DHA) für die Oxylipinbiosynthese verwendet. Die Fettsäure AA ist jedoch bei der Eikosanoidbiosynthese die wichtigste Vorstufe. Die Eikosanoidbiosynthese findet in nahezu allen tierischen Organen, Geweben und Zellen statt. 
AA wird zuerst aus den Phospholipiden der Plasmamembran durch entsprechende Phospholipasen (v. a. des A2-Typs = PLA2) freigesetzt. Extrazelluläre Signale wie Hormone, Neurotransmitter, Stressfaktoren, Umweltreize u. a. können zu einer Aktivierung der zytoplasmatischen PLA2 führen. Die so freigesetzte Arachidonsäure kann dann enzymatisch in verschiedene Oxylipine überführt werden. Durch Cyclooxygenasen (COX-1 und COX-2) werden die Prostaglandine und durch Lipoxygenasen (LOX) u. a. die Leukotriene gebildet (Funk, 2001).

Prostaglandine enthalten einen charakteristischen fünfgliedrigen Ring und sind lokal wirkende Hormone, die Entzündungsreaktionen wie Schmerz, Blutgefäßerweiterung und Fieber stimulieren. Desweiteren regulieren sie den Blutfluss $\mathrm{zu}$ bestimmten Organen, kontrollieren den Ionentransport durch Membranen und lösen den Schlaf aus. Auf der anderen Seite sind Leukotriene azyklische AA-Derivate, die funktionelle Gruppen wie Epoxy- oder Hydroxygruppen enthalten. Leukotriene entstehen bei der Umsetzung von AA durch eine 5LOX und ihnen wird eine wichtige Rolle in entzündlichen und allergischen Reaktionen zugeschrieben (Funk, 2001).

\subsubsection{Vorkommen und Funktion von Oxylipinen in Blütenpflanzen}

Pflanzen müssen sowohl auf Temperaturänderungen, Lichtqualität, UV-Licht, mechanische Belastungen, Vorhandensein von Wasser als auch osmotischen Stress, Verwundung und Pathogenbefall reagieren (Schaller, 2001, Browse, 2005, Lorenzo \& Solano, 2005, Wasternack, 2007). Im Laufe ihrer Evolution haben Landpflanzen verschiedene physische und chemische Barrieren entwickelt, z. B. die Kutikula, epidermale Dornen, Nesselhaare und für Pathogene oder Herbivore toxische Verbindungen. Denn trotz der Tatsache, dass Pflanzen im Gegensatz zu Tieren, weder über ein Immun- noch ein Nervensystem verfügen, sind sie befähigt sich gegen Herbivoren und Pathogene zu verteidigen. Zudem entwickelten Pflanzen komplexe induzierbare Abwehrmechanismen, um auf Veränderungen in ihrer Umwelt zu reagieren. Diese Systeme erfordern die Wahrnehmung äußerer Stressbedingungen, die Übersetzung dieser Stimuli in interne Signale und als Konsequenz die geeignete Anpassung der Genexpression über spezifische Signaltransduktion-Kaskaden. Hinsichtlich der induzierbaren Antwortmechanismen von Pflanzen spielen Oxylipine und v. a. die Vorstufen der Jasmonsäure (JA; Grechkin, 1998), die Oktadekanoide, eine entscheidende Rolle. Als Oktadekanoide werden oxidierte Derivate ungesättigter Oktadekansäuren bezeichnet, wobei Linolsäure und $\alpha$-Linolensäure in Pflanzenmembranen am häufigsten vorkommen (Conconi et al., 1996). Mehrfach ungesättigte $\mathrm{C}_{20}$-Fettsäuren, die in Säugetieren als Vorstufen der Prostaglandin- und Leukotriensynthese (1.2.1) fungieren, fehlen jedoch in den meisten 
Blütenpflanzen. In Blütenpflanzen wurden dagegen diverse andere Oxylipine nachgewiesen. Darunter befinden sich Fettsäure-Hydroperoxide, Hydroxy-, Oxo-, Epoxy- oder Ketofettsäuren, Divinylether, Aldehyde und die Pflanzenhormone 12-Oxophytodiensäure (OPDA), (Wasternack, 2007) und JA (Grechkin, 1998). Die Biosynthese der meisten pflanzlichen Oxylipine beginnt mit der Reaktion einer LOX, welche molekularen Sauerstoff entweder an der C9- oder C13-Position einer $\mathrm{C}_{18}$-Fettsäure einführt (Abbildung 1.4) (Feussner \& Wasternack, 2002). Eine detaillierte Beschreibung der Funktionen von LOXen wird in Abschnitt 1.3 dieser Arbeit erfolgen.

Die durch LOXen gebildeten Fettsäure-Hydroperoxide werden in Pflanzen schnell durch weitere Enzyme metabolisiert und führen somit zu einer Fülle der oben aufgeführten Oxylipine (Blée, 2002). Bisher sind sieben verschiedene Enzyme bekannt, welche die durch LOXen gebildete Fettsäure-Hydroperoxide metabolisieren. Zu ihnen zählen EpoxyalkoholSynthasen (EAS) und Peroxygenasen (PXG). Neben diesen Stoffwechselschritten kommt der Umsetzung der Hydroperoxide durch die CYP74-Superfamilie der Cytochrom-P450-Enzyme eine große Bedeutung zu. $\mathrm{Zu}$ diesen Enzymen gehören die Allenoxidsynthase (AOS), die Hydroperoxidlyase (HPL) und die Divinylethersynthase (DES; Stumpe \& Feussner, 2006). Diese Enzyme bilden Verzweigungspunkte im LOX-Reaktionsweg, welche zur Synthese von Pflanzenhormonen (JA) bzw. hormonähnlichen Substanzen (Traumatin), Phytoalexinen (Aldehyde, Divinylether) und Oxylipinen mit reaktiven Epoxyd- oder $\alpha, \beta$-ungesättigten Carbonylgruppen führen (Feussner \& Wasternack, 2002). Verschiedene Stoffwechselwege der Oxylipinsynthese in Pflanzen sind in Abbildung 1.1 dargestellt.

Neben diesen beschriebenen Reaktionen, kann $\alpha$-DOX die enantioselektive 2Hydroperoxidierung langkettiger ungesättigter Fettsäuren katalysieren, welches zur Bildung weiterer, in die Pathogenabwehr involvierter, Oxylipine führt (Hamberg et al., 1999, Hamberg et al., 2005). 


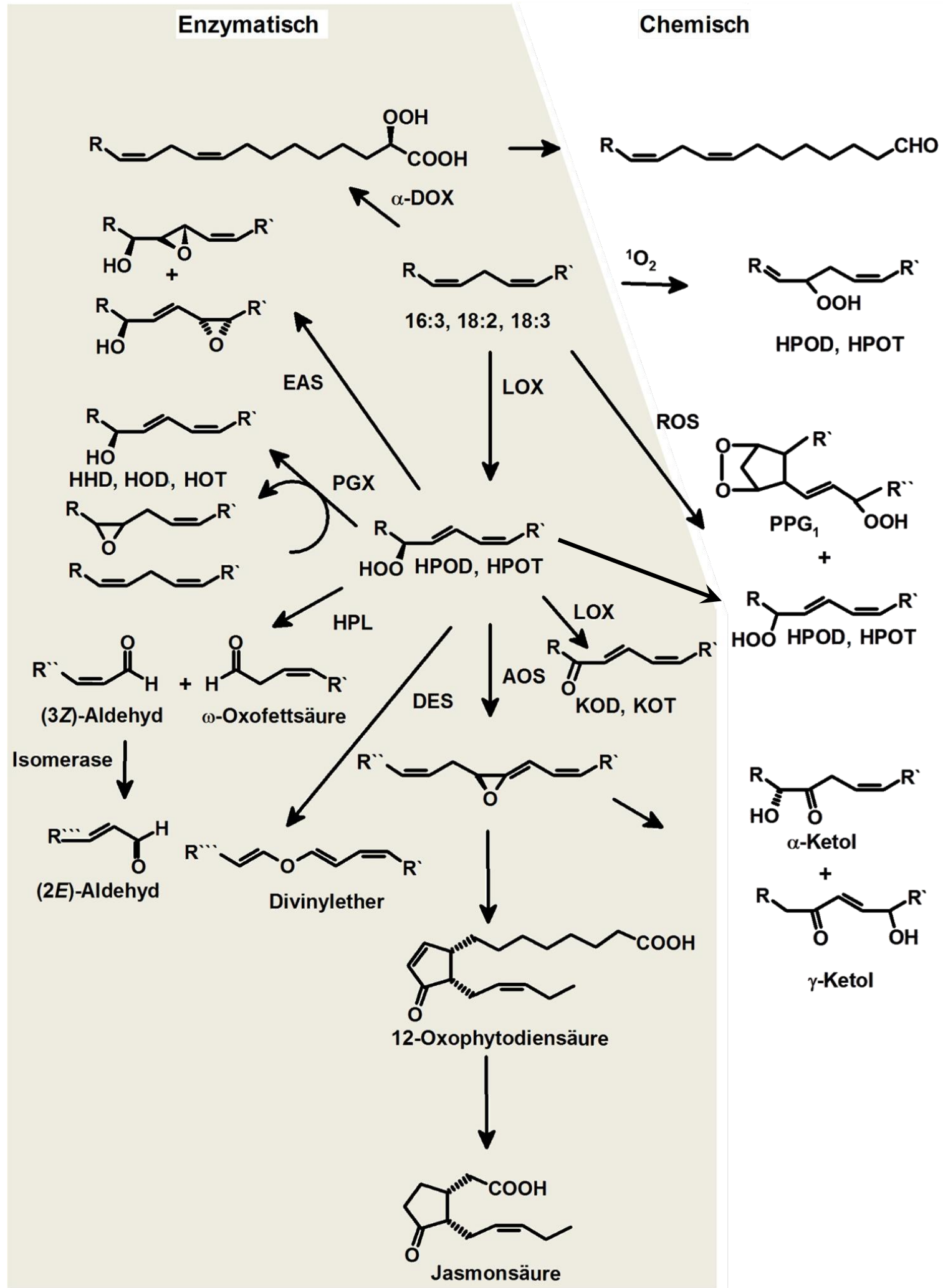

Abbildung 1.1: Schema der Oxylipin-Biosynthese in Blütenpflanzen. (modifiziert nach Mosblech et al., 2009). Die Synthese von Oxylipinen beginnt mit der Umwandlung mehrfach ungesättigter Fettsäuren, welche ein $(1 Z, 4 Z)$-Pentadiensystem enthalten. Die Umwandlung mehrfach ungesättigter Fettsäuren durch eine LOX oder $\alpha$-DOX erzeugt Fettsäure-Hydroperoxide, welche Substrate für weitere Stoffwechselwege sind. Diese werden durch die nachfolgenden Schlüsselenzyme charakterisiert. EOT-Epoxyoktadekatriensäure, HO(D/T)EHydroxyoktadeka(di/tri)ensäure, KO(D/T)E-Ketooktadeka(di/tri)ensäure. Mehrfach ungesättigte Fettsäuren 
können ebenfalls nichtenzymatisch in Hydroperoxide und Hydroxide umgewandelt werden. Allenoxide, die durch die AOS gebildet werden, können spontan zu razemischem OPDA zyklisieren oder zu $\alpha$ - und $\gamma$-Ketolen hydrolysieren.

Bei der Beschreibung der Enzyme der Oxylipinbildung ist zu beachten, dass FettsäureHydroperoxide auch nichtenzymatisch durch Abbauprodukte des antioxidativen Systems, z. B. durch Glutathion oder Tocopherol, gebildet und reduziert werden können (Liavonchanka \& Feussner, 2006, Maeda \& DellaPenna, 2007; Abbildung 1.1). Oxidativer Stress und die Entstehung reaktiver Sauerstoffspezies (ROS) kann zur chemischen Oxidierung von Lipiden führen, die die Entstehung razemischer Verbindungen zur Folge hat (Thoma et al., 2003, Mosblech et al., 2009). Die Fettsäuren LA und ALA sind besonders anfällig für eine Oxidation durch freie Radikale, was $\mathrm{zu}$ razemischen Gemischen von PeroxyFettsäureradikalen führt (Thoma et al., 2003). Diese Radikale können wiederum eine Kette von oxidativen Reaktionen starten, die zur Entstehung von dinor-Isoprostanen/Phytoprostanen führen, welche strukturell den Isoprostanen in Säugetieren ähneln (Parchmann \& Müller, 1998, Imbusch \& Mueller, 2000). Des Weiteren können nichtenzymatische Oxidationen zu unterschiedlichen Positionsisomeren der Fettsäure-Hydroperoxide führen, bei denen der Sauerstoff beispielsweise an der C10- oder C12-Position von LA und C15- oder C16-Position von ALA eingeführt wird (Berger et al., 2001, Przybyla et al., 2008).

Zusammenfassend lässt sich sagen, dass Pflanzen im Gegensatz zu Tieren die enzymatische Kapazität fehlt, langkettige Fettsäuren wie Arachidonsäure $\left(20: 4^{\Delta 5 Z \Delta 8 Z \Delta 11 Z \Delta 14 Z}\right.$, AA) zu synthetisieren. Dafür werden einerseits enzymatisch prostaglandinähnliche Substanzen (JA) und andererseits nicht-enzymatisch $\mathrm{C}_{18}$-Phytoprostane zur Antwort auf biotischen und abiotischen Stress gebildet.

\subsubsection{Biosynthese von JA und Zyklopentenonen in Blütenpflanzen}

Die Forschungen der vergangenen Jahre bestätigten den von Vick \& Zimmermann (1983) zunächst nur postulierten Biosyntheseweg von JA über den Oktadekanoidsyntheseweg, ausgehend von ALA (Abbildung 1.2). Die JA-Biosynthese wird in die nachfolgenden Schritte unterteilt und findet in zwei verschiedenen Zellkompartimenten (Chloroplasten und Peroxisomen) statt.

\section{Die Freisetzung plastidärer ALA}

Analog zur Eikosanoidbiosynthese in Säugern (1.2.1) wird die Aktivität einer Phospholipase $\mathrm{A}_{2}\left(\mathrm{PLA}_{2}\right)$ zur Freilassung der ALA aus Membranlipiden postuliert. Im Einklang mit dieser 
Hypothese wurde erhöhte PLA 2 Aktivität bei wund- oder systemininduzierter JA-Bildung (Narvaez-Vasquez et al., 1999) nachgewiesen.

Die Enzyme der ersten Schritte zur Synthese zyklischer Oktadekanoide (LOX, AOS, AOC), besitzen alle mutmaßliche chloroplastidäre Signalpeptidsequenzen (CTS, Shibata et al., 1988, Song et al., 1993, Ziegler et al., 2000). Der Import und die Lokalisation dieser Enzyme in Chloroplasten wurden auch experimentell bestätigt (Song et al., 1993, Bell et al., 1995, Harms et al., 1995, Feussner et al., 1995, Ziegler et al., 2000, Froehlich et al., 2001, Stenzel et al., 2003b). Die vorwiegend plastidären Lipide Monogalaktosyldiacylglyzerin (MGDG) und Digalaktosyldiacylglyzerin (DGDG) stellen die Hauptquelle für veresterte ALA dar, die als Substrat für den Oktadekanoidweg dienen kann. Somit geht die JA-Biosynthese auf Kosten plastidärer MGDG und DGDG.

\section{Die Oxidierung von ALA durch LOX}

Durch eine an den Chloroplasten lokalisierte 13-LOX kann plastidäre ALA zu (9Z,11E,13S,15E)-13-Hydroperoxy-9,11,15-oktadekatriensäure (13S-HPOTE) oxidiert werden. Neben der 13-LOX wurde auch eine 9-LOX identifiziert, deren Produkt (9S,10E,12Z,15Z)-9-Hydroperoxy-10,12,15-octadecatriensäure (9S-HPOTE) in Kartoffel an Abwehrreaktionen beteiligt ist (Göbel et al., 2001).

Da LOXen in dieser Arbeit eine wichtige Bedeutung haben, wird in einem späteren Abschnitt detaillierter auf diese Enzyme eingegangen (1.3).

\section{Dehydratation von 13S-HPOTE durch die AOS}

13S-HPOTE ist Substrat für verschiedene Enzyme des Oxylipinstoffwechsels (Abbildung 1.1), einschließlich AOS, des nächsten Enzyms der JA-Biosynthese (Schaller, 2001). AOS katalysiert die Abspaltung von Wasserstoff am 13S-HPOTE. Dabei wird das instabile Allenoxid $(9 Z, 11 Z, 12 S, 13 R, 15 Z)-12,13$-Epoxy-9,11,12-Oktadekatriensäure gebildet $(12,13$ EOT $^{\Delta 9 Z \Delta 11 \Delta 15 Z}$ ) (Vick \& Zimmerman, 1987b). Es wurde gezeigt, dass AOS sowohl 13SHPOTE als auch $(9 Z, 11 E, 13 S, 15 E)-13$-Hydroperoxy-9,11,15-oktadekatriensäure (13SHPODE) in Allenoxide umwandelt (Song \& Brash, 1991).

\section{Die Zyklisierung von cis(+)-OPDA}

Das instabile Allenoxid 12,13-EOT wird durch die Allenoxidzyklase (AOC) zu $(9 S, 13 S)$-12-Oxophytodiensäure (OPDA) umgesetzt. OPDA ist wichtig für die endgültige enantiomere Struktur von Jasmonsäure. Das gebildete OPDA ist das erste Oktadekanoid, welches die charakteristische Zyklopentenonstruktur besitzt. 
Entsprechend der Theorie, dass chloroplastidäre Lipide für die JA-Biosynthese metabolisiert werden, ist gezeigt worden, dass mehr als $90 \%$ des OPDA in Arabidopsis Blättern verestert in sogenannten Arabidopsiden an den Chloroplasten-Membranen gebunden ist. Mittels einer sn1-Lipase kann das OPDA rasch aus den Membranen frei gesetzt werden (Stelmach et al., 2001). Die endogene Speicherung der Arabidopside kann so für den schnellen Nachschub von OPDA und anderen Jasmonaten für Signalzwecke nützlich sein. Für die vorliegende Arbeit waren AOCs von besonderer Bedeutung, weshalb in einem späteren Kapitel näher auf sie eingegangen wird (1.4).

\section{Reduktion von 12-OPDA durch die OPDA-Reduktase 3 (OPR3) zu OPC 8:0}

Der nächste Teil der JA-Biosynthese findet nicht mehr in den Chlorplasten sondern in den Peroxisomen statt (Stintzi \& Browse, 2000, Strassner et al., 2002), wobei bisher noch nicht geklärt wurde, ob das OPDA oder sein CoA-Ester von den Chloroplasten in die Peroxisomen transportiert wird. In den Peroxisomen wird das OPDA durch die OPDA-Reduktase (OPR3) zu einem Cyclopentanon, der 3-Oxo-2-[2'(Z)-pentenyl]-cyclopentan-1-oktansäure (OPC 8:0) unter Reduktion der $\mathrm{C}=\mathrm{C}$-Doppelbindung des konjugierten Enonrestes umgewandelt. Verschiedene neuere Studien zeigten, dass Enzyme der Fettsäure B-Oxidation ebenfalls in der Jasmonatbiosynthese aktiv sind (Castillo et al., 2004). Die B-Oxidation wird katalysiert durch eine Acyl-CoA Synthase, eine Acyl-CoA Oxidase (ACX), ein multifunktionelles Protein MFP und eine L-3-Ketoacyl-CoA Thiolase (KAT).

\section{Umsetzung von OPC 8:0 zu Jasmonsäure durch $\beta-O x y d a t i o n$}

Im letzten Schritt der JA-Biosynthese wird die Carbonsäure-Seitenkette von OPC 8:0 in drei Zyklen der B-Oxidation verkürzt (Vick \& Zimmerman, 1984) und es entsteht (1R,2R)-3-Oxo2-pent-2-enyl-cyclopentanessigsäure oder auch (+)-7-iso-JA (Abbildung 1.2). 


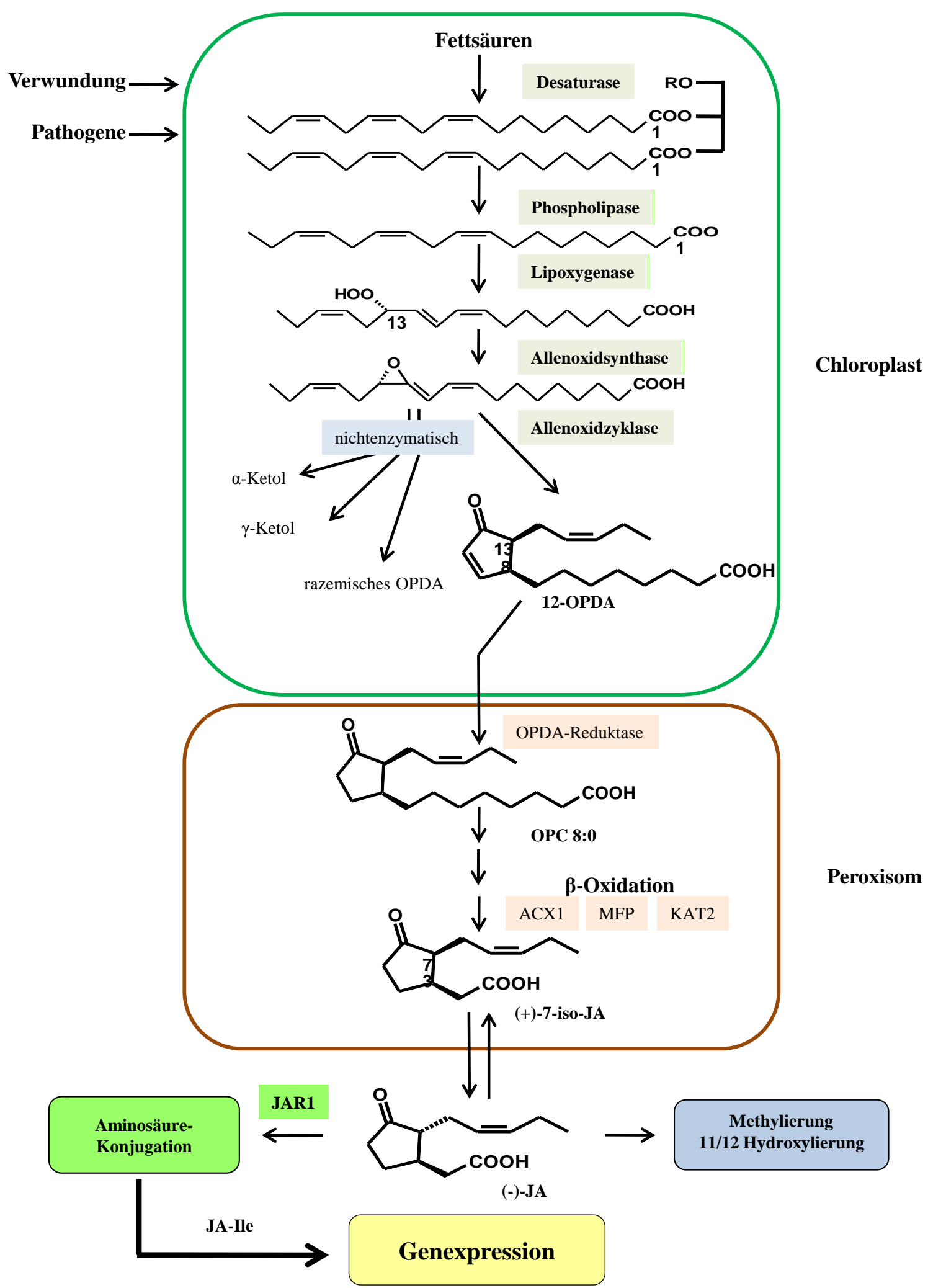

Abbildung 1.2: Der JA-Biosyntheseweg in Pflanzen. Die Biosynthese von JA wird durch Verwundung oder Pathogene ausgelöst und findet in zwei verschiedenen Kompartimenten (Chloroplasten und Peroxisomen) statt (Erläuterungen siehe Text). 


\section{Metabolismus der Jasmonsäure}

Neben der JA verfügen Blütenpflanzen über eine Reihe weiterer biologisch aktiver Zyklopentenone. Diese entstehen durch weitere Umwandlung der JA in verschiedene Derivate. Eine bedeutende Folgereaktion der JA-Biosynthese ist die Adenylierung der Carboxylgruppe durch eine AMP-Transferase (Staswick et al., 2002) bei der eine Aminosäure, vorzugsweise Isoleucin, an JA konjugiert wird (Staswick, 1992, Staswick \& Tiryaki, 2004). Diese Reaktion wird durch das Enzym JAR1 (jasmonate resistance1) katalysiert (Staswick \& Tiryaki, 2004). JAR1 wurde durch die JA-insensitive Arabidopsis Mutante jarl identifiziert (Staswick et al., 1992), was auf eine essentielle Bedeutung der JAKonjugation in der JA-Antwort hinweist. Es wurde gezeigt, dass JA-Isoleucin (JA-ILE) die Bindung des transkriptionellen Repressors JAZ1 an den SCF ${ }^{\text {COI1 }}$ Proteinkomplex aktiviert (Thines et al., 2007). SCF ${ }^{\mathrm{COI} 1}$ ist eine Ubiquitin-Ligase, die für den Abbau von JAZ1 verantwortlich ist. JAZ1 wiederum gehört zur Familie der JA-ZIM-Domänenproteine (JAZ) und reprimiert die Expression von Jasmonatantwortgenen. Bindet JAZ1 an SCF ${ }^{\mathrm{CO} 1}$, wird es abgebaut und die Gene für die JA-Antwort können exprimiert werden. Damit ist der $\mathrm{SCF}^{\mathrm{COI1}}$ JAZ Proteinkomplex ein Rezeptor für JA-ILE und damit für die gesamte JA-gesteuerte Signaltransduktion (Thines et al., 2007).

Bei Methylierung der JA durch eine JA-spezifische Methyltransferase (Seo et al., 2001) entsteht flüchtige Methyl-JA (MeJA), welche als luftverbreitetes Signal in der Pflanzenkommunikation bei Abwehrprozessen beteiligt sein kann (Seo et al., 2001). Außerdem kann JA durch Decarboxylierung in cis-Jasmon umgewandelt werden (Koch (Koch et al., 1997). Die Anreicherung von cis-Jasmon erhöht die Widerstandsfähigkeit gegen Insekten (Birkett et al., 2000).

Zusätzlich wurde 1997 ein weiterer Syntheseweg für JA, ausgehend von Hexadekatriensäure (16:3) entdeckt (Weber et al., 1997), in dem dinor-OPDA (dnOPDA) entsteht, ein OPDAHomolog mit nur 16 Kohlenstoffatomen. Bis jetzt konnte keine OPR (OPDA Reduktase) mit Substratspezifität für dnOPDA gefunden werden. Jedoch werden die Zwischenprodukte der Synthesewege OPDA und dnOPDA, neben JA und ihren biologisch aktiven Derivaten, ebenfalls als starke Signalmoleküle betrachtet (Weber et al., 1997, Stelmach et al., 1998). Abschließend kann gesagt werden, dass OPDA für sich ein starker Genregulator ist, jedoch beide Signale, JA und OPDA, für eine vollständige Abwehrantwort erforderlich sind. Möglicherweise sind sowohl JA, OPDA und dnOPDA als auch ihre Derivate echte Regulatoren und erlauben somit den Zellen in Entwicklung und bei Erkrankung eine fein abgestimmte Genexpression. 
Wegen der detaillierten Kenntnisse des Oxylipinstoffwechsels höherer Pflanzen kann dieser als Grundlage zur Untersuchung weniger gut erforschter Modelle wie der Moose dienen. Im folgenden Abschnitt wird auf die Oxylipine und ihre Biosynthese in P. patens eingegangen.

\subsubsection{Oxylipine in P. patens}

Allen Embryophyta liegt ein Generationswechsel in der Fortpflanzung zu Grunde, bei dem mindestens zwei, häufig verschiedene, Erscheinungsformen gebildet werden. Bei diesen Fortpflanzungsformen handelt es sich um den Gametophyten und den Sporophyten. Für die ungeschlechtliche Vermehrung der Embryophyta erzeugt der Gametophyt die Gameten und der Sporophyt die Sporen. Die Gametophyten der Moose sind die grünen Moospflanzen. Die Gametophyten der Samenpflanzen sind im Vergleich zu den Moosen sehr stark reduziert. Bei ihnen ist der männliche Gametophyt auf das mehrzellige Pollenkorn reduziert, das bei den Angiospermen aus drei Zellen (eine vegetative Zelle und zwei Spermazellen) besteht. Der weibliche Gametophyt verbleibt in der Mutterpflanze und wird Embryosack genannt.

Mit Ausnahme der flüchtigen Verbindungen, z. B. die von den Gametophyten produzierten Aldehyde und Alkohole (Dembitsky, 1993), ist nur wenig über Oxylipine und ihre Biosynthese in $P$. patens bekannt. Aus diesem Grund ist bis jetzt nicht geklärt, welche Oxylipine enzymatisch oder nichtenzymatisch entstehen. Im Vergleich zu höheren Pflanzen besitzen Moose zusätzlich zu den mehrfach ungesättigten $\mathrm{C}_{18}$-Fettsäuren, die tierischen sehr langkettigen Fettsäuren AA und EPA, welche als Vorstufen von Oxylipinen dienen können. Tatsächlich wurde in $P$. patens z. B. ein höherer Anteil an AA (16,1\%) als an LA (13,7 \%) oder ALA (11,9 \%) gefunden (Grimsley, 1981), womit ein komplexeres Oxylipinmuster als in höheren Pflanzen vermutet werden kann. Aus dem Vorkommen zusätzlicher Ausgangsstoffe für die Oxylipinsynthese kann postuliert werden, dass $P$. patens somit keinem bis dahin bekannten Reaktionsweg zur Biosynthese flüchtiger Verbindungen folgt und stattdessen Gemische von sonst für Pflanzen, Pilze und Tiere typische Metaboliten erzeugt (Wichard et al., 2005).

Seit P. patens als Modellorganismus für Bryophyta etabliert ist (Frank et al., 2005, Cove et $a l ., 2006)$ und das vollständige Genom veröffentlicht wurde (Rensing et al., 2008), konnte der LOX-Stoffwechselweg von P. patens eingehender untersucht werden (Senger et al., 2005, Wichard et al., 2005). Bemerkenswerterweise ermöglichten diese Untersuchungen neue Einblicke in einen LOX-Stoffwechselweg, der in höheren Pflanzen nicht existiert (Wichard et $a l ., 2005)$. Für das erste LOX-Enzym, welches aus $P$. patens kloniert wurde ( $P p$ LOX1), konnte ein breites Substratspektrum gezeigt werden. 
(A)

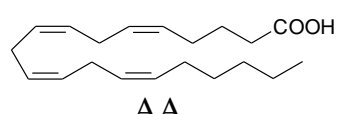

$\mathrm{AA}$

$P p \mathrm{LOX} 1$

$P p \mathrm{LOX} 2$

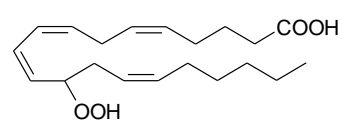

12-HPETE

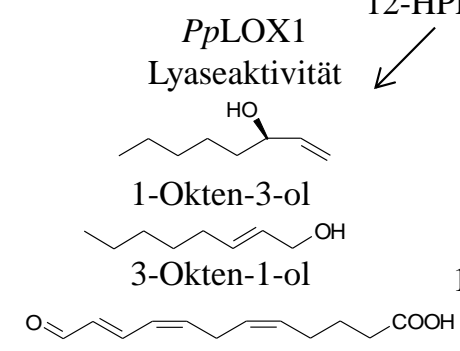

10-Oxodekensäure
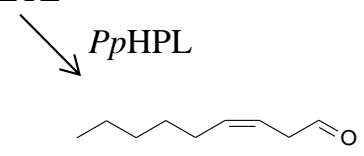

(3Z)-Nonenal

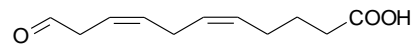

11-Oxo-undeka-5,8-diensäure

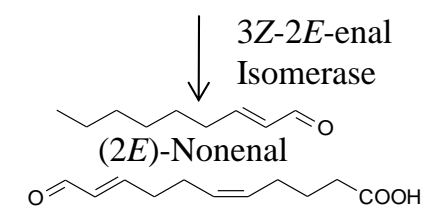

11-Oxo-undeka-5,9-diensäure
(B)

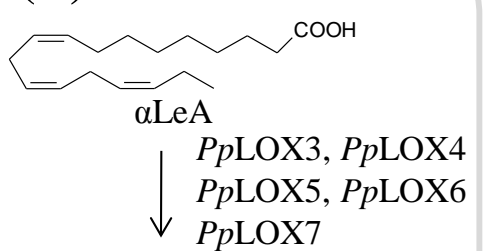

$\sim \mathrm{COOH}$

$\longrightarrow$

$\mathrm{OOH}$

13-HPOTE

(C)

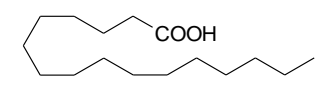

Palmitinsäure

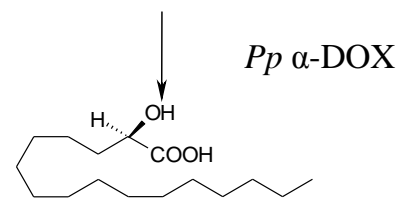

$2 R$-Hydroxy-Palmitinsäure

Abbildung 1.3: Oxylipine in $\boldsymbol{P}$. patens. (modifiziert nach Andreou et al., 2009b) (A) LOX/HPLStoffwechselweg ausgehend von AA; (B) LOX-Stoffwechselweg ausgehend von ALA; (C) Bevorzugte $\alpha$-DOX Reaktion.

PpLOX1 oxidiert Fettsäuren mit Kettenlängen von $\mathrm{C}_{18}$ bis $\mathrm{C}_{22}$ (Senger et al., 2005; Abbildung 1.3) und ist, im Gegensatz $\mathrm{zu}$ allen bisher beschriebenen LOXen anderer Organismen, ein bifunktionales Enzym, das zusätzlich zur LOX-Aktivität eine Lyaseaktivität zeigt (Senger et al., 2005). Demzufolge wird das 12-LOX Produkt (5Z,8Z,10E,12S,14Z)-12Hydroperoxy-5,8,14-eikosatriensäure (12S-HPETE) in $(5 Z, 8 Z, 10 E)$-12-Oxodekatriensäure (12-ODTE), und die flüchtigen Verbindungen 1-Okten-3-ol (Speisepilzaroma) und 3-Okten-1-ol gespalten (Senger et al., 2005; Abbildung 1.3). Das 1-Okten-3-ol aus Pilzen stammt aus LA, welche von einem Ppo-Enzym mit Fettsäure-HämPeroxygenase/Dioxygenase-Domänen (PpoC) in 10-HPODE umgewandelt wird (Brodhun et $a l$, 2009.), und einer zusätzlichen HPL-Aktivität. Bereits 1986 wurde das 12-LOX Produkt 12-ODTE in menschlichen Thrombozyten, welche mit AA stimuliert wurden, nachgewiesen (Glasgow et al., 1986). Zudem ist die 12-ODTE auch als Schreckstoff in Diatomeen bekannt (Pohnert, 2002).

Neben diesen $\mathrm{C}_{8}$-Alkoholen produziert $P$. patens nach Verwundung auch das $\mathrm{C}_{9}$-Aldehyd (2E)-Nonenal (Wichard et al., 2005). In höheren Pflanzen ist - wie in Pilzen - LA die 
Vorstufe des (2E)-Nonenal, wobei LA durch eine 9-LOX und 9-HPL umgewandelt wird (Noordermeer et al., 2000). Diese Verbindung wird in P. patens interessanterweise von AA abgeleitet und ist das Produkt eines CYP74-Enzyms, der PpHPL. PpHPL besitzt ein breites Substratspektrum und ist mit den getesteten Fettsäure-Hydroperoxiden aus LOX-Reaktionen aktiv (Stumpe et al., 2006). In P. patens Mutanten mit Defekten im HPL-Gen wurde nach Verwundung nur die Abwesenheit der flüchtigen C9-Verbindungen detektiert, während die flüchtige Substanz aus grünen Blättern, das (3Z)-Hexenal und die Oktenole noch vorhanden waren. Dafür könnte die PpLOX1-Lyaseaktivität oder eine weitere, bis jetzt nicht charakterisierte, Lyaseaktivität verantwortlich sein. Alternativ könnte das (3Z)-Hexenal durch den Abbau der 13-Hydroperoxy-Fettsäuren gebildet werden. Vielleicht enthält das Genom von $P$. patens auch zusätzliche Enzyme, die die 13-LOX Produkte der $\mathrm{C}_{18}$-Fettsäuren und die 12-LOX Produkte der $\mathrm{C}_{20}$-Fettsäuren metabolisieren. Mögliche Kandidaten wären Genprodukte der kürzlich entdeckten zwei $A O S$ und zwei $A O C$-Gene (M. Stumpe, Dissertation, 2006). Die von Dr. M. Stumpe charakterisierte PpAOS1 wies ein sehr breites Substratspektrum für Fettsäure-Hydroperoxide auf, was mit der Tatsache übereinstimmt, dass in P. patens eine Reihe von Alkoholen und Aldehyde gefunden wurden (Dembitsky, 1993, Wichard et al., 2005). Es wurden verschiedene Fettsäure-Hydroperoxide, die wahrscheinlich in $P$. patens vorkommen, getestet (M. Stumpe, Dissertation, 2006) und bis auf 11-HPETE und 5-HPETE werden die getesteten Fettsäure-Hydroperoxide von PpAOS1 in Allenoxide umgewandelt. Um einen Überblick über die Verteilung der LOX-Produkte in P. patens zu erhalten, wurde der Gehalt an Fettsäure-Hydroperoxiden bestimmt und gezeigt, dass $P$. patens sowohl einen hohen Anteil an 13-LOX Produkten als auch an 12-LOX Produkten enthält. (Julia Bode, Diplomarbeit).

Zusätzlich zu den LOX-Reaktionen, wurde in P. patens eine $\alpha$-DOX beschrieben. Dieses Enzym katalysiert die Umwandlung von Fettsäuren zu $\alpha$-oxidierten Fettsäuren, welche zu Aldehyden mit ungerader Kettenlänge und wechselnden Mengen an Hydroxysäuren abgebaut werden können. Außerdem wurde gezeigt, dass homogenisiertes Gewebe von P. patens Palmitinsäure (16:0) zu (2R)-Hydroxy-Palmitinsäure und (2R)-Hydroxy-Pentadekansäure umwandeln kann (Hamberg et al., 2005).

Die Analyse des P. patens Genoms bestätigte die Existenz aller Gene der JA-Biosynthese, außer der OPR3 und den CoA-Synthetasen (Rensing et al., 2008) Jedoch wurde der Abbau plastidärer Oxylipine zu Jasmonaten in P. patens bisher nicht nachgewiesen (Senger et al., 2005, Wichard et al., 2005, Stumpe et al., 2006). Eine neuere Studie zeigte, dass nach Infektion mit den Phytium Spezies $P$. debaryanum und $P$. irregulare der JA-Gehalt in 
P. patens anstieg (Oliver et al., 2009), was auf einen funktionellen JA-Signalweg in P. patens hinweisen könnte. Eine neue phylogenetische Studie konnte belegen, dass $P$. patens eine Genfamilie mit sechs verschiedenen $O P R$-Genen besitzt (Li et al., 2009). Bis jetzt wurden keine weiteren Untersuchungen zur Funktion der einzelnen OPR-Gene durchgeführt.

\subsection{LOXen}

Wie bereits deutlich wurde, sind LOXen wichtige Enzyme, die in Tieren, Pflanzen und Moosen von sehr zentraler Bedeutung in der Oxylipin-Signalkaskade sind. LOXen katalysieren die Bildung von Hydroperoxy-Fettsäuren aus molekularem Sauerstoff und mehrfach ungesättigter Fettsäuren (1.2.1) und kommen sowohl im Tier- (Brash, 1999, Kühn \& Thiele, 1999), als auch im Pflanzenreich (Grechkin, 1998, Liavonchanka \& Feussner, 2006) vor; wurden aber auch in Pilzen (Bisakowski et al., 1997, Su \& Oliw, 1998, Oliw, 2002), sowie in niederen Meeresorganismen (Brash et al., 1996, Koljak et al., 1997, Mortimer et al., 2006) und in Bakterien nachgewiesen (Porta \& Rocha-Sosa, 2001, Lang \& Feussner, 2007, Lang et al., 2008).

LOXen sind nichthäm-eisenhaltige Dioxygenasen, welche aus einer einzelnen Aminosäurekette mit zwei unterschiedlichen Domänen bestehen. Dabei handelt es sich um eine C-terminale $\alpha$-helikale katalytische Domäne mit der Substratbindungstasche und dem katalytischen Eisen und um eine N-terminale $\beta$-Faltblattdomäne (Boyington et al., 1993, Gillmor et al., 1998). Über die Funktion der $\beta$-Faltblatt-Domäne ist bis jetzt nur wenig bekannt, jedoch wird für diese Domäne eine Funktion bei der Membranbindung des Enzyms diskutiert (Liavonchanka \& Feussner, 2006).

Die Mehrheit der pflanzlichen und tierischen LOXen bevorzugt freie Fettsäuren als Substrat. Übereinstimmend mit der Annahme, dass LOXen an der Permeabilisierung von Biomembranen beteiligt sind (Brash, 1999), zeigten verschiedene Studien die Umsetzung auch veresterter Fettsäure-Substrate, wie z. B. in Phospholipiden, Galaktolipiden (Murray \& Brash, 1988, Brash, 1999), Triacylglyzeriden (Feussner et al., 1997, Holtman et al., 1997, Feussner et al., 1998, Gerhardt et al., 2005) oder Cholesterinestern (Belkner et al., 1991, Belkner et al., 1998).

\subsubsection{Reaktionsmechanismus von LOXen}

Der Katalyse-Mechanismus von LOXen wurde sowohl strukturell (Boyington et al., 1993, Minor et al., 1996, Skrzypczak-Jankun et al., 2001, Gillmor et al., 1998, Choi et al., 2008, Neau et al., 2009) als auch kinetisch durch zielgerichtete Mutagenese (Sloane et al., 1991, Borngräber et al., 1996, Hornung et al., 1999) in vielen Studien untersucht. 
Der Reaktionsmechanismus von LOXen findet über die Bildung von Radikalintermediaten (Abbildung 1.4) statt. Zuerst wird das Nichthämeisen durch Peroxide vom Fe[II] zum Eisen[III] oxidiert. $\mathrm{Zu}$ dieser Oxidation sind z. B. auch die LOX-Produkte selbst, die Hydroperoxy-Fettsäuren in der Lage (Yamamoto, 1992). Bei der LOX-Reaktion werden vier Schritte unterschieden.

\section{Wasserstoffabstraktion einer doppelallylständigen Methylengruppe des}

Substrats. Die Wasserstoffabstraktion geschieht sowohl stereo- als auch regiospezifisch und es wird immer das pro- $S$-Wasserstoffatom (bzw. pro- $R$ bei $R$-LOXen) abstrahiert. Diese Selektivität wird durch die Lage des Substrats in der Bindungstasche des Enzyms bestimmt. Nach der homolytischen Spaltung der C-H Bindung entsteht ein mesomeriestabilisiertes Fettsäure-Radikal.

2. Umlagerung des Radikals. Für das delokalisierte radikalische Elektron gibt es die Möglichkeiten einer Verschiebung in Richtung Methylende der Fettsäure um [+2] Atome oder zum Carboxylende um [-2] Atome (Kühn et al., 1986). Dabei wird immer ein konjugierten $Z$-E-Dien-System gebildet. Die Verschiebung erfolgt je nach Enzym jedoch nur in eine Richtung, was auf eine hohe Spezifität des jeweiligen Enzyms schließen lässt.

3. Sauerstoff-Insertion. Die Insertion des molekularen Sauerstoffs erfolgt stereospezifisch von der gegenüberliegenden Seite der Wasserstoffabstraktion in der von den Doppelbindungen gebildeten Ebene (antarafacialer Charakter; Feussner \& Wasternack, 2002).

4. Reduktion des Peroxidradikals. Unter Oxydierung des Eisens vom Fe[II] zum Eisen[III] (Wiederherstellung des katalytisch aktiven Zustands) wird ein Elektron auf das radikalische Peroxy-Intermediat übertragen und damit zum Peroxyd-Anion reduziert. Die Regio- und Stereospezifität der Reaktion wird hauptsächlich in diesem Schritt determiniert, da das Elektron vermutlich nur in einer ganz bestimmten sterischen Anordnung übertragen werden kann (Schneider et al., 2007a). Durch die Reaktion des Peroxid-Anions mit einem Proton entsteht das Produkt der LOX-Reaktion, die Hydroperoxy-Fettsäure.

Die DOX-Reaktion von $\mathrm{C}_{18}$-Fettsäuren ist in pflanzlichen LOXen unter physiologischen Bedingungen begünstigt. Die beiden unterschiedlichen Regioisomere von HydroperoxyFettsäuren werden von zwei unabhängigen Eigenschaften der Katalyse bestimmt. Zum einen von der Selektivität der initialen Wasserstoffabstraktion und zum anderen von der Position der Sauerstoffeinführung über die Umlagerung des Fettsäure-Radikals. Jedoch zeigten Vergleiche verschiedener pflanzlicher LOXen sowie Mutagenese-Studien, dass nur die doppelallylische Methylgruppe an Position C11 in LA oder ALA verwendet wird (Feussner \& Kühn, 2000). Wird der Wasserstoff an Position C11 entzogen, kann der molekulare Sauerstoff 
an Position [+2] oder [-2] eingebaut werden und führt somit zu Sauerstoffeinführung an Position C13 oder C9 (Abbildung 1.4).

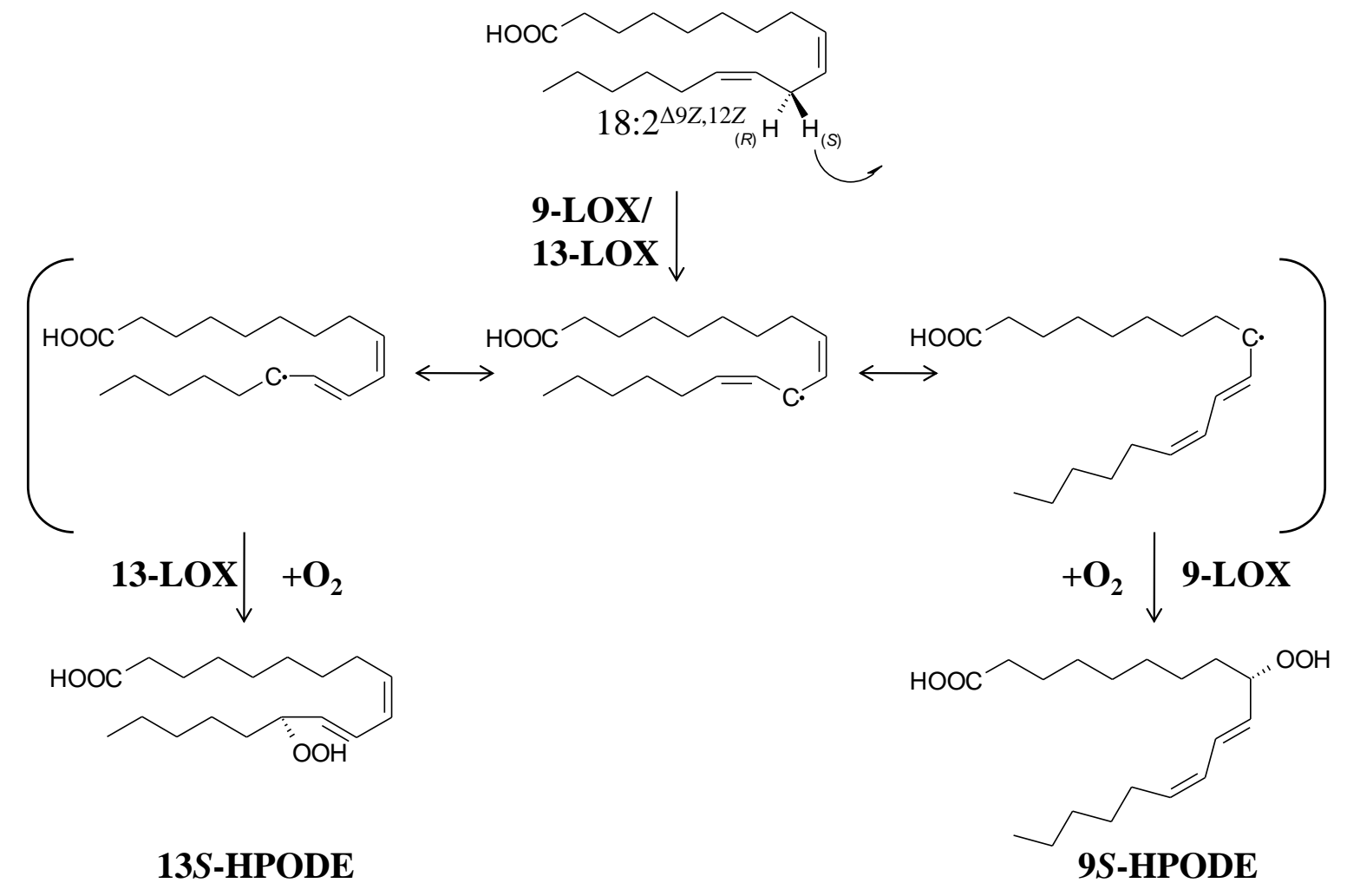

Abbildung 1.4: Die LOX-Reaktionen am Beispiel der LA. (modifiziert nach Liavonchanka \& Feussner, 2006). Bildung des Pentadiensystems aus mehrfach ungesättigten Fettsäuren durch Lipoxygenasen und anschließende Dioxygenierung. In Abhängigkeit der Regioselektivität des Enzyms werden das $9 S$ - bzw. das $13 S$ Hydroperoxid gebildet.

Es wurde gezeigt, dass LOXen mindestens drei verschiedene Arten von Reaktionen katalysieren.

1. Die Dioxygenierung von Fettsäure-Substraten (DOX-Reaktion).

2. Die sekundäre Umwandlung von Hydroperoxy-Fettsäuren (HydroperoxidaseReaktion; Kühn et al., 1991).

3. Die Bildung von Epoxy-Leukotrienen (Leukotrien-Synthase-Reaktion; Shimizu et al., 1984).

\subsubsection{Mutagenesestudien zur Spezifität verschiedener LOXen}

In der Vergangenheit wurden viele Mutagenesestudien mit LOXen (1.3.4) durchgeführt (Kühn et al., 2005). Durch diese Studien wurden mehrere Sequenz-Determinanten bestimmt, die für die Positions-, und Stereospezifität verschiedener LOXen verantwortlich sind. Dabei handelt es sich um die sogenannten Sloane- (Sloane et al., 1991) die Borngräber- (Borngräber 
et al., 1996), die Hornung- (Hornung et al., 1999) und die Coffa-Determinante (Coffa \& Brash, 2004). Bei der Sloane-und Borngräber-Determinanten handelt es sich jeweils um die voluminösen Aminosäurereste Met-419 und Phe-353 der Kaninchen-Retikulozyten und/oder humanen 15-LOX, bei deren Austausch gegen kleinere Aminosäurereste die Reaktionsspezifität in die einer 12-LOX umgewandelt wurde. Vergleiche der sogenannten Sloane-Determinanten auf Sequenzebene zeigten, dass sie auch unter pflanzlichen LOXen, unabhängig von ihrer Positionsspezifität hoch konserviert sind. In pflanzlichen 13-LOXen befindet sich ein Phenylalanin- oder Histidinrest an der Position der Sloane-Determinanten von Säugetier-LOXen. Ein Austausch des Histidins bzw. Phenylalanins durch weniger voluminöse Reste wie Valin oder Methionin verändert die Positionsspezifität einer 13-LOX in die einer 9-LOX (Hornung et al., 1999). Im Gegensatz dazu wurde für alle pflanzlichen 9LOXen ein Valinrest in dieser hochkonservierten Aminosäure-Position identifiziert (Feussner \& Kühn, 2000). Strukturelle Modellierungen der Enzym-/Substrat-Wechselwirkungen zeigten, dass diese Mutation die positiv geladene Guanidinogruppe eines Argininrestes, der Hornung-Determinante (Hornung et al., 1999) möglicherweise an der Unterseite der Substratbindetasche demaskiert. Demzufolge könnten die Guanidinogruppe eine Salzbrücke mit der Carboxylgruppe des Substrates bilden, womit eine inverse Substrat-Orientierung begünstigt ist. Die besondere Rolle dieses Argininrestes wird durch sein hochkonserviertes Vorhandensein in allen pflanzlichen LOXen deutlich. Dafür spricht auch, dass die 9-LOXen im Gegensatz zu den 13-LOXen keine veresterten Substrate umsetzen (Schneider et al., 2007a, Boeglin et al., 2008).

Die strukturellen Faktoren, welche die regio- und stereospezifische Insertion von molekularem Sauerstoff in Säugetier-LOXen und der Korallen-LOX bestimmen, wurden 2004 beschrieben (Coffa \& Brash, 2004). In S-LOXen handelt es sich dabei um Alanin und in $R$-LOXen um Glyzin. Im Gegensatz zu den Determinanten, welche die Positionsspezifität pflanzlicher LOXen bestimmen, ist die stereo- und regiospezifische Coffa-Determinante zwischen Pflanzen- und Säugetier-LOXen konserviert (Coffa et al., 2005).

Studien, in welchen die bisherigen Raumstrukturen pflanzlicher LOXen miteinander verglichen wurden (Liavonchanka \& Feussner, 2006), zeigten dass sich ein konservierter Lysin- und ein Argininrest in der Nähe der Öffnung der mutmaßlichen Substratbindetasche befinden. Diese Reste könnten im Fall einer umgekehrten Substrat-Orientierung mit der Carboxylgruppe des Substrates wechselwirken und die Substratbindung stabilisieren. 
Zusammenfassend lässt sich sagen, dass sowohl das Volumen des aktiven Zentrums als auch die Orientierung des Substrates wichtige Faktoren für die Positionsspezifität pflanzlicher LOXen sind.

\subsubsection{Theorien zur Positionsspezifiät verschiedener LOXen}

Es existieren bis heute zwei verschiedene Hypothesen um die Positionsspezifität der LOXen auf Basis der Substratbindung zu erklären (Funk \& Loll, 1997) - die Volumen-Hypothese und die Orientierungs-Hypothese. Nach der ersten Hypothese wird die Größe der Substratbindungstasche für die unterschiedliche Positionsspezifität verantwortlich gemacht (Gillmor et al., 1998, Browner et al., 1998). Das Substrat wird mit dem Methylende in der Bindungstasche gebunden. Demzufolge besitzen 15-LOXen eine sehr kleine Bindungstasche und das Substrat kann nicht tief eindringen, so dass das C13 des Substrates AA an das katalytisch aktive Eisen kommt. Bei 12-LOXen wird ein weiteres Eindringen des Substrates in die Bindetasche gewährleistet so dass das C10 am Eisen lokalisiert ist. Jedoch scheint in pflanzlichen LOX-Reaktionen nur eine doppelallylische Methylgruppe der natürlichen Substrate LA und ALA zugänglich $\mathrm{zu}$ sein, wodurch die Volumen-Hypothese unwahrscheinlich wird.

Nach der zweiten Hypothese gilt die Substrat-Orientierung als entscheidender Faktor bei der Position der Sauerstoffeinführung und führt zu den unterschiedlichen Regiospezifitäten verschiedener LOX-Isoenzyme. Bei den 13-LOXen bindet das Substrat mit seinem Methylende zuerst in der Bindetasche, während bei 9-LOXen das Substrat gezwungen ist, in umgekehrter Richtung mit der Carboxlgruppe zuerst einzudringen (Gardner, 1991). Folglich ist in beiden Fällen die Umlagerung des Radikals auf entweder [+2] oder [-2] mit dem gleichen Mechanismus im aktiven Zentrum möglich.

Diese zwei Hypothesen wurden kürzlich durch eine weitere Theorie zur Substratbindung ergänzt (Neau et al., 2009). Während die Volumen- und die Substrat-Orientierung-Hypothese von einem aktiven Zentrum mit nur einem Eingang zur Substratbindetasche ausgehen, fanden (Neau et al., 2009) Beweise für eine U-förmige Substratbindetasche, in der das aktive Zentrum von beiden Seiten des Enzyms zugänglich ist.

\subsubsection{Die Enzymfamilie in Blütenpflanzen und Säugetieren}

Pflanzliche LOXen werden seit Anfang der 1980er Jahre mit Pflanzenwachstum, Entwicklung, Reifung und Seneszenz in Verbindung gebracht (Siedow, 1991). Zudem wird ihnen Bedeutung bei pflanzlichen Pathogenantworten (Rance et al., 1998, Veronesi et al., 1996), der Verwundungsreaktion (Farmer \& Ryan, 1992, Saravitz \& Siedow, 1995, Saravitz \& Siedow, 1996) und der Biosynthese von Signalmolekülen wie JA und OPDA (Vick \& 
Zimmerman, 1987a, Creelman \& Mullet, 1997) zugeschrieben. Die verschiedenen pflanzlichen LOX-Isoformen lassen sich in zwei Untergruppen einteilen. Der erste Typ der LOXen (Typ 1) besteht aus allen 9-LOX Isoenzymen, welche ausschließlich außerhalb der Chloroplasten lokalisiert sind. Alle chloroplastidär lokalisierten LOXen, inklusive der 13LOX Isoenzyme gehören zu den LOXen des Typs 2 und besitzen eine CTS (Shibata et al., 1994, Hildebrand, 1996). Die LOXen des Typ 1 sind einander in ihrer Sequenz sehr ähnlich (>75\% Sequenzähnlichkeit), während die LOXen vom Typ 2 untereinander nur mäßige Sequenzähnlichkeit aufweisen ( 35 \% Sequenzähnlichkeit; Liavonchanka \& Feussner, 2006). In Pflanzen kommen LOXen häufig als Multi-Genfamilien vor, z. B. enthält die Modellpflanze Arabidopsis sechs LOX-Gene (Feussner \& Wasternack, 2002) und in Kartoffel (Solanum tuberosum) wurden bis heute mindestens 14 LOX-Gene gefunden (Andreou et al., 2009a). In Sojabohne (Glycine max) wurden acht Isoformen beschrieben, von denen drei in den Samen (Axelrod et al., 1981) und sechs in vegetativen Geweben (Fuller et al., 2001) exprimiert werden. Während pflanzliche LOXen eine molekulare Masse von durchschnittlich $94-110 \mathrm{kDa}$ haben, sind die tierischen LOXen mit 75 - $80 \mathrm{kDa}$ kleiner (Brash, 1999). Auch in Säugetieren werden LOXen als Genfamilien exprimiert, dementsprechend wurden fünf humane LOXen und sieben LOXen in Mäusen charakterisiert. Entsprechend der Klassifizierung pflanzlicher LOXen, werden tierische LOXen nach ihrer Positionsspezifität bei der Einführung des molekularen Sauerstoffs in AA eingeteilt. Die Oxidation von AA kann entweder an den Positionen C5 (5-LOX), C8 (8-LOX), C9 (9-LOX), C11 (C11-LOX), C12 (12-LOX) oder C15 (15-LOX) stattfinden (Schneider et al., 2007a). Ist die Stereospezifität der jeweiligen LOX von Bedeutung, wird diese durch z. B. $12 R$-LOX und $12 S$-LOX angegeben. Phylogenetisch trennen sich pflanzliche und tierische LOXen in zwei Gruppen, wobei gleiche Positionsspezifiät nicht mit Sequenzähnlichkeit einhergeht (Andreou \& Feussner, 2009).

\subsubsection{LOXen in P. patens}

Die erste LOX, die aus $P$. patens charakterisiert wurde, ist eine 13-LOX (PpLOX1), die im folgenden Abschnitt (1.3.5.1) eingehender beschrieben wird. In $P$. patens wurden ausschließlich plastidäre 13-LOXen gefunden, während zytosolische 9-LOXen nicht vorhanden sind (Anterola et al., 2009). Zusätzlich zur PpLOX1 (Senger et al., 2005) wurden cDNAs für sechs weitere LOX-Isoenzyme aus $P$. patens kloniert und charakterisiert (PpLOX2-PpLOX7; Abbildung 1.3; Anterola et al., 2009). Das PpLOX2 Enzym mit $96 \%$ Sequenzhomologie auf Aminosäureebene zur PpLOX1 zeigte ebenfalls AA 12-LOX und ALA 13-LOX Aktivität. Hingegen bevorzugten $P p L O X 3-P p L O X 7 \mathrm{C}_{18}$-Fettsäuren und haben 
eine 13-LOX Aktivität für ALA (Abbildung 1.3). PpLOX3 besitzt zudem eine ähnlich hohe Substrataffinität zu ALA und AA. Das Produkt der AA-Reaktion ist jedoch (5Z,8Z,10E,15S,14Z)-15-Hydroperoxy-5,8,14-eikosatriensäure (15S-HPETE; Anterola et al., 2009). Im Vergleich zu den LOXen aus Samenpflanzen zeigen die LOXen aus $P$. patens eine mittlere Sequenzähnlichkeit von ungefähr $40 \%$, jedoch sind die sogenannten SloaneDeterminanten im aktiven Zentrum konserviert (Andreou et al., 2009b). Dies erscheint relevant, da diese Determinanten weder in LOXen von Säugetieren noch von Cyanobakterien konserviert sind. Dieser Umstand deutet auf die evolutionäre Trennung der LOXen aus Samenpflanzen und Moosen zu einem späteren Zeitpunkt hin (Andreou et al., 2009b).

\subsubsection{Die bifunktionelle PpLOX1}

Wie bereits beschrieben (1.2.4), besitzt $P p L O X 1$ zusätzlich zur LOX-Aktivität hohe Lyaseaktivität und ist damit ein bifunktionelles Enzym (Senger et al., 2005, Anterola et al., 2009). Eine Sequenzanalyse zeigte, dass in PpLOX1 keine HPL-charakteristische CYP74 Domäne vorliegt und somit die LOX-Domäne doppelte Funktionen haben muss (Senger et al., 2005, Andreou et al., 2009b). PpLOX1 hat eine Länge von 937 Aminosäuren und eine molekulare Masse von 105 kDa. Phylogenetische Analysen zeigten, dass PpLOX1 zusammen mit den 13-LOXen des Typs 2 aus Arabidopsis gruppiert (Senger et al., 2005). Die nächstverwandten Enzyme sind die 9-LOXen des Typs 1 aus Pflanzen, wohingegen die tierischen LOXen eindeutig getrennt gruppieren (Senger et al., 2005).

Die bevorzugten Substrate sind AA und EPA, gefolgt von DHA, GLA und ALA. Die Umsetzung von AA und EPA führte auch zur höchsten Regio- und Stereoselektivität, und daher wurde $P p L O X 1$ als AA-12S-LOX eingeordnet. In EPA, AA, GLA und DHA wird der molekulare Sauerstoff bevorzugt an der $\omega$-9-Position eingeführt, während LA und ALA an $\omega$ 6-Position oxidiert werden. Damit weist PpLOX1 ebenfalls eine LA-13S-LOX Aktivität auf. Veresterte und in Glyzerolipiden gebundene Fettsäuren werden von PpLOX1 nicht umgesetzt (Senger et al., 2005).

Voraussetzungen für die beschriebene HPL-Aktivität von PpLOX1 sind eine erhöhte Substratkonzentration $(\geq 0,4 \mathrm{mM})$, eine Doppelbindung, entweder an Position $\Delta 6$ für $\mathrm{C}_{18}$-Fettsäuren oder $\Delta 5$ für $\mathrm{C}_{20}$-Fettsäuren, sowie die Bildung des $S$-Hydroperoxides an der $\omega$-9-Position (Senger et al., 2005). Das zunächst gebildete Zwischenprodukt 12S-HPETE wurde in den Untersuchungen von (Senger et al., 2005). nach 2 min annähernd quantitativ zu 12S-KETE, 12-ODTE und $\mathrm{C}_{8}$-Alkoholen umgesetzt. 
Da die Substrate LA und ALA an den $\omega-6$ Positionen oxidiert werden, entstehen bei ihrer Umsetzung mit PpLOX1 keine Lyaseprodukte (Tabelle 1.1). Die Produkte aller PpLOX1 Reaktionen nach (Senger et al., 2005) sind in Tabelle 1.1 aufgeführt.

Weitere Untersuchungen mit Proteinextrakten, welche LOX-Aktivität von Pflanzen und Säugetieren enthielten, zeigten zusätzlich die Fähigkeit Hydroperoxide zu spalten (Glasgow et al., 1986). Zudem wurde kürzlich eine plastidäre LOX aus Mais (Zea mays, ZmLOX6) charakterisiert, die ausschließlich Lyaseaktivität mit dem Substrat 13S-HPOTE zeigte (Gao et al., 2008).

Tabelle 1.1: Hauptprodukte der PpLOX-Reaktionen mit verschiedenen Fettsäuren (nach Senger et al., 2005).

\begin{tabular}{|c|c|c|c|}
\hline Substrate & $\begin{array}{l}\text { Hauptprodukt der } \\
\text { DOX-Aktivität }\end{array}$ & $\begin{array}{l}\text { Produkte der HPL- } \\
\text { Aktivität }\end{array}$ & $\begin{array}{l}\text { Produkte der PXG- } \\
\text { Aktivität }\end{array}$ \\
\hline $\mathbf{A A}$ & 12S-HPETE & $\begin{array}{l}\text { 12-ODTE } \\
\text { 2Z-Okten-1-ol } \\
\text { 1-Okten-3-ol }\end{array}$ & $\begin{array}{l}\text { 12S-KETE } \\
15 S \text {-KETE }\end{array}$ \\
\hline EPA & $12 S$-HРEPE & $\begin{array}{l}\text { 12-ODTE } \\
\text { 2,5-Oktadien-1-ol } \\
\text { 1,5-Oktadien-3-ol }\end{array}$ & 12S-KEPE \\
\hline DHA & 14S-HDHE & $\begin{array}{l}\text { 14-ODTE } \\
\text { 2,5-Oktadien-1-ol } \\
\text { 1,5-Oktadien-3-ol }\end{array}$ & $14 S-\mathrm{KDHE}$ \\
\hline GLA & 10S- $\gamma$-HOTE & $\begin{array}{l}\text { 10-ODDE } \\
\text { 2Z-Okten-1-ol } \\
\text { 1-Okten-3-ol }\end{array}$ & 10S- $\gamma \mathrm{KOTE}$ \\
\hline ALA & 13S-HPOTE & keine Lyaseprodukte & $\begin{array}{l}9 S \text { - } \alpha \text { KOTЕ } \\
13 S \text { - } \alpha \text { KOTЕ }\end{array}$ \\
\hline LA & 13S-HPODE & keine Lyaseprodukte & $\begin{array}{l}13 S-\mathrm{KODE} \\
9 S-\mathrm{KODE}\end{array}$ \\
\hline
\end{tabular}

\section{$1.4 \mathrm{AOC}$}

Wie bereits erwähnt, ist der AOC-katalysierte Schritt in der JA-Biosynthese von großer Bedeutung (1.2.3), da erst in dieser Reaktion die endgültige enantiomere Struktur von JA gebildet wird. Das instabile AOS-Produkt (12,13-EOT) zerfällt rasch in Ketole (80\% $\alpha$-Ketol und $10 \% \gamma$-Ketol) und razemisches OPDA (10\%). In Anwesenheit einer AOC wird es enzymatisch zu cis(+)-OPDA umgewandelt (Hamberg \& Fahlstadius, 1990). Bereits 1979 postulierten Vick \& Zimmerman (1979) die Existenz einer Hydroperoxidzyklase für die Umwandlung von 12,13S-EOT in OPDA. Das Allenoxid 12,13S-EOT wurde später als direkte OPDA-Vorstufe in Pflanzen entdeckt (Hamberg, 1988, Brash et al., 1988, Crombie \& 
Morgan, 1991). Hamberg und Fahlstadius zeigten, dass die Ringschluss-Reaktion in Mais von einer löslichen AOC katalysiert wird (Hamberg \& Fahlstadius, 1990).

\subsubsection{Struktur und Reaktionsmechanismus der AOC}

Zur Aufklärung des Reaktionsmechanismus von AOC2 aus Arabidopsis konnten Hofmann et al. (2006) und Schaller et al. (2008) beitragen. Dabei gelang es, die Kristallstruktur eines Inhibitor-Komplexes von AtAOC2 zu lösen (Hofmann et al., 2006) und daraufhin Mutagenesestudien an wichtigen Aminosäureresten des aktiven Zentrums durchzuführen (Schaller et al., 2008). Eine Übersichtsdarstellung der Raumstruktur mit gebundenem Liganden von AtAOC2 ist in Abbildung 1.5 gezeigt.
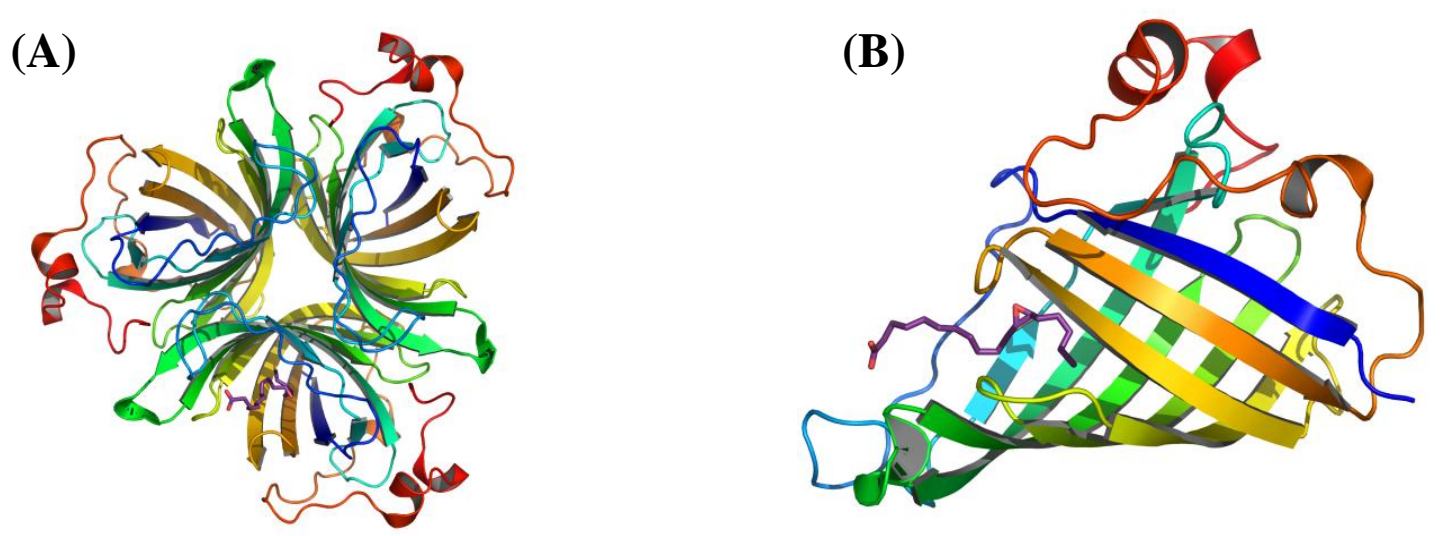

Abbildung 1.5: Raumstruktur von AtAOC2 in Farbbanddarstellung (2DIO.pdb). Die Farben zeigen den Verlauf vom N-terminalen (blau) zum C-terminalen Ende des Proteins (rot). Der Ligand (lila) in einem der Monomere ist in Stäbchenform präsentiert. (A) Trimere Struktur in Farbbanddarstellung. (B) Monomer mit Liganden 12,13-EOT ${ }^{\Delta 15 Z}$ in der Substratbindetasche.

Die AOC besteht aus einem dicht gepackten Homotrimer (Abbildung 1.5) und jedes Monomer besteht aus acht antiparallelen B-Strängen, die zusammen einen Hohlraum bilden. Um Informationen zur Substratbindung zu erhalten, inkubierten Hofmann et al. (2006) die Proteinkristalle mit ( \pm )-cis-12,13-Epoxy-9(Z)-oktadekansäure (Vernolsäure). Vernolsäure ist ein Substratanalogon von 12,13-EOT und stellt einen kompetitiven AOC-Inhibitor dar (Hamberg \& Fahlstadius, 1990, Ziegler et al., 1999). Der Unterschied von Vernolsäure zum AOC-Substrat 12,13-EOT besteht in einer fehlenden Doppelbindung an den Positionen C11 und C15. Die Substratbindetasche von AtAOC2 besteht hauptsächlich aus aromatischen und hydrophoben Resten. Der einzige polare Kontakt des Enzyms zum Substratanalogon entsteht durch einen konservierten Glutamatrest an Position 23 (AtAOC2, Glu-23), der vermutlich die 
Doppelbindung an Position C15 des Substrates stabilisiert (Abbildung 1.6). Weiterhin wurde ein Wassermolekül im aktiven Zentrum lokalisiert, das durch vier polare Aminosäurereste gebunden wird und wahrscheinlich eine Rolle bei der Ringschlussreaktion hat, indem es den Übergangszustand stabilisiert. Zusätzlich konnte ein Phenylalaninrest im aktiven Zentrum ausgemacht werden (AtAOC2 Phe-85), der wahrscheinlich für die Stereoselektivität des Enzyms entscheidend ist. Ein Austausch des AtAOC2 Phe85 in Alanin führte zu 50 \%igem Verlust der Enzymaktivität bei gleichzeitigem Verlust der Stereoselektivität des Enzyms (Hofmann et al., 2006).

Hofmann et al., (2006) diskutieren den Reaktionsmechanismus der Ringschlussreaktion anhand von Bindung und Lage des Substratanalogs in der beschriebenen Raumstruktur (Abbildung 1.6).
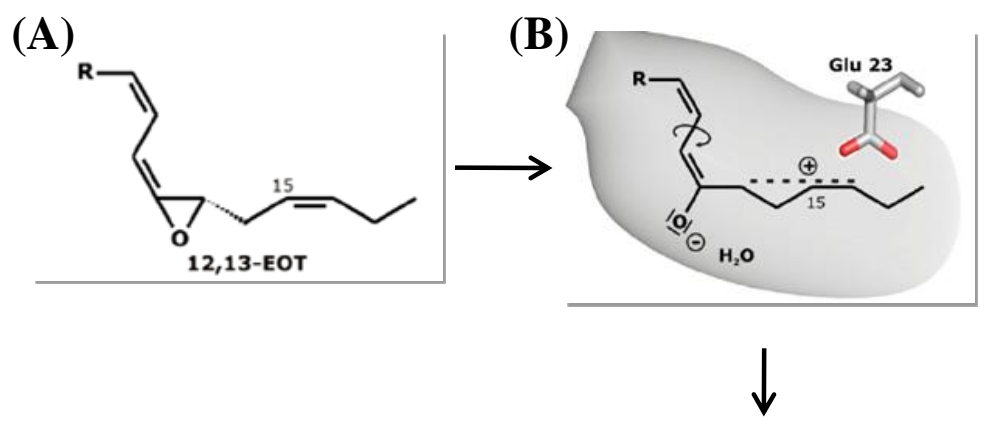

(C)
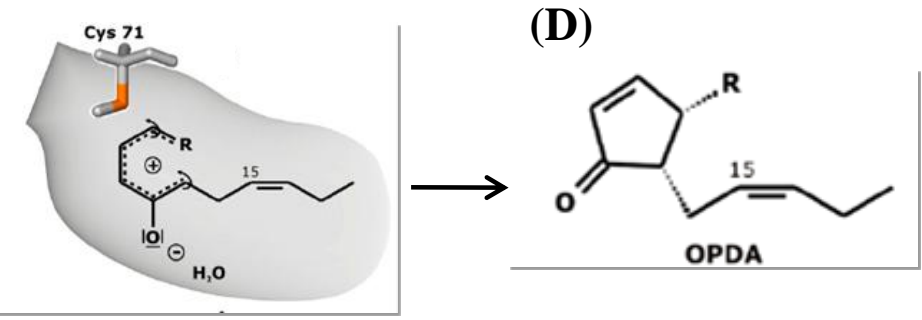

Abbildung 1.6: Hypothetischer AOC-Reaktionsmechanismus. (modifiziert nach Hofmann et al., 2006) (A) Öffnung des Epoxydes; (B) Bildung des Pentadienyl-Kation und Delokalisation der C15-Doppelbindung, (C) Ringschlussreaktion unter Bildung eines Pentadienyl-Carbokations (D) Perizyklischer Ringschluss, entsprechend der Woodward-Hoffmann Regeln.

Nachdem das Substrat gebunden hat, wird das Epoxyd geöffnet und ein Pentadienyl-Kation gebildet. Die negative Ladung des AtAOC2 Glu-23 führt zu Delokalisation der C15-Doppelbindung in Richtung des Epoxydes wodurch dessen Öffnung und die Ringschlussreaktion gefördert werden. Die Bildung des Oxyanions wird durch das konservierte Wassermolekül im aktiven Zentrum stabilisiert. Für den folgenden perizyklischen Ringschluss ist eine Konformationsänderung der C10 - C11 Bindung von cis $\mathrm{zu}$ trans Geometrie unter Bildung eines nicht-planaren, ringähnlichen PentadienylCarbokations erforderlich. Ein Phenylalanin (AtAOC2 Phe-52) sowie ein Cysteinrest 
(AtAOC2 Cys-71) im aktiven Zentrum könnten diesen Vorgang unterstützen. Dieser hypothetische Reaktionsmechanismus ermöglicht als letzten Schritt einen perizyklischen Ringschluss, entsprechend der Woodward-Hoffmann Regeln.

\subsubsection{Die AOCs aus Blütenpflanzen}

Im Jahr 1997 isolierten Ziegler und Mitarbeiter natives AOC-Protein mit einer molekularen Masse von $47 \mathrm{kDa}$ in dimerer Form aus Maiskörnern und später gelang es ihnen, das erste AOC-Gen aus Tomate zu klonieren (Ziegler et al., 1997, Ziegler et al., 2000).

Weitere Untersuchungen zur Substratspezifität von ZmAOC und StAOC wurden ebenfalls von Ziegler et al., (1999) durchgeführt und es wurde u. a. gezeigt, dass AOC 12,13-EOT umsetzen, jedoch nicht 12,13(S)-Epoxy-9(Z),11-oktadekadiensäure (12,13-EOD) (Ziegler et al., 1999). Diese Ergebnisse stehen im Kontrast zur Substratspezifität der AOS, welche sowohl 13S-HPOTE als auch 13S-HPODE als Substrat akzeptiert (Song \& Brash, 1991). Damit ist der AOC-katalysierte Schritt entscheidend für die endgültige enantiomere Struktur von JA. Ziegler et al., (1999) testeten weitere verschiedene Allenoxide von $\mathrm{C}_{16^{-}}$bis $\mathrm{C}_{22^{-}}$ Fettsäure-Hydroperoxiden. Die Ergebnisse der Experimente von Ziegler et al., (1999) sind in Tabelle 1.2 zusammengefasst. Veresterte Substrate wurden von den AOCs nicht umgesetzt (Ziegler et al., 1997). In Tomate (Lycopersicum esculentum, LeAOC; Ziegler et al., 2000) und Gerste (Hordeum vulgare; HvAOC; Maucher et al., 2004) ist die AOC jeweils von einem Einzelgen kodiert und die immunohistologische Lokalisierung an Chloroplasten stimmt mit dem Vorhandensein eines N-terminalen CTS überein (Ziegler et al., 2000, Stenzel et al., 2003a). In Arabidopsis kommen AOCs als kleine Genfamilie mit vier Isoenzymen vor (Stenzel et al., 2003b).

Tabelle 1.2: $\quad$ Substratspezifität von Mais- und Kartoffel-AOC (nach Ziegler et al., 1999).

\begin{tabular}{|c|c|c|}
\hline Fettsäure & Fettsäure-Hydroperoxid & Allenoxid \\
\hline ALA & 13S-HPOTE & 12,13-EOT \\
\hline $16: 3^{\Delta 7 Z \Delta 10 Z \Delta 13 Z}$ & $\begin{array}{l}11 S \text {-Hydroperoxy-7Z,9E,13Z- } \\
\text { Hexadekatriensäure }\end{array}$ & $\begin{array}{l}\text { 10,11S-Epoxy-7Z,9,13Z- } \\
\text { Hexadekatriensäure }\end{array}$ \\
\hline GLA & $\begin{array}{l}\text { 9S-Hydroperoxy-6Z,10E,12Z- } \\
\text { Oktadekatriensäure }\end{array}$ & $\begin{array}{l}9 S, 10 \text {-Epoxy-6Z,10,12Z- } \\
\text { Oktadekatriensäure }\end{array}$ \\
\hline $\mathbf{A A}$ & 15S-HPETE & $\begin{array}{l}\text { 14,15S-Epoxy-11Z,13,17Z- } \\
\text { Eikosatriensäure }\end{array}$ \\
\hline EPA & $\begin{array}{l}15 S \text {-Hydroperoxy-5Z,8Z,11Z,13E,17Z- } \\
\text { Eikosapentaensäure (15S-HPEPE) }\end{array}$ & $\begin{array}{l}\text { 14,15S-Epoxy-5Z,8Z,11Z,13,17Z- } \\
\text { Eikosapentaensäure }\end{array}$ \\
\hline DHA & $\begin{array}{l}17 S \text {-Hydroperoxy-7Z,10Z,13Z,15E,19Z- } \\
\text { Docosapentaensäure }\end{array}$ & $\begin{array}{l}\text { 16,17S-Epoxy-7Z,10Z,13Z,15,19Z } \\
\text { Docosapentaensäure }\end{array}$ \\
\hline $20: 3^{\Delta 11 Z \Delta 14 Z \Delta 17 Z}$ & 15S-Hydroperoxy-11Z,13E,17Z- & 15S-Hydroperoxy-11Z,13E,17Z- \\
\hline
\end{tabular}




\subsubsection{Die AOCs aus $P$. patens}

Zyklische Fettsäuren und ihre Derivate, wie JA und ihre Vorstufe OPDA gehören zu den wichtigsten Signalen bei der Antwort auf biotischen und abiotischen Stress sowie Entwicklungsprozessen in Blütenpflanzen (1.2.4). Bisher ist jedoch wenig über Zyklopentenone und Zyklopentanone und ihre Funktion in Moosen bekannt. Um die Forschungen auf diesem Gebiet voranzutreiben, wurden die cDNA von zwei AOS Genen (PpAOS1 und PpAOS2) und zwei AOC Genen (PpAOC1 und PpAOC2) isoliert (M. Stumpe, Dissertation, 2006). Die AOC Gene kodieren jeweils für Proteine mit einer Länge von 189 (PpAOC1) und 188 (PpAOC2) Aminosäuren und haben eine molekulare Masse von ca. $21 \mathrm{kDa}$. Die Proteinsequenzen sind zu $84 \%$ identisch und beiden Proteinen aus P. patens scheint die für AOC typische N-terminale CTS $\mathrm{zu}$ fehlen, was bereits für die HvAOC beobachtet wurde (Maucher et al., 2004). In Lokalisationsstudien mit fluoreszierenden Markern konnten die AOC-Proteine jedoch in den Chloroplasten nachgewiesen werden (M. Stumpe, Dissertation, 2006). Um herauszufinden, welche Substrate PpAOC1 und PpAOC2 akzeptieren, wurden verschiedene Hydroperoxy-Fettsäuren getestet. Wie erwartet waren $P p A O C 1$ und $P p A O C 2$ mit dem Substrat 12,13-EOT aus 13S-HPOTE aktiv. Zusätzlich zeigte PpAOC2 hohe Aktivität mit dem Allenoxid des Substrates 12S-HPETE. Hingegen wurde für PpAOC1 geringere Aktivität für dieses Substrat beobachtet. Das zyklische Produkt der Umsetzung von 12S-HPETE ist ein neues Phytoprostan (5Z,8S,12S,15Z)-11-Oxo-5,9,15phytotriensäure (11-OPTA), dessen Funktion in $P$. patens noch nicht geklärt wurde.

Damit sind PpAOC1 und PpAOC2 interessante Enzyme um eine vergleichende Strukturanalyse durchzuführen. Es sind kleine Proteine $(21 \mathrm{kDa})$ und PpAOC1 und PpAOC2 besitzen keine CTS, was bei rekombinanter Expression stören könnte (Hofmann et al., 2006). Obwohl StAOC und ZmAOC die Allenoxide der 15S-Hydroperoxy-Fettsäuren von AA, EPA und 20:3 $3^{\Delta 11 \Delta 14 \Delta 17}$ zyklisieren (Ziegler et al., 1999), ist bis jetzt kein weiteres AOC-Enzym bekannt, welches $12 S$-HPETE in ein zyklisches Produkt umwandelt. Es stellt sich zudem die Frage, warum $P p A O C 1$ und PpAOC2 trotz ihrer hohen Sequenzidentität unterschiedliche Substrataffinitäten für das Substrat 12S-HPETE haben. Es gibt darüber hinaus weitere $\mathrm{C}_{20}$-Substrate mit unterschiedlicher Anzahl und Position der Doppelbindungen oder Position der Epoxydgruppe, die von Ziegler und seinen Mitarbeitern für ZmAOC und StAOC nicht verwendet wurden. Durch einen gekoppelten Aktivitätstest mit PpAOS und PpAOC1, bzw. PpAOC2 könnten die unterschiedlichen Substrataffinitäten anhand der Position und Anzahl der Doppelbindungen, bzw. der Position der Epoxydgruppe geklärt werden. 


\subsection{Aufgabenstellung}

In der vorliegenden Dissertation sollten Enyzme des Oxylipinstoffwechsels von P. patens funktionell und strukturell charakterisiert werden. Wie eingangs erläutert sind die bifunktionale $P p L O X 1$, welche eine zusätzliche Lyaseaktivität besitzt und zwei $P p A O C$ Enzyme (PpAOC1 und PpAOC2) mit unterschiedlichen Substratspezifitäten interessante Untersuchungsobjekte. Zur Untersuchung der besonderen Eigenschaften von P $p$ LOX1, PpAOC1 und PpAOC2 standen mehrere biochemische, bioinformatische sowie physikalische Methoden zur Verfügung. Zu Beginn der Arbeiten war die Aufreinigung der rekombinanten Enzyme geplant. Mit den gereinigten Enzymen sollten dann Enzymaktivitätstests mit Umsetzung spezifischer Substrate durchgeführt werden. Darüber hinaus war in dieser Dissertation die strukturelle Aufklärung von $P p L O X 1, P p A O C 1$ und $P p A O C 2$ von besonderer Bedeutung. Es sollten für diese Enzyme geeignete Kristallisationsbedingungen gefunden werden, mit der sich hochauflösende Proteinkristalle erzeugen lassen. Mit diesen Kristallen sollten dann die Enzymstrukturen gelöst werden. Ein weiteres Ziel dieser Arbeit ist die strukturelle Auflösung von Enzym/Substrat-, bzw. Enzym/Produkt-Komplexen, an denen die Lage und Bindung der Substrate, bzw. Produkte diskutiert werden kann. An diese Ergebnisse anschließend und unter Einbezug bioinformatischer Informationen, wie dem Vergleich von Aminosäure-Sequenzen, sollen Aminosäurereste des aktiven Zentrums durch ortsgerichtete Mutagenese ausgetauscht werden. Die so erzeugten Enzymvarianten sollen schließlich in Enzymaktivitätstests mit den Ausgangsenzymen verglichen werden. Anhand dieser Experimente soll eine umfassende Charekterisierung von PpLOX1, PpAOC1 und PpAOC2 möglich sein. 


\section{MATERial Und Methoden}

\subsection{Großgeräte}

ABI Prism 310 Genetic Analyser

ÄKTAprime ${ }^{\mathrm{TM}}$

ÄKTA-FPLCTM

Binokulare

MZ 16

MZ 125

Frac920 Fraktionierer

Gel-Detektionssystem AIDA

Agilent 1100 Series HPLC System

HPLC 1100 series

Surveyor HPLC System

Thermo Finnigan LCQ Ion Trap

Mass Spectrometer

Mini-PROTEAN@3 Elektrophoreseapparatur

Mini Trans-Blot ${ }^{\circledR}$ cell equipment

$\mathrm{pH}-$ Meter inolab $\mathrm{pH}$ level 1

Photometer Ultospec. 1100 pro

Röntgendiffraktometer Micromax 007

Röntgendiffraktometer RU-H3R

Röntgendetektor mar345

Sonifier ${ }^{\circledR}$ cell disrupter B15

Vortex Genie $2 \mathrm{G}$
PE Applied Biosystems,

Weiterstadt, DE

GE Healthcare Lifescience,

München, DE

GE Healthcare Lifescience,

München, DE

Leica, Solms, DE

Leica, Solms, DE

GE Healthcare Lifescience,

München, DE

Raytest, Straubenhardt, DE

Agilent, Heilbronn, DE

Thermo Finnigan (San Jose, CA, USA)

Thermo Finnigan (San Jose, CA, USA)

Bio Rad, München, DE

Bio Rad, München, DE

WTW, Weilheim, DE

GE Healthcare Life Science,

München, DE

Rigaku/MSC, Japan

Rigaku/MSC, Japan

Marresearch GmbH, Norderstedt, DE

Branson, CT, USA

Scientific Industries, NY, USA 
Thermocycler: Mastercycler personal

Thermocycler: Mastercycler gradient

Zentrifugen: Biofuge pico

Kühlzentrifuge 5810 R

Kühlzentrifuge 5417 R

Tischzentrifuge 5415 D

Avanti ${ }^{\mathrm{TM}} \mathrm{J}-25$ Zentrifuge

\subsection{Verbrauchsmaterialien}

Kristallisationsplatten, 24 well

(sitting drop)

Nitrozellulosemembran Protran ${ }^{\circledR}$

Zentrikon Vivaspin 15

\subsection{Chromatographiesäulen}

Glutathion Sepharose 4 FF XK 16/20

HiPrep desalting 26/26

MonoQ® FPLC® HR10/10

Source 30Q FF XK 16/20

Superdex ${ }^{\text {TM }} 75$ HiLoad 16/60

\section{RP-HPLC Säulen:}

EC 250/2 Nucleosil 100-5 C-18

250 x 2,1 mm5 $\mu \mathrm{m}$ Partikelgröße

EC 250/2 Nucleosil 120-5 C18

250 x 2 mm, $5 \mu \mathrm{m}$ Partikelgröße
Eppendorf AG, Hamburg, DE

Eppendorf AG, Hamburg, DE

Heraeus Sepatech, Osterode, DE

Eppendorf AG, Hamburg, DE

Eppendorf AG, Hamburg, DE

Eppendorf AG, Hamburg, DE

Beckmann, Coulter GmbH,

Krefeld, DE

Hampton research, Aliso Viejo, CA, USA

Whatman GmbH, Dassel, DE

Sartorius, Göttingen, DE

GE Healthcare Lifescience,

München, DE

GE Healthcare Lifescience,

München, DE

GE Healthcare Lifescience,

München, DE

GE Healthcare Lifescience,

München, DE

GE Healthcare Lifescience,

München, DE

Macherey-Nagel Düren, DE

Macherey-Nagel Düren, DE 


\section{SP-HPLC Säule:}

Zorbax SIL, 150 x $2,1 \mathrm{~mm}$

Agilent Waldbronn, DE

$5 \mu \mathrm{m}$ Partikelgröße

\subsection{Chemikalien}

Wenn nicht anders erwähnt, wurden alle verwendeten Chemikalien von Sigma-Aldrich (München, DE), Carl Roth \& Co (Karlsruhe, DE), Merck (Darmstadt, DE) oder Fluka (Buchs, DE) bezogen und besitzen den Reiheitsgrad pro analysi. Die Agarose wurde von Biozym Scientific GmbH (Hess. Oldendorf, DE) erworben. Die Fettsäuren wurden von Sigma-Aldrich (München, DE), Larodan (CPS Chemie + Service GmbH, Düren, DE) oder Cayman (Ann Arbor, MI, USA) bezogen.

Die Lösungsmittel mit dem Reinheitsgrad High performance liquid chromatography (HPLC) für die analytischen Methoden wurden bei Acros (Geel, Belgien) oder Baker (Griesheim, DE) gekauft. Wasser wurde mit einer Nanopur-Anlage gereinigt und entspricht in der Qualität zweifach destilliertem Wasser. Es wurde durch Autoklavieren sterilisiert, soweit nicht anders beschrieben.

\subsection{Kitsysteme}

ABI PRISM ${ }^{\circledR}$ BigDye $^{\mathrm{TM}}$ Terminator Cycle

Sequencing Ready Reaction Kit v1.1

cloneJET $^{\mathrm{TM}}$ PCR Cloning Kit

NucleoSpin ${ }^{\mathrm{TM}}$ Extract Kit

NucleoSpin ${ }^{\text {TMPlasmid Kit }}$

pGEM®-T-System

Quick Change Mutagenesis Kit
Applied Biosystems, Foster City, CA,

USA

Fermentas, St.Leon-Rot, DE

Macherey-Nagel, Düren, DE

Macherey-Nagel, Düren, DE

Promega, Heidelberg, DE

Stratagene, Biozyme, Scientific GmbH, Hess. Oldendorf, DE

Sigma Aldrich, München, DE

Stratagene, Biozyme, Scientific GmbH

Finnzymes, Espoo, Finnland

GE Healthcare Lifescience,

München,DE 
Complete mini EDTA-free Proteaseinhibitor

Restriktionsendonukleasen

Tfl-Polymerase

T4-DNA-Ligase
Roche Diagnostics, Mannheim, DE

Fermentas, St.Leon-Rot, DE

Stratagene, Biozyme, Scientific GmbH, Hess. Oldendorf, DE

Fermentas, St.Leon-Rot, DE

\subsection{Vektoren und Oligonukleotide}

\subsubsection{Klonierungvektoren}

pGEM®-T

$\mathrm{Amp}^{\mathrm{R}}$, Promega, Heidelberg, DE

pJET 1.2/blunt

$\mathrm{Amp}^{\mathrm{R}}$, Fermentas, St. Leon-Rot, DE

\subsubsection{Expressionsvektoren}

pet $24 \mathrm{~b}$

$\operatorname{Kan}^{\mathrm{R}}$, Novagen, Schwalbach, DE

pet28a

$\mathrm{Kan}^{\mathrm{R}}$, Novagen, Schwalbach, DE

pGEX-6P-1

$A m p^{R}$ GE Healthcare Lifescience,

München, DE

pQE 30

$\mathrm{Amp}^{\mathrm{R}}$, Qiagen, Hilden, DE

\subsubsection{Oligonukleotide}

Alle in dieser verwendeten Arbeit verwendeten Oligonukleotide wurden bei Biomers (Ulm, DE) oder Invitrogen (Karlsruhe, DE) synthetisiert.

\subsection{DNA - und Protein-Standards}

Gene Ruler ${ }^{\mathrm{TM}} 1 \mathrm{~kb}$ DNA-Ladder

PageRuler ${ }^{\mathrm{TM}}$ Unstained Protein Ladder

Prestained Protein Molecular Weight Marker

Protein Molecular Weight Marker
MBI Fermentas, St. Leon-Roth, DE

MBI Fermentas, St. Leon-Rot, DE

MBI Fermentas, St. Leon-Rot, DE

MBI Fermentas, St. Leon-Rot, DE

\subsection{Bakterien-Zellstämme}

Escherichia coli Xl1Blue (Bullock et al., 1987) recAlendA1 gyrA96 thi-1hsdR17 supE44 relA1lac[F'proAB lac9zM15 Tn19(Tetr)] (Stratagene, Biozyme, Scientific GmbH, Hess. Oldendorf, DE) 
E. coli BL21 star [DE3]

F ompT hsd $S_{B}\left(r_{B}{ }^{-} m_{B}{ }^{-}\right)$gal dem (DE3)

(Invitrogen, Karlsruhe, DE)

E. coli SG 13009 [pREP4]

$\mathrm{Nal}^{S} \mathrm{Str}^{S} \mathrm{rif}^{S}$, lac $\mathrm{ara}^{-} \mathrm{gal}^{-} \mathrm{mtl}^{-} \mathrm{F}^{-} \mathrm{recA}^{+} \mathrm{uvr}^{+}$

(Quiagen, Hilden, DE)

\subsection{Kristallisationscreens}

Additive Screen 1-4

Clear Strategy Screen 1-3

Crystal Screen I/II/Light/Cryo/PEG-ION

Footprint Screen 1-3

JB Screen 1-10

Magic Screen 1-4

Structure Screen 1-3

\subsection{Computersoftware}

Automar

Collaborative Computational Project Number 4

CNS

Coot

ExPASy Proteomics Server

Ligplot

MOSFLM

Origin 6.0

PHASER

PHENIX suite

PRODRG Server2
Hampton research, Aliso Viejo, CA, USA

Jena Bioscienes, Jena, DE

Hampton research, Aliso Viejo, CA, USA

(Stura et al., 1992)

Jena Bioscienes, Jena, DE

Biogenova, Ellicott City, MD, USA

Molecular dimensions, Suffolk, UK

Marresearch GmbH, Norderstedt, DE

Potterton et al., 2003

(CCP4i) programme suite

Brunger et al., 1998

Emsley \& Cowtan, 2004

SIB, Schweiz

Wallace et al., 1995

Leslie et al., 1992

Northampton, USA

McCoy et al., 2007

Adams et al.

Schuttelkopf \& van Aalten, 2004 
SCALA

Xcalibur

XDS
Scientific, Palo Alto, CA, USA

Evans, 2006

Thermo Electron, San Jose, CA, USA

Kabsch, 1988

\subsection{Molekularbiologische Methoden}

Für alle molekularbiologischen und mikrobiologischen Untersuchungen wurden die Standardprotokolle Current Protocols In Molecular Biology (Ausubel et al., 1993) verwendet. Von diesen Protokollen abweichende Methoden werden im Folgenden beschrieben.

Es wurden hitzesterilisierte Glasgefäße $\left(3 \mathrm{~h}\right.$ bei $\left.180^{\circ} \mathrm{C}\right)$ bzw. sterile Plastikartikel verwendet.

\subsubsection{Isolation von Plasmid-DNA}

Die Isolation von Plasmid-DNA aus E. coli erfolgte mit Flüssigkulturen entsprechend dem Protokoll von Birnboim \& Doly 1979. Für Plasmidpräparationen im kleinen Maßstab wurde das Kitsystem NucleoSpin ${ }^{\mathrm{TM}}$ Plasmid-Kit (2.5) entsprechend des Herstellerprotokolls verwendet.

\subsubsection{Amplifikation von DNA-Fragmenten durch Polymerase-Kettenreaktion (PCR)} Zur selektiven Vervielfältigung von DNA-Sequenzen wird standardmäßig die PolymeraseKettenreaktion (PCR; Saiki et al., 1988) genutzt. Doppelsträngige DNA wird in diesem Verfahren zunächst thermisch denaturiert wenn die DNA auf mehr als $80{ }^{\circ} \mathrm{C}$ erhitzt wird. Bei dieser Temperatur trennen sich die beiden Stränge voneinander. Unter Verwendung von hitzestabilen DNA-Polymerasen werden Teile der Einzelstränge repliziert. Grundlage für die Amplifikation der DNA sind zwei spezifische Oligonukleotide, die als Primer eingesetzt werden und an den Enden der Zielsequenz liegen müssen. Die Primer und ein Gemisch aus den vier Desoxynukleotiden werden dem Reaktionsansatz im Überschuss zugesetzt. Wenn die Temperatur sinkt, lagern sich die Primer an komplementäre Sequenzen der denaturierten Matrizen-DNA an und bilden so den Startpunkt zur Synthese des Gegenstrangs durch die DNA-Polymerase. Durch die thermostabile Eigenschaft der DNA-Polymerase durchläuft der Reaktionsansatz immer wieder Zyklen von Denaturierung, Primeranlagerung und Doppelstrangsynthese und die Anzahl der Kopien der DNA-Zielsequenz steigt exponentiell an. Die Reaktionsvolumina betrugen $25 \mu$ für analytische Zwecke und $50 \mu$ l für präparative Zwecke. Beispielhaft ist hier ein Standard-Programm wiedergegeben:

$1.95^{\circ} \mathrm{C} 30 \mathrm{~s}$ (Denaturierung) 
2. $95{ }^{\circ} \mathrm{C} 30 \mathrm{~s}$ (Denaturierung)

3. $\mathrm{T}_{\text {Ann }}{ }^{\circ} \mathrm{C} 30 \mathrm{~s}$ (Annealing, Anlagerung)

4. $72{ }^{\circ} \mathrm{C} \mathrm{n} \mathrm{s}$ (Elongation) (ca. 1 min pro kb erwartetes Produkt)

Der Zyklus von 2. - 4. wurde 18 - 35-mal wiederholt.

$5.72{ }^{\circ} \mathrm{C} 3-10 \mathrm{~min}$

$\mathrm{T}_{A n n}$ ist die Anlagerungs-(Annealing)-Temperatur der verwendeten Primer (ca. $3{ }^{\circ} \mathrm{C}$ unter der Schmelztemperatur). Die Schmelztemperatur lässt sich folgendermaßen berechnen:

$\operatorname{Tm}\left[{ }^{\circ} \mathrm{C}\right]=69,3+0,41[\% \mathrm{GC}]-650 / \mathrm{n}$ (wobei $\mathrm{n}=$ Anzahl der Nukleotide $)$.

\subsubsection{Kolonie-PCR}

Mit der Kolonie-PCR wurden transformierte Einzelklone mit spezifischen Primern auf das Vorhandensein des gesuchten DNA-Fragments überprüft. Einzelne Bakterienkolonien wurden mit sterilen Zahnstochern gepickt und direkt in dem PCR-Reaktionsansatz suspendiert. Zum Aufschließen der Bakterien wurden der eigentlichen Amplifikationsreaktion (2.12.2) 5 min bei $95{ }^{\circ} \mathrm{C}$ im PCR-Programm vorangestellt.

\subsubsection{Zielgerichtete Mutagenese}

Reaktionsgemisch $\left(\mathrm{V}_{\text {ges }} \underline{50 \mu \mathrm{L})}\right.$ : 5x Pfu-DNA-Polymerase Puffer mit $\mathrm{MgCl}_{2}, 0,2 \mathrm{mM}$ dNTP,

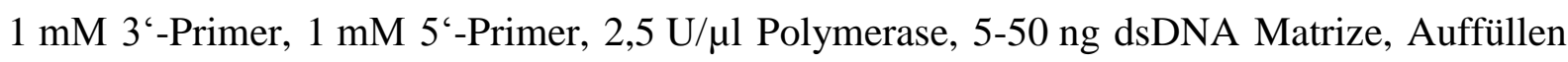
mit $\mathrm{ddH}_{2} \mathrm{O}$ auf $50 \mu \mathrm{l}$

Mit Hilfe des QuickChange ${ }^{\mathrm{TM}}$ Site-Directed Mutagenesis Kits ist es möglich in DoppelstrangPlasmid-DNA genau lokalisierte Mutationen einzufügen. Hierfür wurde die Pfu-DNAPolymerase verwendet, welche Plasmide mit hoher Korrekturfunktion repliziert. Des Weiteren wurden das Plasmid mit dem gewünschten Gen, sowie zwei Oligonukleotid-Primer, welche die gewünschte Mutation tragen, benötigt. Zusätzlich zur Mutation wurde eine Restriktionsschnittstelle eingeführt, die in der Mutter-DNA nicht vorhanden ist. Jedoch wurde darauf geachtet, dass eine stille Mutation entstand und die Basen wurden so ausgetauscht, dass die durch sie codierten Aminosäuren nicht verändert wurden. Durch diese zusätzliche Restriktionsschnittstelle wurden erfolgreich mutierte Klone anhand des Schnittmusters selektiert. Die beiden Oligonukleotid-Primer waren komplementär zum 5'-3'oder zum 3'-5' Strang des Vektors und führten durch die Aktivität der Pfu-DNA-Polymerase zur Kopie des Plasmids.

Nach erfolgter Amplifikation wurde der PCR-Ansatz mit Dpn I verdaut. Dies ist eine Endonuklease, welche spezifisch methylierte und hemimethylierte DNA schneidet. Hierdurch wird der methylierte DNA-Mutterstrang, welcher als Matrize dient verdaut, so dass am Ende 
nur die Tochter-DNA übrig bleibt. Folgendes PCR-Programm wurde für die Mutagenese verwendet:

$1.95^{\circ} \mathrm{C} 30 \mathrm{~s}$ (Denaturierung)

2. $95^{\circ} \mathrm{C} 30 \mathrm{~s}$ (Denaturierung)

3. $55^{\circ} \mathrm{C} 1 \mathrm{~min}$ (Annealing)

4. $68{ }^{\circ} \mathrm{C} 11-16 \mathrm{~min}$ (Elongation)

Der Zyklus von 2. - 4. wurde 15-mal wiederholt.

Anschließend wurde dem PCR-Ansatz $10 \mathrm{U}$ des Dpn I-Restriktionsenzyms hinzugefügt und $1 \mathrm{~h}-4 \mathrm{~h}$ bei $37^{\circ} \mathrm{C}$ inkubiert.

\subsubsection{Agarose-Gelelektrophorese}

TAE-Puffer (50x):, 2 M Tris/HCl pH 7,0, 1 M Essigsäure, 0,05 M EDTA

DNA-Probenpuffer: 100 mM EDTA, 0,1\% (w/v) SDS, $40 \%$ (w/v) Glyzerin, 0,025\% (w/v) Bromphenolblau, 0,025\% (w/v) Xylencyanolblau

Zur Auftrennung und Größenbestimmung von DNA-Fragmenten wurden die PCR-Produkte in $1 \%$ igen (w/v) Agarosegelen elektrophoretisch aufgetrennt. Zu diesem Zweck wurde Agarose mit 1xTAE-Puffer durch kurzes Erhitzen in der Mikrowelle gelöst und in die Gelträger gegossen. Vor dem Auftragen der Proben wurden diese mit 1/10 des Volumens an Probenpuffer versetzt. Als Größenstandard wurden $3 \mu \mathrm{l}$ des GeneRuler ${ }^{\mathrm{TM}} 1$ kb DNA-LadderMixes in einer separaten Geltasche mitgeführt. Die Gelelektrophorese wurde für 20 - 40 min bei einer Spannung von $120 \mathrm{~V}$ in 1x TAE-Puffer durchgeführt. Anschließend wurden die Gele für 10 - 20 min in einer Ethidiumbromid-Färbelösung $(2 \mu \mathrm{g} / \mathrm{ml})$ inkubiert. Ethidiumbromid ist aufgrund seiner planaren Struktur in der Lage sich reversibel in die Basenabfolge der DNA einzulagern (Interkalation). Bei Bestrahlung mit UV-Licht $(\lambda \approx 300 \mathrm{~nm})$ tritt eine Fluoreszenz im sichtbaren Lichtspektrum auf. Damit wurden die DNA-Banden durch UV-Licht sichtbar gemacht und anschließend fotografiert.

\subsubsection{DNA-Sequenzanalyse}

Reaktionsansatz: 200 - 300 ng DNA-Matrize, 1,5 $\mu$ BDT Ready Reaction Mix, 1,5 $\mu 1$ half term-Puffer, $1 \mu \mathrm{l}$ Sequenzierungsprimer $(0,5 \mu \mathrm{M})$, auffüllen auf $10 \mu \mathrm{l}$ mit sterilem $\mathrm{ddH}_{2} \mathrm{O}$

Die Sequenzierung von DNA-Fragmenten erfolgte nach der Methode von (Sanger et al., 1977) an einem Sequenzanalyse-Automaten (ABI PRISM® 3100). Für die Sequenzierungsreaktion wurde der ABI PRISM® BigDye ${ }^{\mathrm{TM}}$ Terminator Cycle Sequencing Ready Reaction Kit v1.1 verwendet. Dieser Kit beruht auf der Verwendung von Didesoxynukleotiden, die aufgrund ihrer fehlenden 3'-OH-Gruppe zum Kettenabbruch bei der 
DNA-Polymerase-Reaktion führen (Cycle Sequencing). Die Didesoxynukleotide sind zusätzlich mit einem basenspezifischen Fluoreszenzfarbstoff konjugiert. Das Temperaturprofil der zyklischen Sequenzierungs-Reaktion:

$1.1 \min 96^{\circ} \mathrm{C}$ (Denaturierung)

2. $5 \mathrm{~s} 96^{\circ} \mathrm{C}$ (Denaturierung)

3. $15 \mathrm{~s} 55{ }^{\circ} \mathrm{C}$ (Annealing)

4. $4 \min 60^{\circ} \mathrm{C}$ (Elongation)

Der Zyklus von 2. - 4. wurde 25-mal wiederholt

Nach der Sequenzierungs-PCR wurden die Ansätze mit $2 \mu 13 \mathrm{M}$ Na-Acetat (pH 5), $2 \mu 1$ $125 \mathrm{mM}$ EDTA und $50 \mu 1$ Ethanol (96\%, v/v) gefällt und die DNA durch Zentrifugation (20000 g, 20 min) sedimentiert. Nach dem Waschen des DNA-Niederschlags mit $70 \mu 170 \%$ (v/v)-igem Ethanol wurde die DNA bei $90{ }^{\circ} \mathrm{C}$ für 1 min getrocknet und in $15 \mu$ deionisiertem Formamid aufgenommen. Die Lagerung bis zur Analyse erfolgte bei $-20{ }^{\circ} \mathrm{C}$.

\subsubsection{Restriktion von Plasmid-DNA}

Restriktionsendonukleasen erkennen spezifisch palindromische Sequenzen in DoppelstrangDNA und schneiden diese spezifisch in der Symmetrieachse, wobei so genannte glatte Enden entstehen, oder versetzt, wobei überhängende 5'- oder 3'-Enden entstehen. Die Plasmid-DNA wurde mit den verschiedenen Restriktionsenzymen in den entsprechenden Puffersystemen des Herstellers geschnitten. Zum Restriktionsverdau wurden die Ansätze für $1-4 \mathrm{~h}$ bei $37{ }^{\circ} \mathrm{C}$ inkubiert.

\subsubsection{Isolierung von DNA-Fragmenten aus Agarosegelen}

Fragmente, die für Ligationen (siehe 12.9) eingesetzt werden sollen, wurden aus Agarosegelen mit Hilfe des „NucleoSpin ${ }^{\circledR}$ Extract Kit“ (Macherey-Nagel, Düren, Deutschland) entsprechend den Angaben des Herstellers isoliert. Die Elution der DNA erfolgte mit $10-30 \mu \mathrm{ldd} \mathrm{H}_{2} \mathrm{O}$.

\subsubsection{Ligation}

Für die Konstruktion von rekombinanten Plasmiden wurden zu ligierende DNA, also Vektor (5-10 ng) und DNA-Fragment, in einem Gesamtvolumen von $10 \mu 1 \mathrm{mit} 1-5 \mathrm{U} / \mu 1 \mathrm{~T} 4-\mathrm{DNA}-$ Ligase über Nacht bei $4{ }^{\circ} \mathrm{C}$ inkubiert. Die T4-DNA-Ligase katalysiert dabei die Bildung von Phosphodiesterbindungen zwischen benachbarten 5'-Phosphat und 3'-OH-Gruppen. Handelte es sich bei dem DNA-Fragment um ein PCR-Produkt, wurde zur Ligation der pJET 1.2 blunt end Vektor verwendet. Die Ligation in den pJET 1.2 blunt end Vektor erfolgte für 30 min bei RT. 


\subsubsection{Präparation chemisch-kompetenter $\boldsymbol{E}$. coli-Zellen}

Transformationspuffer: $10 \mathrm{mM}$ PIPES, $15 \mathrm{mM} \mathrm{CaCl}_{2}, 250 \mathrm{mM} \mathrm{KCl}, \mathrm{pH}$ 6,7, $55 \mathrm{mM} \mathrm{MnCl}_{2}$, sterilfiltriert.

Für die Präparation kompetenter E. coli-Zellen wurde eine modifizierte Methode von Inoue et $a l$. , (1990) verwendet. Es wurden $5 \mathrm{ml}$ LB-Medium mit E. coli-Zellen angeimpft und über Nacht bei $37^{\circ} \mathrm{C}$ geschüttelt. Mit dieser Übernachtkultur wurden $500 \mathrm{ml}$ LB Medium $\left(\mathrm{OD}_{600}=\right.$ 0,25 - 0,3) angeimpft und bei $28^{\circ} \mathrm{C}$ bis zu einer $\mathrm{OD}_{600}$ von 0,6 - 0,7 angezogen. Hatte die Bakterienkultur diese OD erreicht, wurden die Zellen auf $50 \mathrm{ml}$ Reaktionsgefäße verteilt und durch Zentrifugation (3320 g, $10 \mathrm{~min}, 4{ }^{\circ} \mathrm{C}$ ) geerntet. $\mathrm{Zu}$ den Zellsedimenten wurden jeweils $15 \mathrm{ml}$ vorgekühlter Transformationspuffer gegeben und die Zellen vorsichtig resuspendiert. Die Suspensionen wurden für 15 min auf Eis inkubiert und anschließend wurden die Zellen bei $3220 \mathrm{~g}$ für $10 \mathrm{~min}$ bei $4^{\circ} \mathrm{C}$ zentrifugiert. Der Überstand wurde verworfen und die Zellen in $4 \mathrm{ml}$ Transformationspuffer und $300 \mu \mathrm{l}$ DMSO resuspendiert und weitere 5-10 min auf Eis gestellt. Die Zellsuspension wurde in 300-500 $\mu$ l Aliquots aufgeteilt und sofort in flüssigem $\mathrm{N}_{2}$ schockgefroren. Die Lagerung der kompetenten Zellen erfolgte bei $-80{ }^{\circ} \mathrm{C}$.

\subsubsection{Transformation kompetenter $E$. coli-Zellen}

Für jede Transformation von E. coli Zellen mit Plasmid-DNA wurde ein 50 - $100 \mu 1$-Aliquot kompetenter Zellen benötigt. Die kompetenten Zellen wurden dazu auf Eis aufgetaut und es wurden $10 \mu \mathrm{l}$ eines Ligationsansatzes (2.12.9) oder 0,5 $\mu \mathrm{l}$ aus Bakterien isolierte PlasmidDNA (2.12.1) dazu gegeben. Nach vorsichtigem Mischen wurden die Ansätze für 20 min auf Eis inkubiert. Anschließend wurde der Transformationsansatz für $45 \mathrm{~s}$ bei $42{ }^{\circ} \mathrm{C}$ einem Hitzeschock ausgesetzt und für 3 min auf Eis gestellt. Direkt im Anschluss wurden 0,7 ml LB-Medium zugegeben und die Transformationsansätze zur Expression des Gens für die Antibiotikaresistenz für $90 \mathrm{~min}$ bei $37^{\circ} \mathrm{C}$ schüttelnd inkubiert. Abschließend wurden die Transformationsansätze auf LB-Agar mit dem entsprechenden Antibiotikum plattiert und bei $37^{\circ} \mathrm{C}$ über Nacht inkubiert.

\subsection{Strategien zur Klonierung rekombinanter Plasmide für die Expression}

Im Folgenden werden die Klonierungsstrategien zur Herstellung der rekombinanten Plasmide für die Expression der einzelnen Zielproteine beschrieben.

\subsubsection{Klonierung von $P p A O C 1$ und $P$ pAOC2 in den pGEX-6-P-1 Vektor}

Die Gene von PpAOC1 und PpAOC2 waren im Rahmen der Dissertation von M. Stumpe in den pGEM®-T Vektor (Promega, Mannheim, DE) kloniert worden. Da für die Kristallisation 
von Proteinen hohe Proteinausbeuten kombiniert mit einer einfachen Reinigungsmethode vorteilhaft sind, wurden beide Gene in den pGEX-6-P-1 Vektor kloniert. Dieser enthält zusätzlich das Gen für eine Glutathion-S-Transferase, welche mit dem N-Terminus des Zielproteins fusioniert ist. Dazwischen ist eine PreScission Protease Schnittstelle eingefügt, über die Glutathion-S-Transferase und Zielprotein wieder getrennt werden können. Beide Gene konnten über jeweils über eine 5'BamHI und 3'HindIII Schnittstelle aus dem pGEM®T Vektor geschnitten werden (2.12.7). Zunächst wurden beide pGEM®-T Konstrukte mit HindIII verdaut und anschließend eine Auffüllreaktion mit CIAP Enzym durchgeführt. Dadurch wurde die HindIII Schnittstelle vom 5'zum 3'-Ende mit Nukleotiden aufgefüllt und es entstand eine glatte Schnittstelle. Dann wurde die Plasmid-DNA mit BamHI geschnitten. Da die multiple cloning site des pGEX Vektors keine HindIII Schnittstelle enthält, wurde dieser mit BamHI und SmaI verdaut. Anschließend konnten die Fragmente mit dem Vektor ligiert werden (2.12.9), danach wurden XL1 Blue Zellen mit den Konstrukten transformiert und der Ligationserfolg durch eine Kolonie-PCR (2.12.3) mit vektorspezifischen Primern überprüft. Klone, welche ein Fragment in der erwarteten Größe besaßen, wurden für eine Plasmidpräparation (2.12.1) vervielfältigt, anschließend sequenziert (2.12.6) und in die Expressionszelllinie E. coli BL21star transformiert (2.12.11).

\subsubsection{Zielgerichtete Mutagenese von PpAOC1 und PpAOC2}

Für die zielgerichtete Mutagenese von PpAOC1 und PpAOC2 wurden folgende Primer verwendet (Tabelle 2.1).

Tabelle 2.1: $\quad$ Primer für die PpAOC-Mutagenese.

\begin{tabular}{|c|c|}
\hline Primerbezeichnung & Nukleotidsequenz \\
\hline 5'AOC1 E18Q & CAT GTG CAG GAG CTG TTT GTA TAC CAA ATC AAT GAG CGC GAC CG \\
\hline 3'AOC1 E18Q & CG GTC GCG CTC ATT GAT TTG GTA TAC AAA CAG CTC CTG GAC ATG \\
\hline 5'AOC1 E18D & CAG GAG GTG TTT GTG TAC GAT ATC AAT GAC CGC GAC CG \\
\hline 3’AOC1 E18D & CG GTC GCG CTC ATT GAT ATC GTA CAC AAA CAC CTC CTG \\
\hline \multirow[t]{2}{*}{ 5’AOC1 F29I } & C AAT GAG CGC GAC CGT GGA TCC CCT GTG ATC TTG CCC TTC GGA \\
\hline & $\mathrm{AAG}$ \\
\hline \multirow[t]{2}{*}{ 3'AOC1 F29I } & СTT TCC GAA GGG CAA TAT CAC AGG GGA TCC ACG GTC GCG CTC ATT \\
\hline & G \\
\hline 5'AOC2 E18Q & GTA CAG GAG CTC TCA GTA TAC CAG ATT AAT GAG CGA GAT AG \\
\hline 3'AOC2 E18Q & Ст AтC TCG CTC ATт tTA TTG GTA TAC TGA GAg CTC CTG TAC \\
\hline 5'AOC2 E18D & CAG GAG CTC TCA GTA TAT GAT ATC AAT GAG CGA GAT AGA GG \\
\hline $3^{\prime} \mathrm{AOC} 2$ E18D & CC TCT ATC TCG CTC ATT GAT ATC ATA TAC TGA GAG CTC CTG \\
\hline
\end{tabular}




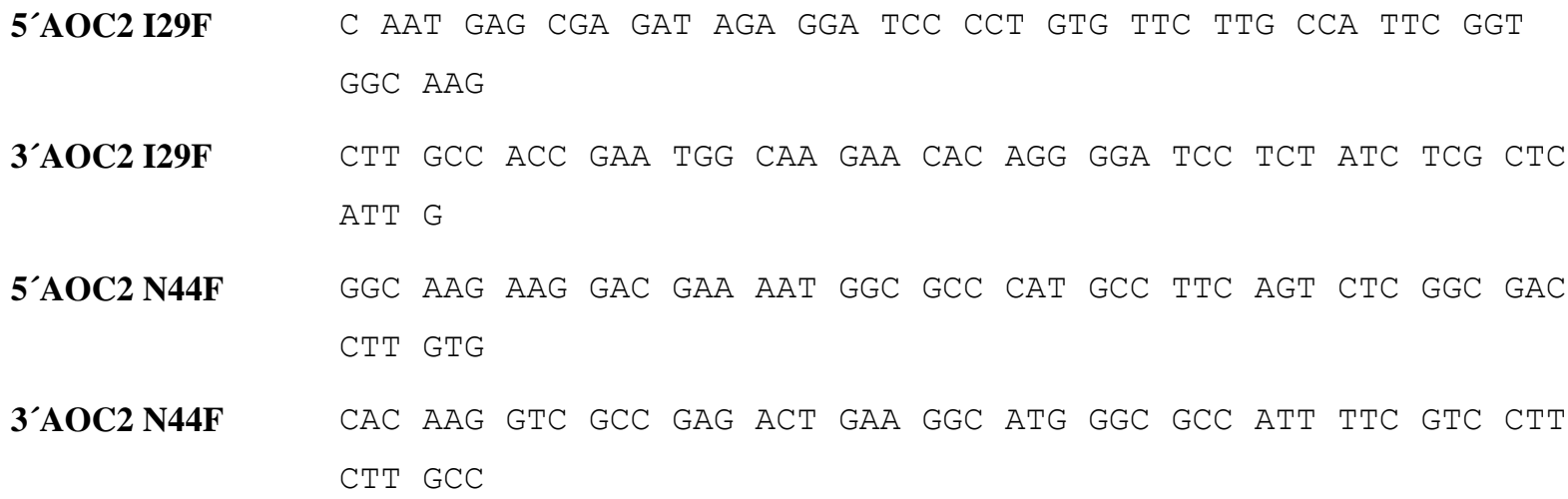

Die PCR wurde, wie in Abschnitt 2.12.4 beschrieben, durchgeführt. Dabei wurde eine Elongationszeit von 11 min gewählt. Anschließend wurden die Ansätze mit DpnI verdaut und für Plasmidpräperation in E. coli XL1 Blue Zellen transformiert. Die Plasmid-DNA wurde parallel zur Wildtyp-DNA mit dem jeweiligen Enzym verdaut, dessen Restriktionsschnittstelle mit der Mutagenese eingeführt worden war. Nach erfolgter Agarosegelelektrophorese wurden die Klone mit einer zusätzlichen Schnittstelle sequenziert und die Expressionszelllinie E. coli BL21star mit den Konstrukten transformiert (2.12.11).

\subsubsection{Klonierung von PpLOX1 in verschiedene Vektoren des pET-Systems}

Für die Klonierung von PpLOX1 in verschiedene Vektoren des pet-Systems (pET24b, pET28a) wurden die in Tabelle 2.2 aufgeführten Primer verwendet. Als Ausgangsplasmid wurde ein Volllängenklon im pQE30-Vektor von T. Senger verwendet.

Tabelle 2.2: $\quad$ Primer für die PpLOX1-Klonierung.

\begin{tabular}{|c|c|}
\hline Primerbezeichnung & Nukleotidsequenz \\
\hline 5'PpLOX1 NheIa & 5’AAA GCT AGC ATG CTC AAC CGG TTG GAG ACG GGG AGC \\
\hline PpLOX1-NheIa- & 5'ACG GCT AGC CAC CAT CAC CAT CAC CAT CAC CAT CAC CAT CTG \\
\hline 10His & $\begin{array}{l}\text { GAA GTT CTG TTC CAG GGG CCC ATG ATG CTC AAC CGG TTG GAG } \\
\text { ACG }\end{array}$ \\
\hline PpLOX1-HindIIIb & $\begin{array}{l}\text { 3`ATC AAC AGG AGT CCA AGC TCA GCT AAT TAA GCT TCT ATA GCT } \\
\text { TCT ATA TGG TGA TGC TGT TGG GC }\end{array}$ \\
\hline
\end{tabular}

Die PCR wurde, wie in Abschnitt 2.12.2 beschrieben, durchgeführt. Dabei wurde das folgende Programm gewählt.

$1.98^{\circ} \mathrm{C} 30 \mathrm{~s}$

$2.98^{\circ} \mathrm{C} 20 \mathrm{~s}$

3. $72{ }^{\circ} \mathrm{C} 2,15 \mathrm{~min}$ 
Der Zyklus von 2. - 3. wurde 10-mal wiederholt.

$4.98{ }^{\circ} \mathrm{C} 20 \mathrm{~s}$

$5.70{ }^{\circ} \mathrm{C} 30 \mathrm{~s}$

$6.72{ }^{\circ} \mathrm{C} 1,30 \mathrm{~min}$

Der Zyklus von 4. - 6. wurde 15-mal wiederholt.

7. $72{ }^{\circ} \mathrm{C} 10 \mathrm{~min}$

Die PCR-Produkte mit der erwarteten Größe von $2822 \mathrm{~kb}$ wurden direkt in den pJET blunt end 1.2 Vektor ligiert. Von positiven Klonen wurde die Plasmid DNA präpariert und das PpLOX1 Fragment durch Enzymverdau (NheI, HindIII) isoliert. Parallel dazu wurde die Vektor-DNA mit den entsprechenden Enzymen geschnitten. Das PpLOX1 Fragment wurde anschließend in den Vektor ligiert. Die Ligationsansätze wurden vollständig in XL1 Blue Zellen transformiert und der Ligationserfolg durch eine Kolonie-PCR (2.12.3) mit genspezifischen Primern überprüft. Klone, welche ein Fragment in der erwarteten Größe besaßen, wurden für eine Plasmidpräparation (2.12.1) vervielfältigt, anschließend sequenziert (2.12.6) und die Expressionszelllinie E. coli BL21star mit den Konstrukten transformiert (2.12.11).

\subsubsection{Herstellung von PpLOX1 ohne Signalpeptid ( $\triangle P p L O X 1)$}

Für die Herstellung von $P p L O X 1$ ohne CTS $(\triangle P p L O X 1)$ und anschließender Klonierung in den pET24a Vektor wurde der in Tabelle 2.3 aufgeführte 5’Primer verwendet.

Tabelle 2.3: $\quad$ Primer für die Klonierung von PpLOX1 ohne Signalpeptid.

\begin{tabular}{lll}
\hline Primerbezeichnung & \multicolumn{2}{l}{ Nukleotidsequenz } \\
\hline PPLOXshort_fw & AAA AGA TCT ATG AAG AAG CTG AAG GTG CT GGA C \\
\hline
\end{tabular}

Die gesamte Klonierung wurde wie in Abschnitt 2.13.3 beschrieben durchgeführt. Das PpLOX1 Fragment ohne CTS besitzt eine Größe von 2200 kb.

\subsubsection{Zielgerichtete Mutagenese von PpLOX1}

Für die zielgerichtete Mutagenese von PpLOX1 wurden die in Tabelle 2.4 aufgeführten Primer verwendet.

Tabelle 2.4: $\quad$ Primer für die PpLOX1 Mutagenese.

\begin{tabular}{ll}
\hline Primerbezeichnung & \multicolumn{2}{l}{ Nukleotidsequenz } \\
\hline \multirow{2}{*}{ ppLOX_5'_Y851F } & CAC CAC AAC TGC GAT GTC TGT CTT CGA AGT GCT GTC \\
& GGC GCA CTG TC \\
\hline
\end{tabular}




\begin{tabular}{|c|c|c|c|c|c|c|c|c|c|c|c|c|}
\hline \multirow{2}{*}{ ppLOX_3'_Y851F } & GAC & $\mathrm{AGT}$ & GCG & $\mathrm{CCG}$ & $\mathrm{ACA}$ & $\mathrm{GCA}$ & $\mathrm{CTT}$ & $\mathrm{CGA}$ & AGA & $\mathrm{CAG}$ & $\mathrm{ACA}$ & $\mathrm{TCG}$ \\
\hline & $\mathrm{CAG}$ & TTG & TGG & TG & & & & & & & & \\
\hline \multirow{2}{*}{ ppLOX_5'_Y851I } & CAC & AAC & TGC & GAT & GTC & TGT & GAT & CGA & AGT & $\mathrm{ACT}$ & GTC & GGC \\
\hline & $\mathrm{GCA}$ & $\mathrm{CTG}$ & $\mathrm{TCC}$ & G & & & & & & & & \\
\hline \multirow{2}{*}{ ppLOX_3'_Y851I } & CGG & $\mathrm{ACA}$ & GTG & CGC & CGA & $\mathrm{CAG}$ & $\mathrm{TAC}$ & TTC & GAT & $\mathrm{CAC}$ & AGA & $\mathrm{CAT}$ \\
\hline & CGC & AGT & TGT & G & & & & & & & & \\
\hline \multirow{2}{*}{ ppLOX_5'_R345L } & GAT & TTC & CTG & GCG & GAC & GGA & TTC & TTA & TCG & $\mathrm{ATC}$ & GGT & $\mathrm{CAC}$ \\
\hline & $\mathrm{TCC}$ & GTA & TCG & TCG & & & & & & & & \\
\hline \multirow{2}{*}{ ppLOX_3'_R345L } & $\mathrm{CGA}$ & $\mathrm{CGA}$ & TAC & GGA & GTG & $\mathrm{ACC}$ & GAT & CGA & TAA & GAA & $\mathrm{TCC}$ & GTC \\
\hline & CGC & $\mathrm{CAG}$ & GAA & ATC & & & & & & & & \\
\hline \multirow{2}{*}{ ppLOX_5'_R638L } & $\mathrm{AAG}$ & AGT & $\mathrm{ACG}$ & $\mathrm{CTC}$ & GAG & ATC & $\mathrm{AAC}$ & GTG & CAG & $\mathrm{GCA}$ & CGA & $\mathrm{GCG}$ \\
\hline & $\mathrm{ACT}$ & TTG & $\mathrm{ATC}$ & & & & & & & & & \\
\hline \multirow{2}{*}{ ppLOX_3'_R638L } & GAT & $C A A$ & $\mathrm{AGT}$ & GGC & TCG & TGC & CTG & CAG & GTT & $\mathrm{GAT}$ & $\mathrm{CTC}$ & GAG \\
\hline & CGT & $\mathrm{ACT}$ & $\mathrm{CTT}$ & G & & & & & & & & \\
\hline
\end{tabular}

Die PCR wurde wie in Abschnitt 2.12.4 beschrieben durchgeführt. Dabei wurde eine Elongationszeit von 16 min gewählt. Anschließend wurden die Ansätze mit DpnI verdaut und für Plasmidpräperation in E. coli XL1 Blue Zellen transformiert. Die Plasmid-DNA der Klone wurde parallel zur Wildform-DNA mit dem jeweiligen Enzym verdaut, dessen Restriktionsschnittstelle eingeführt worden war (2.12.7). Nach erfolgter Agarosegelelektrophorese wurden die Klone mit einer zusätzlichen Schnittstelle sequenziert und die Expressionszelllinie E. coli SG13009 mit den Konstrukten transformiert (2.12.6 und 2.12.11).

\subsection{Mikrobiologische Methoden}

\subsubsection{Kultivierung von E.coli}

\section{$\underline{\text { LB-Medium }}$}

10 g Trypton, 5 g Hefeextrakt, $10 \mathrm{~g} \mathrm{NaCl}$, ad $11 \mathrm{ddH}_{2} \mathrm{O}$

\section{$\underline{\text { LB-Agar }}$}

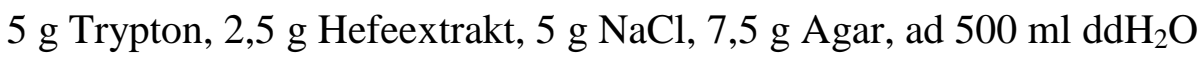

\section{YT-Medium}

20 g Trypton, 10 g Hefeextrakt, $5 \mathrm{~g} \mathrm{NaCl}$, ad $11 \mathrm{ddH}_{2} \mathrm{O}$

Die Flüssigmedien wurden entweder zur Plasmidpräparation (LB-Medium) oder zur Proteinexpression (LB-Medium, 2YT-Medium) verwendet. Zur Selektion auf plasmidvermittelte Antibiotikaresistenzen wurden alle Medien mit den entsprechenden 
Antibiotika versetzt. Die jeweiligen Antibiotika wurden in den folgenden Konzentrationen verwendet: Carbenicillin $(100 \mu \mathrm{g} / \mathrm{ml})$, Chloramphenicol $(34 \mu \mathrm{g} / \mathrm{ml})$ in $100 \%$ Ethanol und Kanamycin $(25 \mu \mathrm{g} / \mathrm{ml})$.

Für die Aufbewahrung von E. coli Klonen wurden diese bei $-80^{\circ} \mathrm{C}$ gelagert. Dafür wurde der Bakteriensuspension $30 \%(\mathrm{v} / \mathrm{v})$ Glyzerin zugesetzt und es wurden $800 \mu \mathrm{l}$ Aliquots eingefroren.

\subsubsection{IPTG-induzierte Proteinexpresion in E.coli}

Für alle in dieser Arbeit verwendeten Expressionssysteme erfolgte die Expression des Zielgens über das Lactose-Analogon Isopropy- $\beta$-D-thiogalaktopyranosid (IPTG) mittels eines lac-Promotors. Zur Expression eines Proteins wurden $500 \mathrm{ml}$ 2YT-Medium mit $5 \mathrm{ml}$ einer Übernachkultur, die den entsprechenden Vektor mit der für das Protein codierenden Sequenz enthielt, bei $37^{\circ} \mathrm{C}$ unter Schütteln $\left(180\right.$ - 220 rpm) bis zu einer OD $_{600}$ von 0,6 - 0,8 inkubiert. Anschließend wurde die Expression des Zielproteins durch Zugabe von $1 \mu \mathrm{M}$ IPTG Endkonzentration induziert.

Induzierte E. coli Kulturen wurden vier bis fünf Tage bei $16{ }^{\circ} \mathrm{C}$ (PpLOX1-Expression) oder einen Tag bei $28^{\circ} \mathrm{C}$ (PpAOC1- und PpAOC2-Expression) unter Schütteln inkubiert und abschließend durch Zentrifugation $\left(3220 \mathrm{~g}, 4{ }^{\circ} \mathrm{C}, 20 \mathrm{~min}\right)$ geerntet. Die sedimentierten Zellen wurden in flüssigem Stickstoff tiefgefroren und bis zur Verwendung bei $-20{ }^{\circ} \mathrm{C}$ gelagert.

\subsubsection{Zellaufschluss}

Tiefgefrorene Bakteriensedimente wurden als Vorbereitung für den Zellaufschluss auf Eis in Lysispuffer resuspendiert, welcher sich in seiner Zusammensetzung nach dem Puffer des ersten Reinigungsschrittes richtet. Zusätzlich wurden folgende Proteaseinhibitoren hinzu gegeben: $1 \mu 1$ 0,2 M PMSF je ml Suspension und je 1/2 Tablette Inhibitor Cocktail „Complete mini EDTA-free“ (Roche Diagnostics, München, DE) je $10 \mathrm{~g}$ Zellen.

Nach dem Resuspendieren wurden die Zellen durch Ultraschall mit dem Sonifier mit einer Amplitude von $50 \%$ (gerätespezifische Einheit), auf Stufe 4 für eine Minute aufgeschlossen und für eine weitere Minute unbeschallt abgekühlt. Dieser Vorgang wurde solange wiederholt bis die Suspension homogen war. Dabei richtete sich die Anzahl der Wiederholungen auch nach dem Volumen der Zellsuspension. Zelltrümmer und weitere unlösliche Bestandteile des Zelllysats wurden anschließend durch Zentrifugation entfernt.

\subsection{Proteinbiochemische Methoden}

\subsubsection{Affinitätschromatographie über Glutathion-Sepharose}

GSH Puffer A (PpAOC1/PpAOC2): 
$20 \mathrm{mM}$ Tris/HCl pH 7,5, $150 \mathrm{mM} \mathrm{NaCl}, 2 \mathrm{mM}$ DTT

GSH Waschpuffer (PpAOC1/PpAOC2):

$20 \mathrm{mM}$ Tris/HCl pH 7,5, $200 \mathrm{mM} \mathrm{NaCl}, 0,1 \%$ (v/v) Triton-X, 2 mM DTT

GSH Puffer B (PpAOC1/PpAOC2):

$20 \mathrm{mM}$ Tris/HCl pH 7,5, $150 \mathrm{mM} \mathrm{NaCl}, 2 \mathrm{mM}$ DTT, $10 \mathrm{mM}$ red. GSH

Zielproteine, welche N-terminal mit Glutathion-S-Transferase (GST) fusioniert sind, können über eine Sepharosematrix mit kovalent gebundenem Glutathion (GSH) gereinigt werden. $\mathrm{Zu}$ diesem Zweck wurde die Probe über eine 30 ml GSH-Sepharose-Säule XK 16/20 (GE Healthcare, München, DE) geleitet. Das GST-Fusionsprotein wurde spezifisch immobilisiert und nach Waschen mit Waschpuffer mit $10 \mathrm{mM}$ reduziertem Glutathion im Elutionspuffer GSH B von der Säule eluiert. Nach Nutzung der Säule wurde diese mit 6 M GuanidiniumHydrochlorid regeneriert und in $20 \%$ (v/v) Ethanol gelagert. Zwischen dem Zielprotein und dem GST-Fusionsprotein befindet sich eine spezifische Erkennungssequenz für die PreScission-Protease, Durch spezifische Proteolyse mit PreScission-Protease kann die GSTMarkierung des Zielproteins entfernt werden. Für den proteolytischen Verdau wurde das GST-Fusionsprotein und die PreScission-Protease im Verhältnis 1:100 eingesetzt und über Nacht bei $10{ }^{\circ} \mathrm{C}$ inkubiert.

\subsubsection{Anionenaustauschchromatographie}

Puffer A (PpAOC1/PpAOC2):

$20 \mathrm{mM}$ Tris/HCl pH 8, 0,2 mM DTT

Puffer B (PpAOC1/PpAOC2):

20 mM Tris/HCl pH 8,0, $1 \mathrm{M} \mathrm{NaCl,} \mathrm{2m} \mathrm{M} \mathrm{DTT}$

Hierfür wurde die Probe auf eine $30 \mathrm{ml}$ Source $^{\mathrm{TM}}$ 30Q XK 16/20 oder MonoQ ${ }^{\mathrm{TM}}$ HR 10/10 aufgetragen und anschließend in einem Gradienten von Puffer A nach Puffer B aufgetrennt. Nach Nutzung wurde die Säule zunächst mit $1 \mathrm{M} \mathrm{NaOH}$ und anschließend mit $1 \mathrm{M} \mathrm{HCl}$ gewaschen und in $20 \%(\mathrm{v} / \mathrm{v})$ Ethanol gelagert.

\subsubsection{Größenausschlusschromatografie}

Gelfilrationspuffer (PpAOC1/PpAOC2):

20mM Tris/HCl pH 7,5, $150 \mathrm{mM} \mathrm{NaCl,} 2$ mM DTT

Bei der Größenausschlusschromatografie oder Gelfiltration werden Moleküle nach ihrer Größe getrennt. Über die Proteintrennung hinaus kann die Gelfiltration auch zur Molekulargewichtsbestimmung eingesetzt werden. Die Gelfiltrationsäule wurde mit 1,5 Säulenvolumen Wasser gewaschen und anschließend mit Puffer äquilibriert. Für die 
präparative Gelfiltration wurden Superdex 75 XK 26/60 oder Superdex 200 XK 26/60 Säulen verwendet, wobei das Auftragsvolumen zwischen 1 und $4 \mathrm{ml}$ Probe lag. Das nötige Konzentrieren der Proteinlösung vor der Gelfiltration erfolgte über Vivaspin Konzentratoren, wobei die Ausschlussgröße der Membranen, angegeben als Molekulargewicht, so gewählt wurde, dass sie unter der Hälfte des Molekulargewichts des zu konzentrierenden Proteins lag. Nach Nutzung der Säule wurde diese mit dem dreifachen Säulenvolumen Wasser gewaschen und in $20 \%(\mathrm{v} / \mathrm{v})$ Ethanol gelagert.

Nach der Gelfiltration wurden die Präparate auf eine Konzentration von 15-25 mg/ml konzentriert und frisch verwendet oder aliquotiert, in flüssigem Stickstoff tiefgefroren und bei $-80{ }^{\circ} \mathrm{C}$ gelagert.

\subsubsection{Umpufferung einer Proteinlösung}

Proteinlösungen können z. B. durch Dialyse umgepuffert werden. Eine andere Methode ist die Umpufferung mit Hilfe einer HiPrep 16/26 Entsalzungssäule. Analog zu der Gelfiltration werden Partikel nach ihrer Größe aufgetrennt. Dazu wurde die Säule mit $265 \mathrm{ml}$ des gewünschten Puffers äquilibriert und anschließend $15 \mathrm{ml}$ der Proteinlösung aufgetragen. Beim Waschen mit dem gewünschten Puffer erfolgte die Elution der Proteine.

2.15.5 Diskontinuierliche SDS-PAGE, modifiziert nach Laemmli (Laemmli, 1970) 30 \% Acrylamid-Stammlösung (PAA30; Verhältnis Acrylamid:Bisacrylamid von 37,5:1)

Trenngelpuffer: $1,88 \mathrm{M}$ Tris/HCl, $\mathrm{pH} 8,8$

Sammelgelpuffer: 0,625 M Tris/HCl, pH 6,8

$100 \%$ N,N,N',N'-Tetramethylendiamin (TEMED)

$10 \%(w / v)$ Ammoniumpersulfat (APS)

Laufpuffer: 25 mM Tris/HCl, pH 8,8, 192 mM Glyzin, 0,1\% (w/v) SDS

2 x SDS-Probenpuffer: $20 \%$ 0,625 M Tris/HCl, pH 6,8, $2 \%(\mathrm{w} / \mathrm{v})$ SDS, $50 \%$ (v/v)

Glyzerin, $5 \%$ (v/v) B-Mercaptoethanol, $1 \%$ (v/v) Bromphenolblau

Coomassie-Färbelösung: $25 \%$ (v/v) Methanol, $10 \%$ (v/v) Eisessig, 0,2 \% (w/v) Coomassie Brilliant Blau R250, 0,05\% (w/v), Coomassie G250

Entfärbelösung: $45 \%$ (v/v) Methanol, $10 \%$ (v/v) Essigsäure

Tabelle 2.5: Zusammensetzung von SDS-Gelen.

\begin{tabular}{llll}
\hline Komponenten & Trenngel 8\% & Trenngel 15 \% & Sammelgel 5 \% \\
& $(1.5 \mathrm{~mm}$ Stärke $)$ & $(0,75 \mathrm{~mm}$ Stärke $)$ & $(0,75$ mm Stärke $)$ \\
\hline Bis-Acrylamid (30 \%) [ml] & 2,128 & 4,0 & 0,24 \\
\hline
\end{tabular}




\begin{tabular}{|c|c|c|c|}
\hline Puffer [ml] & 2,0 & 1,0 & 0,375 \\
\hline $\mathrm{H}_{2} \mathrm{O}[\mathrm{ml}]$ & 3,872 & 1,0 & 0,885 \\
\hline TEMED $[\mu \mathrm{l}]$ & 12,2 & 6,1 & 6,0 \\
\hline $25 \%(w / v)$ APS $[\mu \mathrm{l}]$ & 6,2 & 3,1 & 3,0 \\
\hline
\end{tabular}

Bei der SDS-Polyacrylamidgelelektrophorese (SDS-PAGE) werden Proteine denaturiert und nach ihren Molekulargewichten aufgetrennt. Dabei werden die Disulfidbrücken durch $\beta$ Mercaptoethanol reduziert und das Protein mit Hilfe von SDS denaturiert. Durch die Bindung des SDS an das Protein wird eine starke negative Ladung an die Polypeptidkette angelagert. Als Gelmatrix dient polymeres Acrylamid, das je nach erwarteter Größe des Zielproteins konzentriert ist. Bei Auftrennung großer Proteine ( $P p$ LOX1) wurden $8 \%$ ige Trenngele und bei Auftrennung von kleinen Proteinen (PpAOC1 und PpAOC2) 15\%ige Trenngele verwendet. Die Zusammensetzung der einzelnen Gele ist in Tabelle 2.5 aufgeführt. Es wurden 10-50 $\mu$ Proteinprobe 1:1 mit 2 x SDS Probenpuffer versetzt und davon 10-20 $\mu 1$ in die zuvor mit einer Pipette gespülten Geltaschen geladen. Um die Molekulargewichte gelelektrophoretisch aufgetrennter, denaturierter Proteine abschätzen zu können, wurden parallel $10 \mu \mathrm{l}$ Standard für das Protein-Molekulargewicht aufgetragen. Die Auftrennung der Proteine erfolgte bei $25 \mathrm{~mA}$ bis kurz nach Auslaufen des Bromphenolblau. Nach der SDSPAGE wurde das Gel in Coomassie-Färbelösung mindestens 15 min bis über Nacht unter leichtem Schütteln inkubiert. Anschließend wurde das Proteingel solange in Entfärbelösung inkubiert bis Banden zu erkennen waren. Abschließend wurde das Gel in Wasser aufbewahrt und dokumentiert.

\subsubsection{Proteinbestimmung nach Bradford (1976)}

Bradford-Reagenz:

$35 \mathrm{mg}$ Serva Blue G in $25 \mathrm{ml} 96 \%$ igem (v/v) Ethanol, $50 \mathrm{ml} 85$ \%ige (v/v) Phosphorsäure, add $\mathrm{H}_{2} \mathrm{O} 500 \mathrm{ml}$

Es wurden $20 \mu \mathrm{l}$ Proteinsuspension zu $980 \mu$ Bradfordlösung in eine Küvette pipettiert und sorgfältig vermischt. Es folgte eine Inkubation für $5 \mathrm{~min}$ bei RT. Die Probe wurde anschließend im Photometer gegen den Leerwert bei $595 \mathrm{~nm}$ gemessen und die Proteinkonzentration in $\mathrm{mg} / \mathrm{ml}$ mit Hilfe einer Eichgerade (angefertigt mit BSA in definierten Konzentrationen) über die Extinktion bestimmt.

\subsubsection{Western-Blot Analyse und Immunodetektion}

Transferpuffer: $25 \mathrm{mM}$ Tris, $150 \mathrm{mM}$ Glyzin, $10 \%$ (v/v) Methanol 
TBST-Puffer: $10 \mathrm{mM}$ Tris/HCl pH 8.0, $150 \mathrm{mM} \mathrm{NaCl,} 0.05 \%$ Tween 20

Blockierlösung: TBST-Puffer, $3 \%$ (w/v) Milchpulver

AP-Puffer: $100 \mathrm{mM}$ Tris/HCl pH 9,5, $100 \mathrm{mM} \mathrm{NaCl}, 5 \mathrm{mM} \mathrm{MgCl}$

primäre Antikörper: Ziege anti-GST (GE Healthcare, München, DE), Kaninchen anti-LOX (Abt. Feußner)

sekundäre Antikörper: anti-Ziege (GE Healthcare, München, DE), Ziege anti-Kaninchen (Sigma, München, DE)

Die über SDS-PAGE (2.15.5) aufgetrennten Proteine wurden anschließend auf eine Nitrozellulosemembran transferiert. Das Zielprotein kann mit einem spezifischen primären Antikörper und einem sekundären Antikörper, an welchen eine alkalische Phosphatase konjugiert ist, sichtbar gemacht werden. Dafür wurden das SDS-Gel und die Membran in eine Blotapparatur (Bio-Rad, München, DE) mit Transferpuffer überführt. Der Transfer lief bei $60 \mathrm{~V}$ für 60 - 90 min, abhängig von der Größe des Zielproteins. Anschließend wurde die Membran mit TBST-Puffer gewaschen und danach über Nacht in Blockierlösung inkubiert. Am folgenden Tag wurde die Membran mit TBST-Puffer gewaschen um die Blockierlösung $\mathrm{zu}$ entfernen. Um das rekombinante Zielprotein $\mathrm{zu}$ detektieren wurde die Membran anschließend für $2 \mathrm{~h}$ bei Raumtemperatur oder über Nacht bei $4{ }^{\circ} \mathrm{C}$ mit dem primären Antikörper inkubiert (1:1000 verdünnt in TBST-Puffer). Danach wurde die Membran dreimal 15 min mit TBST-Puffer gewaschen und anschließend mit dem sekundären Antikörper für eine Stunde inkubiert (1:30000 verdünnt in TBST-Puffer). Daraufhin wurde die Membran dreimal 10 min mit TBST-Puffer gewaschen und es folgte ein Waschschritt mit AP-Puffer. Um die detektierten Proteine zu visualisieren wurde die alkalische Phosphatasereaktion unter Zugabe von $33 \mu \mathrm{l}$ 5-Bromo-4-chloro-3-indolylphosphat (BCiP) und $66 \mu 1$ Nitroblautetrazolium (NBT) gestartet. Die Reaktion wurde bei erfolgter Färbung der erwarteten Proteinbande mit Wasser gestoppt.

\subsection{Lipidanalytik}

\subsubsection{Herstellung von Hydroperoxy-Fettsäurederivaten}

PpAOS/PpAOC-Aufschlusspuffer: $20 \mathrm{mM}$ Tris/HCl pH 7,5

PpLOX1-Aufschlusspuffer: 20 mM Tris/HCl pH 8,0, $300 \mathrm{mM} \mathrm{NaCl}, 10 \%$ Glyzerin

Soja-LOX-Typ-V-Puffer: 100 mM Boratpuffer pH 10,4

Da die Substrate (Allenoxide) für den Nachweis von AOC-Aktivität eine Halbwertszeit von $30 \mathrm{~s}$ bei $0{ }^{\circ} \mathrm{C}$ besitzen (Ziegler et al., 1997), wurde ein gekoppelter Enzymtest in Anwesenheit von AOS-Protein durchgeführt. Das Substrat für die AOS wiederum ist eine stabile 
Hydroperoxy-Fettsäure, Produkt einer LOX-Enzymreaktion mit freier Fettsäure und Sauerstoff. In Tabelle 2.6 sind die dafür verwendeten LOXen und Fettsäuren aufgeführt.

Für den gekoppelten LOX/AOS/AOC-Aktivitätstest wurden die entsprechenden Expressionszellen wie in Abschnitt 2.14.3 beschrieben aufbereitet. Für die Herstellung von Hydroperoxy-Fettsäurederivaten, mit rekombinanter LOX wurden die Bakterien einer $30 \mathrm{ml}$ PpLOX1 Kultur in $10 \mathrm{ml} P p L O X 1-A u f s c h l u s s p u f f e r$ aufgeschlossen. Es wurden $3 \mathrm{ml}$ Zelllysat mit $7 \mathrm{ml} P p$ LOX1-Puffer verdünnt. Für die Herstellung von FettsäureHydroperoxiden mit industriell gereinigter LOX (Soja-LOX Typ V, Sigma-Aldrich) wurde eine Spatelspitze des Pulvers in $10 \mathrm{ml}$ Soja-LOX-Typ-V-Puffer gegeben. Anschließend wurde das Gemisch mit $25 \mathrm{mg}$ freier Fettsäure versetzt und für 30 min rührend bei RT inkubiert. Danach erfolgte eine Ansäuerung mit $1 \mathrm{ml}$ Eisessig und eine Extraktion mit $20 \mathrm{ml}$ Chloroform/Methanol (1/1, v/v). Die organische Phase wurde im $\mathrm{N}_{2}$-Strom bis zur Trockene eingedampft und die Rückstände in Ethanol aufgenommen. Die Konzentration des jeweiligen Substrates wurde mittels HPLC-Analyse bestimmt (2.16.4.2).

Tabelle 2.6: Verwendete Fettsäuren für die Herstellung von Hydroperoxy-Fettsäurederivaten.

\begin{tabular}{|c|c|c|}
\hline Fettsäure & LOX & Hydroperoxid \\
\hline ALA & Soja-LOX-Typ-V & 13-HPOTE \\
\hline $\mathbf{A A}$ & Soja-LOX-Typ-V & 15-HPETE \\
\hline EPA & Soja-LOX-Typ-V & 15-НРEPE \\
\hline $20: 3^{(\Delta 11 Z, \Delta 14 Z, \Delta 17 Z)}$ & Soja-LOX-Typ-V & 15-HPETE \\
\hline $\mathbf{A A}$ & $P p \mathrm{LOX} 1$ & 12-HPETE \\
\hline EPA & $P p \mathrm{LOX} 1$ & 12-HPEPE \\
\hline $20: 3^{(\Delta 8 Z, \Delta 11 Z, \Delta 14 Z)}$ & $P p \mathrm{LOX} 1$ & 12-HPETE \\
\hline
\end{tabular}

\subsubsection{Gekoppelter PpAOS/PpAOC-Aktivitätstest}

PpAOS/PpAOC-Puffer: $20 \mathrm{mM}$ Tris/HCl pH 7,5

Von den Hydroperoxiden wurden jeweils $30 \mu \mathrm{g}$ (1-10 $\mu \mathrm{l})$ für den Umsatz mit AOS und PpAOC1 oder PpAOC2 Enzym verwendet.

Zuerst wurde gereinigtes PpAOC1- oder PpAOC2-Enzym (50 $\mu$ g pro Ansatz) auf Eis in $500 \mu \mathrm{l}$ AOS/AOC-Puffer gegeben. Anschließend wurde zu jedem Ansatz eine ausreichende Menge rekombinanter PpAOS gegeben, wobei entweder Bakterien-Zelllysat (2.14.3) oder bereits vorgereinigtes Enzym (10 $\mu \mathrm{g}$ pro Ansatz) verwendet wurde. Die Reinigung der PpAOS erfolgte nach dem Protokoll von Stumpe et al. (2001). 
Bei der Umsetzung von PpAOS mit einer Hydroperoxy-Fettsäure entsteht neben dem Allenoxid ein geringer Anteil des zyklischen Produktes in razemischer Form. Deshalb wurde zum Vergleich des Anteils an enzymatisch entstandenem zyklischem Produkt immer eine parallele Umsetzung mit PpAOS und Puffer durchgeführt.

Die Reaktion wurde durch Zugabe von $30 \mu \mathrm{g}$ Hydroperoxy-Fettsäure gestartet und 30 min auf Eis inkubiert. Anschließend wurde die Reaktion durch Zugabe von $40 \mu$ l Eisessig gestoppt und die Produkte mit $1 \mathrm{ml}$ Chloroform/Methanol (1/1, v/v) extrahiert. Die organische Phase wurde im $\mathrm{N}_{2}$-Strom bis zur Trockene eingedampft und abschließend die Rückstände in $50 \mu 1$ Methanol aufgenommen und bei $-20^{\circ} \mathrm{C}$ bis zur Analyse aufbewahrt.

\subsubsection{PpLOX1-Aktivitätstest}

Die Aktivität der rekombinanten $P p L O X 1$ wurde im Rohextrakt des Expressionszellstammes E. coli SG 13009 getestet. Dazu wurden $500 \mu \mathrm{g}$ des Fettsäuresubstrates mit $1 \mathrm{ml}$ Bakterienzelllysat gemischt und 30 min bei RT schüttelnd inkubiert. Zur Protonierung wurde der Ansatz vor der Extraktion mit $100 \mu \mathrm{l}$ Essigsäure angesäuert. Die Extraktion erfolgte mit $2 \mathrm{ml}$ Chloroform/Methanol (1/1, v/v), wobei zur besseren Phasentrennung kurz bei RT zentrifugiert $(3220 \mathrm{~g}, 10 \mathrm{~min})$ wurde. Die organische Phase wurde in ein 1,5 ml Eppendorfgefäß überführt und im $\mathrm{N}_{2}$-Strom bis zur Trockene eingedampft. Abschließend wurden die Rückstände in $50 \mu \mathrm{l}$ Methanol aufgenommen und bei $-20^{\circ} \mathrm{C}$ bis zur Analyse aufbewahrt.

\subsubsection{Hochleistungs-Flüssigkeitschromatographie (HPLC)}

Zur Auftrennung und Analyse flüssiger Substanzgemische wird die HochleistungsFlüssigkeitschromatographie (HPLC) verwendet. Die Trennung erfolgt wie bei allen chromatographischen Verfahren über eine stationäre, sowie eine mobile Phase. Die stationäre Phase besteht aus einem inerten und porösen Säulenmaterial (Kieselgel). Die mobile Phase ist ein Lösungsmittel, in welchem sich die zu analysierenden Substanzen befinden, welches unter hohem Druck durch die Säule geleitet wird.

\subsubsection{Umkehrphasen-HPLC (RP-HPLC)-Trennung von freien Oxylipinen}

Säule $\quad$ EC 250/2 Nucleosil 120-5 C18 (2.3)

Laufmittel: $\quad \quad \mathrm{A}_{1}$ : Acetonitril/ $\mathrm{H}_{2} \mathrm{O} /$ Essigsäure (50/50/0,1, v/v/v)

$\mathrm{A}_{2}:$ Acetonitril/ $\mathrm{H}_{2} \mathrm{O} /$ Essigsäure (40/60/0,1, v/v/v)

B: Acetonitril/Essigsäure (100/0,1, v/v)

Bei dieser speziellen Form der HPLC interagieren die Analyten in der mobilen Phase hydrophob mit der stationären Phase. Die stationäre Phase ist ein mit C18-Kohlenstoffketten 
überzogenes Kieselgel. Die Elution der Proben erfolgte durch ein organisches Lösungsmittel, welches mit den adsorbierten Molekülen um die Bindung an das Kieselgel konkurriert. Für ein höchstmögliches Auflösungsvermögen und eine optimale Trennkapazität wurde ein Lösungsmittelgradient verwendet. Durch schrittweise Erhöhung des Anteils an organischem Lösungsmittels wurde die Polarität vermindert und die Elutionskraft erhöht. Zur RP-HPLCAnalyse wurde ein Agilent 1110-System mit einem Dioden-Array-Detektor (2.1) verwendet. Die Fettsäuren und Oxylipine wurden auf der HPLC-Säule EC 250/2 Nucleosil 120-5 C18 (2.3) aufgetrennt und gleichzeitig die Absorption bei $202 \mathrm{~nm}, 224 \mathrm{~nm}, 234 \mathrm{~nm}$ und $268 \mathrm{~nm}$ durch den Detektor aufgezeichnet. Alle Analysen wurden bei einer Säulentemperatur von $25^{\circ} \mathrm{C}$ durchgeführt. Die aufbereiteten Proben (2.16.2 und 2.16.3) wurden in $100 \mu 1$ Laufmittel $\mathrm{A}_{1}$, bzw. $\mathrm{A}_{2}$ (siehe oben) aufgenommen und jeweils $80 \mu \mathrm{l}$ injiziert. Die Produkte der PpAOC1/PpAOC2-Aktivität ( $\alpha / \gamma$-Ketole, OPDA bzw. Phytoprostane wurden in Laufmittel $\mathrm{A}_{2}$ und mit dem in Tabelle 2.7 aufgeführten Gradienten aufgetrennt und analysiert. Die PpLOX1 Produkte ( $\omega$-Oxofettsäuren, Hydroperoxy-Fettsäuren und Ketofettsäuren) wurden in Laufmittel $A_{1}$ und mit dem in Tabelle 2.7 aufgeführten Gradienten aufgetrennt und analysiert.

Tabelle 2.7: $\quad$ RP-HPLC-Gradient für die Trennung von PpLOX1- und PpAOC1/PpAOC2-Produkten.

\begin{tabular}{lll}
\hline Zeit $[\mathbf{m i n}]$ & \% Laufmittel B & Flussrate (ml/min) \\
\hline $\mathbf{0}$ & 0 & 0,2 \\
$\mathbf{2 0}$ & 100 & 0,2 \\
$\mathbf{2 5}$ & 100 & 0,2 \\
$\mathbf{2 7}$ & 0 & 0,2 \\
$\mathbf{3 0}$ & 0 & 0,2 \\
& 0 & 0,2
\end{tabular}

\subsubsection{Normalphasen HPLC (SP-HPLC) Analyse von freien Oxylipinen}

Säule: $\quad$ Zorbax SIL (2.3)

Laufmittel: $\quad$ n-Hexan/Isopropanol/TFA (100/1/0,1, v/v/v)

Flussrate: $\quad 0,2 \mathrm{ml} / \mathrm{min}$

Diese Form der Flüssigchromatographie ist zur Trennung der durch die PpLOX1- 
Enzymreaktion entstehenden Hydroperoxy-Fettsäurepositionsisomere (234-238 nm) und Ketofettsäuren $(270 \mathrm{~nm})$ geeignet. Für die Trennung der einzelnen Produkte wurden die Proben in $100 \mu$ l Laufmittel aufgenommen und $30 \mu 1$ injiziert. Die im Eluat vorhandenen Verbindungen wurden an Hand ihres Absorptionsmaximums simultan während der gesamten Analyse identifiziert. Diese Analyse wurde von einem Agilent 1110-System mit einem Dioden-Array-Detektor durchgeführt. Alle Analysen wurden bei einer Säulentemperatur von $25{ }^{\circ} \mathrm{C}$ durchgeführt.

\subsubsection{Kopplung von LC mit Massenspektroskopie (LC/MS und LC/MS-MS)} Flüssigchromatographie:

Säule:

EC-250/2-Nucleosil-100-5-C 18 -Säule (250 x 2,1 mm, $5 \mu \mathrm{m}$

Partikelgröße (Macherey Nagel, Düren, DE)

Gerät:

Surveyor HPLC-System (Fisher Thermo Scientific, Waltham, MA, USA

Laufmittel: $\quad \mathrm{A}_{1}: P p A O C 1 / P p A O C 2$ Produkte: Acetonitril/ $\mathrm{H}_{2} \mathrm{O} /$ Essigsäure $(40 / 60 / 0,1, \mathrm{v} / \mathrm{v} / \mathrm{v})$

$\mathrm{A}_{2}: P p L O X 1-P r o d u k t e:$ Acetonitril/Wasser/Essigsäure $(50 / 50 / 0,1, \mathrm{v} / \mathrm{v} / \mathrm{v})$

B: Acetonitril/Essigsäure (100/0,1, v/v)

Massenspektrometrie:

Gerät: $\quad$ LCQ-Ionenfallen-Massenspektrometer

Ionisierung: $\quad$ Elektronen-Spray-Ionisierung (ESI)

Quellspannung: $\quad 4 \mathrm{kV}$

Kapillarspannung: $27 \mathrm{~V}$

Kapillartemperatur: $300^{\circ} \mathrm{C}$

Die HPLC/MS ist eine Kombination aus Flüssigchromatographie (HPLC) und Massenspektrometrie (MS). Die Auftrennung der Analytenmischung erfolgt zunächst über eine RP-HPLC gefolgt von einer massenspektrometrischen Analyse. Die getrennten Probenmoleküle wurden in das Vakuum des Massenspektrometers mit Hilfe der Elektronensprayionisation (ESI) überführt und ionisiert. Die so erzeugten Ionen wurden in einer Ionenfalle entsprechend ihres Masse/Ladungs-Quotienten $(\mathrm{m} / \mathrm{z})$ analysiert. Darüber hinaus war es möglich, Ionen eines spezifischen $\mathrm{m} / \mathrm{z}$-Quotienten in der Ionenfalle gefangen zu halten, diese mittels kollisions-induzierter Dissoziation (CID = collision-induced dissociation) in Tochterionen $\mathrm{zu}$ fragmentieren und $\mathrm{zu}$ analysieren (LC/MS-MS). Als Trägergas diente 
Helium. Für Tandem-MS-Analysen wurde eine Kollisionsenergie von 1 V verwendet.

Nach Umsetzung der Substrate und anschließender Extraktion (2.16.2 und 2.16.3) wurden die Rückstände in $50 \mu$ l Methanol aufgenommen. Davon wurden $25 \mu$ labgenommen, bis zur Trockene eingedampft und in $25 \mu \mathrm{l}$ Laufmittel $\mathrm{A}_{1}$ oder $\mathrm{A}_{2}$ (siehe oben) für die LC/MSMessung aufgenommen. In Tabelle 2.8 und Tabelle 2.9 sind die verwendeten Gradienten für die Trennung mit HPLC/MS von PpAOC-Produkten und PpLOX1-Produkten aufgeführt.

Tabelle 2.8: Gradient für die RP-HPLC-Trennung von PpAOC-Produkten.

\begin{tabular}{lll}
\hline Zeit [min] & Laufmittel B [\%] & Fluss [ml/min] \\
\hline $\mathbf{0}$ & 40 & 0,18 \\
$\mathbf{1 0}$ & 40 & 0,18 \\
$\mathbf{1 5}$ & 100 & 0,3 \\
$\mathbf{1 7}$ & 100 & 0,3 \\
$\mathbf{2 5}$ & 100 & 0,3 \\
$\mathbf{2 7}$ & 40 & 0,3 \\
$\mathbf{3 0}$ & 40 & 0,18 \\
\hline
\end{tabular}

Tabelle 2.9: Gradient für die RP-HPLC-Trennung von PpLOX1-Produkten.

\begin{tabular}{lll}
\hline Zeit [min] & Laufmittel B [\%] & Fluss [ml/min] \\
\hline $\mathbf{0}$ & 0 & 0,2 \\
$\mathbf{2 0}$ & 100 & 0,2 \\
$\mathbf{2 5}$ & 100 & 0,2 \\
$\mathbf{2 7}$ & 0 & 0,2 \\
$\mathbf{3 0}$ & 0 & 0,2 \\
\hline
\end{tabular}

Über den ermittelten Masse/Ladungs-Quotienten $(\mathrm{m} / \mathrm{z})$ und den Vergleich mit Referenzstandards wurde die Absorption der unterschiedlichen Verbindungen in relativen Einheiten vergleichen. Dabei wurde jeweils die relative Menge in Prozent (\%) errechnet und grafisch dargestellt.

\subsection{Röntgenkristallographische Methoden}

\subsubsection{Kristallisation von Proteinen}

Zur Bestimmung einer Proteinstruktur mittels Röntgenkristallographie werden geordnete Proteinkristalle benötigt. Der Kristallisationsvorgang ist eine fortlaufende Anlagerung von Proteinmolekülen zu einer dichten Kristallpackung in geometrisch gleichen Einheiten und 
Ausrichtungen. Bei diesem Vorgang spielen sowohl die thermodynamische als auch die kinetische Komponente eine entscheidende Rolle.

Die kleinstmöglichen Fragmente eines makroskopischen Kristalls werden als Einheitszelle bezeichnet. Die Einheitszelle ist durch die Länge ihrer drei Achsen a, b und c und der eingeschlossenen Winkel $\alpha, \beta$ und $\gamma$ eindeutig charakterisiert. Die Einheitszelle stellt somit ein mathematisches Modell dar, so dass nur wenige Parameter notwendig sind, um die Anordnung der Moleküle zu beschreiben. Die Aufgabe, die Struktur eines gesamten Kristalls zu bestimmen, reduziert sich demzufolge auf die Struktur der Einheitszelle. Im einfachsten Fall besteht die Einheitszelle aus einer einzigen molekularen Einheit, jedoch enthalten Einheitszellen von Kristallen oft mehrere Molekülkopien. Sind diese Kopien so angeordnet, dass Rotationen, Translationen oder Inversionen der Einheitszelle eine Überlagerung mit den Original-Koordinaten ermöglichen, handelt es sich um eine höhere Symmetrie. Die Einheitszelle umfasst dann mehrere asymmetrische Einheiten, aus denen die Einheitszelle, und schließlich der gesamte Kristall, durch mathematische Symmetrieoperationen rekonstruiert werden kann.

In übersättigter Lösung ist die Kristallisation von Proteinen ein entropisch bevorzugter Prozess. Beim Kristallisationsvorgang leiset die Gitterenergie bzw. die Wasserfreisetzung aus der Hydrathülle der Proteine einen Beitrag zur freien Kristallisationsenthalpie, weshalb die Reaktion freiwillig abläuft. Passiert dieser Vorgang jedoch zu schnell, wie z. B. in sehr stark übersättigten Proteinlösungen, bilden sich keine geordneten Kristalle sondern das Protein präzipitiert ungeordnet. Geschieht es wiederum zu langsam, wie in nicht oder nur leicht übersättigten Proteinlösungen, bilden sich keine Kristalle oder sie entstehen erst nach Monaten oder Jahren.

Um eine übersättigte Proteinlösung zu erzeugen, wird das Prinzip der Dampfdiffusion angewendet. Dafür wird eine definierte Menge des reinen Proteins zu einer Lösung verschiedener Substanzen gegeben. Diese Lösung ist über die Gasphase in direkter Verbindung mit einem großen Volumen der Lösung in einem Reservoir. Die Verdünnung der ersten Lösung durch das Protein führt zu einer Erhöhung des Dampfdrucks und damit zum Wasserentzug aus dem Proteinlösungstropfen. Das damit einhergehende Ansteigen der Ionenstärken und der Proteinkonzentration ermöglicht die Kristallisation des Proteins. Die verschiedenen Zusätze in den Lösungen wirken sich entsprechend ihrer chemischen Eigenschaften auf die Parameter des Kristallisationsverhaltens aus. Sie wirken stabilisierend auf das Protein, sind an Wasserstoffbrückenbindungen beteiligt sind und verändern die 
Löslichkeit oder den pH-Wert. Zudem wirken sich Faktoren wie die Proteinkonzentration und die Temperatur entscheidend auf den Kristallisationsprozess aus.

Aufgrund der Vielzahl an beeinflussenden Parametern ist das Kristallwachstum von Proteinen nicht vorhersehbar und es wurden zu Anfang initiale Kristallisationstests verwendet (2.10). Bei diesen initialen Kristallisationsansätzen handelt es sich um eine Sammlung von empirisch ermittelten Anfangsbedingungen, die relativ häufig zur Kristallisation verschiedener Proteine geführt haben. Die Kristallisationsexperimente wurden in dieser Arbeit im so genannten sitzenden Tropfen (engl. sitting drop) durchgeführt. Dabei wurden CrysChem-Platten der Firma Hampton Research mit 24 Ansätzen verwendet, deren einzelne Kammern eine zentrale Säule enthalten, die in der Mitte eine Vertiefung für die Proteinlösung hat. Die Säule ist umgeben von einem Reservoir in der die Lösung vorgelegt wird, in der das Protein kristallisieren soll. Das Volumen der vorgelegten Bedingung betrug in den durchgeführten Kristallisationsversuchen immer $500 \mu \mathrm{l}$ und die Temperatur, wenn nicht anders angegeben, $4{ }^{\circ} \mathrm{C}$. Für die initialen Kristallisationstests wurde $1 \mu \mathrm{l}$ aus dem Reservoir in die Vertiefung der Säule gegeben und $1 \mu \mathrm{l}$ der konzentrierten Proteinlösung zugesetzt. Um Austrocknung zu vermeiden und ein geschlossenes Kompartiment herzustellen, wurden die Kristallisationsplatten nach dem Pipettieren von 12 Bedingungen sofort mit Klarsichtklebeband verschlossen.

In regelmäßigen Abständen wurden die Kristallisationsplatten mit einem Binokular nach möglichen Kristallen oder erfolgsversprechenden Bedingungen überprüft und die Entwicklungen notiert. Mit einer Digitalkamera auf einem Binokular wurden die Kristalle unter normalem und polarisiertem Licht fotografiert.

\subsubsection{Fein-screening und Additive}

In wenigen Fällen finden sich gut streuende Kristalle in den initialen Kristallisationsbedingungen. Um die Diffraktionseigenschaften zu verbessern, wurde mit erfolgversprechenden Bedingungen ein so genanntes Fein-screening durchgeführt. Dabei wurden pH-Wert, Proteinkonzentration, Substratkonzentration, Proteinlösung- /ReservoirTropfenverhältnis, prozentuale Anteile einzelner Reservoirzusätze, Puffer, Temperatur, Additive, Mikro-und Makro-Seeding an den Ursprungsbedingungen geändert.

In diesen Experimenten gewachsene Kristalle von PpAOC1 und PpAOC2 wurden im Röntgenbeugungsexperiment auf ihre Streuleistung getestet.

\subsubsection{Kryokristallographie}

Die Zusammensetzung des jeweiligen Kryopuffers muss die Eiskristallbildung bei $100 \mathrm{~K}$ verhindern, da die Eiskristalle ein eigenes Beugungsmuster zeigen sowie den Proteinkristall 
durch Scherkräfte zerstören können. Der Kryopuffer, in welchem ein Kristall für die Kryokristallographie inkubiert wird, hat einen sehr großen Einfluss auf das Beugungsverhalten des Kristalles. Üblicherweise wurden Kristalle direkt mit einer kleinen Nylonschleife (engl. loop) aus der Kristallisationsbedingung herausgehoben, mit Kryopuffer benetzt und anschließend für die Messung im $100 \mathrm{~K}$ kalten $\mathrm{N}_{2}$-Strom auf dem Goniometerkopf montiert.

\subsubsection{Soaking-Experimente}

Da die Kristallisationsexperimente sowohl von PpAOC1 und PpAOC2 zu gut streuenden Proteinkristallen führten, wurde diese mit Substratanalogen und dem zyklischen Produkt der Enzymreaktion OPDA inkubiert (engl. soaking). Das heißt den Proteinkristallen wurde ein 10 - 20-, bzw. 10 - 100facher molarer Überschuss an diesen Substanzen zugegeben und über einen bestimmten Zeitraum inkubiert. Anschließend wurden die Kristalle in flüssigem $\mathrm{N}_{2}$ für spätere Synchrotronmessungen schockgefroren und bei $-180{ }^{\circ} \mathrm{C}$ gelagert. Die in Tabelle 2.10 aufgelisteten Substanzen wurden für die Soaking-Experimente verwendet. Zur Veranschaulichung sind die verwendeten Substrate in Abbildung 2.1 dargestellt.
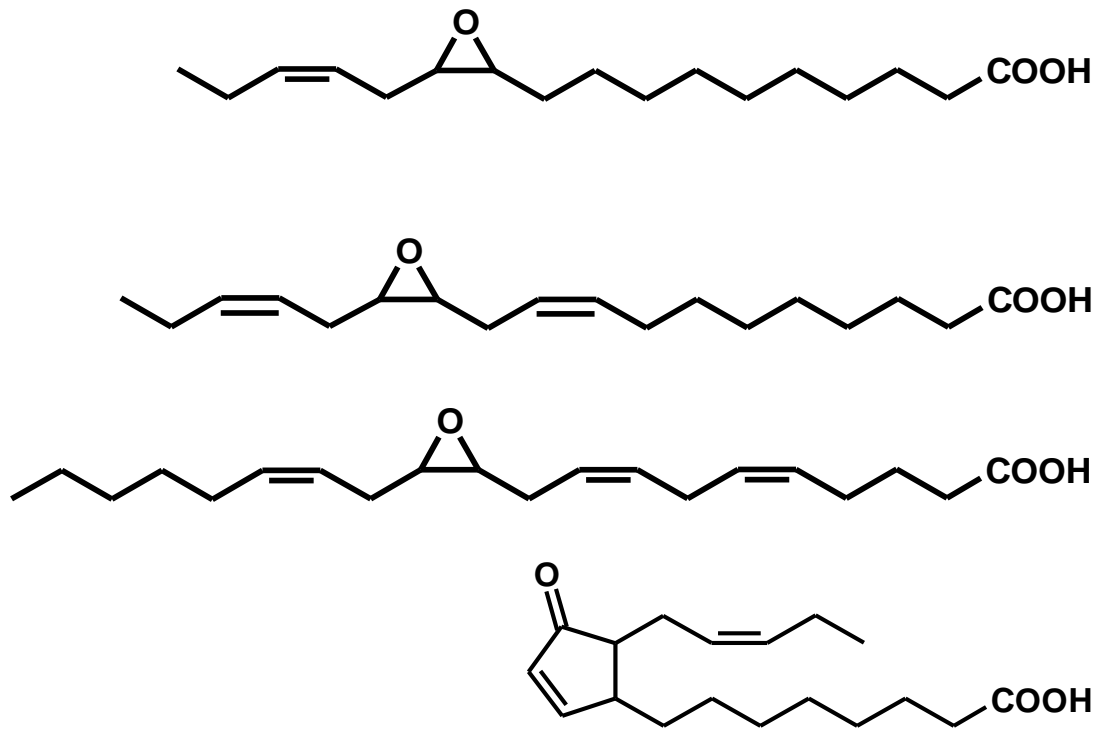

Abbildung 2.1: Soakingsubstanzen für PpAOC1 und PpAOC2. (A) ( \pm )Vernolsäure $\left(12,13-\mathrm{EOD}^{\Delta 9 Z}\right)$; (B)

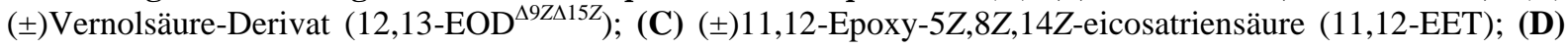
cis(+)12-OPDA.

Tabelle 2.10: Verwendete Soaking-Substanzen und deren Inkubationsdauer.

\begin{tabular}{llcc}
\hline Enzym & Soaking-Substanz & Molarer Überschuss $^{\text {Inkubationsdauer }}$ \\
\hline PpAOC1/PpAOC2 & $12,13-$ EOD $^{(\Delta 9 Z \Delta 15 \mathrm{Z})}$ & $10-20$ & $48 \mathrm{~h}-72 \mathrm{~h}$ \\
PpAOC1/PpAOC2 & $12,13-$ EOD $^{(\Delta 9 Z)}$ & $10-20$ & $48 \mathrm{~h}-72 \mathrm{~h}$ \\
PрАOC1/PpAOC2 & $11,12-E E T$ & $10-20$ & $48 \mathrm{~h}-72 \mathrm{~h}$ \\
\hline
\end{tabular}




\subsubsection{Röntgenbeugungsexperimente}

Röntgenstrahlen sind elektromagnetische Wellen mit hoher Energie, bzw. kurzer Wellenlänge. Wellen sind durch ihre Amplitude, die Frequenz und ihre Phase charakterisiert. Trifft ein Röntgen-Photon auf ein Elektron, so beginnt dieses zu oszillieren und fungiert dadurch als sekundäre Röntgenquelle. Die sich ergebenden Wellen breiten sich mit derselben Wellenlänge wie die der ankommenden Welle radial vom Oszillationszentrum aus, jedoch mit einer der Streukraft des Elektrons korrespondierenden Amplitude und einer Phasenverschiebung von $180^{\circ}$. Ein zweites Elektron in unmittelbarer Umgebung erzeugt dieselbe Streuung, besitzt jedoch aufgrund seiner anderen Position eine andere Phasenverschiebung im Vergleich zum ersten Elektron. Wird ein Detektor mit einem bestimmtem Abstand hinter einem Objekt platziert, nimmt dieser die Summe der einzelnen gestreuten Wellen als Diffraktions- bzw. Streumuster auf. Die Amplitude ist dabei als Funktion der Position von den unterschiedlichen Phasen entlang des Detektors moduliert. Durch die Lösung der Schrödinger-Gleichung kann, bei gegebener Wellenlänge die Elektronendichteverteilung und dadurch der Grad der Streuung der einzelnen Atome abgeleitet werden (der Streu- bzw. Form-Faktor).

Das Ziel von Röntgenbeugungsexperimenten an Proteinkristallen ist es die Elektronendichteverteilung in der dreidimensionalen Einheitszelle des Kristalls zu erhalten. Durch den Bau eines dreidimensionalen Proteinmodells erfolgt die Interpretation dieser Elektronendichte. Dabei folgt die Beugung der Röntgenstrahlung an Elektronen des Proteinkristalls nach dem Bragg'schen Gesetz (Formel 2.1).

$$
2 d \cdot \sin (\theta)=n \cdot \lambda
$$

Dabei ist $\lambda$ die Wellenlänge, $d$ der Abstand der Ebenenschar im Kristall, $\theta$ der halbierte Winkel zwischen eintretendem und austretendem Strahl und n ein ganzzahliges Vielfaches. Bei allen anderen Werten für n führt die Anzahl der Kristallgitterebenen zu einer Auslöschung der gestreuten Strahlung. Sind die schwächsten Reflexe eines Streubildes bei einem Winkel von $2 \theta_{\max }$ zu sehen, so definiert man dies als den minimalen Abstand $d_{\min }=\lambda / \sin \theta_{\max }$, der von diesem Kristall aufgelöst werden kann. Dieser Wert wird auch als Auflösung von Röntgendiffraktionsdaten bezeichnet. Schlecht geordnete Kristalle zeigen daher ein geringes Streuvermögen. Als schwach aufgelöst werden Röntgendiffraktionsdaten mit Werten größer 2,8 Å bezeichnet, eine mittlere Auflösung liegt zwischen 2,8 $⿱$ und $1.5 \AA$ A. Darunter liegende 
Auflösungen sind so genau, dass Differenzen zwischen Kohlenstoff-, Stickstoff- und Sauerstoffatomen oder gar Wasserstoffatome sichtbar werden können. Die gemessen Beugungsreflexe entstehen dabei durch konstruktive Interferenz von gebeugten Röntgenphotonen an parallelen Netzebenen unter Bedingung des Bragg'schen Gesetzes.

Für die Aufnahme von Röntgenbeugungsmustern wurde der Proteinkristall mit einem loop aus dem Kristallisationstropfen entnommen und auf den Goniometerkopf im Schnittpunkt des Röntgenstrahls mit der Rotationsachse des Diffraktometers montiert. Während der Kristall zweidimensional um vorher definierte Gradzahlen rotiert, um so durch die Drehung der theoretischen Ebenen des Kristalls ein Beugungsspektrum zu erhalten, wird er durch einen Stickstoffgasstrahl (100 K) gekühlt.

Das auftretende Beugungsmuster des Kristalls wurde mit einem Detektor aufgezeichnet und durch den maximalen Beugungswinkel die Auflösungsgrenze des Kristalls für Röntgenbeugungsexperimente eingeschätzt. Die Kristalle, die zufrieden stellende Signale bei hohen Beugungswinkeln zeigten, wurden für spätere Messungen durch Synchrotronstrahlung in flüssigem Stickstoff aufbewahrt.

\subsection{Testen von Kristallen und Strategie zur Aufnahme von Datensätzen}

\subsubsection{Testen von Kristallen}

Um Kristalle auf ihren Proteingehalt und ihre Streuung zu testen, wurden zunächst nur wenige Röntgenbeugungsmuster mit hohem Detektorabstand aufgenommen. Bei schwachen Signalen wurde die Belichtungszeit schrittweise erhöht. Waren ausreichend starke Signale vorhanden wurde der Kristall für Testbilder in $45^{\circ}$ Schritten gedreht und der Abstand zum Detektor verringert. Mit den Informationen aus den Testbildern konnte dann eine Strategie zur Aufnahme eines Datensatzes erstellt werden. Dazu wurde z. B. das Programm MOSFLM verwendet, mit dem die Raumgruppe, der Minimumoszillationsbereich, der Oszillationswinkel, die Belichtungszeit und die Distanz zum Detektor bestimmt wurden.

\subsubsection{Datenaufnahme}

Die Datensätze der Kristalle von PpAOC und PpAOC2 wurden an den Strahlen X13 des Deutschen Elektronensynchrotrons (DESY) bei entsprechenden Wellenlängen sowie am BL14_1-Strahl des Berliner Elektronensynchrotrons (BESSY) aufgenommen. Die einzelnen Parameter für die Datensammlung sind in Tabelle 8.1 im Anhang zusammengefasst. 


\subsubsection{Datenprozessierung}

\subsubsection{Integration und Skalierung}

Die gemessenen Beugungsreflexe wurden mit den Miller'schen Indizes (h,k,l) indiziert, welche eine Nummerierung der verschieden Netzebenen im Kristallgitter ermöglichen. Jedem so indizierten Reflex wird eine Intensität I zugewiesen, die über die Integration einer auf den Beugungspunkt angepassten Verteilungskurve ermittelt wird. Mit Programmen, die für akademische Zwecke kostenfrei sind (XDS, MOSFLM/SCALA), werden anschließend die Reflexe der verschiedenen Oszillationswinkel in einem Datensatz zueinander in Relation gesetzt und vereinigt. Die einzelnen Reflexe und ihre Intensität werden über den Verlauf der der Kristallrotation verfolgt und ihre Parameter gemittelt. Die Skalierung und Summierung der partiellen Reflexe der Daten bietet ein effektives Instrument zur Bewertung der Qualität eines gemessenen Datensatzes, wobei verschiedene Parameter Aufschluss über die Signalstärke, die Redundanz, die Vollständigkeit der beobachteten Reflexe sowie die Abweichungen und die Qualität der Auflösungsschalen geben. Das Ergebnis der Skalierung ist ein Datensatz, der die über die einzelnen Beugungsbilder „laufenden“ Reflexe zusammenfasst und für die Lösung der Proteinstruktur genutzt werden kann. Die Datenparameter eines einzigartigen Reflexes sind dabei die Miller'schen Indizes: h,k,l, die Amplitude I sowie das Rausch-Signalverhältnis I/ $\sigma$.

\subsubsection{Amplitudeninformation}

Neben dem Index der Reflexe $(h, k, l)$ liefert ein Beugungsbild auch die Information über deren Intensität. Dabei entsprechen die Intensitäten den Amplituden der für die Berechnung der Elektronendichte benötigten Strukturfaktoren und stehen in folgender Beziehung zueinander (Formel 2.2).

$$
I(h, k, l)=k \cdot|F(h, k, l)|^{2}
$$

Dabei ist I die Intensität, $|\mathrm{F}|$ die Strukturfaktoramplitude und k eine Skalierungskonstante. Die Strukturfaktoramplitude ist ein Teil des Strukturfaktors F(h,k,l), der jedem Beugungsreflex eine Wellenfunktion zuweist und als Komponenten die Amplitude $(|\mathrm{F}|)$ und den Phasenwinkel ( $\varphi$ ) des Reflexes enthält (Formel 2.3).

$$
F(h, k, l)=|F(h, k, l)| e^{i \varphi(h k)}
$$

Da die Phase $\phi$ jedes einzelnen Reflexes jedoch nicht messbar ist, wird dies als Phasenproblem der Röntgenstrukturanalyse bezeichnet. Um die Intensitätsinformation der 
skalierten Daten in Amplitudeninformation $\mathrm{zu}$ konvertieren, werden die bearbeiteten Rohdaten mit dem Programm CCP4 (F2MTZ) in ein mtz-Datenformat umgewandelt und die Intensitätsinformationen mittels CTRUNCATE in die Amplitudeninformationen $|\mathrm{F}|$ umgerechnet (Padilla \& Yeates, 2003).

\subsubsection{Lösung des Phasenproblems}

Zur Lösung des Phasenproblems existieren verschiedene Ansatzmöglichkeiten. Die Phaseninformation kann bei kleinen Molekülen (bis 1000 Atome) durch direkte Methoden und bei komplexeren Molekülen durch isomorphen Ersatz (SIR/MIR) oder kombiniert mit anormaler Dispersion (SIRAS/MIRAS) erhalten werden. Ist ein Molekül mit ähnlicher 3DStruktur in der Datenbank (www.pdb.org) verfügbar, kann die Methode des molekularen Ersatzes (Molecular Replacement, MR) angewendet werden.

Die genannten Methoden verwenden als Grundlage die Patterson-Methode, welche in Formel 2.4 dargestellt ist.

$$
P(u, v, w)=\frac{1}{V} \sum_{h k l}\left|F_{h k l}\right|^{2} \cos (2 \pi(h u+k v+l w))
$$

Die Patterson-Funktion $P$ ist eine Fourier-Reihe, deren Koeffizienten die Strukturfaktoramplituden bilden. Das Maximum an der Stelle u, v, w gibt in der PattersonFunktion den relativen Abstand u, v, w zweier Atome an. Die Höhe des Maximums der Patterson-Funktion ist proportional zur Ordnungszahl der Atome und somit ergeben die Abstände zweier schwerer Atome besonders hohe Intensitäten. Das Zellvolumen V lässt sich aus den 6 Gitterkonstanten $\mathrm{a}, \mathrm{b}, \mathrm{c}, \alpha, \beta$ und $\gamma$, welche ihrerseits aus der geometrischen Lage der Reflexe zueinander bestimmt werden können, berechnen

\subsubsection{Lösung des Phasenproblems durch Molekularen Ersatz}

Sind bereits Proteinstrukturen mit ähnlicher dreidimensionaler Struktur bekannt, ist es möglich die Patterson-Funktion durch MR (2.18.3.3) zu lösen. Die Lösung der PattersonFunktion besteht aus zwei verschiedenen Sätzen von Vektoren. Der erste Satz an Vektoren beschreibt die intramolekularen Abstände zweier Atome innerhalb eines Proteinmoleküls, der zweite Satz die intermolekularen Abstände der Atome. Für die MR-Methode werden zunächst die intramolekularen Vektoren der Patterson-Funktion gesucht und durch Rotation und Translation des Modells kann die beste Lösung der Patterson-Funktion ermittelt werden.

\subsubsection{Strukturbau in Elektronendichtekarte und Verfeinerung}

Sobald die Phasen gut bestimmt waren, wurden sie für initiale Elektronendichtekarten zum Bau des Proteinmodells genutzt. Anschließend wurde das Modell mit Hilfe des 
Computerprogramms COOT manuell in diese Elektronendichtekarte eingebaut. Zur Verbesserung der kalkulierten Phaseninformation, der Qualität der Elektronendichtekarte und somit des Molekülmodels wurden danach kristallographische Strukturverfeinerungen durchgeführt. Das erfolgte zum einen gegen Strukturfaktoren mit dem CCP4-Programm REFMAC5 (Murshudov et al., 1997) und zum anderen gegen Intensitäten mit den Programmen CNS oder PHENIX. In diesen Verfeinerungen wurden aus dem gebauten Proteinmodell die Strukturfaktoramplituden $F_{\text {calc }}$ berechnet und mit den gemessenen Strukturfaktoramplituden $\mathrm{F}_{\mathrm{obs}}$ verglichen. Durch diese Prozesse wurde eine neue Elektronendichtekarte generiert, in welche das Proteinmodell erneut manuell eingebaut wurde. Die Verfeinerung ist ein iterativer Prozess, bei dem die Positionen der Atome um die Position im Modell solange variiert werden, bis eine Minimierung der Differenz zwischen $\mathrm{F}_{\mathrm{calc}}$ und $\mathrm{F}_{\mathrm{obs}}$ erreicht ist. Dieser Minimierungsprozess unterliegt gewissen Beschränkungen, die durch die Energien für Bindungslängen, Ionenabstände und Winkel gegeben sind. Die Qualität des Angleichens wurde durch Vergleich der beobachteten und der aus dem Modell berechneten Strukturfaktoramplituden überprüft (R-Faktor). Der kristallographische R-Faktor $\mathrm{R}_{\text {cryst }}$ ist der aus diesem Vergleich berechnete Fehler und ist definiert wie Formel 2.5 angegeben.

$$
R_{\text {cryst }}=\frac{\sum \| F_{o b s}|-| F_{c a l c}||}{\sum\left|F_{o b s}\right|}
$$

Dabei entspricht $F_{\text {obs }}$ den tatsächlich beobachteten und $F_{\text {calc }}$ den neu berechneten Strukturfaktoramplituden. Zur weiteren Kontrolle der Strukturverfeinerung wird der freie RFaktor $\left(\mathrm{R}_{\text {free }}\right)$ herangezogen, der sich wie $\mathrm{R}_{\text {cryst }}$ berechnen lässt, jedoch Gebrauch von nicht in die Verfeinerung einbezogenen Reflexen (5\% der Reflexe eines Datensatzes) macht. Dieses sogenannte „Testset“ wurde nur zur Kreuzvalidierung eingesetzt um die Konvergenz der Strukturverfeinerung $\mathrm{zu}$ kontrollieren. Darüberhinaus wurde die verfeinerte Elektronendichtekarte mit der ursprünglichen Dichte verglichen und eine $\mathrm{F}_{\mathrm{obs}}-\mathrm{F}_{\text {calc }}$ Elektronendichtekarte zum Abgleich verwendet. Wassermoleküle wurden mit der ARP/waters Option des Programms REFMAC5 automatisch detektiert und eingebaut.

Zur grafischen Wiedergabe der Strukturdaten wurde mit dem Programm PyMol (DeLano Scientific LLC, South San Francisco, USA) gearbeitet. 


\section{ERGEBNISSE}

Zur näheren Charakterisierung des Oxylipinstoffwechsels in $P$. patens wurden in der vorliegenden Arbeit die bifunktionellen PpLOX1, sowie die monofunktionellen AOC, PpAOC1 und PpAOC2, untersucht. Dazu werden kurz die Ergebnisse einer Sequenzanalyse und der biochemischen Charakterisierung von $P p L O X 1$ erläutert. Es wurden verschiedene $P p L O X 1-V a r i a n t e n$ erzeugt und diese Varianten sowie die Wildform in Enzymaktivitätstests mit verschiedenen Substraten untersucht.

Der zweite Teil der Arbeit konzentriert sich auf die Ergebnisse der biochemischen und strukturellen Aufklärung von $P p A O C 1$ und $P p A O C 2$. Dazu wurde ein Reinigungsprotokoll für beide Enzyme etabliert. Die gereinigten Enzyme wurden für die Umsetzung verschiedener Hydroperoxy-Fettsäuren in gekoppelten Enzymaktivitätstests verwendet. Darüber hinaus wurden die gereinigten Enzyme für Proteinkristallisations-Experimente verwendet. In den Proteinkristallisations-Experimenten wurden für $P p A O C 1$ und $P p A O C 2$ hochauflösende Kristalle erzeugt, die für eine Strukturaufklärung beider Enzyme geeignet waren.

\subsection{Charakterisierung von $P p L O X 1$}

Im folgenden Abschnitt werden die Ergebnisse der Charakterisierung von PpLOX1 beschrieben. Senger et al. (2005) zeigten, dass PpLOX1 Fettsäuren mit einer Kettenlänge von $\mathrm{C}_{18}$ bis $\mathrm{C}_{22}$ oxidiert und somit ein breites Substratspektrum besitzt (1.3.5.1). Im Gegensatz zu anderen LOXen, ist PpLOX1 ein bifunktionales Enzym, welches zusätzlich zur DOX- eine HPL-Aktivität besitzt. An diese Ergebnisse anschließend, sollten in der vorliegenden Arbeit die molekularen Ursachen für die Bifunktionalität gefunden werden. Zunächst wurde ein Aminosäure-Sequenzvergleich von PpLOX1 mit verschiedenen pflanzlicher LOXen, einer eukaryotischen LOX und einer bakteriellen LOX durchgeführt. Anschließend wurden durch ortsgerichteten Aminosäureaustausch $P p$ LOX1-Varianten generiert und mit dem Ausgangsenzym in Enzymaktivitätstests mit verschiedenen Fettsäuresubstraten verglichen.

\subsubsection{Sequenzanalyse von $P p L O X 1$}

Zuerst wurde mittels eines Sequenzvergleichs von verschiedenen LOXen nach konservierten und variablen Aminosäuren in der Substratbindungstasche gesucht. Dafür wurden sowohl Sequenzen höherer als auch niederer Organismen verwendet. In Abbildung 3.1 ist ein Ausschnitt der Analyse dargestellt. Der gesamte Sequenzvergleich ist in Abbildung $8.1 \mathrm{im}$ Anhang angefügt. 


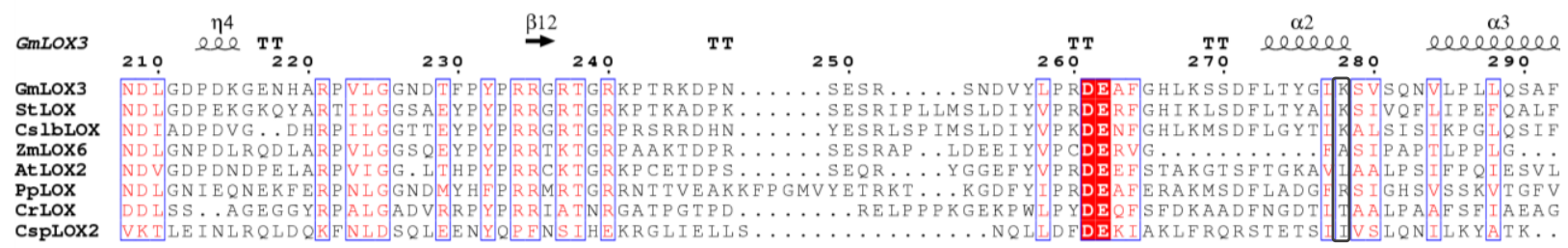

PpLOX1 R345
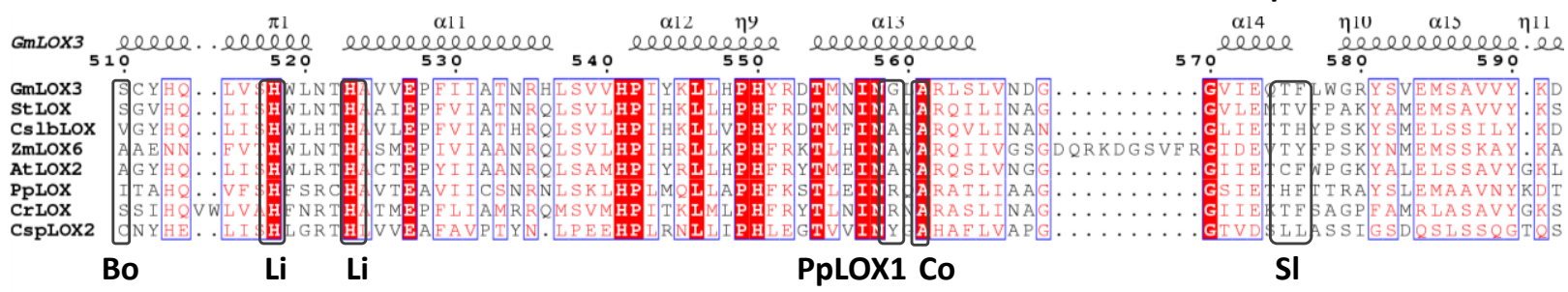

SI
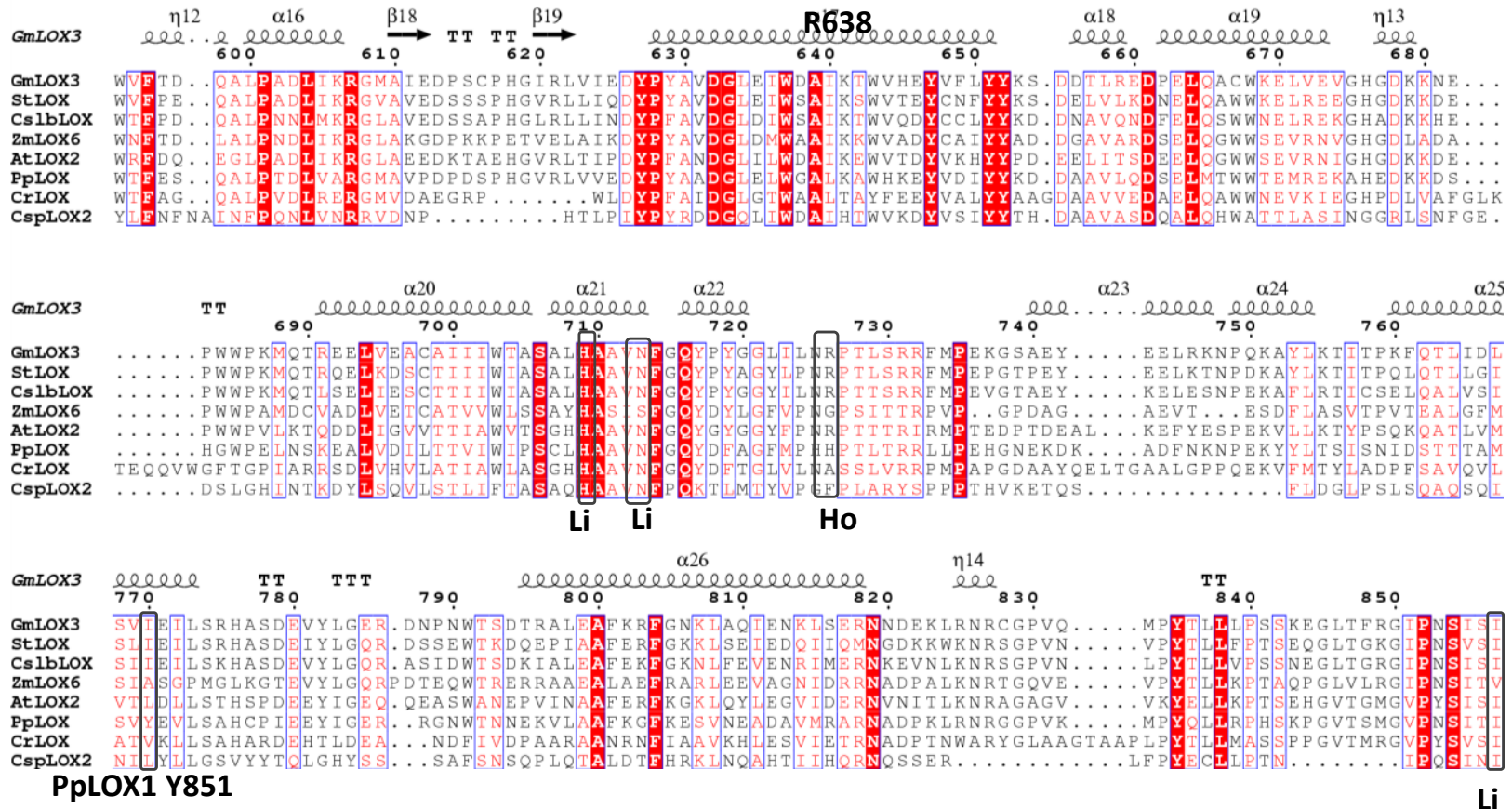

Abbildung 3.1: Ausschnitt aus einem Alignment verschiedener LOXen. [erstellt mit ESPript (Gouet et al., 1999)] Sekundärstrukturelemente und Nummerierung basierend auf der GmLOX3-Struktur (Skrzypczak-Jankun et al., 2001; 1IK3.pdb). Die folgenden LOXen sind aufgeführt (Accession-Nummern sind eingeklammert): GmLOX3 (P09186), StLOX (AAB31252), A. thaliana LOX3 (P38418), Cucumis sativus [(CsLOX; (CAA63483)], ZmLOX6 (NM_001112506), Cyanothece sp. [CspLOX; (YP_001804062)], Chlamydomonas reinhardtii [CrLOX (XP_0016908829] und PpLOX1 (CAE47464). Gerahmt: Bo = Borngräber-Determinante; $\mathrm{Co}=$ Coffa-Determinante, $\mathrm{Ho}=$ Hornung-Determinante, $\mathrm{Sl}=$ Sloane-Determinante; $\mathrm{Li}=$ Eisenliganden; PpLOX1-Aminosäurereste für Mutagenesestudien.

Die Sequenzanalyse zeigt, dass PpLOX1 größere Ähnlichkeit zu den pflanzlichen 13-LOXen als zu LOXen aus Cyanobakterien, bzw. aus eukaryotischen Grünalgen hat. Wie bereits erwähnt wurde, besitzt $P p L O X 1$ eine CTS und gehört somit zu den Typ-2-LOXen. Hingegen ist die GmLOX3 eine Typ-1-LOX ohne CTS. Die Aminosäuresequenzen von PpLOX1 und der pflanzlichen GmLOX3 sind zu $41 \%$ identisch bei einer Ähnlichkeit von 55,4\%. Im Gegensatz dazu sind die CspLOX2 aus Cyanobakterien und PpLOX1 nur zu 24,7 \% identisch 
und zu 37,8 \% ähnlich. Die CrLOX und PpLOX1 sind zu 28,1\% identisch und zu $42 \%$ ähnlich.

Wie eingangs beschrieben (1.3.2) besitzen LOXen bestimmte Determinanten zur regio- und stereospezifischen Umsetzung von Fettsäuren. Die Sloane-Determinanten (Sloane et al., 1991) nehmen in PpLOX1 die voluminösen Reste Histidin und Phenylalanin ein. An der Stelle der Borngräber-Determinante (Borngräber et al., 1996) befindet sich in PpLOX1 ein Isoleucinrest. Die Hornung-Determinante (Hornung et al., 1999) ist ein polarer Histidinrest. An der Position der Coffa-Determinante (Coffa \& Brash, 2004) befindet sich, wie in allen $S$ LOXen, ein Alaninrest (Abbildung 3.1 und Abbildung 3.3).

Um einen ersten Eindruck vom aktiven Zentrum von $P p L O X 1 \mathrm{zu}$ bekommen und mögliche Determinanten für die Bifunktionalität des Enzyms zu finden, wurde ein Strukturmodell errechnet (Swiss-Modell, http://swissmodel.expasy.org/), welches in Abbildung 3.2 dargestellt ist.

\section{C-terminale \\ katalytische Domäne}

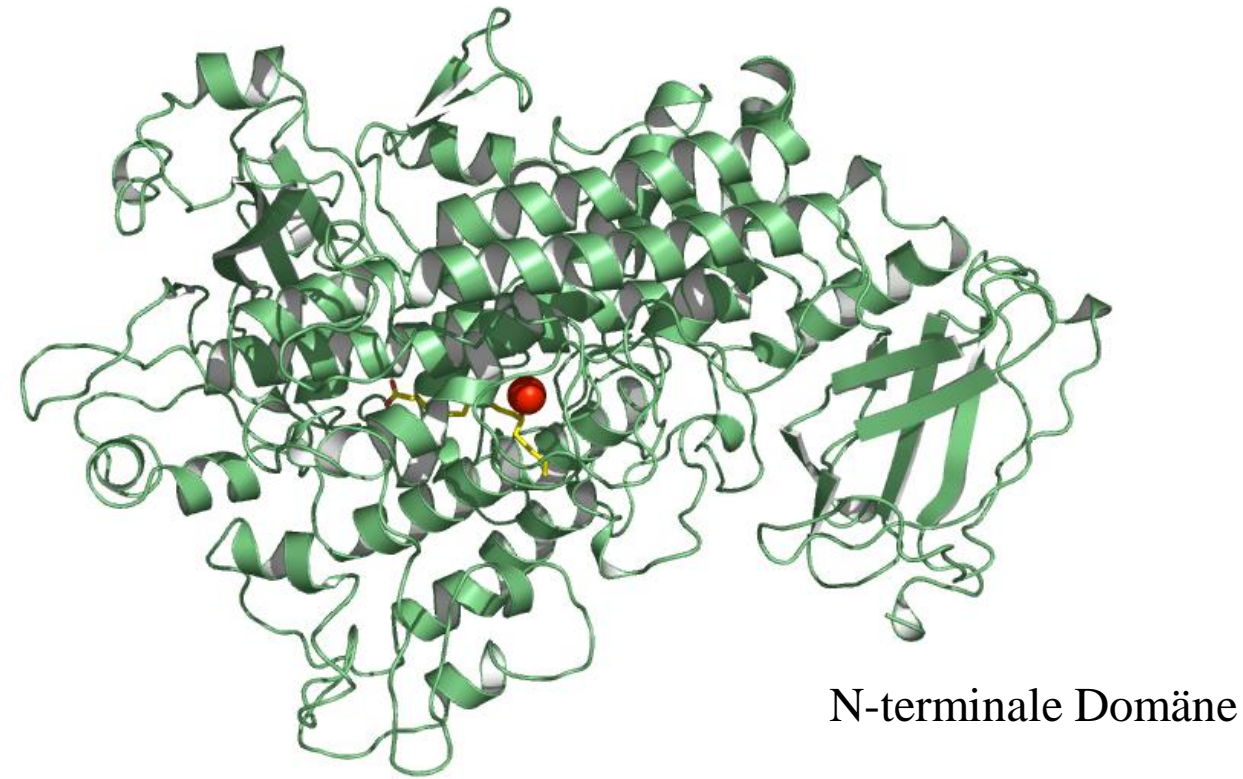

Abbildung 3.2: Die dreidimensionale Proteinstruktur des PpLOX1-Modells im Überblick. Aminosäurerückgrat in Farbbanddarstellung (grün); Produkt 13-HPOTE als Stabmodell (gelb); Eisenligand als Kugel (rot).

Als Vorlage diente die oben beschriebene GmLOX3-Struktur mit dem Reaktionsprodukt 13SHPOTE im aktiven Zentrum (Skrzypczak-Jankun et al., 2001; 1IK3.pdb). Das errechnete PpLOX1-Modell hat eine für LOX typische Zwei-Domänenstruktur. Die C-terminale, 
katalytisch aktive Domäne wird hauptsächlich durch $\alpha$-Helices gebildet, wohingegen die Nterminale Domäne aus $\beta$-Faltblättern aufgebaut ist.

Interessanterweise befinden sich am Eingang der Substratbindetasche zwei positiv geladene Argininreste (Arg-345 und Arg-638; Abbildung 3.3 B) und in der Substratbindetasche ein Tyrosinrest an Position 851 (Abbildung 3.3 C).

(A)

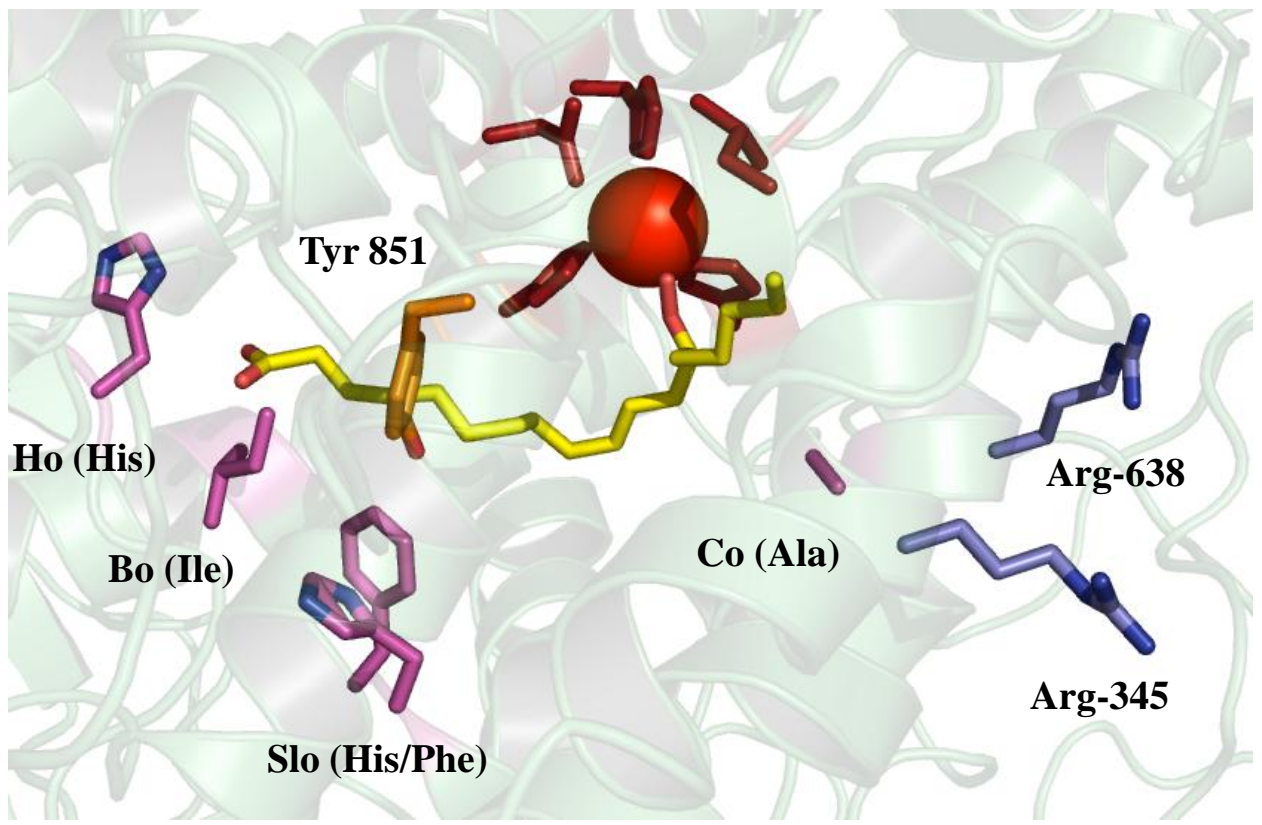

(B)

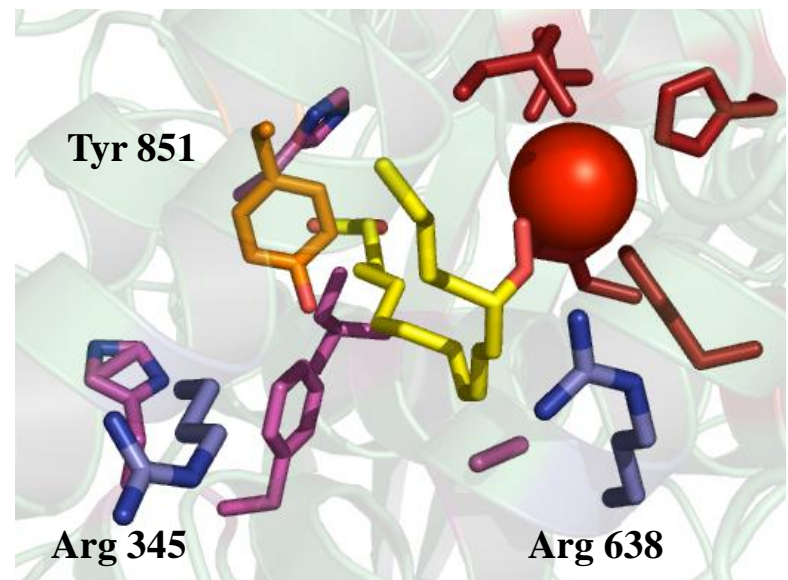

(C)

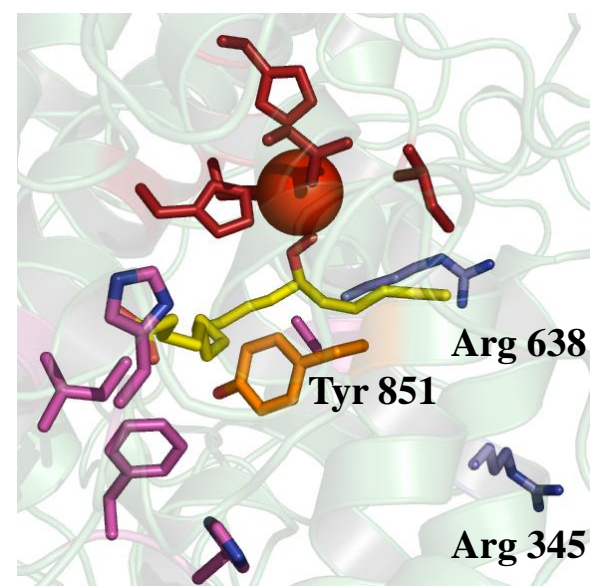

Abbildung 3.3: Modell des aktiven Zentrums von PpLOX1. Aminosäurerückgrat in Farbbanddarstellung (grün); Produkt 13-HPOTE als Stabmodell (gelb); Eisenligand als Kugel (rot); Arg-345 und Arg-638 als Stabmodelle (cyan); Tyr-851als Stabmodell (orange); Determinanten zur Stereo- und Regioselektivität als Stabmodelle (magenta); Aminosäurereste, die das Eisen binden, als Stabmodelle (rot). (A) Überblick (B) Eingang zur Substratbindetasche; (C) Boden der Substratbindetasche. 
In der Aminosäuresequenz befindet sich in den anderen untersuchten Pflanzen-LOXen an Position 345 von $P p L O X 1$ ein ebenfalls positiv geladener Lysinrest, jedoch befinden sich an Position 638 in den anderen LOXen ungeladene Alanin- oder Glyzinreste (Abbildung 3.1). Möglicherweise sind die zwei Reste Arg-345 und Arg-638 in PpLOX1 an der Fixierung der negativ geladenen Carboxylgruppe des Substrates beteiligt. Diese Hypothese wurde durch zielgerichtete Mutagenese überprüft, bei welcher die Arg-Reste jeweils durch die ungeladene Aminosäure Leucin ausgetauscht wurden (Varianten R345L, R638L und R345L/R638L).

In der Aminosäuresequenz der untersuchten LOXen befindet sich an Position 851 untersuchten LOXen ein Isoleucin statt des Tyrosins (Abbildung 3.1). Hydroxidgruppen an Tyrosinresten sind sehr reaktiv und sind z. B. an der Delokalisation von Ladungen, bzw. Radikalen beteiligt. Möglicherweise ist Tyr-851 an der enzymatischen Spaltung des Hydroperoxy-Fettsäureproduktes in ungesättigte Alkohole und 12-ODTE beteiligt (Senger et al., 2005). Um diese Hypothese zu prüfen, wurde mithilfe zielgerichteter Mutagenese das Tyr-851 durch Phenylalanin sowie Isoleucin ausgetauscht.

In Abbildung 3.3 A ist das modellierte aktive Zentrum von PpLOX1 dargestellt. Es sind sowohl die Aminosäurereste für die zielgerichtete Mutagenese (Arg-345, Arg-638 und Tyr851), als auch die für Stereo- und Regioselektivität des Enzyms verantwortlichen Determinanten gezeigt. In der Struktur von Skrzypczak-Jankun et al. (2001) bindet das Produkt 13S-HPOTE invers orientiert, mit dem Carboxylende zuerst, im aktiven Zentrum.

\subsubsection{Untersuchung des Produktspektrums von PpLOX1 und ihren Varianten durch Umsetzung verschiedener Fettsäuresubstrate}

Die Analyse der Produktspektren nach Umsetzung verschiedener Fettsäuren durch die PpLOX1-Varianten im Vergleich zum Ausgangsenzym sollte den Einfluss der einzelnen Punktmutationen auf den Reaktionsmechanismus zeigen. Die Umsetzungen sowie die nachfolgende Aufnahme und Analyse der Daten erfolgten nach Senger et al. $(2005 ; 2.16 .3)$. Es wurden die Fettsäuresubstrate GLA, AA und EPA verwendet (Abbildung 3.4 - Abbildung 3.6).

\subsubsection{Umsetzung von AA}

In Abbildung 3.4 sind die Ergebnisse der Umsetzungen mit AA dargestellt. Die PpLOX1Tyr-851-Varianten zeigten im Vergleich zum Ausgangsenzym eine unterschiedliche Verteilung der Produkte (Abbildung 3.4). Die Phenylalanin-Variante (Y851F) erzeugte einen höheren relativen Anteil des Lyaseproduktes 12-ODTE (24\%). Im Vergleich dazu erzeugte das Ausgangsenzym $16 \%$ 12-ODTE. Der relative Anteil an Hydroxy-Fettsäuren im Reaktionsgemisch der Phenylalanin-Variante war hingegen geringer (66\% statt $74 \%$ ). Der 
relative Anteil an Keto-Fettsäuren war gleich. Es wurde zudem beobachtet, dass die absoluten Flächen der Absorptionspeaks der Reaktionsprodukte der Phenylalanin-Variante insgesamt größer waren als die Flächen der Produkte des Wildform-Enzyms.

Die Auswertung der Messungen für die Isoleucin-Variante (Y851I) ergab einen entgegengesetzten Trend. Im Vergleich zur Ausgangsform erzeugte sie einen geringeren relativen Anteil an 12-ODTE (10\%) als auch an Ketofettsäuren (7\% statt $10 \%)$. Im Gegensatz dazu war der relative Anteil an Hydroxy-Fettsäuren im Reaktionsgemisch der Isoleucin-Variante größer und lag bei 82 \%. Die absoluten Flächen der Absorptionspeaks der Reaktionsprodukte der Isoleucin-Variante waren insgesamt kleiner als die Flächen der Produkte des Ausgangsenzyms. Durch den Austausch an Position 345 erzeugte die LeucinVariante (R345L) im Vergleich zum Ausgangsenzym einen erhöhten prozentualen Anteil an 12-ODTE bei reduziertem prozentualen Anteil an Hydroxid- und Keto-Fettsäuren (Abbildung 3.4). Hingegen erzeugte die Variante R638L einen leicht reduzierten prozentualen Anteil an Oxo- und Keto-Fettsäuren und damit erhöhten prozentualen Anteil an Hydroxy-Fettsäuren (Abbildung 3.4). Es muss an dieser Stelle darauf hingewiesen werden, dass die beschriebenen Unterschiede in den Produktgemischen der P $p$ LOX1-Varianten und dem Ausgangsenzym nach Umetzung von AA nicht signifikant sind. 

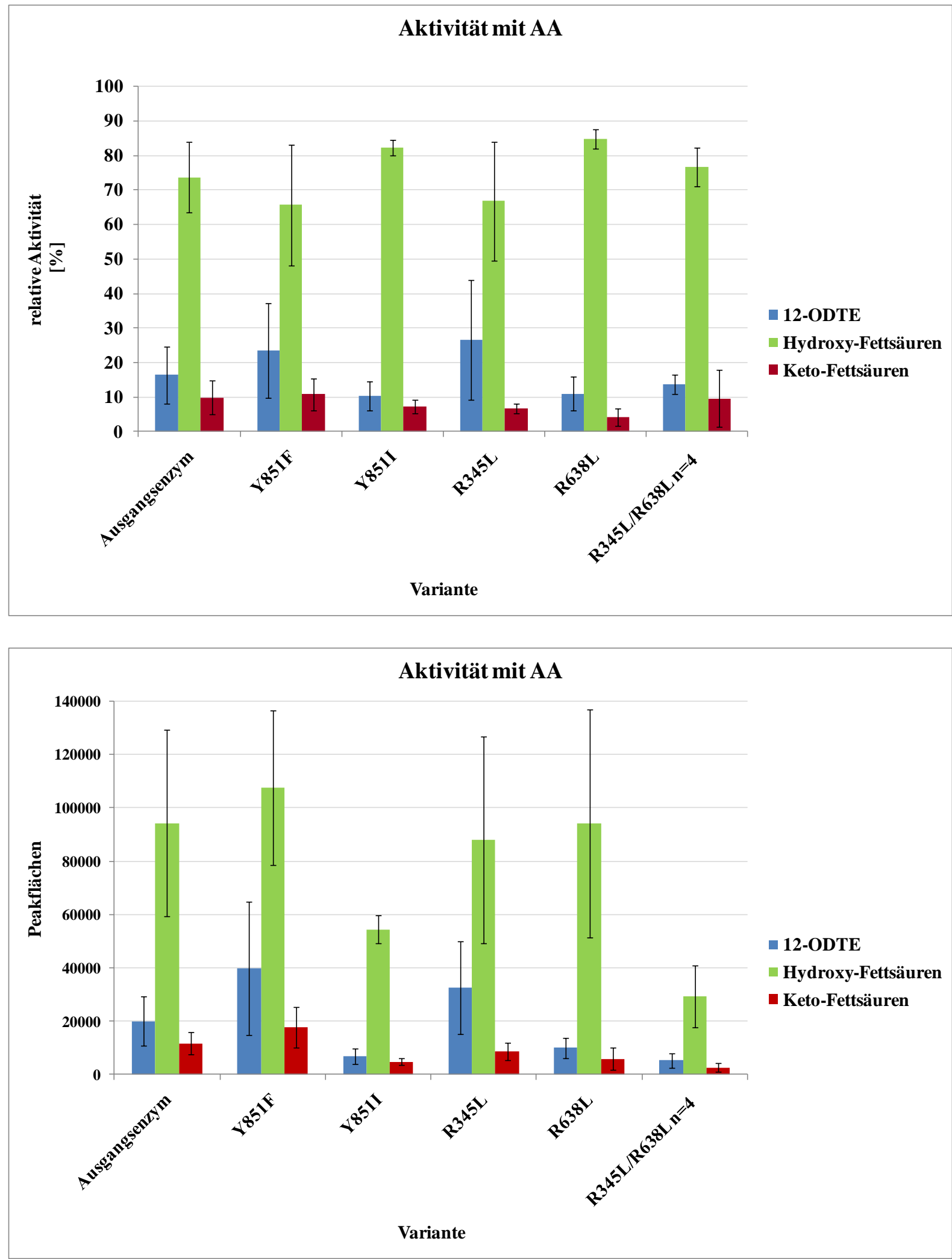

Abbildung 3.4: HPLC-Analyse der Umsetzung von AA durch verschiedene PpLOX1-Varianten im Vergleich zum Ausgangsenzym. Unten: Verteilung der Produkte der unterschiedlichen Varianten im Vergleich zum Ausgangsenzym als Flächen unter den Absorptionspeaks; oben: relative Menge der Produkte in Prozent. Lyaseprodukt (12-ODTE, blau); Hydroxy-Fettsäuren (grün); Keto-Fettsäuren (rot). Gezeigt wird der Mittelwert aus vier unabhängigen Experimenten mit Standardabweichung. 
Die erzeugte Doppelmutante (R345L/R638L) bildete bei Umsetzung im Vergleich zum Ausgangsenzym einen leicht reduzierten prozentualen Anteil an Oxo- und Keto-Fettsäuren (Abbildung 3.4 ). Besonders auffällig waren die im Vergleich zum Ausgangsenzym und den Einzelmutanten sehr kleinen Flächen der Absorptionssignale der AA-Produkte (Abbildung 3.4). Somit kann geringere Enzymaktivität der Arginin-Doppelmutante angenommen werden.

\subsubsection{Umsetzung von EPA}

In Abbildung 3.5 sind die Resultate der Umsetzungen mit EPA durch die PpLOX1-Varianten im Vergleich zur Kontrolle dargestellt. Die Umsetzungen mit EPA ergaben ähnliche Resultate wie mit AA (Abbildung 3.5). Die Phenylalanin-Variante (Y851F) erzeugte einen größeren relativen Anteil der 12-ODTE, sie produzierte $28 \%$ an 12-ODTE. Im Vergleich dazu erzeugte das Ausgangsenzym $19 \%$ an 12-ODTE. Der relative Anteil an Hydroxy-Fettsäuren im Reaktionsgemisch der Phenylalanin-Variante lag bei $61 \%$, statt $73 \%$ in der Kontrolle. Der relative Anteil an Keto-Fettsäuren im Reaktionsgemisch der Phenylalanin-Variante war leicht erhöht im Vergleich zum Ausgangsenzym. Es wurde ebenfalls beobachtet, dass die absoluten Flächen der Absorptionssignale der EPA-Reaktionsprodukte der Phenylalanin-Variante insgesamt größer waren als die Flächen der Produkte des Ausgangsenzyms.

Im Vergleich zum Ausgangsenzym erzeugte die Variante Y851I einen geringeren relativen Anteil an $\omega$-Oxofettsäure (17\%) als auch der Keto-Fettsäuren (5\% statt $8 \%$ ). Im Gegensatz dazu war der relative Anteil an Hydroxy-Fettsäuren im Reaktionsgemisch der IsoleucinVariante mit $79 \%$ größer. Die Flächen der Absorptionssignale der EPA-Reaktionsprodukte der Isoleucin-Variante waren insgesamt kleiner als die Flächen der Produkte in den Kontrollmessungen.

Die Leucinvariante (R345L) erzeugte im Vergleich zum Ausgangsenzym einen geringeren prozentualen Anteil an Oxo- und Keto-Fettsäuren bei größerem prozentualen Anteil an Hydroxy-Fettsäuren (Abbildung 3.5). Hingegen erzeugte die Variante R638L einen kleineren prozentualen Anteil an Oxo- und Keto-Fettsäuren und folglich erhöhten prozentualen Anteil an Hydroxid-Fettsäuren (Abbildung 3.5). Die absoluten Flächen der Absorptionspeaks der EPA-Reaktionsprodukte, erzeugt durch die R345L-Variante, waren insgesamt größer und die der R638L-Variante insgesamt kleiner als die Flächen der Produkte in der Kontrolle. 

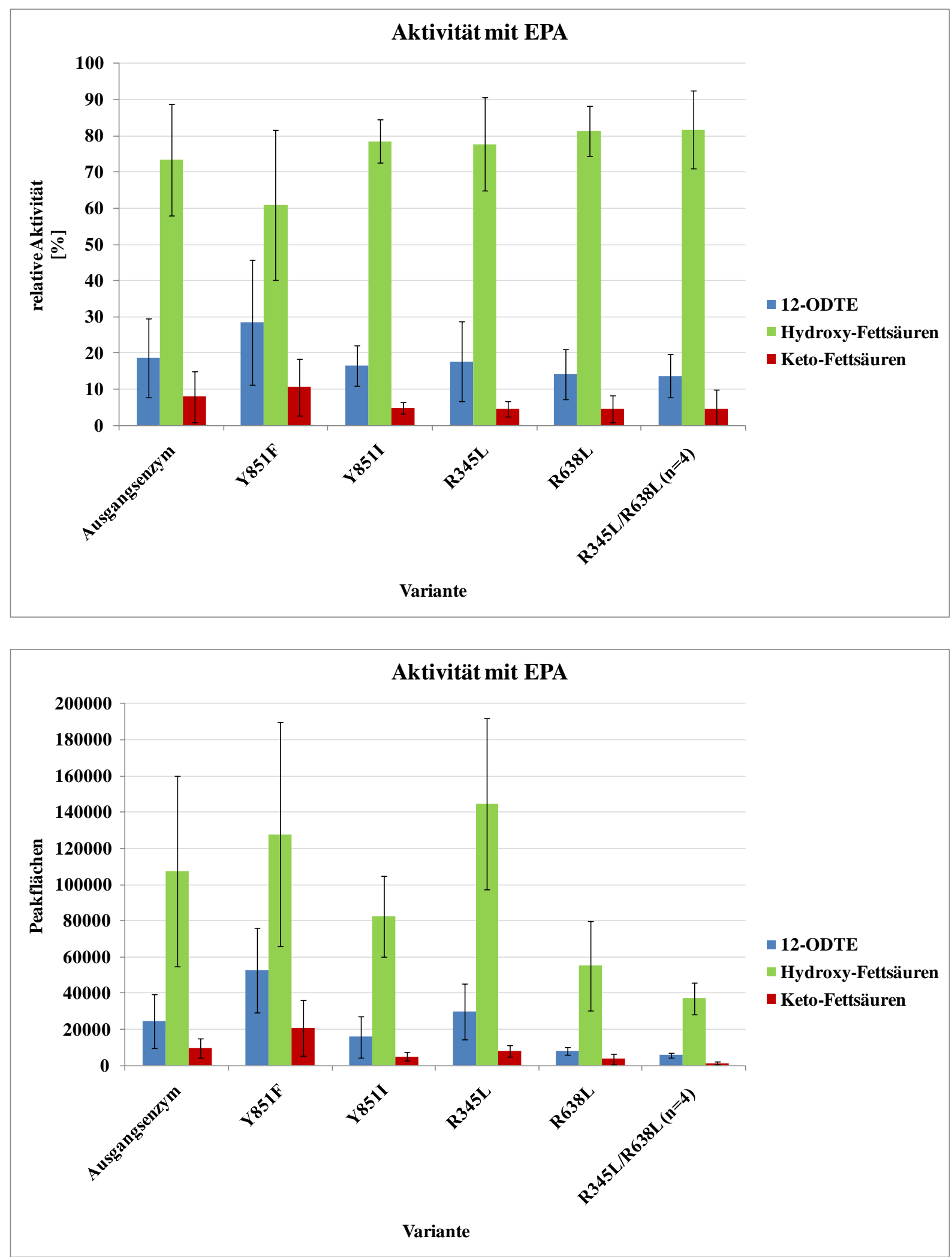

Abbildung 3.5: HPLC-Analyse der Umsetzung von EPA durch verschiedene PpLOX1-Varianten im Vergleich zum Ausgangsenzym. Unten: Verteilung der Produkte der unterschiedlichen Varianten im Vergleich zum Ausgangsenzym als Flächen unter den Absorptionssignalen; oben: relative Menge der Produkte in Prozent. Lyaseprodukt (12-ODTE, blau); Hydroxy-Fettsäuren (grün); Keto-Fettsäuren (rot). Gezeigt wird der Mittelwert aus vier unabhängigen Experimenten mit dazugehöriger Standardabweichung. 
Die erzeugte Doppelmutante (R345L/R638L) bildete bei Umsetzung von EPA im Vergleich zum Ausgangsenzym einen leicht reduzierten prozentualen Anteil an Oxo- und KetoFettsäuren (Abbildung 3.5). Auch für die Umsetzungen der PpLOX1-Varianten im Vergleich zur Ausgangsform wurden keine signifikanten Unterschiede in der Produktverteilung beobachtet.

Interessanterweise waren die Flächen der Absorptionssignale der EPA-Produkte im Vergleich zur Y851- und R345L-Variante kleiner (Abbildung 3.5). Wie bereits für AA beobachtet, war die Enzymaktivität der Arginin-Doppelmutanten wahrscheinlich geringer.

\subsubsection{Umsetzung von GLA}

In Abbildung 3.6 sind die Ergebnisse der Umsetzungen von GLA durch die Y851-Varianten im Vergleich zum Ausgangsenzym dargestellt. Die Arginin-Varianten wurden mit diesem Substrat nicht analysiert. Die Ergebnisse der Umsetzungen von GLA durch die TyrosinVarianten bestätigten die Beobachtungen der Umsetzungen mit ARA und EPA (Abbildung 3.6). Für die Mutation an PpLOX1-Position 851 ist für alle untersuchten Substrate (ARA, EPA und GLA) zu erkennen, dass die Isoleucin-Variante im Vergleich zum Ausgangsenzym einen leicht reduzierten prozentualen Anteil an Oxo- und Keto-Fettsäuren und damit erhöhten prozentualen Anteil an Hydroxy-Fettsäuren erzeugt (Abbildung 3.4 bis Abbildung 3.6). Im Gegensatz dazu erzeugte die Phenylalanin-Variante im Vergleich zur Kontrolle einen etwas höheren prozentualen Anteil an Oxo- und Keto-Fettsäuren und damit einen reduzierten prozentualen Anteil an Hydroxy-Fettsäuren (Abbildung 3.4 bis Abbildung 3.6). Zusätzlich sind die integrierten Flächen der Absorptionssignale für die Produkte der einzelnen Substrate für die Phenylalanin-Variante größer und für die Isoleucin-Variante kleiner als in der Kontrolle (Abbildung 3.4 bis Abbildung 3.6).

Abschließend kann zusammengefasst werden, dass die Unterschiede in den Produktspektren der einzelnen $P p L O X 1-V a r i a n t e n$ im Vergleich zum Ausgangsenzym bei Umsetzungen mit verschiedenen Fettsäuren wenig signifikant sind. Es wurde jedoch beobachtet dass die Arginin 345/638 Doppelmutation in ein Leucin, Klone mit deutlich reduzierter Enzymaktivität erzeugt. 

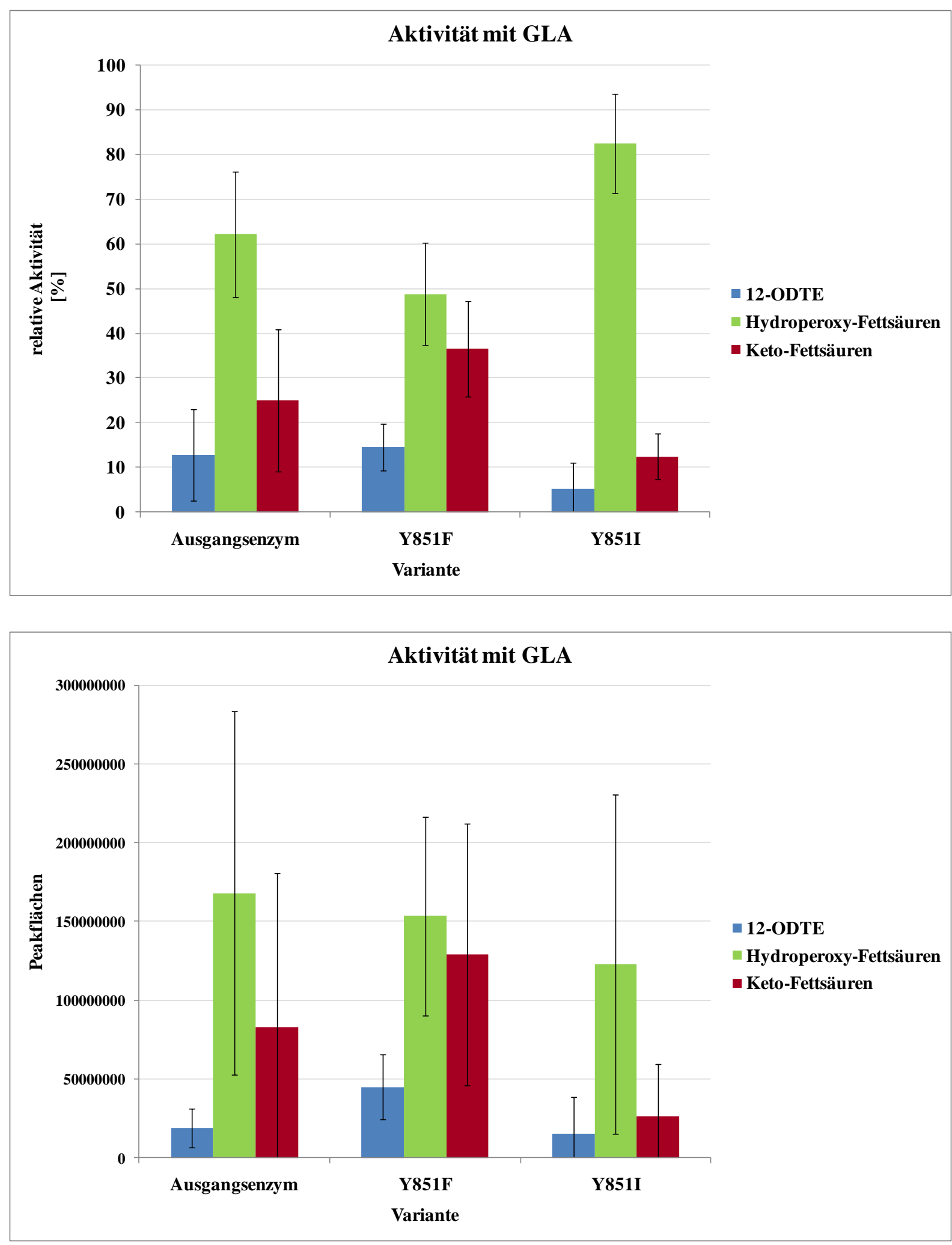

Abbildung 3.6: HPLC-Analyse der Umsetzung von GLA durch verschiedene PpLOX1-Varianten im Vergleich zum Ausgangsenzym. Unten: Verteilung der Produkte der unterschiedlichen Varianten im Vergleich zum $P p$ LOX1-Ausgangsenzym als Flächen unter den Absorptionssignalen; oben: relative Menge der Produkte in Prozent. Lyaseprodukte (blau), Hydroxy-Fettsäuren (grün), Keto-Fettsäuren (rot). Gezeigt wird der Mittelwert aus vier unabhängigen Experimenten mit Standardabweichung. 


\subsection{Biochemische Charakterisierung von PpAOC1 und PpAOC2}

Kürzlich wurde gezeigt, dass rekombinant erzeugte PpAOC2 eine zusätzliche Aktivität für das Allenoxid besitzt, welches sich von 12S-HPETE ableitet (M. Stumpe, Dissertation, 2006). Zusätzlich setzt PpAOC2 wie auch PpAOC1 das Allenoxid um, das sich von $13 S$-HPOTE ableitet. Daraus erschlossen sich die weiteren Ziele der vorliegenden Dissertation - die Etablierung der Reinigung für die rekombinanten Proteine PpAOC1 und PpAOC2 sowie die biochemische und strukturbiologische Aufklärung der unterschiedlichen Substratspezifität.

\subsubsection{Klonierung und Expression von PpAOC1 und PpAOC2}

$\mathrm{Zu}$ Beginn der Arbeiten wurden die Vektoren pGEM ${ }^{\circledR}$-T-PpAOC1 und pGEM®-T-PpAOC2 von Dr. M. Stumpe zur Verfügung gestellt. Bei dem pGEM ${ }^{\circledR}-\mathrm{T}-P p A O C 2$ Klon befand sich im Vergleich zur publizierten PpAOC2-Sequenz eine Punktmutation an Position 40. Statt eines Glyzins befindet sich in diesem Klon ein Serin. Die Punktmutation befindet sich in einem flexiblen Bereich des Enzyms (3.4.4.2) und zeigte keinen Einfluss auf die Enzymaktivität von PpAOC2 (nicht gezeigt). Zur heterologen Expression in E. coli wurden beide Gene aus dem pGEM $^{\circledR}$-T Vektor in den pGEX-6-P-1 Vektor kloniert. Durch die Verwendung des Vektors pGEX-6P-1 wurde das Zielprotein mit einem N-terminalen Glutathion- $S$-TransferaseFusionsprotein (GST) exprimiert, welche die Affinitätsreinigung des Zielproteins erleichtern sollte. Es wurden E. coli BL21star (DE3)-Zellen mit Plasmid-DNA von je fünf positiven pGEX Klonen transformiert und exprimiert. Die Expressionsausbeute wurde mit SDS-PAGE und die Aktivität der Klone durch die Umsetzung des Substrates 13S-HPOTE in einem gekoppelten Enzymaktivitätstest mit Zelllysat von PpAOS1/PpAOC1, bzw. PpAOS1/PpAOC2 überprüft. Die Expression erfolgte im analytischen Maßstab bei $28{ }^{\circ} \mathrm{C}$ für 16 h. Die SDS-PAGE Analyse zeigte jeweils für den PpAOC1 Klon 1 und den PpAOC2 Klon 2 die beste Expression (nicht gezeigt).

Im Vergleich zur Umsetzung von 13-HPOTE durch PpAOS1 (Vergleichsmessung) zeigten die Produktgemische von pGEX-PpAOC1 Klon 1, bzw. pGEX-PpAOC2 Klon 2 einen deutlich höheren OPDA-Anteil (jeweils $15 \%$ vs. $63 \%$ vs. $58 \%$ ). Aufgrund dieser Ergebnisse wurden die Konstrukte pGEX-PpAOC1 Klon 1 und pGEX-PpAOC2 Klon 2 für die heterologe Expression in E. coli BL21star (DE3) ausgewählt. Alle im Folgenden beschriebenen Versuche wurden mit diesen Klonen durchgeführt.

\subsubsection{Reinigung von rekombinanter $P p \mathrm{AOC1}$ und $P p \mathrm{AOC} 2$}

Der erste Reinigungsschritt der PpAOC1/2-GST-Fusionsproteine erfolgte aus dem Zelllysat über eine GSH-Sepharose-Säule. Danach folgten die Abspaltung des N-terminalen GST- 
Proteins durch PreScission-Protease und die Reinigung vom GST-Protein und anderen Proteinen mittels der Anionenaustauschchromatographie. Zur finalen Trennung von aggregiertem Protein wurde eine Größenausschlusschromatographie durchgeführt. Im Folgenden werden die Resultate der einzelnen Reinigungsschritte beschrieben.

Der Überstand des Bakterienzellaufschlusses (2.14.3) wurde über eine GSH-Sepharose-Säule gegeben und das gebundene Protein eluiert (2.15.1). Die Elutionsprofile zeigten jeweils einen Peak von ca. 1000 mAU (Abbildung 3.7 A und Abbildung 3.8 A). Die SDS-Gele in Abbildung 3.9 und Abbildung 3.10 zeigen neben der Analyse der Expression und des Aufschlusses (Spur 1) ein Aliquot des ersten Reinigungsschrittes (Spur 2). Die PpAOC1/2GST-Fusionsproteine besitzen ein apparentes Molekulargewicht von etwa $48 \mathrm{kDa}$ und sind als deutliche Bande im Gel erkennbar. Nach diesem ersten Reinigungsschritt lagen beide GST-Fusionsproteine schon sehr rein in Lösung vor (Abbildung 3.9 und Abbildung 3.10, jeweils Spur 2). Zur Abspaltung der GST-Affinitätssequenz von den PpAOC-Fragmenten wurden die vereinigten Fraktionen über Nacht bei $10^{\circ} \mathrm{C}$ mit der PreScission-Protease geschnitten (2.15.1). Eine Analyse mit SDS-PAGE ließ erkennen, dass das Fusionsprotein nahezu vollständig in seine Bestandteile GST und PpAOC1 bzw. PpAOC2 gespalten wurde (Abbildung 3.9 und Abbildung 3.10, Spur 3). Die erwarteten Größen für die jeweiligen PpAOC-Proteine von 21 kDa und des GST-Proteins von 26 kDa wurden dabei bestätigt. 
(A)

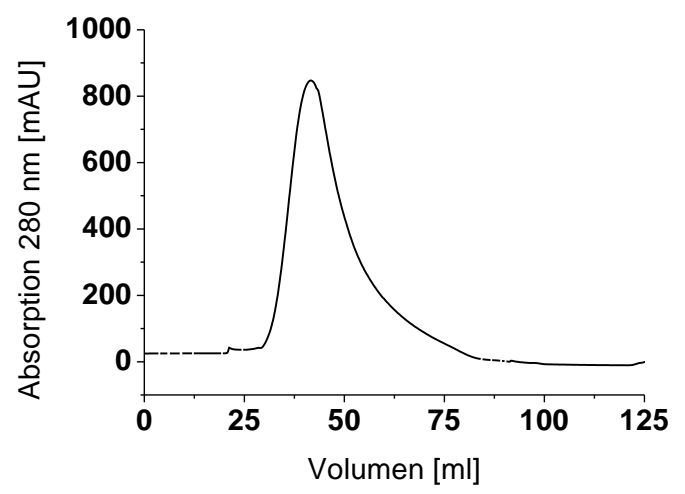

(B)

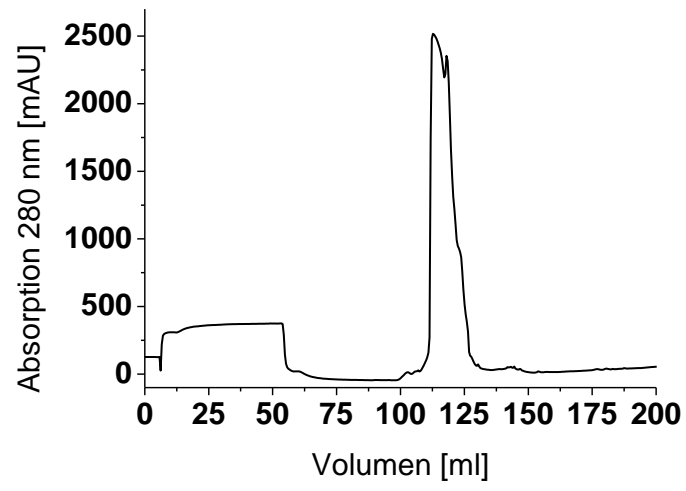

(C)

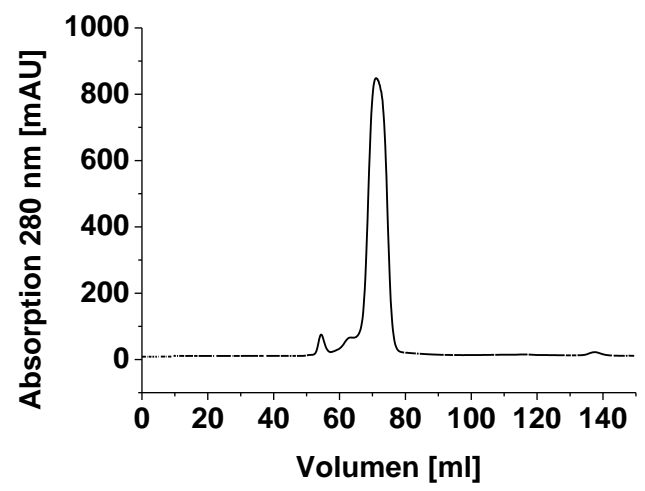

Abbildung 3.7: Elutionsprofile der Aufreinigung von PpAOC1. (A) Elutionsprofil der Affinitätschromatographie über eine $30 \mathrm{ml}$ GSH-Sepharose-Säule, PpAOC1 eluierte bei einem Volumen von $32 \mathrm{ml}$; (B) Elutionsprofil der Anionenaustauschchromatographie, PpAOC1 befand sich im Säulendurchfluss; (C) Elutionsprofil der Gelfiltration, PpAOC1 eluierte bei einem Volumen von $60 \mathrm{ml}$ nach Proteininjektion. Das dargestellte Experiment zeigt ein repräsentatives Ergebnis von 10 unabhängigen Experimenten.

Der nächste Schritt der Reinigung bestand aus einer Anionenaustauschchromatographie der vereinigten und geschnittenen Fraktionen von PpAOC1 bzw. PpAOC2. Dabei sollten alle Fremdproteine, die in der Affinitätschromatographie mit von der Säule eluierten, wie GST und eventuell nicht gespaltenes Fusionsprotein, von den PpAOC-Molekülen getrennt werden. Dazu wurde die Probe mit dem geschnittenem Fusionsprotein über die Entsalzungsäule gegeben und in einen Puffer ohne $\mathrm{NaCl}$ und mit $\mathrm{pH} \mathrm{8,0} \mathrm{umgepuffert} \mathrm{(2.15.4).} \mathrm{Die}$ Proteinlösungen wurde anschließend auf eine MonoQ® FPLC® HR10/10 Säule geladen (2.15.2). Das Elutionsprofil eines Säulenlaufes ist für beide Proteine beispielhaft in Abbildung 3.7 B und Abbildung 3.8 B dargestellt. Im Unterschied zu PpAOC2 band PpAOC1 bei pH 8,0 nicht an den Anionenaustauscher (Abbildung 3.7 B und Abbildung 3.8 B). Versuche die Anionenaustauschchromatographie bei höheren $\mathrm{pH}-$ Werten oder mit anderen 
Säulenmaterialien durchzuführen, zeigten die gleichen Ergebnisse (nicht dargestellt). Die anschließende SDS-PAGE-Analyse zeigte, dass sich das PpAOC1-Protein vollständig im Durchfluss der Säule befand (Abbildung 3.9 Spur 4). GST und andere Proteine banden vollständig an das Säulenmaterial und wurden vom Zielprotein getrennt.

(A)

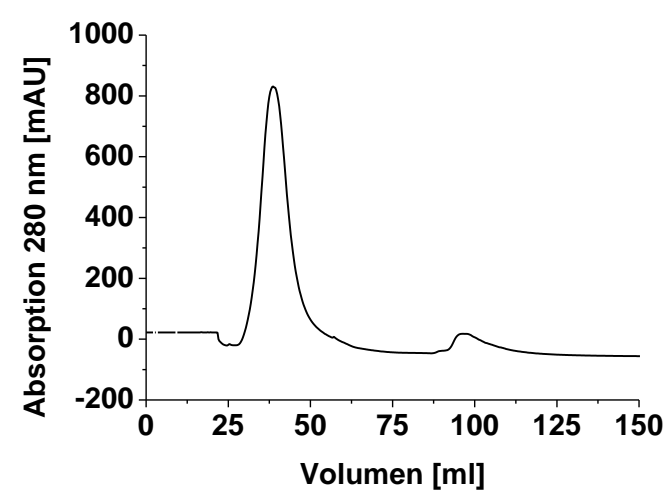

(C)
(B)

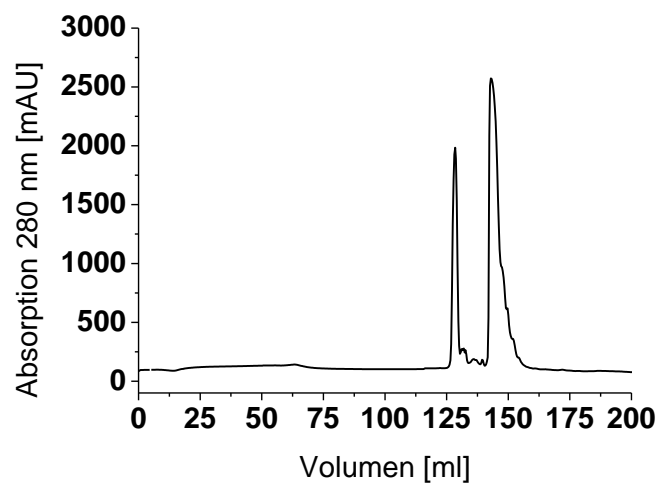

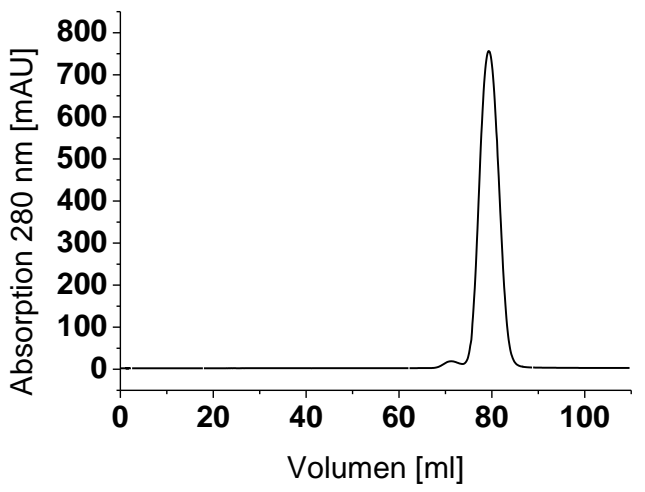

Abbildung 3.8: Elutionsprofile der Aufreinigung von PpAOC2. (A) Elutionsprofil der Affinitätschromatographie über eine $30 \mathrm{ml}$ GSH-Sepharose-Säule, PpAOC2 eluierte bei $32 \mathrm{ml}$ (B) Elutionsprofil der Anionenaustauschchromatographie, PpAOC2 eluierte bei $125 \mathrm{ml}$; (C) Elutionsprofil der Gelfiltration, PpAOC2 eluierte bei $60 \mathrm{ml}$ nach Proteininjektion. Das gezeigte Experiment zeigt ein representatives Ergebnis von 10 unabhängigen Experimenten.

Im Gegensatz dazu band das PpAOC2-Protein an das Säulenmaterial und wurde mit einem $\mathrm{NaCl}-G r a d i e n t e n$ von GST und anderen Proteinen getrennt (Abbildung 3.8 B). Die folgende SDS-PAGE-Analyse zeigte, dass sich das PpAOC2-Protein in den ersten Elutionsfraktionen befand (Abbildung 3.10, Spur 4). Die Kontrolle des Reinigungserfolges nach der Anionenaustauschchromatographie mit SDS-PAGE zeigte, dass PpAOC1 und PpAOC2 schon sehr rein in Lösung vorlagen (Abbildung 3.9 und Abbildung 3.10, Spur 4). 


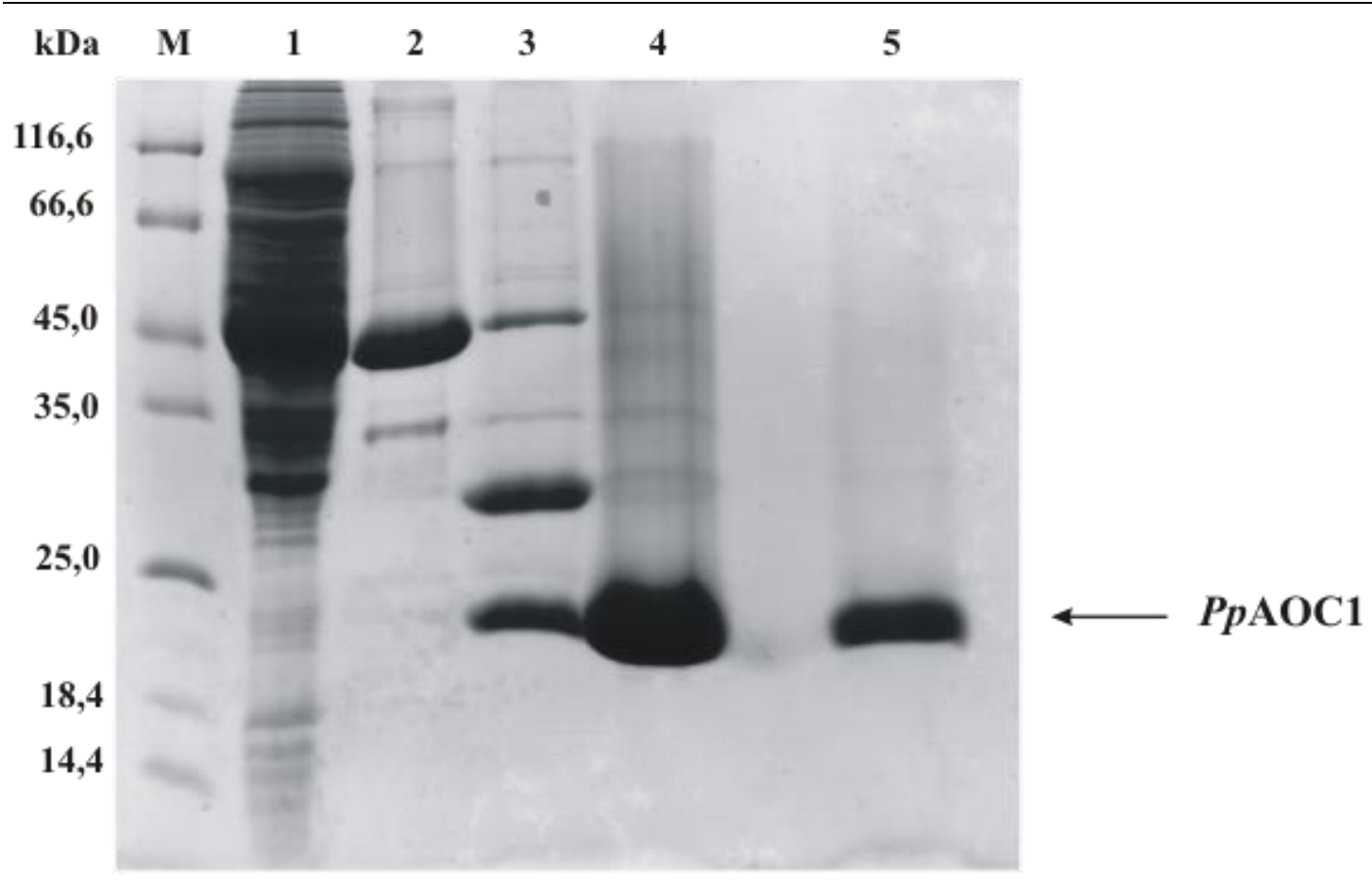

Abbildung 3.9: SDS-PAGE der Reinigung von PpAOC1. Spur 1: Bakterienzelllysat nach Aufschluss und Zentrifugation; Spur 2: Elutionsfraktionen nach Affinitätschromatographie über GSH-Sepharose; Spur 3: Proteinlösung nach proteolytischem Verdau mit PreScission-Protease (2.15.1); Spur 4: Proteinfraktionen des Durchflusses der Anionenaustauschchromatographie; Spur 5: Proteinfraktionen von PpAOC1 nach der Gelfiltration; 15\% SDS-Gel, Fraktionen, welche PpAOC1 enthielten wurden vereinigt und davon $10 \mu \mathrm{l}$ auf das Gel geladen; $\mathrm{M}=$ Molekulargewichtsstandard.

Da es jedoch auch möglich sein konnte, dass ein Teil der Proteine aggregiert vorlag, wurde zur abschließenden Reinigung eine Gelfiltration durchgeführt (2.15.3). (Abbildung 3.7 C, und Abbildung $3.8 \mathrm{C})$.

Bei einem Elutionsvolumen von etwa $50 \mathrm{ml}$ war zunächst nur ein kleines Proteinsignal erkennbar. Bei einem Volumen von ca. $60 \mathrm{ml}$ nach Proteininjektion eluierte der größte Anteil des Proteins (Abbildung 3.7C und Abbildung $3.8 \mathrm{C}$ ). Im Vorfeld der Reinigungsversuche wurde für die Gelfiltrationssäule mit kommerziell erhältlichen Proteinstandards eine Eichgerade erstellt. Demnach entsprach das Elutionsvolumen von $60 \mathrm{ml}$ einem Molekulargewicht von $77 \mathrm{kDa}$ (nicht dargestellt). Damit könnte es sich bei dem nativen Protein um ein Trimer mit einem erwarteten Molekulargewicht von 66 kDa oder einem Tetramer mit einem erwarteten Molekulargewicht von $88 \mathrm{kDa}$ handeln. 


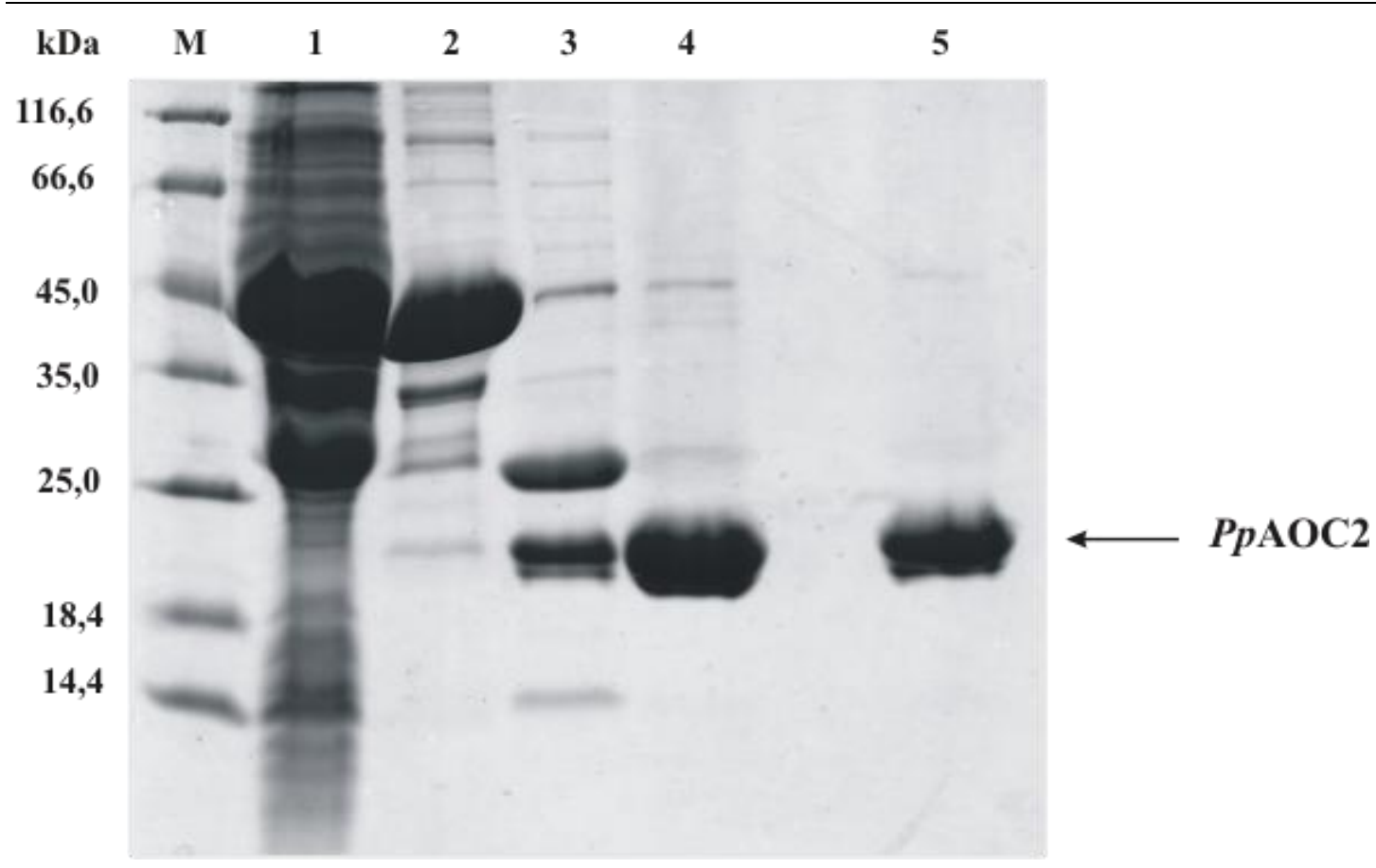

Abbildung 3.10: SDS-PAGE der Reinigung von PpAOC2. Spur 1: Bakterienzelllysat nach Aufschluss und Zentrifugation; Spur 2: Elutionsfraktionen nach Affinitätschromatographie über GSH-Sepharose; Spur 3: Proteinlösung nach proteolytischem Verdau mit PreScission Protease (2.15.1); Spur 4: Elutionsfraktionen (Peak 1 des $\mathrm{NaCl}$ Gradienten) der Anionenaustauschchromatographie; Spur 5: Proteinfraktionen von PpAOC2 der Gelfiltration; 15\% SDS-Gel, Fraktionen, welche PpAOC2 enthielten wurden vereinigt und davon 5-10 $\mu 1$ auf das Gel geladen; $\mathrm{M}=$ Molekularewichtsstandard.

Die SDS-PAGE Analyse zeigte, dass beide Proteine in elektrophoretisch reiner Form gewonnen werden konnten (Abbildung 3.9 und Abbildung 3.10, Spur 5). Es wurde eine Proteinausbeute von 20-30 mg reinem PpAOC1 bzw. PpAOC2 pro Liter Expressionskultur erreicht.

\subsubsection{Ko-Expression von PpAOC1 und PpAOC2 in E. coli}

$\mathrm{Ob}$ AOC-Enzyme aus den jeweiligen AOC-Monomeren sogenannte AOC-Heterotrimere bilden können, wurde bislang weder in vivo noch in vitro nachgewiesen. Daher wurde untersucht, ob in vitro PpAOC1 und PpAOC2 Heterotrimere bilden können. Dies wurde durch Ko-Expression der beiden Proteine mit unterschiedlichen N-terminalen Affinitätssequenzen überprüft. Dazu wurden beide $P p A O C$-Gene in den pet28a-Vektor kloniert, welcher für einen N-terminalen Histidinmarker zur Proteinreinigung kodiert. Mit diesen Konstrukten und den GST markierten PpAOC-Genen (pGEX-6-P-1-PpAOC1 und pGEX-6-P-1-PpAOC2) wurde eine Ko-Expression im E. coli Stamm BL21 star durchgeführt. Aufgrund unterschiedlicher Antibiotikaresistenzen ließen sich die Bakterienzellen, welche beide Gene enthielten, selektieren. Die ko-transformierten Gene wurden standardmäßig (2.14.2) in Bakterienzellen exprimiert und die Zellen wie in 2.14 .3 beschrieben zur 
Proteinreinigung aufgeschlossen. In der folgenden Darstellung ist die Reinigung von HisPpAOC1 zusammen mit GST-PpAOC2 aus einer Expression beschrieben. Dabei sind die Ergebnisse aus einem Experiment präsentiert,

Der Überstand des Bakterienzellaufschlusses (2.15.1) wurde zunächst über eine GSHSepharose Säule gegeben und das gebundene Protein mit reduziertem GSH eluiert (3.11 A und B).

(A)

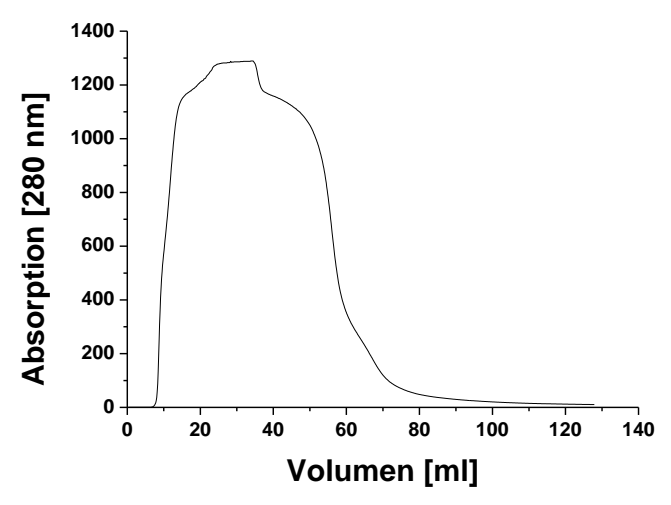

(C)

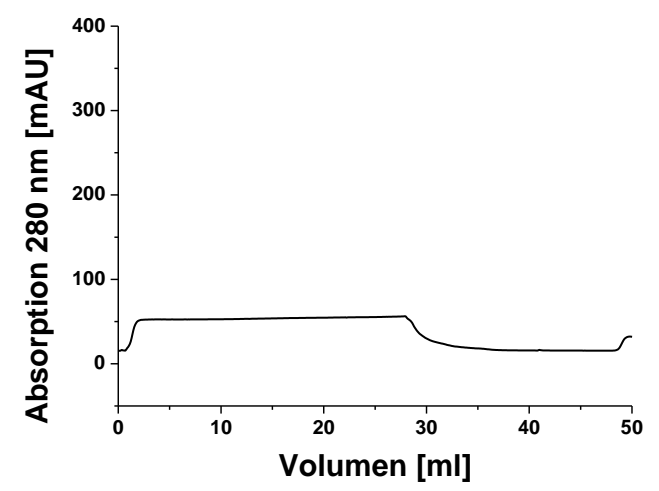

(B)

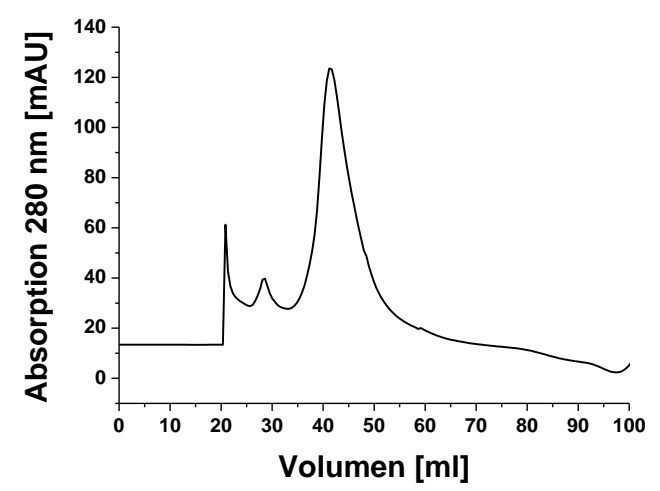

(D)

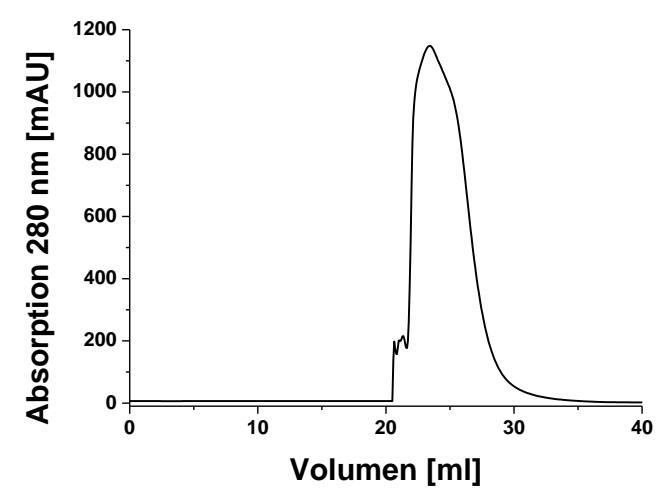

Abbildung 3.11: Reinigungsschritte von ko-exprimierten His-PpAOC1 und GST-PpAOC2. (A) Durchflussprofil der Affinitätschromatographie über eine $30 \mathrm{ml}$ GSH-Sepharose Säule (B) Elutionsprofil der Affinitätschromatographie über eine $30 \mathrm{ml}$ GSH-Sepharose Säule; (C) Durchflussprofil der Metallaffinitätschromatographie (Schritt 1); (D) Elutionsprofil der Metallaffinitätschromatographie (Schritt 2).

Die Elutionsfraktionen (Schritt eins) sowie die Durchflussfraktionen (Schritt zwei) wurden anschließend getrennt über eine Metallaffinitätschromatographie-Säule gegeben. Das Protein, welches zuvor von der GSH-Sepharose eluierte, band jedoch nicht an das Säulenmaterial (3.11 C). Dagegen konnte die Bindung von Proteinen aus der Durchflussfraktion des GSHSepharose-Schrittes an das Metallaffinitätschromatographie-Material beobachtet werden (3.11 
D). Anschließend wurden die Proteinfraktionen aller Reinigungsschritte mittels SDS-PAGE analysiert (Abbildung 3.12).

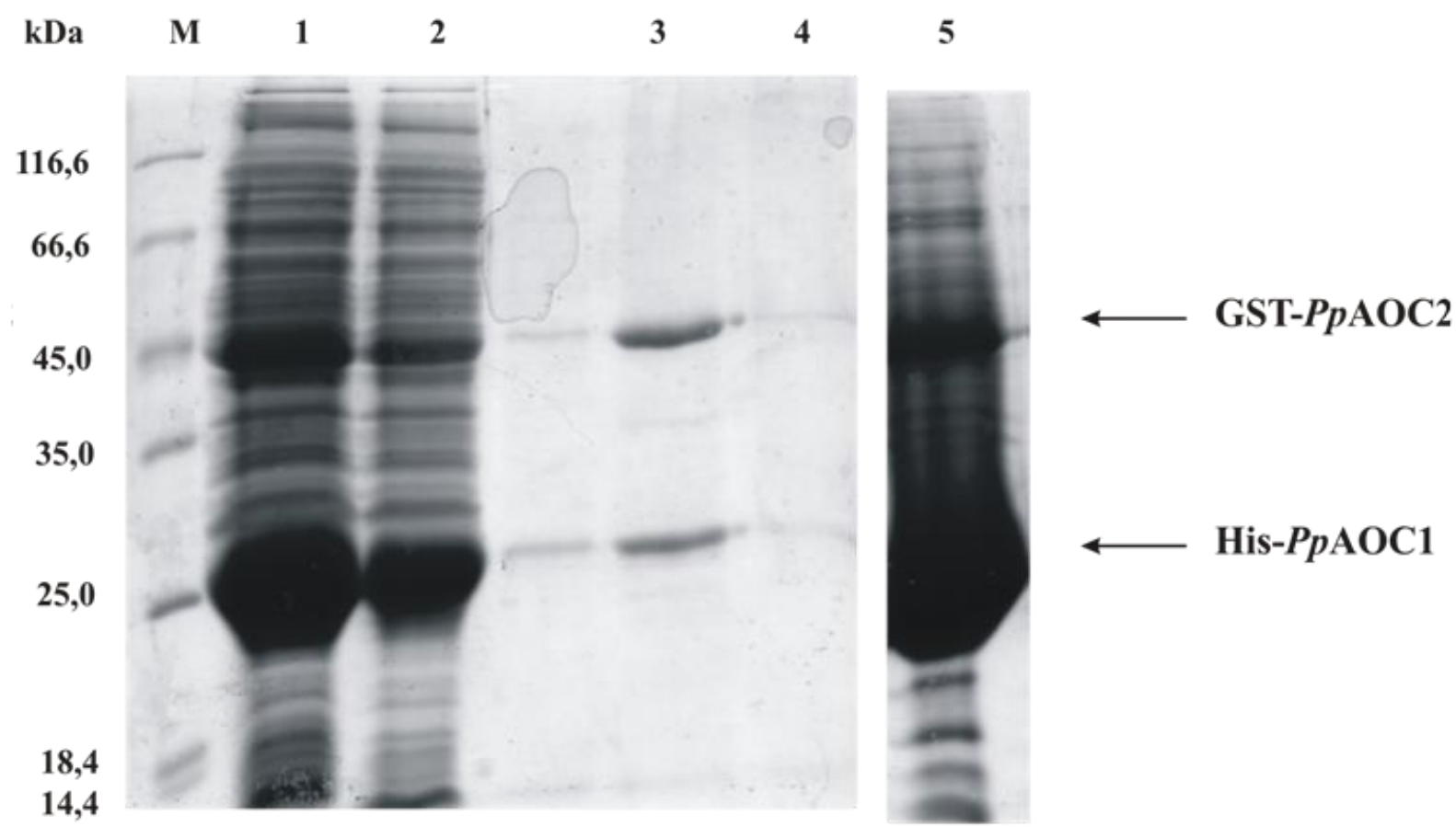

Abbildung 3.12: SDS-PAGE der Ko-Expression von PpAOC1 und PpAOC2. Spur 1: Bakterienzelllysat nach Aufschluss und Zentrifugation; Spur 2: Durchflussfraktionen nach Affinitätschromatographie über GSHSepharose; Spur 3: Elutionsfraktionen der Affinitätschromatographie über GSH-Sepharose; Spur 4: Proteinfraktionen des Durchflusses Metallaffinitätschromatographie-Sepharose mit Elution aus GSH-Sepharose; Spur 5: Proteinfraktionen der Elutionsfraktionen der Metallaffinitätschromatographie mit Durchflussfraktionen aus GSH-Sepharose; 15\% SDS-Gel; Fraktionen, welche PpAOC1 enthielten wurden vereinigt und davon $10 \mu \mathrm{l}$ auf das Gel geladen; $\mathrm{M}=$ Molekulargewichtsstandard.

Die SDS-PAGE-Analyse zeigte, dass nach Aufschluss und Zentrifugation der Expressionskultur sowohl histidinmarkiertes AOC-Protein (Bande bei 25,0 kDa) als auch GST-markiertes AOC-Protein (Bande bei 45,0 kDa) in der Lösung vorlag (Spur 1). Beim Auftragen der Lösung auf die GSH-Sepharose wurden neben Fremdproteinen auch ein Großteil der PpAOC1- und PpAOC2-Fusionsproteine im Durchfluss gefunden (Spur 2). Das Vorliegen von GST-PpAOC2 im Durchlauf weist auf eine Überladung des Säulenmaterials hin. Nach Elution durch Zugabe von GSH konnten zwei Proteinbanden auf dem SDS-Gel detektiert werden (Spur 3). Während die größere der Banden eindeutig dem GST-PpAOC2Fusionsprotein zuzuordnen ist, könnte das kleinere Protein sowohl His-PpAOC1 als auch bereits gespaltenes PpAOC2 sein. Beim Auftragen dieser Fraktion auf eine Metallaffinitätschromatografie wurden beide Banden im Durchlauf detektiert (Spur 4). Eine Bindung an das Säulenmaterial wurde nicht beobachtet. Dieses Ergebnis favorisiert das Vorliegen von bereits degradierter PpAOC2. Alternativ könnte auch der Histidinmarker von 
His- $P p A O C 1$ in einem Heterotrimer durch die GST-Markierung von GST-PpAOC2 maskiert und somit die Bindung an das Metallaffinitätschromatografie-Material blockiert werden.

Während die Elutionsfraktionen aus der GST-Affinitätschromatographie nicht zur Bindung an das Metallaffinitätschromatographie-Material befähigt war, wurde für die entsprechende Durchflussfraktion eine Bindung an das Metallaffinitätschromatographie-Material gefunden (Spur 5). In den Elutionsfraktionen wurden wiederum Banden für beide Fusionsproteine gefunden. Das Vorliegen von GST-PpAOC2 in den Elutionsfraktionen der Metallaffinitätschromatographie stellt - im Gegensatz zu den oben genannten Ergebnissen mit den Elutionsfraktionen der GST-Affinittschromatographie - einen starken Hinweis auf das Vorliegen von Heterotrimeren dar. Demnach scheint also die Bildung von Heterotrimeren prinzipiell möglich zu sein. Allerdings sollte der Widerspuch mit den GST-Elutionsfraktionen noch geklärt werden. Dafür könnte mittels Westernblot-Analyse mit einem $\alpha$-AOC- bzw. $\alpha$ His-Antikörper die Identität des kleineren Proteins (untere Bande in Spur 3) geklärt werden.

\subsection{Analyse der Produktspektren von PpAOC1 und PpAOC2}

Die gereinigten PpAOC-Enzyme wurden für die Umsetzung unterschiedlicher $\mathrm{C}_{20}$-Hydroperoxy-Fettsäuren im gekoppelten Test verwendet. Zur Analyse der Produktspektren wird zuvor das Experimentdesign erläutert. Da die Substrate der AOCs sehr instabil sind (1.4.2), müssen sie direkt im Reaktionsansatz aus Hydroperoxiden durch ein Hilfsenzym, hier die PpAOS1 gebildet werden. Ohne AOC-Aktivität hydrolysieren Allenoxide in Ketole und zyklisieren in ein razemisches zyklisches Produkt. Daher wurde zur Kontrolle der AOC-Aktivität ein Reaktionsansatz ausschließlich mit AOS und HydroperoxyFettsäure durchgeführt. In den AOC-Aktivitätstests wurde zusätzlich gereinigtes AOC-Enzym dazugegeben. Wenn das jeweilige AOC-Enzym aktiv ist, sollte das Allenoxid im Vergleich zum Kontrollansatz in größere Mengen an zyklischem enantiomeren Produkt umgewandelt werden.

Zusätzlich zum 12,13-EOT ${ }^{\Delta 9 Z \Delta 11 \Delta 15 Z}$ (Abbildung 3.13 A) wurden Allenoxide verwendet, die sich von $\mathrm{C}_{20}$-Hydroperoxid-Fettsäuren mit unterschiedlicher Anzahl und Position der Doppelbindungen ableiteten. Darüber hinaus besaßen die Allenoxide diese funktionelle Gruppe an unterschiedlichen Positionen des Kohlenstoffgerüsts (Abbildung 3.13). 
A)<smiles>CC/C=C/CC1O/C1=C\C=C\CCCCCCCC(=O)O</smiles>

B)<smiles>CCCCC/C=C/CC1O/C1=C\C=C\C/C=C/CCCC(=O)O</smiles>

C)<smiles>CC/C=C/C/C=C/CC1O/C1=C\C=C\C/C=C/CCCC(=O)O</smiles>

D)

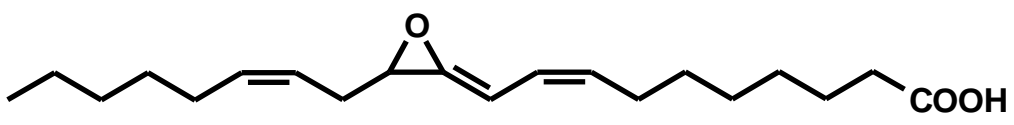

E)

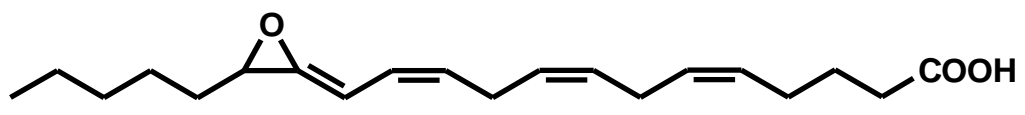

F)

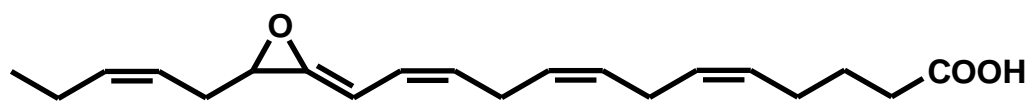

G)

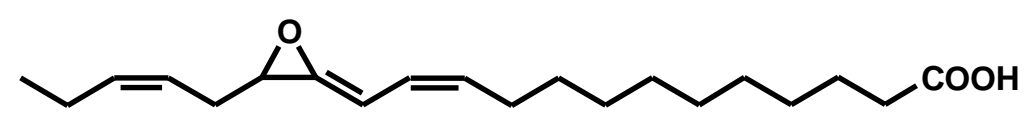

Abbildung 3.13: Substrate zur Charakterisierung von PpAOC1 und PpAOC2. (A) 12,13-EOT ${ }^{\Delta 9 Z \Delta 11 \Delta 15 Z}$ aus 13-HPOTE (B) 11,12(S)-Epoxy-5,8,10,14-eikosatetriensäure (11,12-EET ${ }^{\triangle 5 Z \Delta 8 Z \Delta 10 \Delta 15 Z}$ ) aus 12S-HPETE (C) 11,12(S)-Epoxy-5,8,10,14,17-eikosapentansäure (11,12-EEP ${ }^{\triangle 5 Z \Delta 8 Z \Delta 10 \Delta 14 Z \Delta 17 Z)}$ aus 12S-HPEPE (D) 11,12(S)Epoxy-8,10,14-eikosatriensäure $\quad\left(11,12-\mathrm{EET}^{\Delta 8 Z \Delta 10 \Delta 14 Z}\right) \quad$ aus $\quad 12 S$-HPET $\quad$ (E) $14,15(S)$-Epoxy-5,8,11,13-

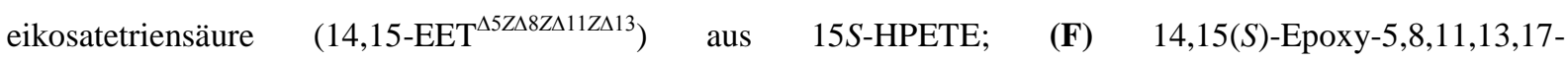
eikosapentansäure $\left(14,15\right.$-EEP $\left.{ }^{\Delta 5 Z \Delta 8 Z \Delta 11 Z \Delta 13 \Delta 17 Z}\right)$ aus 15S-HPEPE; (G) 14,15(S)-Epoxy-11,13,17-eikosatetriensäure $\left(14,15-\mathrm{EET}^{\Delta 11 Z \Delta 13 \Delta 17 Z}\right)$ aus $15 S$-HPET.

Die Umsetzungen erfolgten wie in Abschnitt 2.16.2 beschrieben und im Anschluss wurden die Reaktionsgemische über RP-HPLC-ESI/MS-MS getrennt und analysiert (2.16.4.3). Als Referenz wurde parallel die Aktivität von PpAOS1/PpAOC1 bzw. PpAOS1/PpAOC2 mit dem Substrat 13S-HPOTE gemessen. Anschließend wurden die Masse/Ladungsquotienten $(\mathrm{m} / \mathrm{z})$ und die relative Menge (in \%) der einzelnen Verbindungen in den Reaktionsgemischen bestimmt.

\subsubsection{Die Umsetzung von 12-Hydroperoxy-Fettsäuren}

Zunächst werden die Reaktionsgemische der 12-Hydroperoxy-Fettsäuresubstrate miteinander verglichen. Die Abbildung 3.14 zeigt die Ergebnisse der Umsetzung von 13S-HPOTE und verschiedenen 12-Hydroperoxy-Fettsäuresubstraten durch gereinigte PpAOS1-, PpAOS1/PpAOC1 sowie PpAOS1/PpAOC2-Enzyme in einem gekoppelten Enzymtest (3.3). 


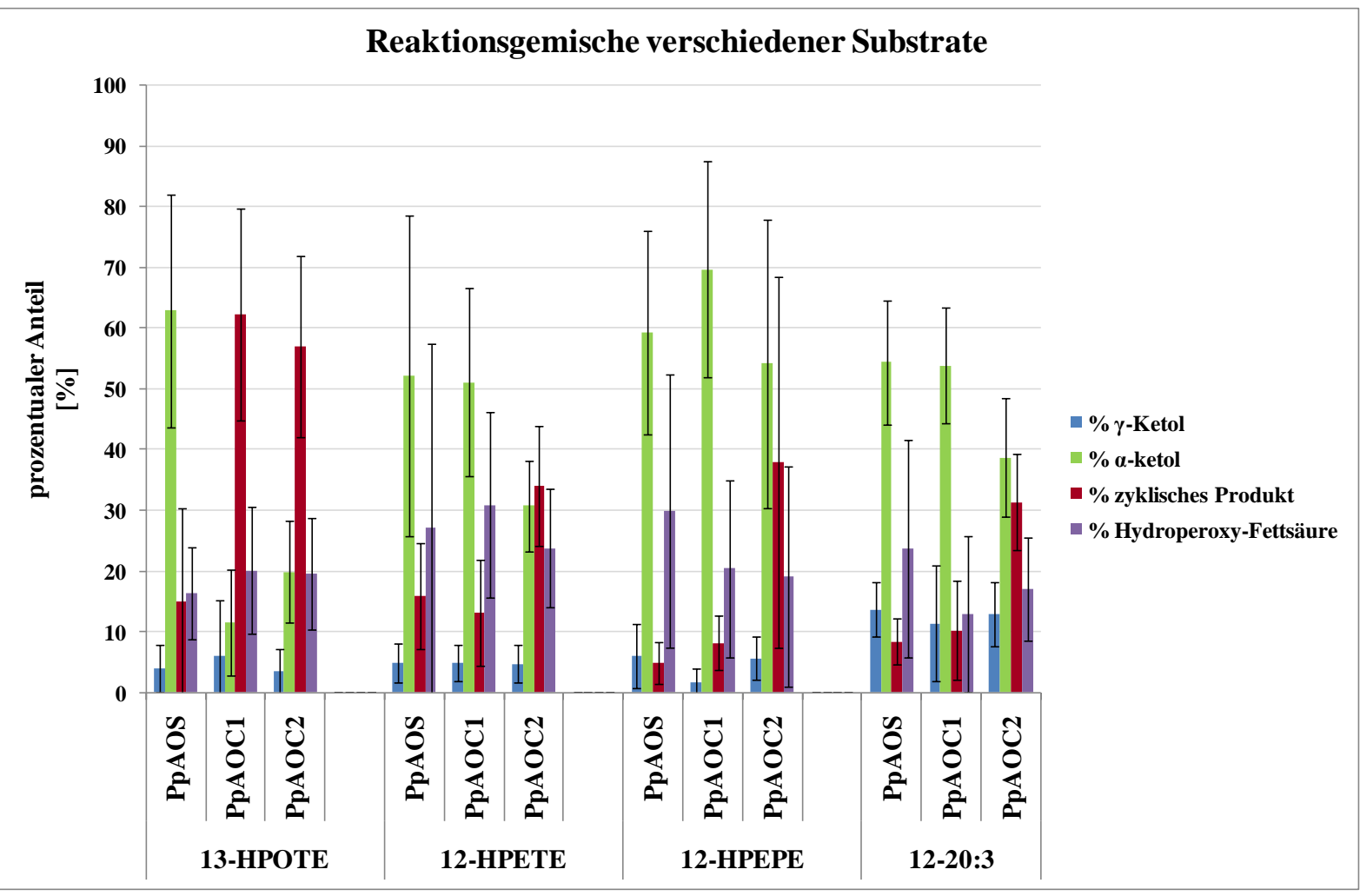

Abbildung 3.14: Reaktionsgemische enzymatischer Umsetzungen von 12-Hydroperoxy-Fettsäuren durch PpAOC1 und PpAOC2. Verteilung der Produkte der beiden Enzyme im Vergleich zur Umsetzung von 13HPOTE als relative Menge der Produkte in Prozent; dargestellt: prozentualer Anteil von $\gamma$-Ketol (blau), $\alpha$-Ketol (grün), zyklischem Produkt (rot) und des Substrates (violett). Gezeigt wird der Mittelwert aus vier unabhängigen Experimenten mit dazugehöriger Standardabweichung.

Die Abbildung 3.14 zeigt, dass sowohl PpAOS1/PpAOC1 als auch PpAOS1/PpAOC2 das Substrat 13S-HPOTE zum zyklischen Produkt OPDA umsetzen. Dagegen wurde im Reaktionsgemisch der PpAOS1-Umsetzung von 13S-HPOTE in Abwesenheit einer AOC ein deutlich geringerer OPDA-Anteil nachgewiesen. Zusätzlich ist der Anteil an gebildetem $\alpha$ Ketol deutlich erhöht.

In den Reaktionsgemischen der Umsetzungen mit 12S-HPETE hingegen ist nur für die PpAOS1/PpAOC2-Umsetzung ein erhöhter Anteil an zyklischem Produkt $(\mathrm{m} / \mathrm{z}=317) \mathrm{zu}$ erkennen. In den Reaktionsgemischen der PpAOS1- und PpAOS1/PpAOC1-Umsetzung ist dieser Anteil geringer, jedoch wurde ein höherer Anteil von $\alpha$-Ketol nachgewiesen. Damit besitzt PpAOC2 im Gegensatz zur PpAOC1 Enzymaktivität für das Allenoxid der $12 S$ HPETE-Umsetzung durch PpAOS1.

Weiterhin wurde das Substrat 12S-HPEPE durch die gereinigten Enzyme umgesetzt. Es wurde ebenfalls ein höherer Anteil an zyklischem Produkt $(\mathrm{m} / \mathrm{z}=315)$ in den Reaktionsgemischen der PpAOS1/PpAOC2-Umsetzung im Vergleich zur PpAOS1 und PpAOS1/PpAOC1-Umsetzung beobachtet. Jedoch war der relative Anteil an $\alpha$-Ketol im 
Vergleich zum relativen Anteil an zyklischem Produkt in den Reaktionsgemischen der PpAOS1/PpAOC2-Umsetzung erhöht. Dennoch blieb der relative Anteil an $\alpha$-Ketol im Reaktionsgemisch von PpAOS1/PpAOC2 unter dem von PpAOS1 bzw. PpAOS1/PpAOC1. Ein weiteres Substrat zur Untersuchung der Spezifität von PpAOC1 und PpAOC2 war die 12Hydroperoxy-Fettsäure von di-Homo- $\gamma$-Linolensäure (20:3 $3^{\Delta 8 Z \Delta 11 Z \Delta 14 Z}$, DGLA) und das daraus resultierende Allenoxid. Hier zeigte sich ein höherer Anteil an zyklischem Produkt $(\mathrm{m} / \mathrm{z}=$ 319 ) in den Reaktionsgemischen der PpAOS1/PpAOC2-Umsetzung im Vergleich zur PpAOS1 und PpAOS1/PpAOC1-Umsetzung. Der Anteil an $\alpha$-Ketol im Vergleich zum Anteil an zyklischem Produkt in den Reaktionsgemischen der PpAOS1/PpAOC2-Umsetzung war ebenfalls erhöht. Dennoch blieb der relative Anteil an $\alpha$-Ketol im Reaktionsgemisch von PpAOS1/PpAOC2 unter dem von PpAOS1 bzw. PpAOS1/PpAOC1.

In Abbildung 3.15 ist die strukturelle Charakterisierung der durch PpAOC2 gebildeten zyklischen $\mathrm{C}_{20}$-Produkte durch HPLC-ESI-MS-Analyse dargestellt (durchgeführt von Frau Dr. C. Göbel). Die Fragmentierung der zyklischen Produkte durch ESI zeigt jeweils die Abspaltung von Wasser (-18), $\mathrm{CO}_{2}(-44)$ und einer Seitenkette (-112). 
273

(A)
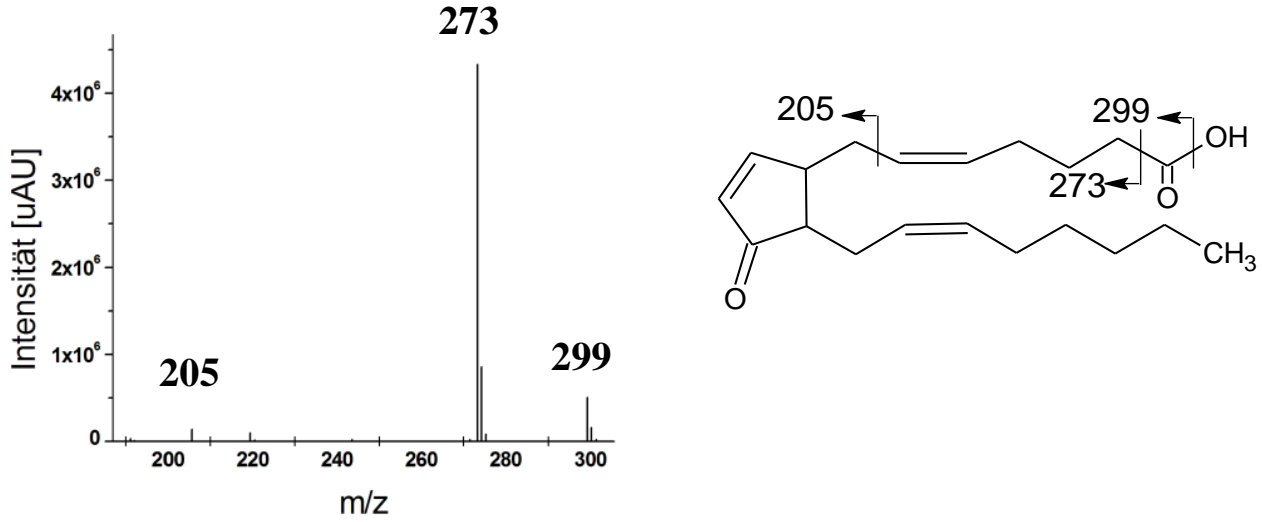

299

(B)
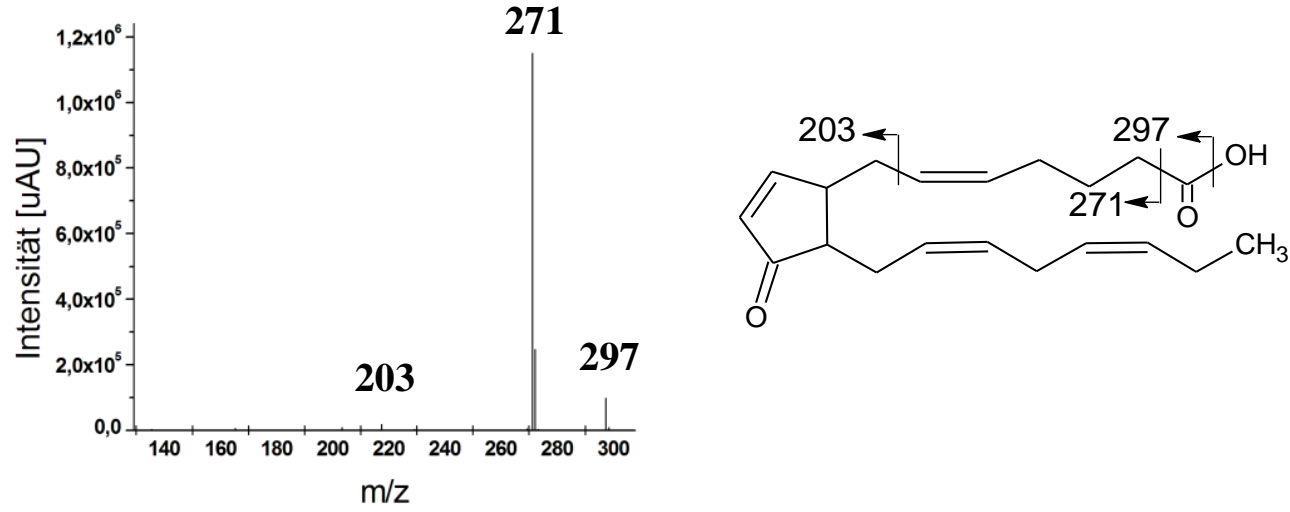

(C)
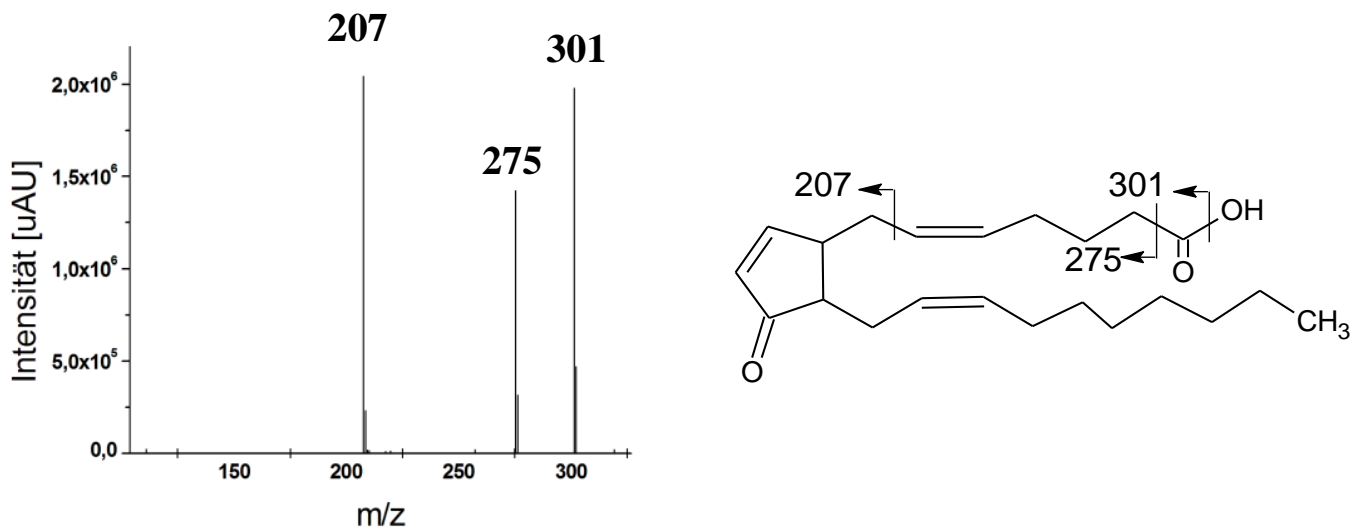

Abbildung 3.15: MS/MS-Spektren der zyklischen Produkte von 12-Hydroperoxiden. MS/MS-Spektren der gebildeten zyklischen Verbindung (m/z in Klammern) (A) aus 12S-HPETE (11-OPTA, m/z = 317); (B) aus 12SHPEPE $(\mathrm{m} / \mathrm{z}=315)$; $(\mathbf{C})$ aus $12 S$-HPET $(\mathrm{m} / \mathrm{z}=319)$. Die ESI-MS/MS-Spektren zeigen die Fragmentierung der zyklischen Verbindung durch Abspaltung von $\mathrm{H}_{2} \mathrm{O}(-18), \mathrm{CO}_{2}(-44)$ und einer Seitenkette (-112).

\subsubsection{Die Umsetzung von 15-Hydroperoxy-Fettsäuren}

Des Weiteren wurden die Umsetzungen von 13S-HPOTE sowie verschiedenen 15Hydroperoxy-Fettsäuren durch gereinigte PpAOS1-, PpAOS1/PpAOC1- sowie PpAOS1/PpAOC2-Enzyme in einem gekoppelten Enzymtest analysiert (Abbildung 3.16).

PpAOS1/PpAOC1 und PpAOS1/PpAOC2 setzen 13S-HPOTE zum zyklischen Produkt OPDA um (Abbildung 3.16). Dagegen wurde im Reaktionsgemisch der PpAOS-Umsetzung 
von 13S-HPOTE ein deutlich geringerer OPDA-Anteil nachgewiesen. Zusätzlich ist der Anteil an $\alpha$-Ketol im Reaktionsgemisch der PpAOS1-Umsetzung deutlich höher im Vergleich zur Umsetzung durch $P p$ AOS1/PpAOC1 und PpAOS1/PpAOC2.

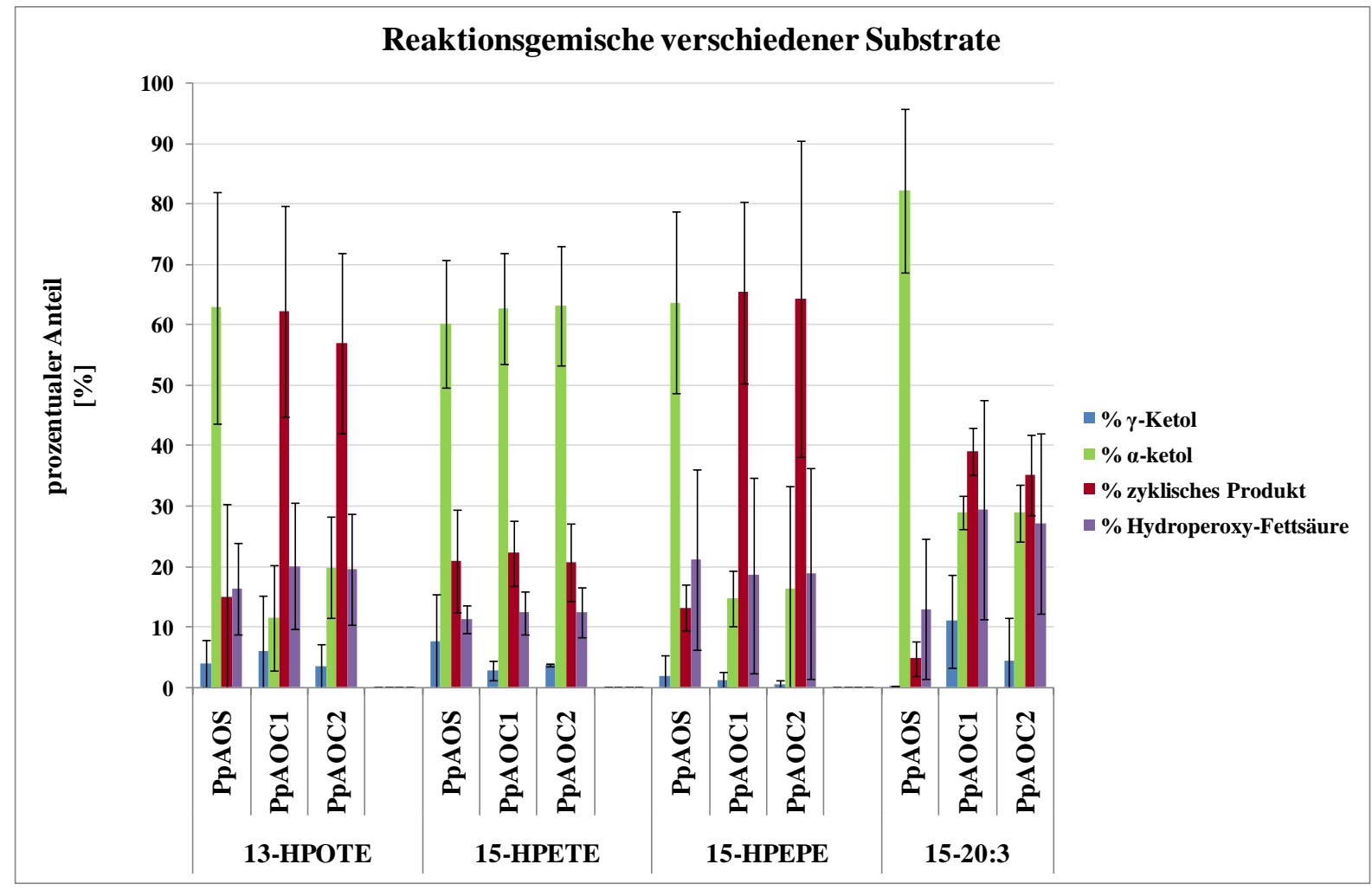

Abbildung 3.16: Reaktionsgemische enzymatischer Umsetzungen von 15-Hydroperoxy-Fettsäuren. Verteilung der Produkte der beiden Enzyme im Vergleich zur Umsetzung von 13-HPOTE als relative Menge der Produkte in Prozent. Es ist der prozentuale Anteil an $\gamma$-Ketol (blau), $\alpha$-Ketol (grün), zyklischem Produkt (rot) und des Substrates (violett) dargestellt. Dargestellt ist der Mittelwert aus vier unabhängigen Experimenten mit dazugehöriger Standardabweichung.

In den Reaktionsgemischen der Umsetzungen von 15S-HPETE hingegen ist die Verteilung der Produktanteile gleich. Alle Reaktionsgemische wiesen einen gleich hohen relativen Anteil an zyklischem Produkt bei gleichzeitig hohem relativem Anteil an $\alpha$-Ketol auf. Damit zeigte weder PpAOC1 noch PpAOC2 Enzymaktivität mit dem Allenoxid von 15S-HPETE.

Ein anderes Ergebnis war bei der Umsetzung von 15S-HPEPE durch die gereinigten Enzyme zu beobachten. Es wurde ein größer Anteil an zyklischem Produkt in den Reaktionsgemischen der PpAOS1/PpAOC1- sowie PpAOS1/PAOC2-Umsetzungen im Vergleich zur PpAOS1Umsetzung beobachtet. Die Reaktionsgemische der PpAOS1-Umsetzung hingegen, enthielten einen großen relativen Anteil an $\alpha$-Ketol. Zudem war der relative Anteil an $\alpha$-Ketol im Vergleich zum relativen Anteil an zyklischem Produkt in den Reaktionsgemischen der PpAOS1/PpAOC1- und PpAOS1/PpAOC2-Umsetzungen niedriger. 
Ein weiteres Substrat zur Untersuchung der Spezifität von PpAOC1 und PpAOC2 war das 15-Hydroperoxid von Eikosatriensäure (ETA, 20:3 $3^{\Delta 11 Z \Delta 14 Z \Delta 17 Z}$ ) und das resultierende Allenoxid. Auch hier zeigte sich ein höherer relativer Anteil an zyklischem Produkt in den Reaktionsgemischen der PpAOS1/PpAOC1- und PpAOS1/PAOC2-Umsetzungen im Vergleich zur PpAOS1-Umsetzung. Gleichzeitig enthielt das Reaktionsgemisch der PpAOS1Umsetzung einen großen relativen Anteil an $\alpha$-Ketol. Der relative Anteil an $\alpha$-Ketol im Vergleich zum relativen Anteil an zyklischem Produkt in den Reaktionsgemischen der PpAOS1/PpAOC1- und PpAOS1/PpAOC2-Umsetzungen war hingegen geringer. Demnach besitzen sowohl PpAOC1 als auch PpAOC2 Enzymaktivität für die Allenoxide von 15SHPEPE und $15 S$-HPET, jedoch nicht von $15 S$-HPETE.

In Abbildung 3.17 sind die MS/MS-Spektren der von PpAOS/PpAOC1 und PpAOS/PpAOC2 gebildeten zyklischen Verbindungen der Hydroperoxide 15S-HPEPE und 15S-HPET dargestellt (durchgeführt von Dr. C. Göbel). Die zyklischen Produkte fragmentieren jeweils durch Abspaltung von Wasser (-18), $\mathrm{CO}_{2}(-44)$ und einer Seitenkette (jeweils -112 und -154).

(A)
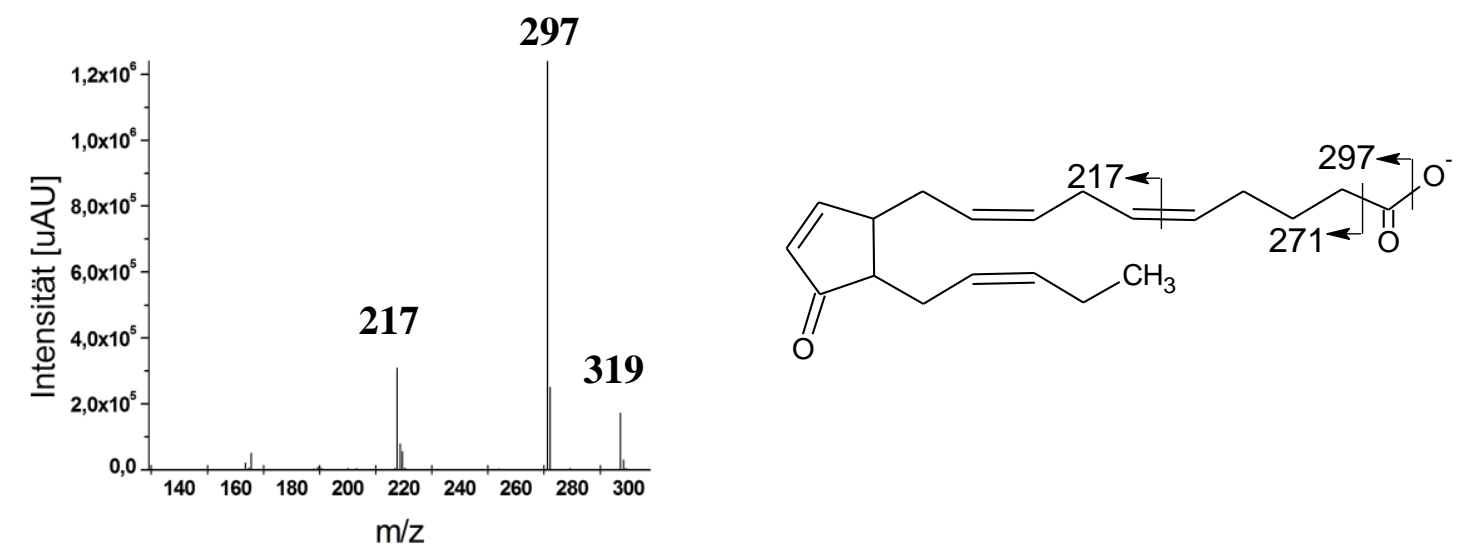

(B)
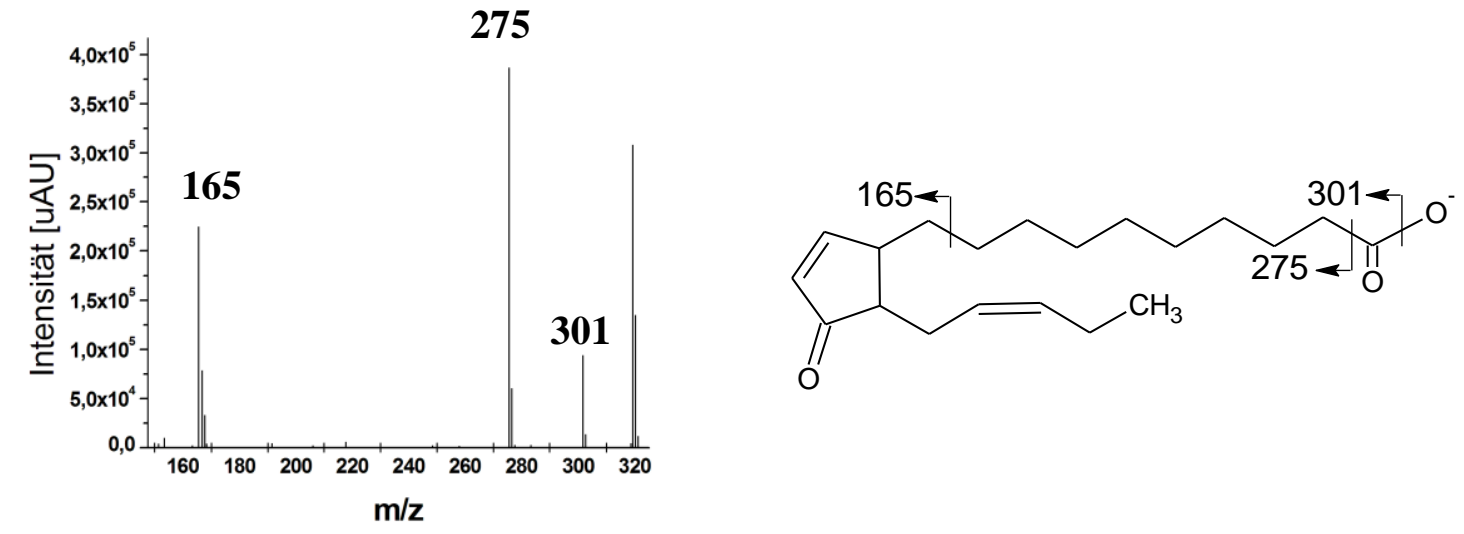

Abbildung 3.17: MS/MS-Spektren der zyklischen 15-Produkte. MS/MS-Spektren der gebildeten zyklischen Verbindung ( $\mathrm{m} / \mathrm{z}$ in Klammern) (A) aus 15S-HPEPE (m/z = 315); (B) aus 15S-HPET (m/z = 319). Die MS/MSSpektren zeigen die Fragmentierung der zyklischen Verbindung durch Abspaltung von $\mathrm{H}_{2} \mathrm{O}(-18), \mathrm{CO}_{2}(-44)$ und einer Seitenkette (jeweils -112 und -154). 


\subsection{Strukturanalyse von $P p A O C 1$ und $P p A O C 2$}

Eines der Hauptziele dieser Arbeit bestand in der strukturellen Charakterisierung der Substratspezifitätsunterschiede von PpAOC1 und PpAOC2. Hierzu stand die Bindung von Substratanalogen und dem Produkt OPDA in den Enzymen im Vordergrund. Aus diesen Gründen musste für beide gereinigte Proteine zunächst eine geeignete Bedingung gefunden werden, mit der sich Proteinkristalle erzeugen lassen. Um eine geeignete Kristallisationsbedingung zu finden, wurden beide Proteine bei einer Konzentration von 20$30 \mathrm{mg} / \mathrm{ml}$ für initiale Screens verwendet. Es wurden die Footprint Screens 1-3, Crystal Screens -1, -2, -Lite, -Cryo, -PEG/ION, Structure Screens 1-2, die JB Screens 1-10, der Clear Strategy Screen 1-2 und die Magic Screens 1-4 pipettiert (2.17.1). Die Platten wurden zunächst bei $20^{\circ} \mathrm{C}$ inkubiert. Für die Kristallisationsexperimente spielte die finale Gelfiltration der Proteinlösungen eine entscheidende Rolle, da erst nach Einführung dieses Schrittes positive Ergebnisse erzielt werden konnten. Diese Arbeiten wurden in Kooperation mit der Abteilung Molekulare Strukturbiologie der Georg-August-Universität Göttingen durchgeführt.

\subsubsection{Kristallisation von $P p A O C 1$}

Für PpAOC1 wurden nach sechs Tagen in der Bedingung 49 des Magic Screens $(20 \%(\mathrm{w} / \mathrm{v})$ PEG 8000 und $0,1 \mathrm{M} \mathrm{Na}_{3} \mathrm{PO}_{4}, \quad \mathrm{pH} 4,2$ ) kristalline dreidimensionale Nadeln gefunden (Abbildung 3.18 A). Diese Nadeln streuten bis zu $6 \AA$ und die Kristallisationsbedingungen wurden als Startpunkt eines Fein-screenings genutzt (2.17.2) (Abbildung 3.18 B). Parallel dazu wurde mit dieser Bedingung der Additiv Screen 1-4 getestet (Abbildung 3.18 C). Diese Platten wurden bei $20{ }^{\circ} \mathrm{C}$ inkubiert.

Die feinen Kristallnadeln aus dem ersten Fein-screening ähnelten den Nadeln der Anfangsbedingung und waren für die Strukturaufklärung nicht ausreichend (Abbildung 3.18 B). Jedoch fand sich in der Bedingung 74 aus dem Additiv Screen durch Zusatz von $30 \%(w / v)$ 1,6-Hexandiol ein dreidimensionaler, aber stark verwachsener Kristall (Abbildung $3.18 \mathrm{C})$. 
(A)

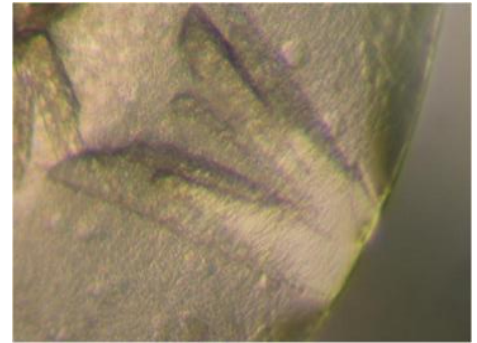

(B)

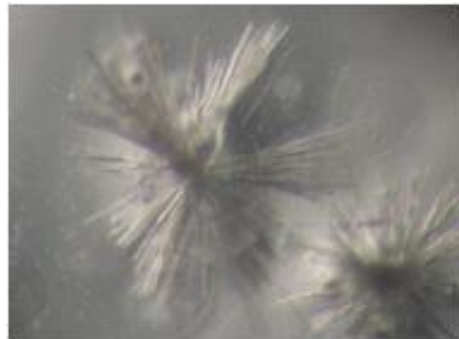

(C)

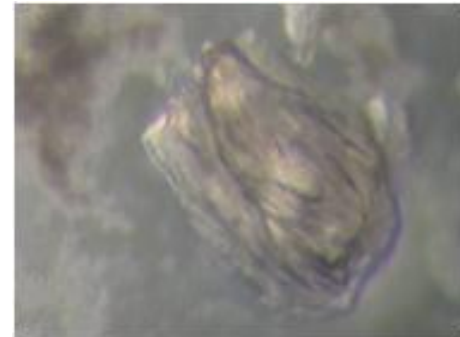

Abbildung 3.18: Initiale Kristallisationsbedingungen von PpAOC1. (A) Dreidimensionale Nadeln von PpAOC1 aus der Magic Screen Bedingung 49; (B) Nadeln aus einer Bedingung mit $22 \%$ (w/v) PEG 8000 und 0,05 $\mathrm{M} \mathrm{Na}_{3} \mathrm{PO}_{4}, \mathrm{pH} 4,2$; (C) dreidimensionaler stark verwachsener Kristall aus einer Bedingung mit $20 \%$ (w/v) PEG 8000, 0,1 $\mathrm{M} \mathrm{Na}_{3} \mathrm{PO}_{4}$, pH 4,2 und 30 \% (w/v) 1,6-Hexandiol (Additiv Screen Bedingung 74).

Daraufhin wurde ein Fein-screening mit dieser Bedingung durchgeführt wobei verschiedene Konzentrationen an 1,6-Hexandiol mit Puffer und PEG 8000 in das Reservoir gegeben wurden. Da auch dieses Fein-screening zu mäßigem Erfolg führte, wurde das Screening wiederholt und dabei das 1,6-Hexandiol in verschiedenen Konzentrationen als Additiv in den Kristallisationstropfen gegeben. Diese Platten wurden doppelt angefertigt und sowohl bei $20{ }^{\circ} \mathrm{C}$ als auch bei $4{ }^{\circ} \mathrm{C}$ gelagert. Bedingungen welche bei $20{ }^{\circ} \mathrm{C}$ inkubiert wurden, zeigten nach zwei Tagen erneut mäßige Kristalle als stark verwachsene dreidimensionale Nadeln, welche denen aus Abbildung 3.18 sehr ähnelten. Im Gegensatz dazu waren in mehreren Bedingungen der bei $4{ }^{\circ} \mathrm{C}$ inkubierten Platten nach 5-7 Tagen kleine rechteckige, dreidimensionale Kristalle gewachsen (Abbildung 3.19). Zum Teil waren diese Kristalle verwachsen (Abbildung 3.19), aber es waren auch einzelne freiliegende Kristalle vorhanden. Diese Kristalle streuten unter Verwendung des hauseigenen Röntgendiffraktometer bis ca. $2,5 \AA$ und einige dieser Kristalle wurden durch Transfer in flüssigen Stickstoff schockgefroren und für Messungen am Synchrotron gelagert.

Durch Optimierung dieser Kristallisationsbedingungen wurden die für die Strukturanalyse benötigten ausreichend großen, dreidimensionalen Kristalle gewonnen (Abbildung 3.19). Erste kleine Kristalle konnten nach 7-10 Tagen beobachtet werden. Nach ca. vier Wochen war das Kristallwachstum abgeschlossen und die Kristalle wurden verwendet. Nach dieser Zeit wurde stärkeres Verwachsen der Kristalle beobachtet. Proteinkristalle von PpAOC1 mit hoher Qualität konnten in verschieden Bedingungen reproduziert werden. Unabhängig von der Bedingung wurden entweder wenige große Einzelkristalle oder viele (20-30) kleine Kristalle beobachtet. Zwischen diesen Kristallen gab es wenig Unterschiede in der Auflösung, so dass sich alle so gezüchteten Kristalle zum späteren Inkubieren (engl. soaken) mit Substratanalogen, bzw. OPDA eigneten (2.17.4). In Abbildung 3.19 sind beispielhaft einige 
der Kristalle dargestellt, die für Soaking-Experimente und anschließende Messungen am Synchrotron verwendet wurden.

Für röntgenkristallographische Messungen mussten die Proteinkristalle in eine geeignete Kryobedingung überführt werden (2.17.3). Ausgehend von einem initialen Kryoprotektionsmittel wurde ein Screening durchgeführt. Als geeignete Kryobedingung stellte sich eine Erhöhung auf 35 \% (w/v) PEG 8000 und 35 \% (w/v) 1,6-Hexandiol heraus. Die Pufferkonzentration betrug 0,15 $\mathrm{M} \mathrm{Na}_{3} \mathrm{PO}_{4}, \mathrm{pH} 4,2$. In dieser Bedingung blieben die PpAOC1-Kristalle aus allen Bedingungen über einen Zeitraum von $48 \mathrm{~h}$ stabil. Aus diesem Grund wurde getestet, ob sich diese Bedingung ebenfalls zur Inkubation der Kristalle mit verschiedenen Substratanalogen oder OPDA eignete. Dafür wurde wie in Abschnitt 2.17.4 beschrieben, das jeweilige Substratanlogon, bzw. das OPDA in dieser Bedingung aufgenommen und dann in 10-20fachem sowie 10-100fachem molarem Überschuss zum Kryotropfen dazu gegeben. Dabei wurden jeweils mehrere Kristalle aus einer oder mehreren Bedingungen pro Kryotropfen bei $4{ }^{\circ} \mathrm{C}$ für 2-6 h inkubiert. Es stellte sich heraus, dass die Kristalle über diesen Zeitraum sehr stabil blieben und nicht an Qualität verloren. Die Kristalle wurden zunächst an der hauseigenen Drehanode (Rigaku) getestet (2.18.1). Kristalle mit einer Auflösung unter 2,0 $\AA$ wurden in flüssigem $\mathrm{N}_{2}$ bei $-180{ }^{\circ} \mathrm{C}$ für Messungen am Synchrotron gelagert. 
(A)

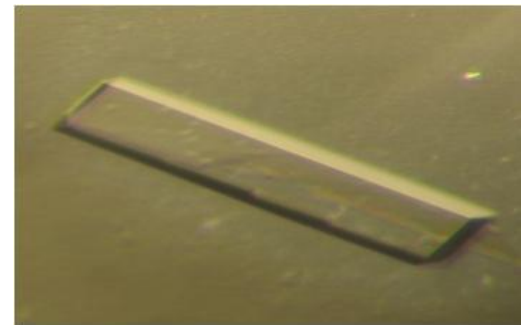

(D)

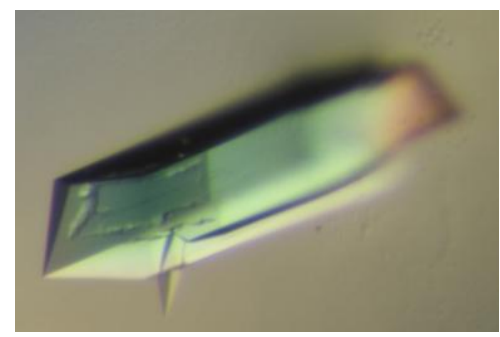

(G)

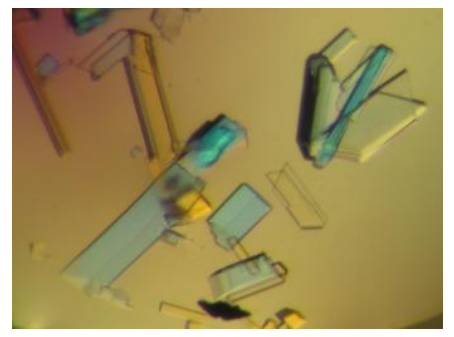

(B)

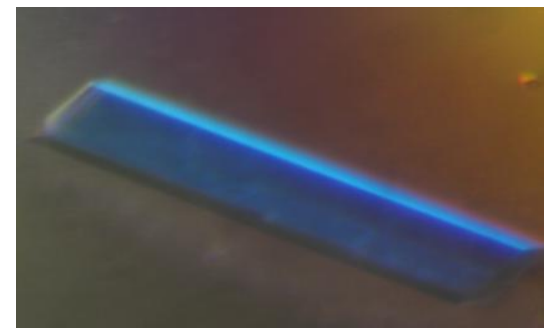

(E)

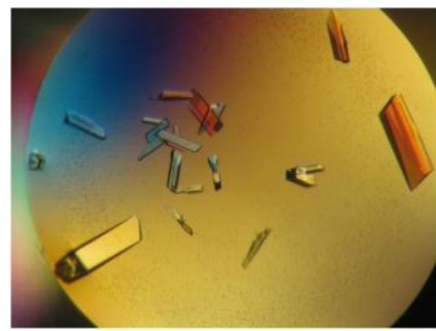

(H)

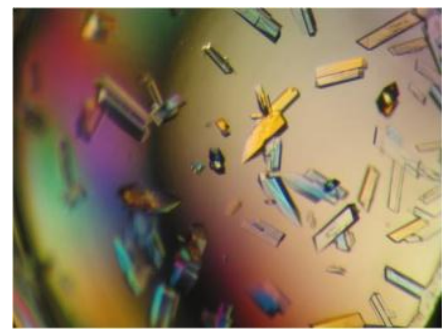

(C)

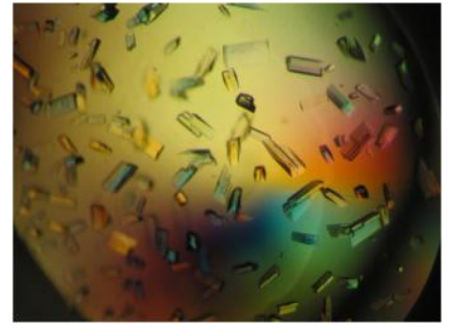

(F)

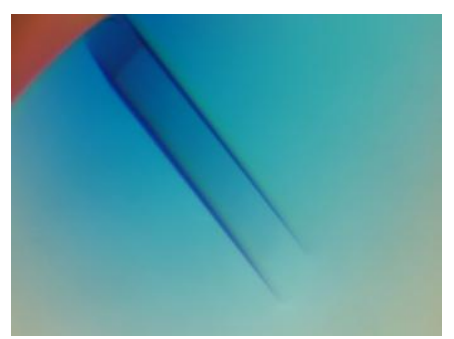

(I)

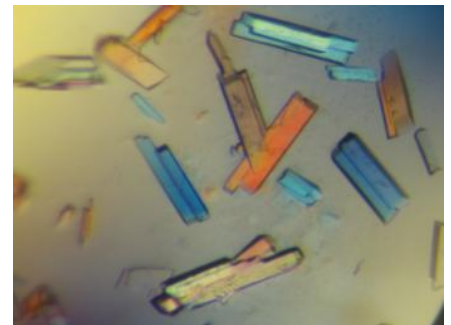

Abbildung 3.19: Verschiedene PpAOC1-Kristalle (A) Kristall aus einer Bedingung mit $22 \%$ (w/v) PEG 8000, $0,1 \mathrm{M} \mathrm{Na}_{3} \mathrm{PO}_{4}, \mathrm{pH} 4,2$ und $25 \%$ (w/v) 1,6-Hexandiol (als Additiv); (B) Kristall aus einer Bedingung mit $22 \%$ (w/v) PEG 8000, 0,1 M Na $3 \mathrm{PO}_{4}, \mathrm{pH} 4,2$ und $25 \%$ (w/v) 1,6-Hexandiol (als Additiv); (C) Kristalle und Kristallplatten, oft verwachsen aus einer Bedingung mit $22 \%$ (w/v) PEG 8000, 0,18 $\mathrm{M} \mathrm{Na}_{3} \mathrm{PO}_{4}, \mathrm{pH} 4,2$ und $15 \%(\mathrm{w} / \mathrm{v})$ 1,6-Hexandiol (als Additiv); (D) Kristall mit spitz zulaufenden Enden aus einer Bedingung mit $16 \%$ (w/v) PEG 8000, 0,1 $\mathrm{M} \mathrm{Na}_{3} \mathrm{PO}_{4}, \mathrm{pH} 4,2$ und $5 \%$ (w/v) 1,6-Hexandiol (als Additiv); (E) Kristalle und Platten aus einer Bedingung mit $20 \%$ (w/v) PEG 8000, 0,1 $\mathrm{M} \mathrm{Na}_{3} \mathrm{PO}_{4}, \mathrm{pH} 4,2$ und $10 \%$ (w/v) 1,6-Hexandiol (als Additiv); (F) Kristall aus einer Bedingung mit $18 \%$ (w/v) PEG 8000, 0,15 $\mathrm{M} \mathrm{Na}_{3} \mathrm{PO}_{4}$, pH 4,2 und $10 \%$ (w/v) 1,6Hexandiol (als Additiv); (G) Rechteckige Kristalle und Kristallplatten aus einer Bedingung mit 22 \% (w/v) PEG 8000, 0,15 $\mathrm{M} \mathrm{Na}_{3} \mathrm{PO}_{4}, \mathrm{pH} 4,2$ und $20 \%$ (w/v) 1,6-Hexandiol (als Additiv); (H) Kristalle und Kristallplatten aus einer Bedingung mit $26 \%$ (w/v) PEG 8000, 0,12 $\mathrm{M} \mathrm{Na}_{3} \mathrm{PO}_{4}, \mathrm{pH}$ 4,2 und $20 \%$ (w/v) 1,6-Hexandiol (als Additiv); (I) Kristalle und Kristallplatten aus einer Bedingung mit $24 \%$ (w/v) PEG 8000, 0,1 M Na $3 \mathrm{PO}_{4}, \mathrm{pH}_{4,2}$ und $20 \%$ (w/v) 1,6-Hexandiol (als Additiv). Alle Bedingungen wurden bei $4{ }^{\circ} \mathrm{C}$ inkubiert; (B)-(I) unter polarisiertem Licht dokumentiert.

\subsubsection{Kristallisation von PpAOC2}

Da für PpAOC2 nach zweimaligem Pipettieren der Initialscreens und anschließender Inkubation bei $20^{\circ} \mathrm{C}$ keine Kristalle gewachsen waren, wurden beim dritten Pipettierdurchgang die Platten bei $4{ }^{\circ} \mathrm{C}$ inkubiert. Bei diesem Versuch konnten nach vier 
Tagen geeignete Kristalle in der Bedingung neun des JB Screens 3 gefunden werden (Abbildung 3.20 A). Diese enthielt $16 \%$ (w/v) PEG 4000, 0,2 M $\left(\mathrm{NH}_{4}\right)_{2} \mathrm{SO}_{4}, 10 \%(\mathrm{w} / \mathrm{v})$ Isopropanol und 0.1 M HEPES-KOH, pH 7,5. Die Kristalle streuten bis ca. $3.0 \AA$ und somit wurde diese Bedingung für Fein-screening Versuche verwendet. Dabei wurden die PEG 4000-, die Salz-, die Isopropanolkonzentration und der pH-Wert variiert. Eine Erhöhung der PEG 4000- und $\left(\mathrm{NH}_{4}\right)_{2} \mathrm{SO}_{4}$-Konzentration und gleichzeitige Verringerung der Isopropanolkonzentration führte zu gleichmäßig geformten PpAOC2-Kristallen (Abbildung 3.20 B und C), jedoch streuten diese nicht wesentlich besser als die Kristalle aus dem JB Screen 3. Erst eine Verringerung der PEG 4000 Konzentration, bei leichter Erhöhung der $\left(\mathrm{NH}_{4}\right)_{2} \mathrm{SO}_{4}$-Konzentration auf 0,25 $\mathrm{M}$ führte $\mathrm{zu}$ dreidimensionalen Kristallen, welche bis ca. 2,0 Å streuten (Abbildung 3.20 D-F). Eine Änderung des pH-Wertes im Bereich von pH 7,0 pH 8,5 hatte keinen entscheidenden Einfluss auf die Qualität der Kristalle. Für die anschließenden Inkubations-Experimente wurden Kristalle aus der reproduzierbaren Bedingung mit $12 \%$ oder $14 \%$ (w/v) PEG 4000, 0,25 M ( $\left.\mathrm{NH}_{4}\right)_{2} \mathrm{SO}_{4}, 10 \%$ (w/v) Isopropanol und 0,1 M HEPES-KOH pH 7,0 - pH 8,5 verwendet.

(A)

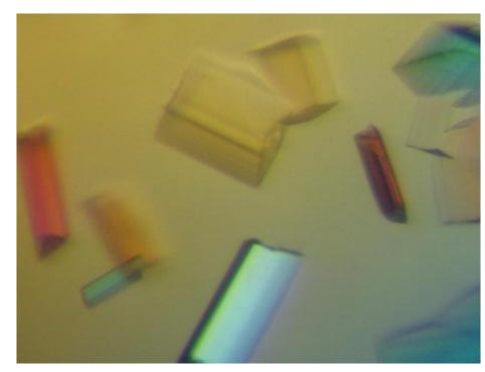

(D)

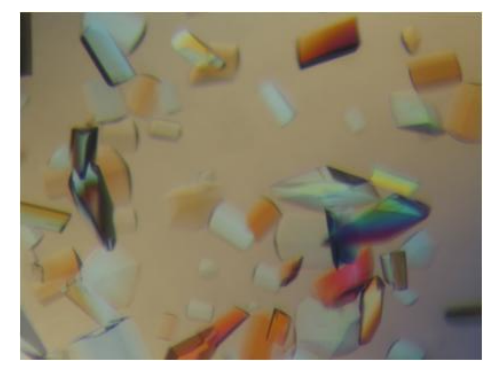

(B)

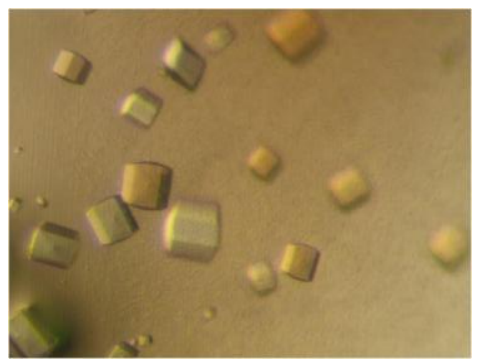

(E)

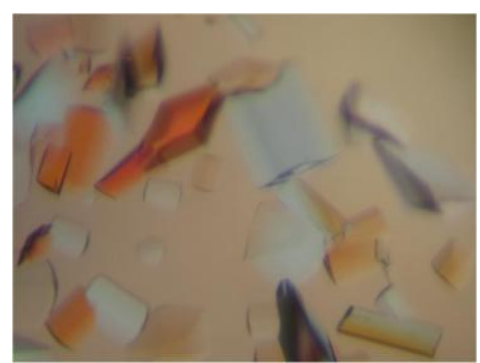

(C)

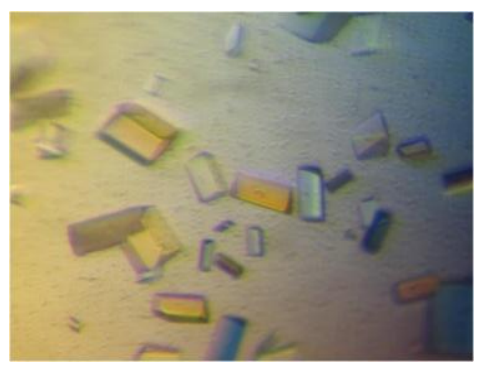

(F)

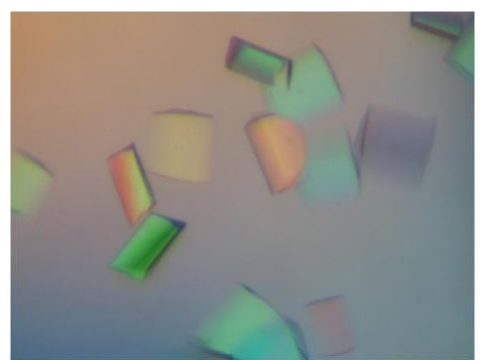

Abbildung 3.20: Verschiedene PpAOC2-Kristalle. (A) Dreidimensionale Kristalle in länglicher Form aus Bedingung neun des JB Screen 3; (B) Kristalle aus einer Bedingung mit $22 \%$ (w/v) PEG 4000, 0,25 M $\left(\mathrm{NH}_{4}\right)_{2} \mathrm{SO}_{4}, 5 \%$ (w/v) Isopropanol und 0,1 M HEPES-KOH, pH 8,0; (C) Kristalle aus einer Bedingung mit $20 \%$ (w/v) PEG 4000, 0,25 M ( $\left.\mathrm{NH}_{4}\right)_{2} \mathrm{SO}_{4}, 5 \%$ (w/v) Isopropanol und 0,1 M HEPES-KOH, pH 7,5; (D)-(F) Kristalle in verschiedenen dreidimensionalen Formen aus einer Bedingung mit $14 \%(\mathrm{w} / \mathrm{v}) \mathrm{PEG}$ 4000, 0,25 $\mathrm{M}\left(\mathrm{NH}_{4}\right)_{2} \mathrm{SO}_{4}$, $10 \%$ (w/v) Isopropanol und 0,1 M HEPES-KOH, pH 7,5; (A)-(F) unter polarisiertem Licht aufgenommen. 
Als geeignete Kryobedingung stellte sich die Zugabe von $25 \%$ (w/v) MPD heraus. In dieser Bedingung blieben die PpAOC2-Kristalle aus allen Bedingungen über einen Zeitraum von 48 h stabil. Auch für PpAOC2 wurde getestet, ob diese Bedingung zum Inkubieren der Kristalle mit verschiedenen Substratanalogen oder OPDA geeignet war. Deshalb wurde wie in Abschnitt 2.17.4 beschrieben das jeweilige Substratanlogon, bzw. OPDA in Isopropanol aufgenommen und in 10-20fachem, bzw. 10-100fachem molaren Überschuss zum Kryotropfen dazu gegeben. Dabei wurden jeweils mehrere Kristalle aus einer oder mehreren Bedingungen pro Kryotropfen bei $4{ }^{\circ} \mathrm{C}$ für 2-6 h inkubiert. Die PpAOC2-Kristalle blieben über diesen Zeitraum sehr stabil und verloren nicht an Qualität. Das initiale Testen und die Aufbewahrung geeigneter Kristalle erfolgte entsprechend den PpAOC1-Kristallen (3.4.1).

\subsubsection{Datenaufnahme und Datenprozessierung von PpAOC1 und PpAOC2}

Es wurden verschiedene Datensätze von PpAOC1 und PpAOC2 im Grundzustand sowie in nichtkovalentem Komplex mit verschiedenen Substratanalogen und dem Produkt OPDA gesammelt. Diese Arbeiten wurden zunächst von Jens Brinkmann und später von Dr. Piotr Neumann unter Leitung von Prof. Dr. Ralf Ficner (Molekulare Strukturbiologie, GeorgAugust-Universität Göttingen) durchgeführt. Die Daten wurden an der BW7A-Beamline am Deutschen-Elektronensynchrotron Hamburg (DESY) mit Synchrotronstrahlung des DORISSpeicherringes und an der MX_Beamline_14-1 sowie der MX_Beamline_14_2 (BL_14-1, BL_14-2) am Helmholtz-Zentrum Berlin (HZB) mit Synchrotronstrahlung des BESSY II Speicherringes gesammelt. Die Statistiken der Datenaufnahme und -prozessierung (2.18.2 und 2.18.3) für alle gesammelten Datensätze sind in Tabelle $8.1 \mathrm{im}$ Anhang zusammengefasst.

\subsubsection{Datenaufnahme und Datenprozessierung von $P p A O C 1$}

Nach Indizierung und Datenreduktion mit XDS, XSCALE und XPREP konnte den gemessenen PpAOC1-Kristallen die Raumgruppe P1 eindeutig zugeordnet werden. Trotz Inkubation der PpAOC1-Kristalle für bis zu $72 \mathrm{~h}$ mit den Substratanalogen, bzw. dem OPDA fand sich bei Verfeinerung der Messdaten nur ein Datensatz mit gebundenem Liganden (3.4.6). Dabei handelt es sich um einen Datensatz von PpAOC1 mit dem Substratanalogon $12,13-\mathrm{EOD}^{\triangle 9 Z \Delta 15 Z} \mathrm{im}$ aktiven Zentrum. Zudem wurden mehrere Datensätze des Enzyms aufgenommen in denen sich das Kristallisationsadditiv 1,6-Hexandiol im aktiven Zentrum befand. Somit stand kein Apo-Datensatz von PpAOC1 zur Verfügung. Für PpAOC1 gilt als Apo-Protein, eine der Strukturen, die ohne soaking aufgenommen wurde und ausschließlich 1,6-Hexandiol enthält. Diese wurde bis zu bis zu kristallografischen R-Faktoren von $\mathbf{R}_{s y m}=$ 2,4\% und einer Auflösung von 1,32 ̊ verfeinert und mit in die Diskussion einbezogen. 
Im Folgenden werden die Datenstatistiken des Datensatzes mit 12,13 EOD ${ }^{\Delta 9 Z \Delta 15 Z}$ beschrieben. Der Datensatz wurde mit hoher Auflösung von 1,33 Å gesammelt.

Die $\mathbf{R}_{\text {sym }}$-Faktoren wiesen nach der Datenreduktion Werte von 3,2\% für die gesamten Auflösungsbereiche auf. Der $\mathrm{R}_{s y m}$-Faktor in der äußersten Schale war 52,4\% bei einer Signalstärke I/Sigma von noch 1,90. Die Vollständigkeit der Daten lag in diesem Auflösungsbereich bei $77 \%$ und somit wurden die kompletten Daten bis zur Auflösung von $1,33 \AA$ verwendet.

Um zu bestimmen, wie viele Proteinmoleküle sich in einer asymmetrischen Einheit befinden, wird der Matthews-Koeffizient berechnet (Matthews, 1968). Die einzig sinnvolle Lösung bei einem Lösungsmittelgehalt der Proteinkristalle von etwa $50 \%$ ergab sich, wenn die asymmetrische Einheit 12 Monomere enthielt (Abbildung 3.21).

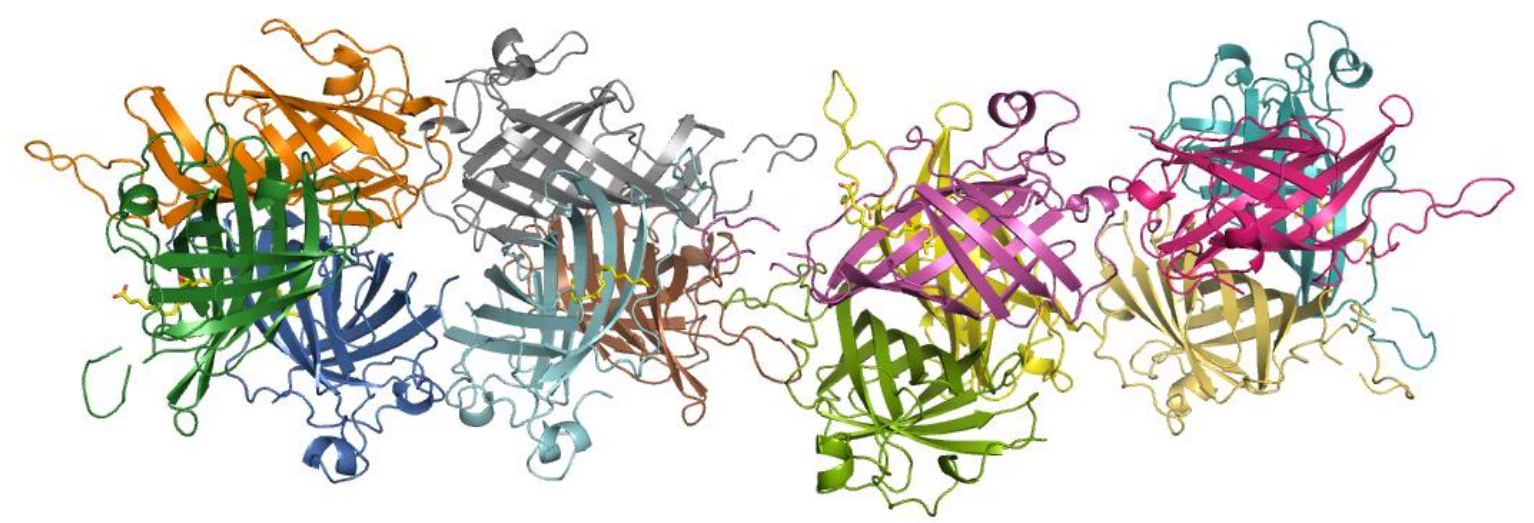

Abbildung 3.21: Die asymmetrische Einheit des PpAOC1-Kristalls mit gebundenen Liganden 12,13EOD $^{\Delta 9 Z \Delta 15 Z}$. Gezeigt sind die vier Trimere einer asymmetrischen Einheit, wobei jedes Monomer in einer anderen Farbe dargestellt ist. Kette A (gelb); Kette B (türkis); Kette C (magenta); Kette D (grau); Kette E (braun); Kette F (orange); Kette G (blau); Kette H (grün); Kette J (lila); Kette K (olivgrün). Der Ligand 12,13-EOD ${ }^{\Delta 9 Z 1 \Delta 5 Z}$ in den Ketten A, B, C, G und H ist jeweils als Stabmodell in gelb dargestellt.

In Abbildung 3.21 ist die Anordnung der vier Proteintrimere in der asymmetrischen Einheit des PpAOC1-Kristalls gezeigt. In fünf der 12 Ketten befand sich der Ligand 12,13EOD $^{\triangle 9 Z \Delta 15 Z}$ im aktiven Zentrum. Alle übrigen Substratbindetaschen waren mit 1,6-Hexandiol besetzt.

\subsubsection{Datenaufnahme und Datenprozessierung von $P$ PAOC2}

Den gemessenen $P p A O C 2-K r i s t a l l e n$ wurde nach Indizierung und Datenreduktion mit XDS, XSCALE und XPREP eindeutig die Raumgruppe P2 ${ }_{1}$ zugeordnet. In drei Datensätzen von PpAOC2 befand sich das Substratanalogon 12,13-EOD ${ }^{\triangle 9 Z \Delta 15 Z}$ im aktiven Zentrum, je ein Datensatz enthielt Vernolsäure $12,13-\mathrm{EOD}^{9 Z}$, bzw. das $\mathrm{C}_{20}$-Substratanalogon 11,12$\mathrm{EET}^{\triangle 5 Z \Delta 8 Z \Delta 15 Z}$ im aktiven Zentrum. Außerdem wurde ein Datensatz des Enzyms ohne 
Liganden (APO) aufgenommen. Nach der Datenreduktion wiesen die $\mathrm{R}_{\text {sym }}$-Faktoren Werte von 5,5\% (APO), 7,0 \% (12,13-EOD ${ }^{\triangle 9 Z \Delta 15 Z}$-I), 11,1\% (12,13-EOD ${ }^{\triangle 9 Z \Delta 15 Z}$-II), 8,2 \% (12,13EOD $\left.^{\triangle 9 Z \Delta 15 Z}-\mathrm{III}\right), 10,0 \%\left(12,13-\mathrm{EOD}^{9 Z}\right)$ und 9,0\% (11,12-EET $\left.{ }^{\triangle 5 Z \Delta 8 Z \Delta 15 Z}\right)$ für die gesamten Auflösungsbereiche auf. Weitere Messparameter der Datensammlung sind in Tabelle 8.2 (Anhang) zusammengefasst.

Eine sinnvolle Lösung der PpAOC2-Struktur war nach Berechnung des MatthewsKoeffizienten (Matthews, 1968) bei einem Lösungsmittelgehalt von etwa $50 \%$ gegeben, wenn die asymmetrische Einheit sechs Monomere enthielt (Abbildung 3.22). Die Abbildung 3.22 zeigt die Anordnung von zwei Trimeren in der asymmetrischen Einheit des PpAOC2Kristalls mit dem Liganden 12,13-EOD ${ }^{\Delta 9 Z \Delta 15 Z}$. Alle sechs Monomere hatten den Liganden $12,13-\mathrm{EOD}^{\triangle 9 Z 1 \triangle 5 Z}$ im aktiven Zentrum gebunden.

Für PpAOC1 und PpAOC2 wurden mehrere Versuche unternommen die Kristalle mit dem Produkt OPDA zu inkubieren um eine Enzym/Produkt-Struktur zu erhalten. Es wurden verschiedene Inkubationszeiten $(6 \mathrm{~h}-48 \mathrm{~h})$ und Konzentrationen $(10$ - 100facher OPDAÜberschuss) gewählt, jedoch führte keine der Methoden zum Erfolg. 
(A)

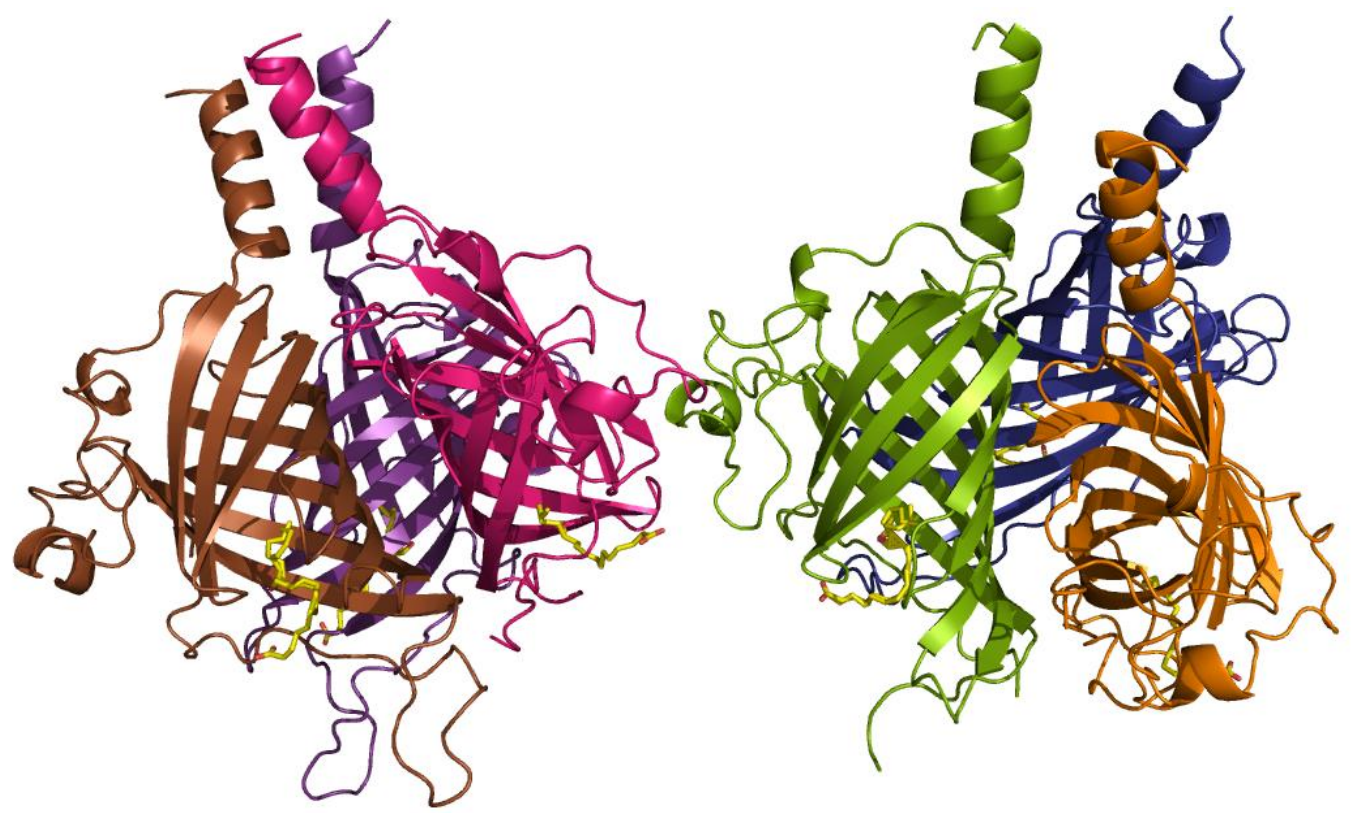

(B)

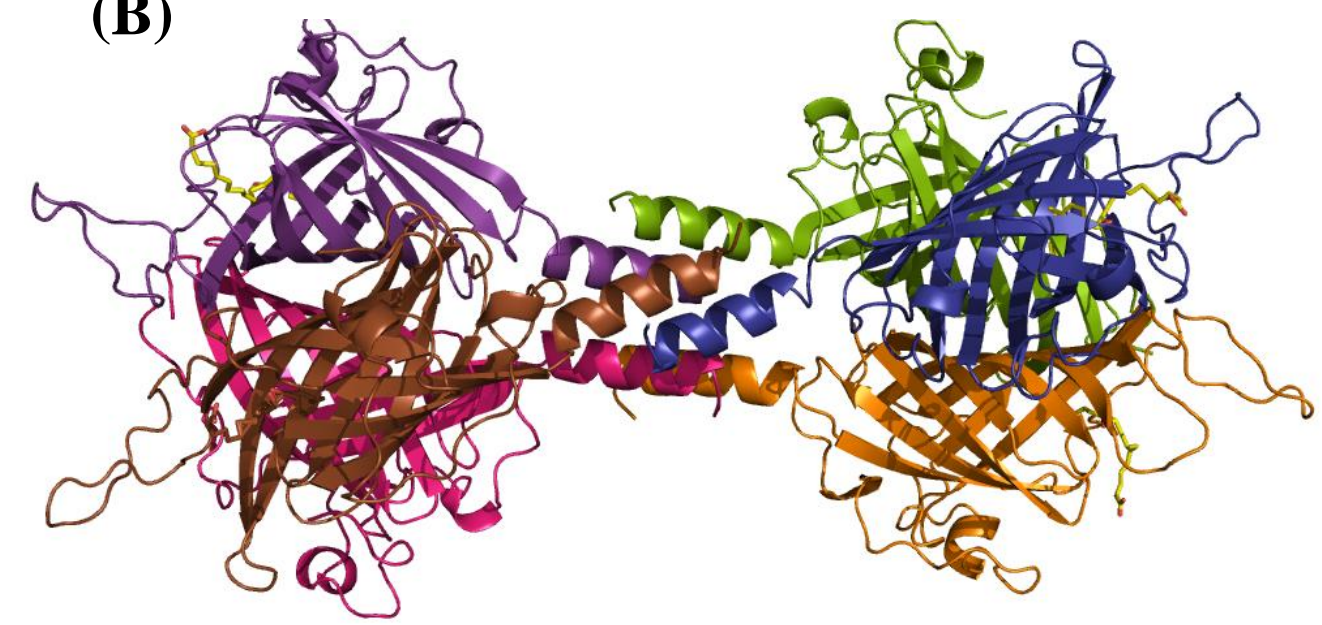

Abbildung 3.22: Die asymmetrische Einheit der PpAOC2-Kristalle mit gebundenem Liganden 12,13EOD $^{\Delta 9 Z \Delta 15 Z}$. Gezeigt sind zwei Trimere einer asymmetrischen Einheit des Datensatzes AOC2 12,13-EOD-I, wobei jedes Monomer in einer andere Farbe dargestellt ist. Kette A (lila); Kette B (magenta); Kette C (grün); Kette D (braun); Kette E (orange); Kette F (blau). Der Ligand 12,13-EOD in den Ketten A - F ist als Stabmodell in gelb dargestellt. (A) asymmetrische Einheit des Kristalls (B) durch den $\alpha$-helikalen N-Terminus verbundene asymmetrische Nachbartrimere.

\subsubsection{Phasenbestimmung durch molekularen Ersatz und Verfeinerung der Daten}

In der Proteindatenbank (protein data base, pdb; www.pdb.org) sind bereits Röntgenkristallstrukturen von pflanzlichen AOC deponiert. Darunter befindet sich die Struktur von Arabidopsis thaliana AOC2 (AtAOC2) mit dem Inhibitor Vernolsäure 12,13EOD $^{\Delta 9 Z}$ im aktiven Zentrum (2DIO.pdb). Da AtAOC2 und PpAOC1 bzw., PpAOC2 eine Sequenzähnlichkeit von jeweils $41,3 \%$ und 40,7 \% haben, wurden diese Koordinaten als Suchmodell zur Bestimmung der Phaseninformation durch molekularen Ersatz (MR) 
herangezogen. Die Phasenbestimmung zur Berechnung der Strukturfaktoren und einer ersten Elektronendichtekarte erfolgte somit über MR. Die Phasenbestimmung sowie die anschließenden Verfeinerungen der PpAOC-Strukturen wurden von Dr. Piotr Neumann durchgeführt.

Wie in Abschnitt 2.18.3.5 beschrieben, erfolgte der Modellbau mithilfe des Programmes COOT (Emsley \& Cowtan, 2004). Die Strukturverfeinerung wurde mit dem CCP4Softwarepaket sowie dem Programm PHENIX durchgeführt. Verbesserungen am Modell mit anschließender Verfeinerung wurden solange durchgeführt bis der kristallographische und der freie R-Faktor jeweils konvergierten und dabei gleichzeitig maximal um $5 \%$ auseinander lagen. Während zu Beginn des Modellbaus gerade die Seitenketten der neu einzusetzenden Aminosäuren häufig suboptimal definiert waren, steigerte sich die Genauigkeit der Elektronendichtekarte durch die Phasenverbesserung im fortschreitenden Modellbau zunehmend.

Dies wurde durch Löschen der entsprechenden Teile und einer anschließenden Verfeinerung iterativ verifiziert. Mithilfe des Ramachandran-Diagramms (Ramachandran et al., 1963) wurde überprüft, ob die Bindungswinkel des C $\alpha$-Rückgrats ( $\varphi$ - und $\psi$-Winkel) in sterisch erlaubten Bereichen liegen. Darüber hinaus wurde die korrekte Stereochemie der Seitenketten ständig überprüft. Weiterhin wurden die B-Faktoren für die Strukturmodelle berechnet. Der B-Faktor ist ein Maß für die positionelle Auslenkung eines Atoms, das um die angegebenen Koordinaten oszilliert, und wird deshalb auch als Temperatur-Faktor bezeichnet. Je höher der B-Faktor eines Atoms ist, desto größer ist die räumliche Ausdehnung der Elektronenwolke. Die dadurch entstehende statistische Unordnung führt zur einer unterschiedlichen Position und Orientierung der Moleküle in den Einheitszellen.

Die Tabelle 8.2 (Anhang) fasst eine Übersicht der kristallografischen R-Faktoren (Brunger, 1997) und weitere statistische Daten des Verfeinerungsprozesses für alle PpAOC-Strukturen zusammen.

\subsubsection{Verfeinerung PpAOC1 mit gebundenem Substratanalogon 12,13-EOD ${ }^{\text {9Z15Z }}$}

Der Gesamtverfeinerungsprozess wurde bis zu kristallographischen R-Faktoren von $\mathrm{R}_{\text {work }}=$ $14,80 \%$ und $\mathrm{R}_{\text {free }}=18,17 \%$ und einer Auflösung von 1,33 $\AA$ durchgeführt. Nach der Verfeinerung wurden der PpAOC1-Struktur 178, bzw. 179 Aminosäuren für Monomere zugeordnet. Zusätzlich enthielt die PpAOC1-Struktur 3008 Wassermoleküle, von denen sich jeweils zwei im aktiven Zentrum befanden.

In den Ketten A, B, D - G, I - K war für die ersten neun Aminosäurereste keine eindeutige Elektronendichte in der Struktur definiert. In den übrigen Ketten $(\mathrm{C}, \mathrm{H}$ und L) war für die 
ersten 10 Aminosäurereste keine Elektronendichte definiert. Diese Reste wurden auch nach mehreren Verfeinerungszyklen nicht in die Struktur eingebaut. Die jeweiligen Ketten beginnen somit N-terminal mit dem Aminosäurerest Histidin 10, bzw. Valin 11. Die Proteinschleife von Aminosäurerest 32 - 45 war allgemein ungünstig in der Struktur definiert, was auch durch die kalkulierten B-Faktoren (3.4.4) erkennbar ist. In Abbildung 3.23 ist eine Übersicht über die kalkulierten B-Faktoren für die PpAOC1-Struktur gezeigt. Dabei sind die Bereiche mit niedrigen B-Faktoren blau dargestellt, die Bereiche mit mittleren B-Faktoren sind grün und gelbe bis rote Bereiche besitzen einen hohen B-Faktor.

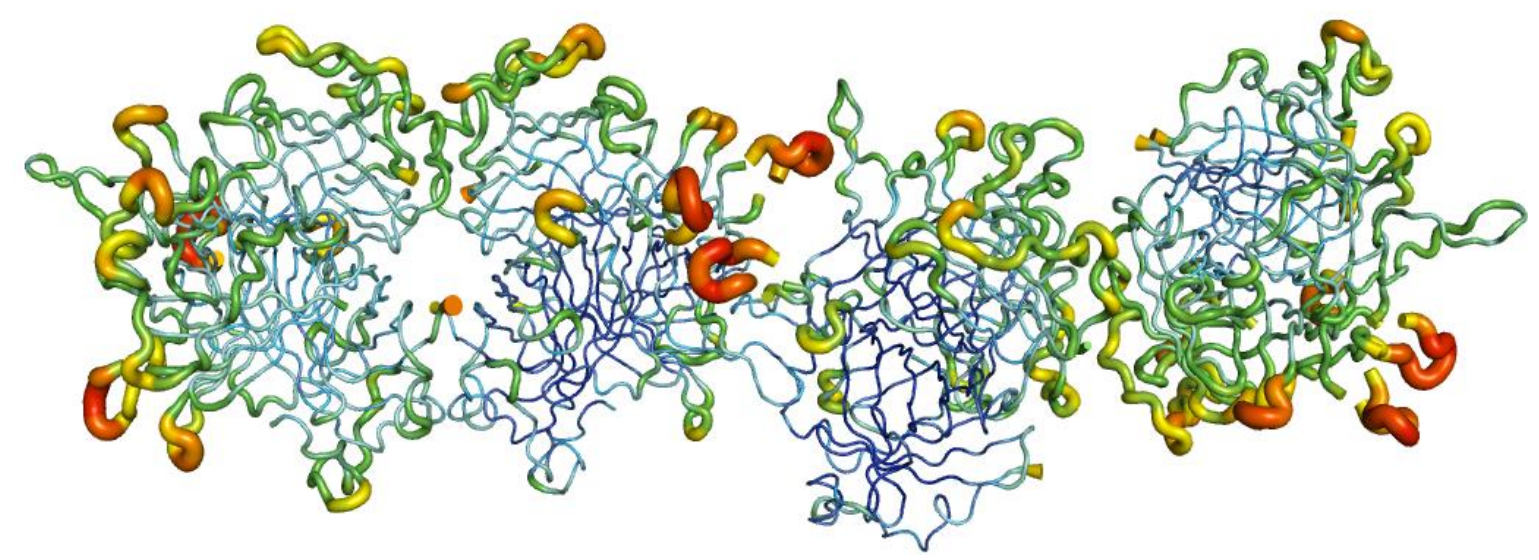

Abbildung 3.23: Die asymmetrische Einheit des PpAOC1-Kristalls mit den B-Faktoren der Ca-Atome. Niedrige B-Faktoren (blau); Mittlere B-Faktoren (grün); hohe B-Faktoren (gelb und rot).

Über die Strukturverfeinerungen wurde in diesen ungünstig definierten Bereichen wenig Verbesserung erreicht. Das weist darauf hin, dass die PpAOC1-Proteine im Kristall in dieser Region flexibel sind. Darüber hinaus sind die Aminosäurereste 32 - 45 in ihrer Anordnung im Molekül flexibel, was bei grafischer Überlagerung der einzelnen Monomere deutlich wurde (Abbildung 3.24). 


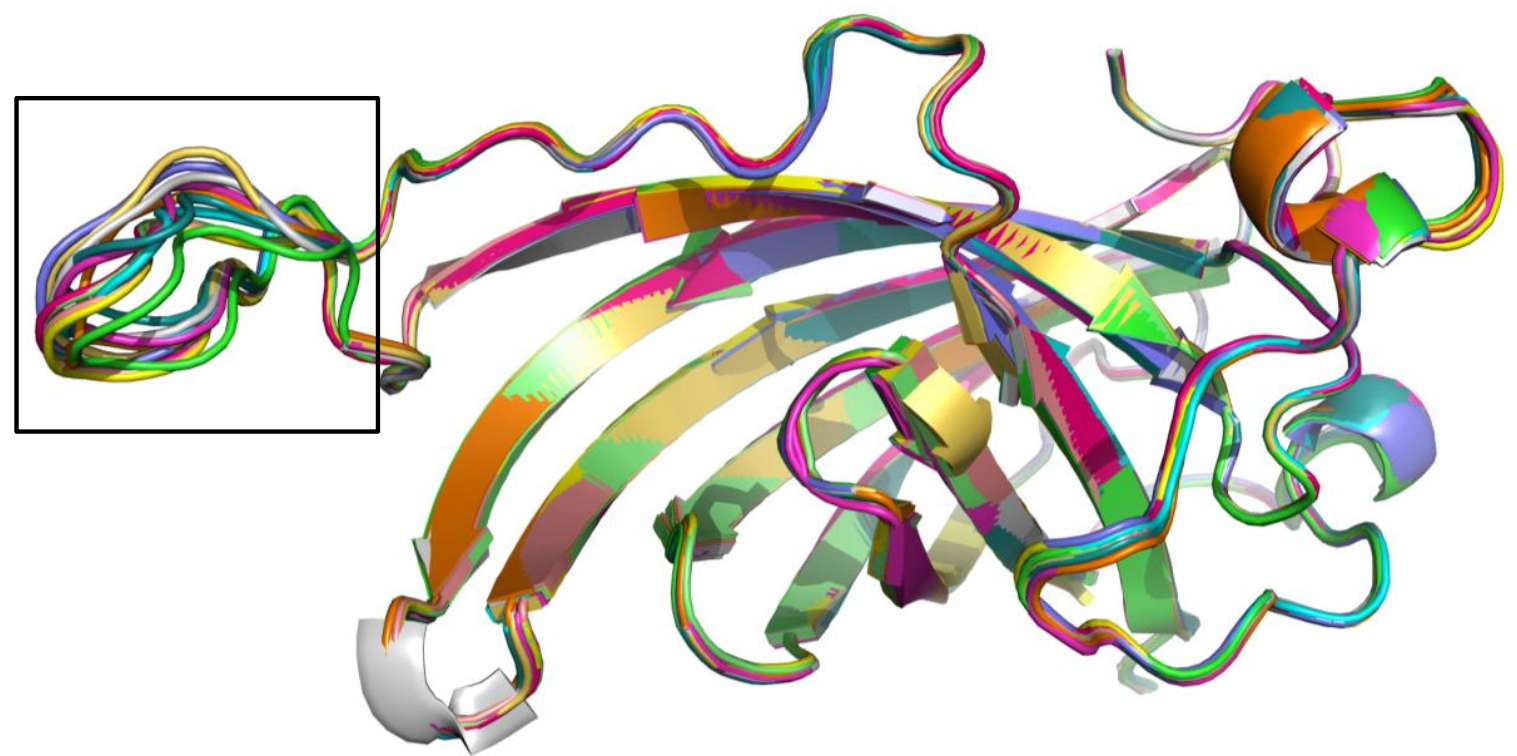

Abbildung 3.24: Graphische Überlagerung der 12 PpAOC1-Monomere einer asymmetrischen Einheit. Die einzelnen Monomeren sind in unterschiedlichen Farben dargestellt. Die flexible Proteinschleife der Aminosäurereste $32-45$ ist schwarz gerahmt.

Insgesamt zeigte sich jedoch eine sehr gute Übereinstimmung des C $\alpha$-Rückgrates der einzelnen Monomere. Die mittlere Standardabweichung (Root Mean Square Deviation; RMSD) bei Überlagerung von $\mathrm{C} \alpha$-Atomen der vier Trimere in der asymmetrischen Einheit von PpAOC1 beträgt $0.2 \AA$ - $0.35 \AA$. Aufgrund der flexiblen Bereiche in der PpAOC1Struktur (Abbildung 3.23 und Abbildung 3.24) wurden bei Berechnung der RMSD Atome, die eine Abweichung von 3,5 $\AA$ aufwiesen herausgelassen.

In Abbildung 3.25 ist das Ramachandran-Diagramm für endgültige Struktur von $P p A O C 1$ in Komplex mit 12,13-EOD ${ }^{\Delta 9 Z \Delta 15 Z}$ gezeigt. 


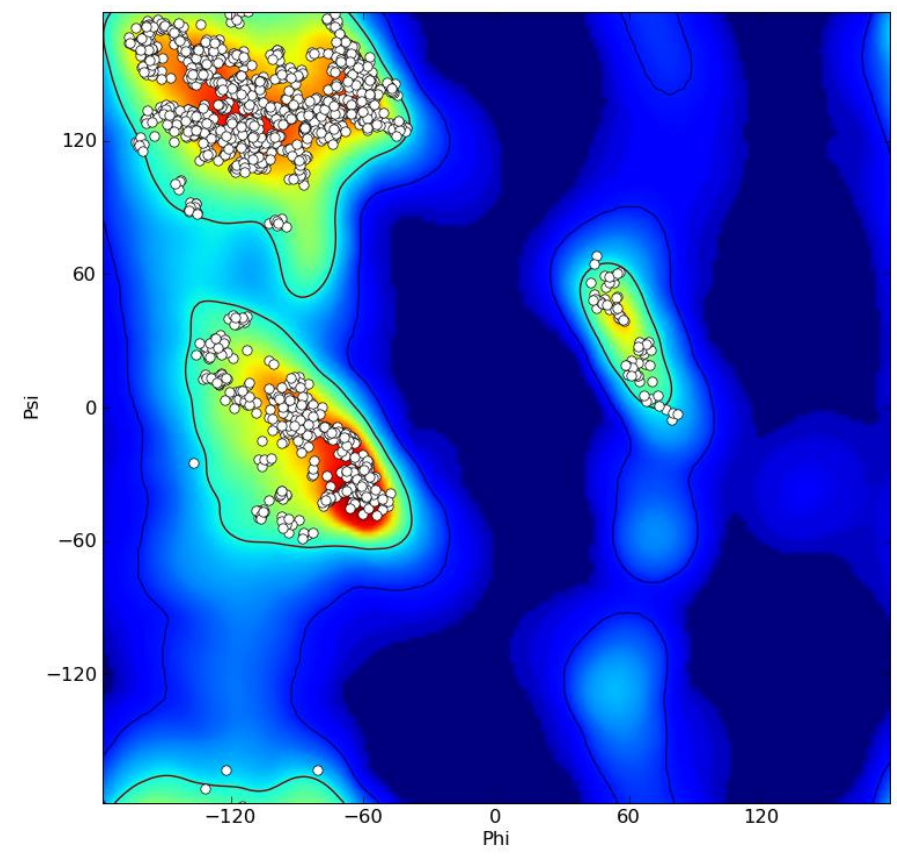

Abbildung 3.25: Ramachandran-Diagramm für die PpAOC1-Struktur mit gebundenem Ligand 12,13EOD $^{\triangle 9 Z \Delta 15 Z}$ (erstellt mit PHENIX). Gegeneinander aufgetragen sind die Rotationswinkel psi und phi $(\varphi$ - und $\psi$ Winkel). Weiße Kreise kennzeichnen Aminosäurereste in bevorzugten (rot), erlaubten (gelb-grün) und bedingt erlaubten (blau) Regionen.

Das Ramachandran-Diagramm zeigte, dass die Geometrie von 98,8 \% aller Aminosäuren der PpAOC1-Struktur innerhalb erlaubter Bereiche des Ramachandran-Diagramms liegt. Nur ein kleiner Teil von 0,1\% der Aminosäuren, liegt in bedingt erlaubten Bereichen.

\subsubsection{Verfeinerung von PpAOC2 (Apo) und von PpAOC2 mit 12,13-EOD ${ }^{\triangle 9 Z \Delta 15 Z}$ im aktiven Zentrum}

Zum derzeitigen Stand der Arbeit war nur ein PpAOC2-Datensatz endgültig verfeinert. Dabei handelt es sich um einen Datensatz von PpAOC2 mit Ligand 12,13-EOD ${ }^{\triangle 9 Z \Delta 15 Z}$ mit der höchsten Auflösung von $1.85 \AA$ (AOC2-12,13-EOD-I). Ein ligandenfreier Datensatz mit einer Auflösung von 1,95 $\AA$ (AOC2-APO) wurde bis zu kristallografischen R-Faktoren von $\mathrm{R}_{\text {work }}=$ $20,24 \%$ und $\mathrm{R}_{\text {free }}=23,75 \%$ sowie einer Auflösung von $1,95 \AA$ verfeinert und mit in die Diskussion einbezogen. Die restlichen Datensätze werden in die Beschreibung derPpAOC2Struktur in der vorliegenden Arbeit nicht einbezogen.

Der Gesamtverfeinerungsprozess von PpAOC2 mit gebundenem 12,13-EOD ${ }^{\triangle 9 Z \Delta 15 Z}$ wurde bis zu kristallographischen R-Faktoren von $\mathrm{R}_{\text {work }}=20,09 \%$ sowie $\mathrm{R}_{\text {free }}=23,71 \%$ durchgeführt. Nach der iterativen Verfeinerung konnten der PpAOC2-Struktur 188 Aminosäuren plus fünf Reste der Schnittstelle für das GST-Protein (GGPLG) für ein Monomer zugeordnet werden. Zusätzlich enthielt das PpAOC2-Struktur 955 Wassermoleküle, von denen sich jeweils zwei 
(Kette A - D, F) bzw. drei (Kette E) im aktiven Zentrum befanden. Die Proteinschleife von Aminosäurerest 32 - 45 ist, wie in der PpAOC1-Struktur mäßig definiert, was auch durch die hohen B-Faktoren in diesen Regionen deutlich wurde (3.4.4.1). In Abbildung 3.26 ist eine Übersicht über die kalkulierten B-Faktoren für die PpAOC2-Struktur gezeigt.

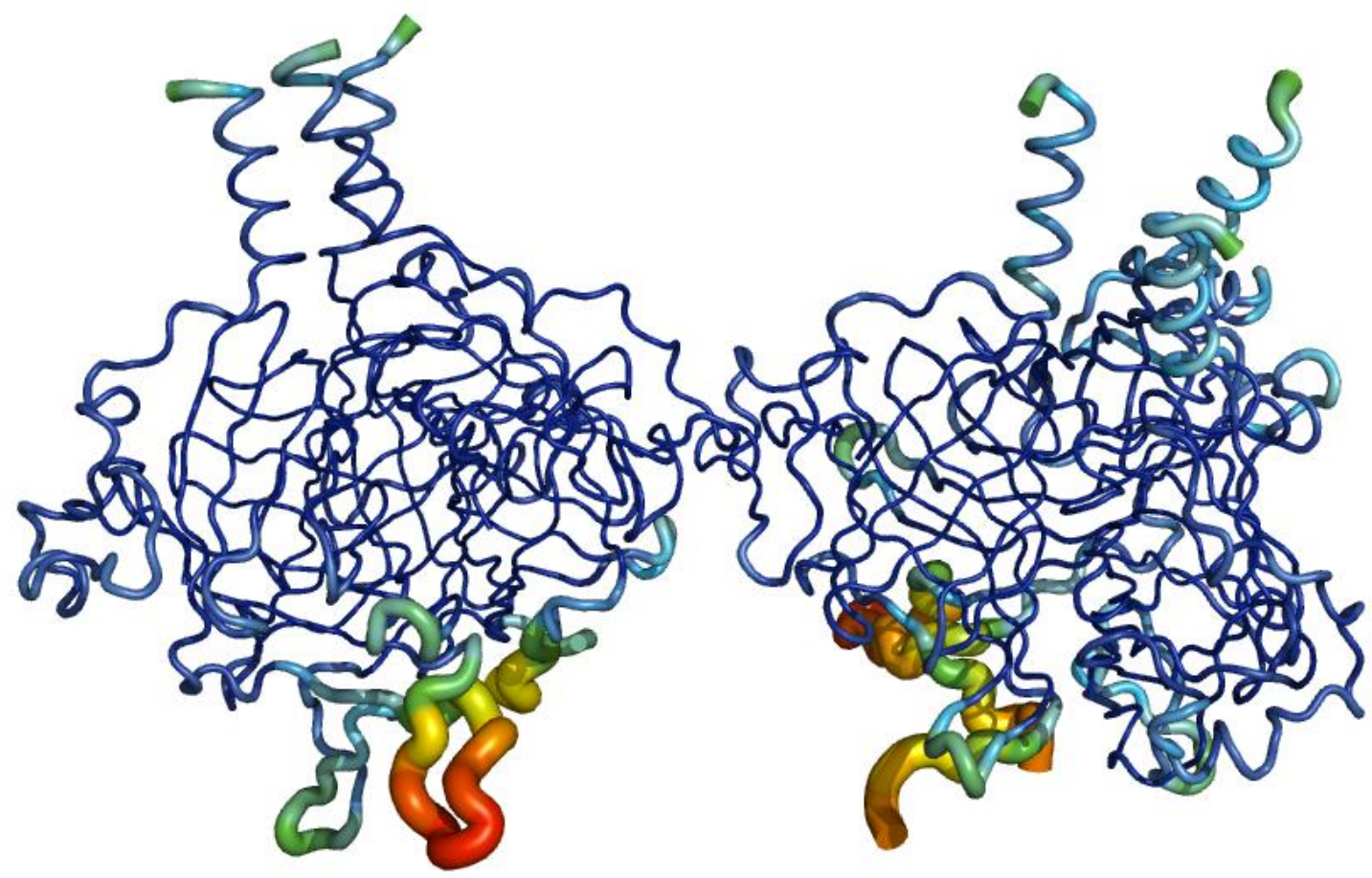

Abbildung 3.26: Die asymmetrische Einheit von PpAOC2 mit den B-Faktoren der Ca-Atome. Es handelt sich um den Datensatz 12-13-EOD ${ }^{\triangle 9 Z \Delta 15 Z}$; niedrige B-Faktoren (blau); Mittlere B-Faktoren (grün); hohe BFaktoren (gelb und rot).

Auch durch die Strukturverfeinerungen konnte in diesen ungünstig definierten Bereichen wenig Verbesserung erreicht werden, für die Ketten B (magenta) und C (grün) konnten einzelne Abschnitte der flexiblen Proteinschleife nicht in die PpAOC2-Struktur eingebaut werden. Bei graphischer Überlagerung der einzelnen Monomere waren mehrere flexible Bereiche in den Molekülen sichtbar (Abbildung 3.27). 


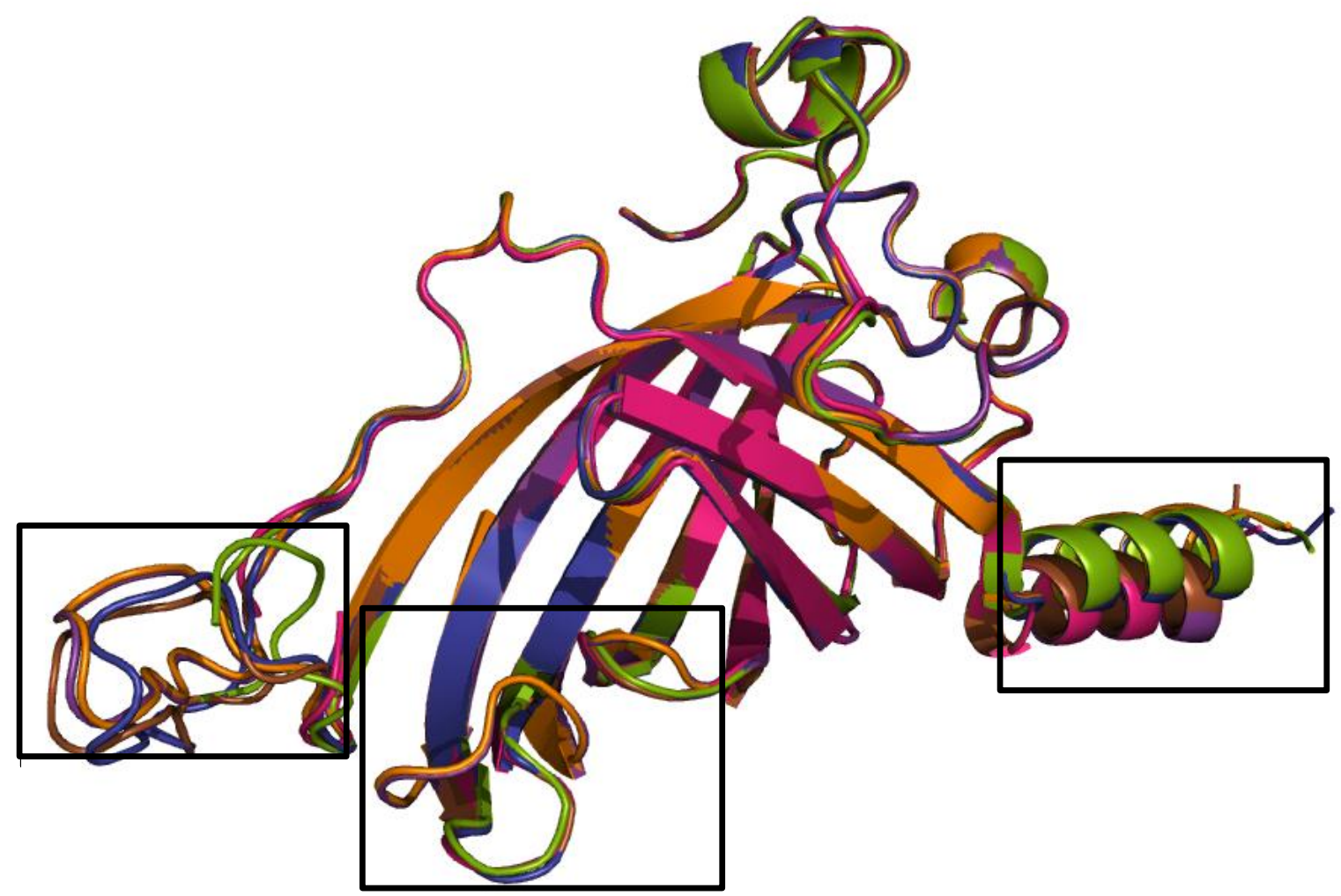

Abbildung 3.27: Graphische Überlagerung der sechs PpAOC2-Monomere einer asymmetrischen Einheit. Die einzelnen Monomeren sind in unterschiedlichen Farben dargestellt. Flexible Proteinschleifen in den Regionen von Aminosäurerest 32-45 sowie 78-84 und die Unterschiede am $\alpha$-helikalen N-Terminus sind schwarz gerahmt.

Die N-terminalen $\alpha$-Helices sind nur für die Ketten eines Trimers genau überlagert. Damit passen die $\alpha$-Helices des einen Trimers genau in die $\alpha$-Helices des zweiten Trimers einer asymmetrischen Einheit (auch Abbildung 3.27 B). Insgesamt zeigte sich jedoch eine gute Übereinstimmung des C $\alpha$-Rückgrates der einzelnen Monomere von PpAOC2. Der RMSDWert der Überlagerung aller $\mathrm{C} \alpha$-Atome der sechs Monomere in der asymmetrischen Einheit von PpAOC2 beträgt 0,4 $\mathrm{A}-0,8 \AA$. C $\alpha$-Atome, die beim Vergleich mehr als 3,5 A voneinander abwichen, wurden bei der Berechnung des RMSD-Wertes nicht berücksichtigt.

Die Abbildung 3.30 zeigt das Ramachandran-Diagramm für die endgültige Struktur von PpAOC2. Für die PpAOC2-Struktur zeigte das Ramachandran-Diagramm zwei Aminosäuren (Kette B Aminosäurerest 46 und Kette D Aminosäurerest 44) deren Geometrie innerhalb nichterlaubter Bereiche des Ramachandran-Diagramms lagen. 


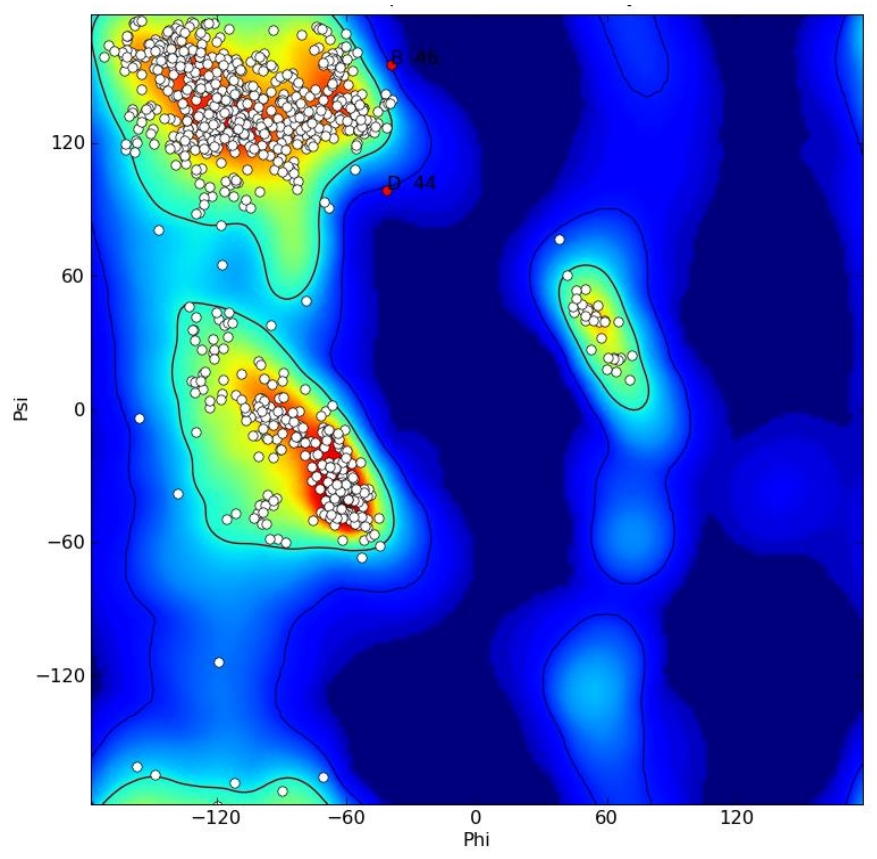

Abbildung 3.28: Ramachandran-Diagramm für die PpAOC2-Struktur mit 12,13-EOD ${ }^{\triangle 9 Z \Delta 15 Z}$ (erstellt mit Phenix). Gegeneinander aufgetragen sind die Rotationswinkel psi und phi ( $\varphi$ - und $\psi$-Winkel). Weiße Kreise kennzeichnen Aminosäurereste in sterisch bevorzugten (rot) und erlaubten (gelb - grün) Regionen. Rote Kreise kennzeichnen Reste in nicht erlaubten (hellblau) oder nur bedingt erlaubten Regionen (blau).

\subsubsection{Die dreidimensionale Proteinstruktur von $P$ AOC1 und PpAOC2}

PpAOC1 und PpAOC2 kristallisierten in unterschiedlichen Raumgruppen, wobei die Einheitszelle aus entweder 12 oder sechs Monomeren besteht. Beide Proteine bilden jedoch dicht gepackte Trimere, bestehend aus drei identischen Monomeren (Abbildung 3.29).

Der wesentlichste Unterschied zwischen den beiden Strukturen besteht im verlängerten NTerminus von PpAOC2. Im Gegensatz zur PpAOC1-Raumstruktur, welche bei Aminosäurerest 10 oder 11 anfängt, bilden in der PpAOC2-Raumstruktur die ersten zehn Aminosäuren plus der fünf Aminosäuren der GST-Schnittstelle eine $\alpha$-Helix (Abbildung 3.29).

In Abbildung 3.30 sind jeweils zwei verschiedene Ansichten der monomeren Struktur von $P p A O C 1$ und $P p A O C 2$ gezeigt. Beide Proteine falten sich in ein achtsträngiges antiparalleles $\beta$-Fass ( $\beta$-barrel) mit einer $\mathrm{C}$-terminalen teilweisen helikalen Verlängerung. Dieses $\beta$-Fass formt in beiden Proteinen die Substratbindetasche (Abbildung 3.30 B und D). 


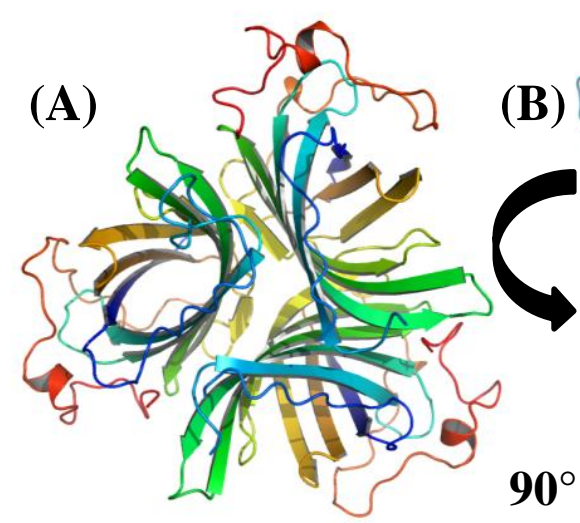

$90^{\circ}$

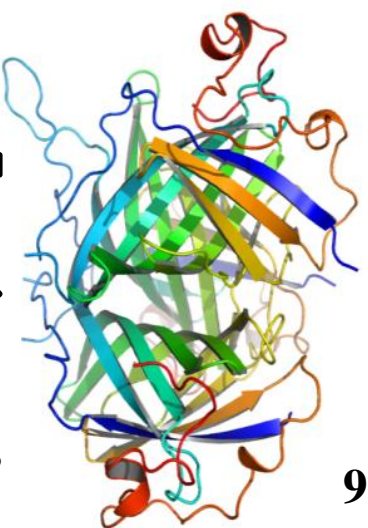

(E)

(D)
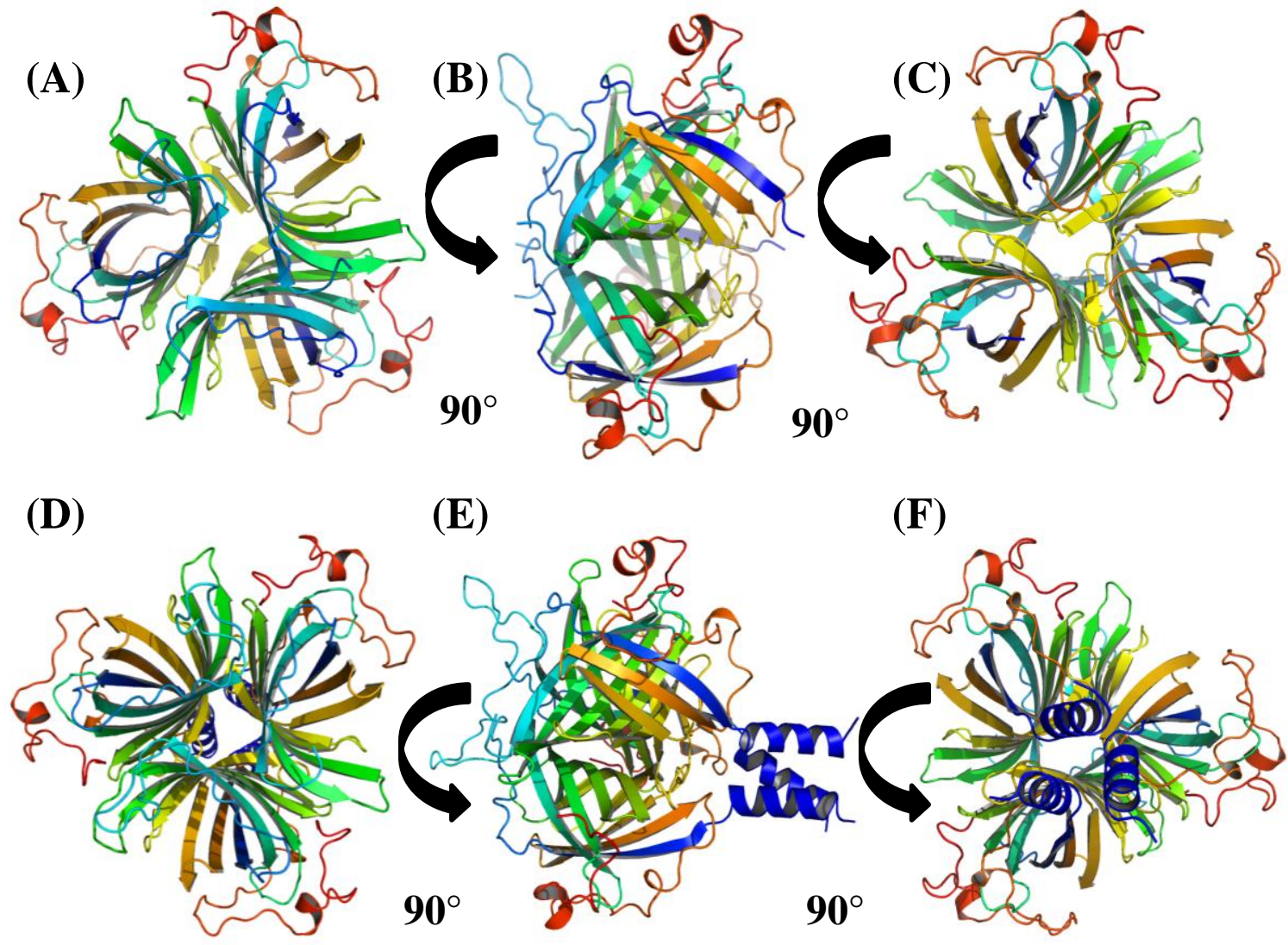

(F)

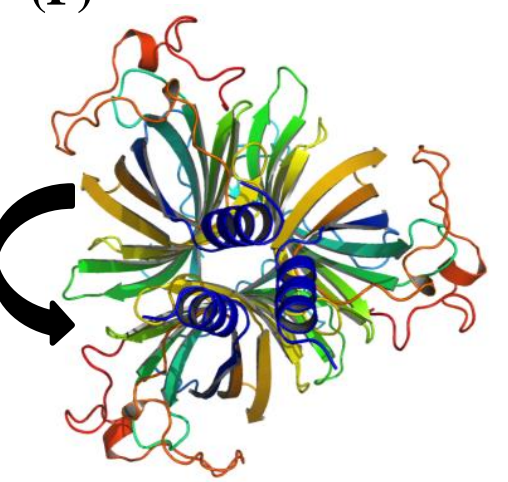

Abbildung 3.29: Verschiedene Ansichten des PpAOC1- und PpAOC2-Trimers. Trimere Struktur in Farbbanddarstellung. Die Farben zeigen den Verlauf vom N-terminalen (blau) zum C-terminalen Ende des Proteins (rot). (A)-(C) PpAOC1; (D)-(F) PpAOC2.
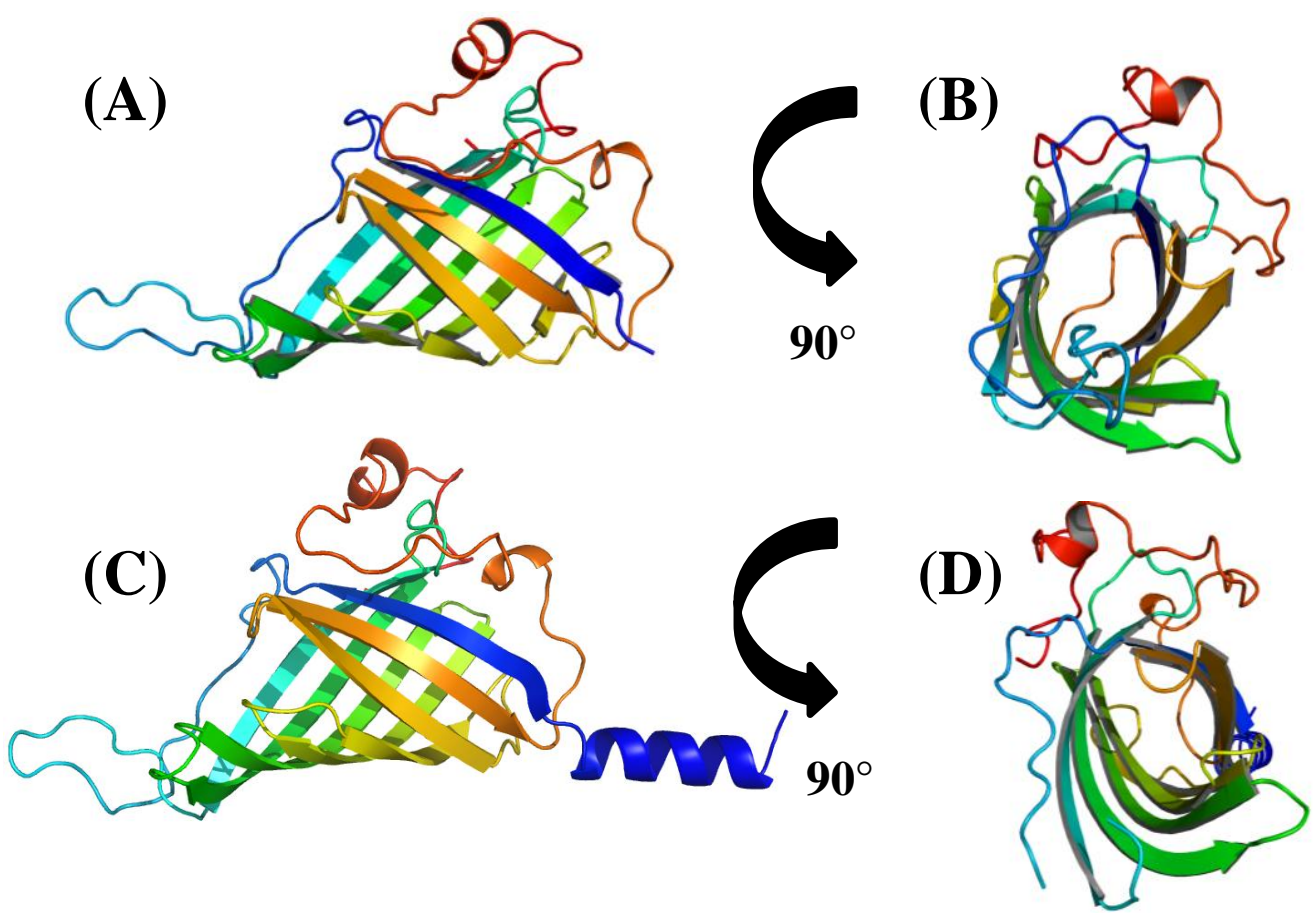

Abbildung 3.30: Das PpAOC1- und PpAOC2-Monomer. Gezeigt ist die monomere Struktur in Farbbanddarstellung. Die Farben zeigen den Verlauf vom N-terminalen (blau) zum C-terminalen Ende des Proteins (rot). (A)-(B) PpAOC1; (C)-(D) PpAOC2. 
Um die strukturellen Unterschiede zwischen den PpAOC1- und PpAOC2-Molekülen zu verdeutlichen sind in Abbildung 3.31 die beiden Proteintrimere verschiedenfarbig übereinander gelegt gezeigt.

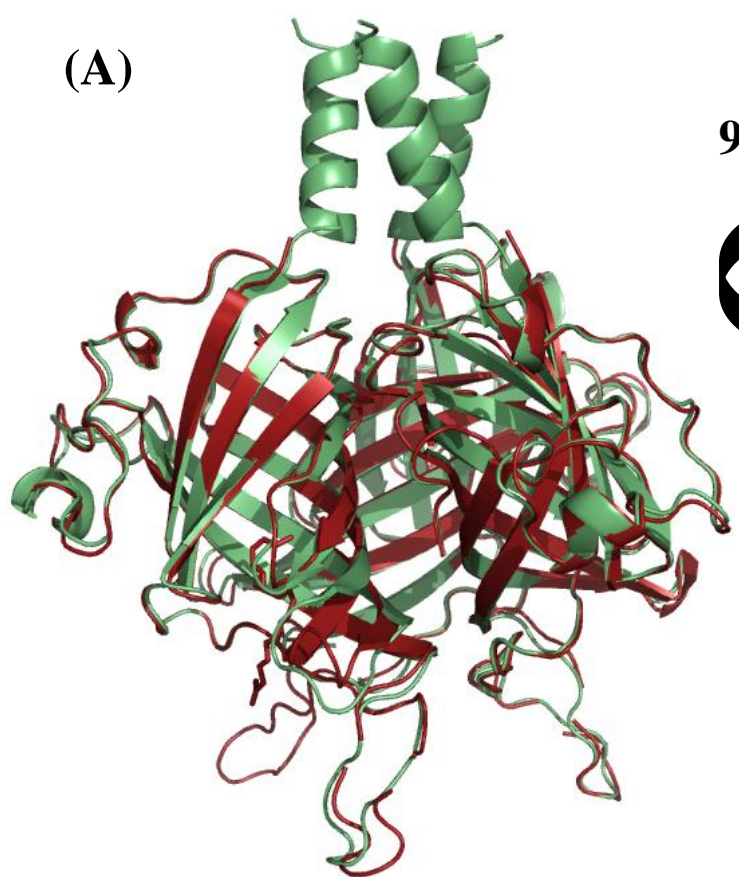

\section{(B)}
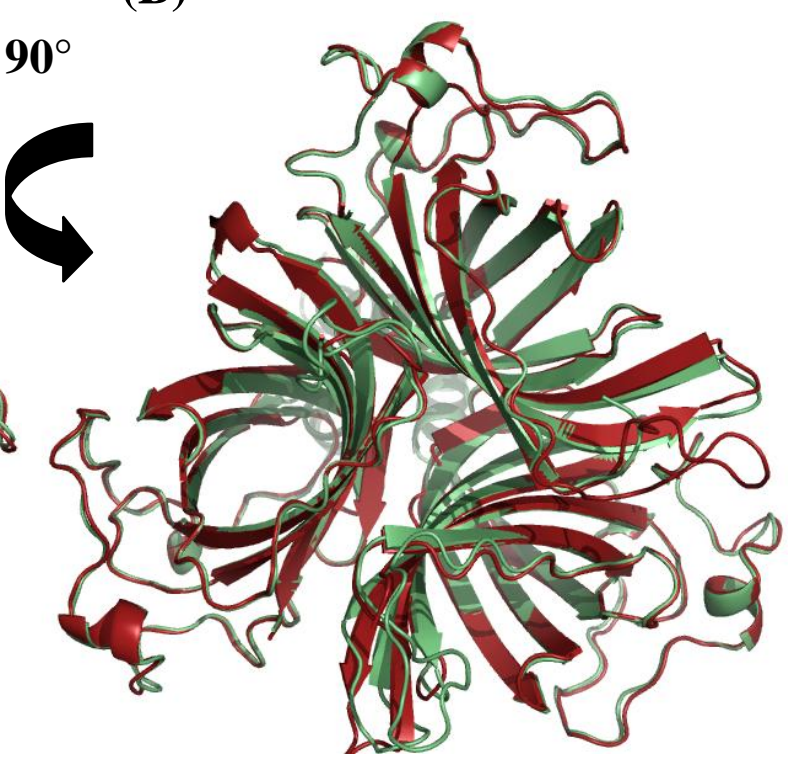

Abbildung 3.31: Grafische Überlagerung des PpAOC1- und PpAOC2-Moleküls. Gezeigt sind die trimeren Strukturen von $P p A O C 1$, Kette A, B und D (rot) und $P p A O C 2$, Kette B, E und F (grün) in Farbbanddarstellung. (A) Blick auf den N-Terminus (oben) und den C-Terminus (unten); (B) Blick um $90^{\circ}$ Richtung N-Terminus gedreht.

In der graphischen Überlagerung der Strukturen von PpAOC1 (Kette A, B, F) und PpAOC2 (Kette A, B, D) ist der Unterschied zwischen den N-terminalen Enden der jeweiligen Moleküle deutlich erkennbar. Die PpAOC2-Struktur und die GST-Schnittstelle bilden eine Nterminale $\alpha$-Helix. Die restlichen Bereiche der PpAOC1- und PpAOC2-Strukturen wiesen keine besonderen Unterschiede auf. Zusätzlich wurde ein RMSD-Wert von $0,79 \AA$ für die Überlagerung von PpAOC1-Kette A und PpAOC2-Kette A berechnet. Es wurden jeweils die Strukturen der Apo-Proteine verwendet. Von $180 \mathrm{C} \alpha$-Atomen für PpAOC1 und $188 \mathrm{C} \alpha$ Atomen für PpAOC2 wurden $173 \mathrm{C} \alpha$-Atome bei der Berechnung der RMSD berücksichtigt. Die übrigen $\mathrm{C} \alpha$-Atome liegen beim Vergleich mehr als 3,5 berücksichtigten $\mathrm{C} \alpha$-Atomen sind 139 identisch. Der RMSD-Wert für die Überlagerung der C $\alpha$-Atome eines PpAOC1- und eines PpAOC2-Trimer beträgt 0,69 $\AA$ für $512 \mathrm{C} \alpha$-Atome. Es wurden $535 \mathrm{C} \alpha$-Atome von PpAOC1 und $554 \mathrm{C} \alpha$-Atome von PpAOC2 für die Berechnung berücksichtigt, jedoch wurden erneut $\mathrm{C} \alpha$-Atome mit einer Abweichung von 3,5 $\AA$ nicht 
einbezogen. Von den 512 berücksichtigten $\mathrm{C} \alpha$-Atomen sind 413 identisch, somit sind $80 \%$ der verglichenen $\mathrm{C} \alpha$-Atome von PpAOC1 und PpAOC2 identisch.

Zusammenfassend lässt sich sagen, dass sowohl die Monomere als auch die Trimere von PpAOC1 und PpAOC2 eine mittlere Übereinstimmung von RMSD = 0,7 Å besitzen.

\subsubsection{Dreidimensionale Proteinstruktur von $P$ AOC1 mit 12,13-EOD ${ }^{9 \mathrm{Z15Z}}$ im aktiven Zentrum}

Von allen gemessenen PpAOC1-Kristallen befindet sich nur in einem Datensatz das Vernolsäurederivat $12,13-\mathrm{EOD}^{\triangle 9 Z \Delta 15 Z}$ in der Substratbindetasche von fünf Monomeren. Die übrigen neun Monomere waren jeweils von 1,6-Hexandiol besetzt, welches als Additiv bei der Kristallisation diente.

Beim Vergleich der 12 PpAOC1-Monomere mittels graphischer Überlagerung sind nahezu keine konformellen Unterschiede zwischen den Aminosäureresten, die das aktive Zentrum bilden und entweder 1,6-Hexandiol oder 12,13-EOD ${ }^{\triangle 9 Z \Delta 15 Z}$ binden, zu erkennen. Leichte Konformationsänderungen im aktiven Zentrum sind zwischen den Tyrosinresten an Position 107 (PpAOC1 Tyr-107) und den Phenylalaninresten an Position 138 (PpAOC1 Phe-138) sowie 140 (PpAOC1 Phe-140) sichtbar. Eine wichtige Rolle in der Betrachtung der folgenden Strukturen spielen ebenfalls der Glutamatrest an Position 18 (PpAOC1 Glu-18) und der Argininrest an Position 22. Das PpAOC1 Glu-18 ist das Strukturäquivalent zu AtAOC2 Glu23, welches als wichtige Aminosäure für den AOC-Reaktionsmechanismus beschrieben wurde (Hofmann et al., 2006) und unter allen AOC-Sequenzen konserviert ist. Der Aminosäurerest PpAOC1 Arg-22 befindet sich am Eingang der Substratbindetasche und ist eventuell an der Bindung des Substrats an das Enzym beteiligt, indem die positive Ladung des Arginins eine Salzbrücke mit der Carboxylgruppe des Substrates bildet. Diese Hypothesen wurden ebenfalls durch Austausch von Glu-18 und Arg-22 in Mutagenesestudien (3.4.9) bestätigt.

Es befinden sich jeweils zwei Wassermoleküle im aktiven Zentrum von PpAOC1 (rot dargestellt). Die Farbe der einzelnen Ketten mit den jeweiligen Liganden richtet sich dabei nach den Farben in Abbildung 3.21. In Abbildung 3.32 wird anhand des Beispiels für die Kette B die Lage des Substrates im Molekül und der dazugehörigen Elektronendichte (2fofcMappe; Konturlevel, $\sigma=1,0)$ gezeigt. 


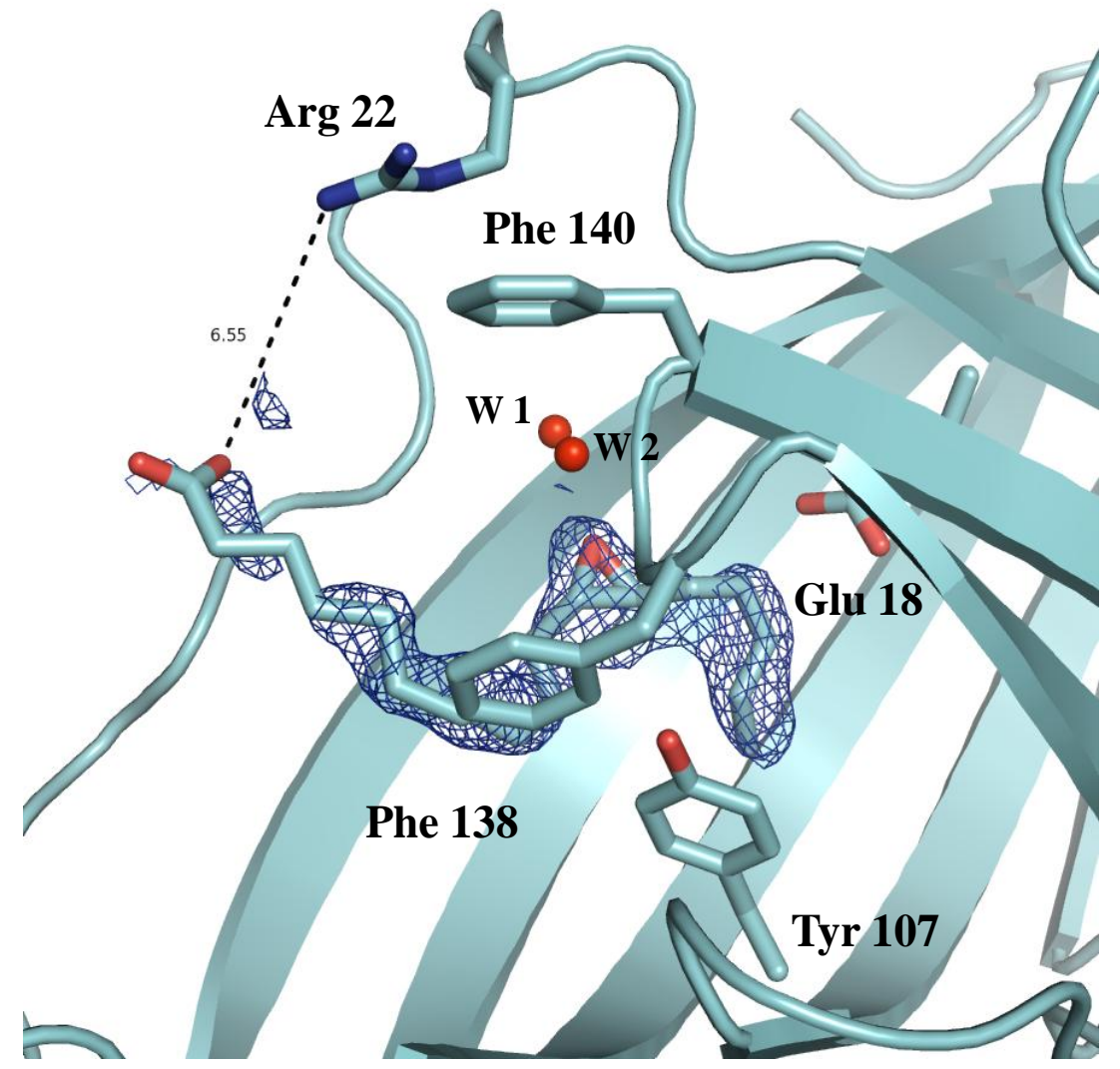

Abbildung 3.32: PpAOC1 Kette B mit Ligand 12,13-EOD ${ }^{\triangle 9 Z \Delta 15 Z}$ in Farbbanddarstellung. Anordnung des gebundenen Liganden 12,13-EOD ${ }^{\triangle 9 Z \Delta 15 Z}$ und der Aminosäurereste (Erläuterungen siehe Text) dargestellt als Stabmodelle. Zusätzlich ist für den Liganden die Elektronendichte der 2fofc-Mappe bei $\sigma=1$ in blau gezeigt. Wassermoleküle (rot); Abstand zwischen der Carboxylgruppe des Liganden und dem Arg-22 in Å (gestrichelte Linie).

Wie erwartet ist das Substratanalogon in der Aushöhlung gebunden, welche von den acht antiparallelen $\beta$-Strängen eines Monomers gebildet werden (Abbildung 3.32). Dabei reichte der Ligand mit dem Methylende tief in die Substratbindetasche hinein. Die jeweilige C15Doppelbindung des Liganden ist in Richtung des Glu-18 orientiert. Die Carboxylgruppe des Liganden reicht aus dem Enzym heraus und ist zum Arg-22 orientiert. Der Abstand zwischen der Carboxylgruppe des Liganden und dem Arg-22 beträgt 6,55 ̊.

Interessanterweise liegt die Allenoxidgruppe des Substratanalogons nicht wie erwartet in cisGeometrie, sondern in trans-Geometrie vor. Das Substratanalogon 12,13-EOD ${ }^{\triangle 9 Z \Delta 15 Z}$ liegt in gestreckter Form vor, womit es nicht direkt vergleichbar mit der Zyklisierungsreaktion des Enzyms ist. Die zwei Wassermoleküle sind in Richtung der Allenoxidgruppe des Liganden orientiert. Mit dem Programm Ligplot (Wallace et al., 1995) wurden die Aminosäurereste bestimmt, welche den Liganden und die Wassermoleküle im aktiven Zentrum über polare Kontakte koordinieren (Abbildung 3.33). 
(A)

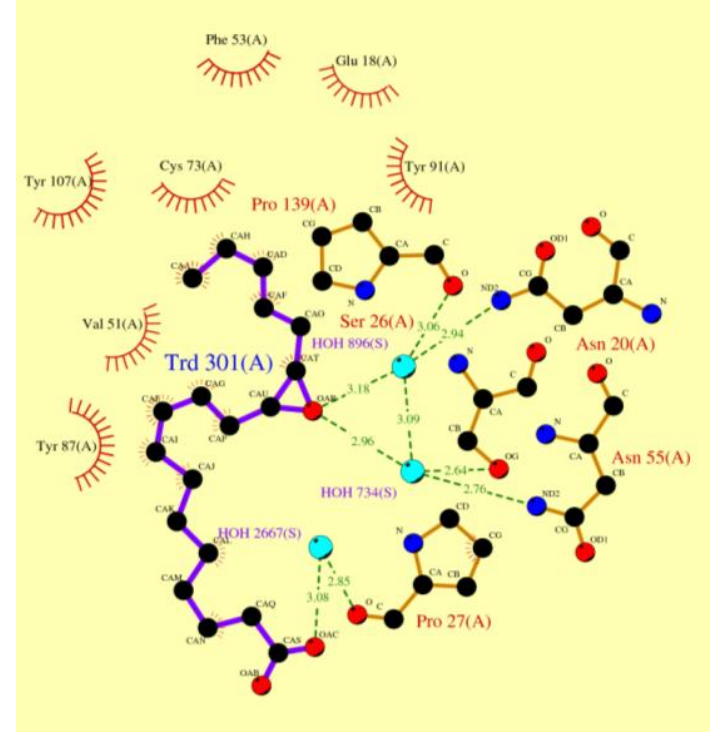

(B)

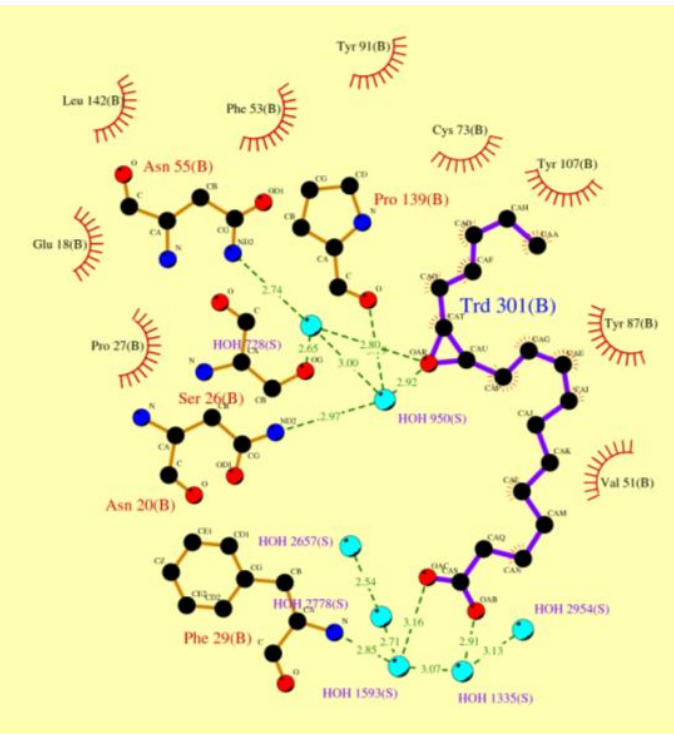

Abbildung 3.33: Darstellung polarer Kontakte im aktiven Zentrum von PpAOC1: Ligandbindung (lila); Andere Bindung (braun); Wasserstoffbrückenbindung und ihre Länge (erzeugt mit Ligplot). Gezeigt sind Ligplot-Skizzen für zwei PpAOC1-Ketten. Folgende Bindungen und Kontakte (grün, gestrichelt); Aminosäurereste, involviert in hydrophobe Kontakte (rot, gestrichelt); Atome, involviert in polare Kontakte (schwarze Kreise mit rotgestricheltem Rand). (A) Kette A; (B) Kette B.

In Abbildung 3.33 sind die polaren Kontakte des Liganden 12,13-EOT ${ }^{\Delta 9 Z \Delta 15 Z}$ in PpAOC1 beispielhaft für die Ketten A und B dargestellt. In Kette A sind sieben Aminosäurereste von PpAOC1 an molekularen Interaktionen mit dem Liganden beteiligt. Dabei handelt es sich um die konservierten Reste Glu-18, Val-51, Phe-53, Cys-73, Tyr-91, und Tyr-107. Der Aminosäurerest PpAOC1 Tyr-87 ist in den bekannten AOC-Sequenzen entweder als Tyrosin oder als Phenylalanin enthalten. Die zwei Wassermoleküle werden jeweils von Asn-20 und Pro-139 bzw. Ser-26 und Asn-55 koordiniert. Zusätzlich befindet sich ein drittes Wassermolekül in der Nähe der Carboxylgruppe des Liganden, dieses Wasser wird durch Pro-27 und der Carboxylgruppe des Liganden gebunden.

In Kette B (Abbildung 3.33 B) sind zusätzlich zu den in Kette A beobachten Interaktionspartnern die Reste Pro-27, Phe-29 und Leu-142 an molekularen Interaktionen beteiligt. Von diesen Resten ist lediglich das Pro-27 in den bekannten AOC-Sequenzen konserviert. Die Wassermoleküle im aktiven Zentrum sind wie in Kette A jeweils von Asn20/Pro-139 und Ser-26/Asn-55 koordiniert. Außerdem befinden sich vier Wassermoleküle in der Nähe der Carboxylgruppe des Liganden, welche zusätzlich mit Phe-29 interagierten.

In Abbildung 3.34 ist ein Vergleich der einzelnen Ketten mit gebundenem Liganden (Kette A, $\mathrm{B}, \mathrm{C}, \mathrm{G}, \mathrm{H})$ in verschiedenen Orientierungen gezeigt indem sie graphisch überlagert dargestellt sind. Zusätzlich sind die Aminosäurereste, welche den Liganden koordinieren und 
in AOCs konserviert sind, als Stabmodelle dargestellt. Das Phe-138 und Phe-140 sind ebenfalls gezeigt, da es zwischen diesen Resten kleine konformelle Unterschiede gab. Die Ketten B, C, G und H wurden dabei über die Kette A gelagert. Der Blick auf das aktive Zentrum in Abbildung 3.34 A-D ist jeweils $90^{\circ}$ nach links um den Liganden gedreht, wobei in Abbildung 3.34 A der Blick vom Eingang der Substratbindetasche in das aktive Zentrum gerichtet ist. Da der Ligand in Kette A, B, G und H jeweils in der gleichen Konformation gebunden ist, sind diese Liganden in Abbildung 3.34 jeweils grau dargestellt. Der Ligand in Kette $\mathrm{C}$ hat eine etwas veränderte Konformation und ist zum Vergleich in magenta gezeigt.

Die Carboxylgruppe der jeweiligen Liganden hat in allen Ketten die gleiche Orientierung zum Arg-22. Die Ketten A, C, G, und H weisen nur kleine konformelle Unterschiede zwischen den Aminosäureresten des aktiven Zentrums auf. Das Arg-22 ist in Kette H (grün) seitlich vom Carboxylende des Liganden weggedreht. Der Ligand und die Aminosäurereste in Kette C zeigen leichte konformelle Unterschiede zu den anderen Ketten auf. Wie in Abbildung 3.34 A - D gezeigt, ist eine leichte Veränderung der Lage des Phe-138 und des Phe-140 zu erkennen. Im Gegensatz dazu weisen die Aminosäurereste Glu-18 und Tyr-107 keine konformellen Unterschiede zwischen den einzelnen Ketten auf. Darüber hinaus ist der Ligand in Kette C leicht verändert in der Substratbindetasche orientiert als in den restlichen Ketten. Während das Methylende und die C-Atome von Position 13 - 18 in Kette C gleich orientiert sind, wies die Allenoxidgruppe zwischen $\mathrm{C} 12$ und $\mathrm{C} 13$ eine leichte Konformationsänderung im Vergleich zu den restlichen Liganden auf (Abbildung 3.34 B-D). 
(A)
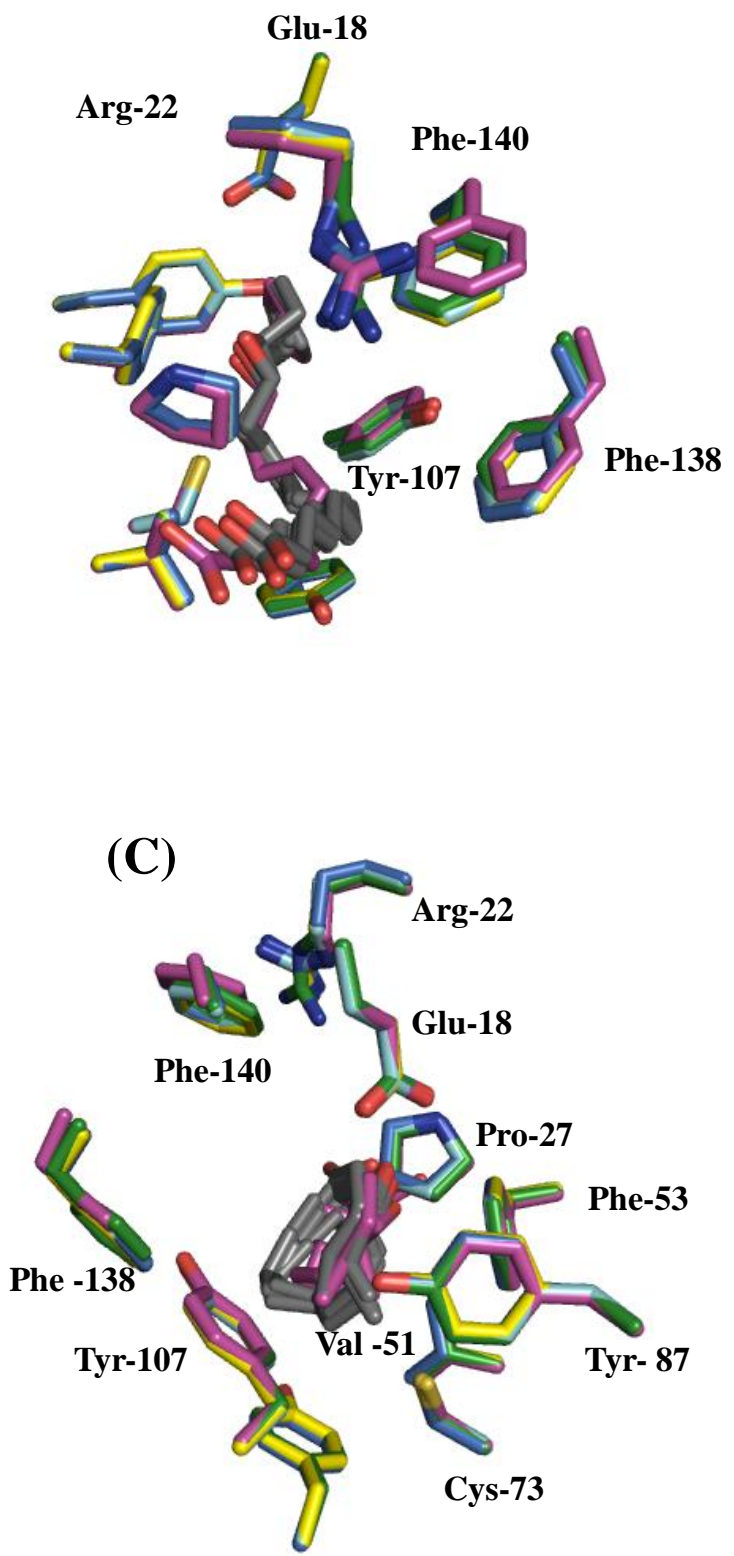

Tyr -91
(B)

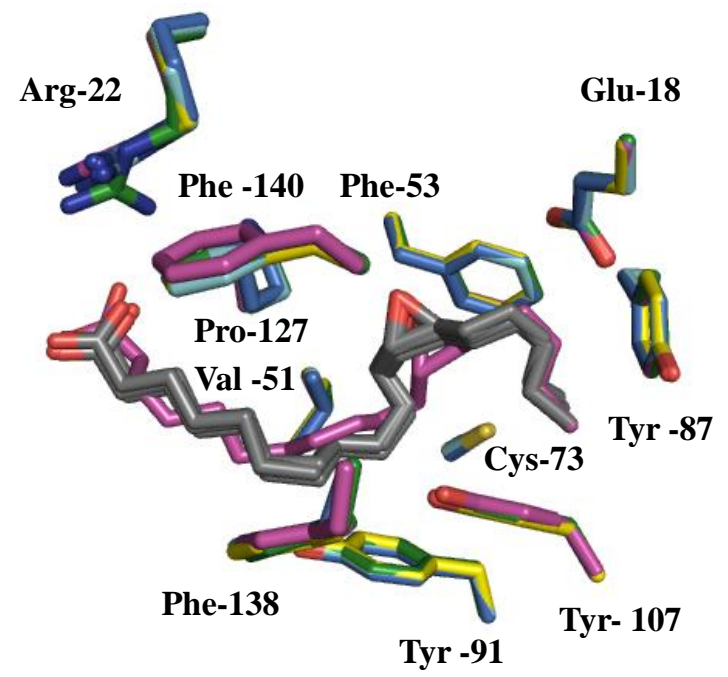

(D)

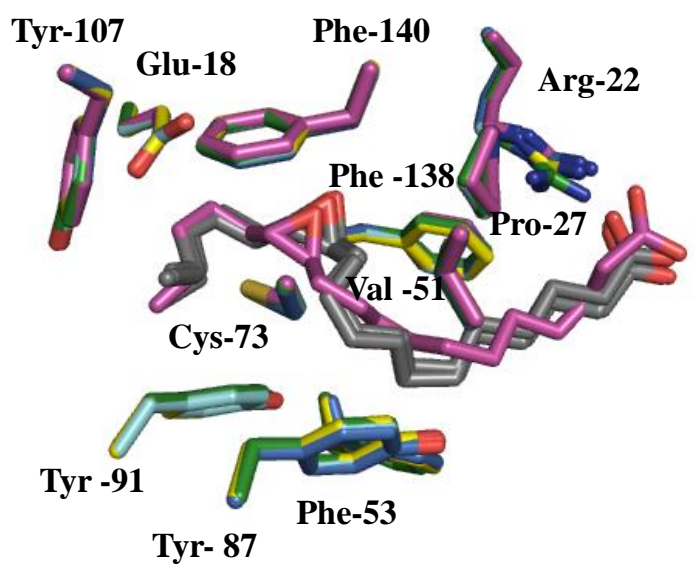

Abbildung 3.34: PpAOC1 Kette A, B, C, G und H mit Ligand 12,13-EOD ${ }^{\triangle 9 Z \triangle 15 Z}$ im Überblick. Anordnung des gebundenen Liganden 12,13-EOD ${ }^{\triangle 9 Z \Delta 15 Z}$ als Stabmodelle A, B, G, H (grau), C (magenta). Aminosäurereste als Stabmodelle Kette A (gelb); Kette B (türkis); Kette C (magenta); Kette G (blau); Kette H (grün). (A) Blick vom Eingang der Substratbindetasche in das aktive Zentrum (B) im Vgl. zu (A) $90^{\circ}$ nach links gedreht; Blick seitlich auf den Liganden (C) im Vgl. zu (A) $180^{\circ}$ nach links gedreht; Blick auf die Methylgruppe der Liganden (D) im Vgl. zu (A) $270^{\circ}$ nach links gedreht; Blick seitlich auf den Liganden.

Die C9-Doppelbindung des Liganden in Kette $\mathrm{C}$ weist ebenfalls eine andere Orientierung als in den restlichen Ketten auf. Durch eine leichte Drehung des Winkels zwischen C11- und C12-Atomen ist die C9-Doppelbindung leicht in Richtung Tyr-107 verschoben (Abbildung 3.34 A, B und D). Dadurch veränderte sich auch die Lage der restlichen C-Atome (C1-C8) des Liganden in Kette B. Im Gegensatz zu den anderen Liganden, sind die C-Atome jeweils 
um eine Bindungslänge verschoben (Abbildung 3.34 B und D). Die zwei Wassermoleküle haben in den aktiven Zentren der Ketten A, B, C, G und H dieselbe Lage zur Allenoxidgruppe orientiert und werden jeweils von Aminosäureresten koordiniert (Abbildung 3.33) Die graphische Überlagerung der PpAOC1-Ketten mit gebunden Liganden zeigte deutlich, dass alle Allenoxidgruppen der Liganden in trans-Geometrie gebunden sind.

Zusammenfassend lässt sich sagen, dass die Liganden in allen Ketten in der gleichen Orientierung gleich gebunden werden. Die einzige Ausnahme war in Kette $\mathrm{C}$ zu erkennen, in der sowohl der Ligand als auch Phe-138 und Phe-140 leichte Konformationsänderungen aufweisen. Die Wassermoleküle sind in Richtung Allenoxidgruppe orientiert, welche in transGeometrie vorliegt.

\subsubsection{Oberflächenladung von $P p A O C 1$}

Zusätzlich zur Charakterisierung des aktiven Zentrums von PpAOC1, wurde das elektrostatische Oberflächenpotential mit dem Programm Pymol errechnet. Damit können negative (rote) sowie positive (blaue) Bereiche eines Moleküls sichtbar gemacht werden (Abbildung 3.35). Wie in der Darstellung zu erkennen ist, bilden die N-terminale Enden der PpAOC1-Monomere einen positiv geladenen Bereich des Moleküls (Abbildung 3.35 A).
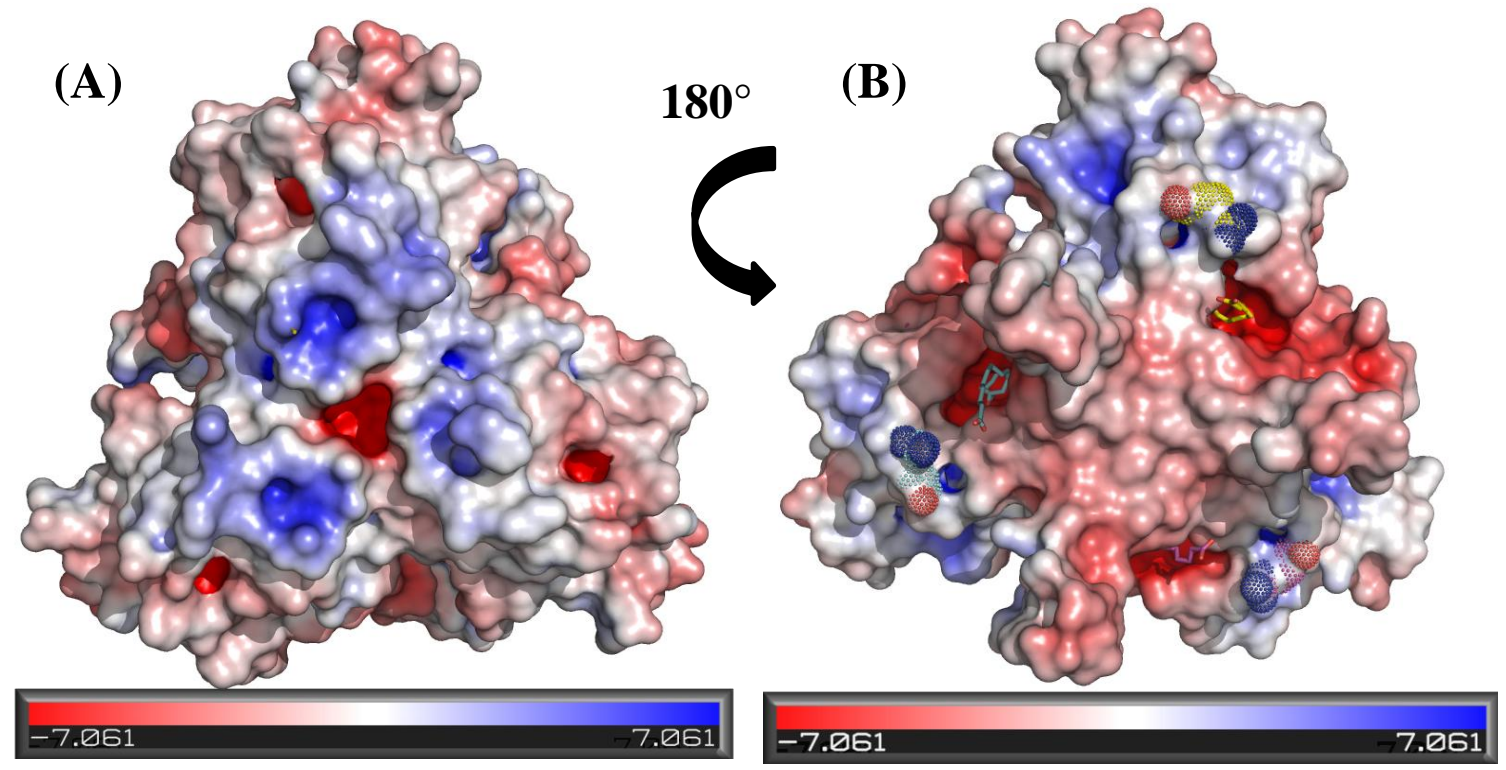

Abbildung 3.35: Oberflächendarstellung eines PpAOC1-Trimers. (erzeugt mit Pymol) Das elektrostatische Oberflächenpotential von PpAOC1 Kette A, B und C zeigt negative (blau), neutrale (weiß) und positive (rot) Bereiche des Moleküls. (A) Blick auf den N-terminalen Bereich (B) (180 gedreht) Blick auf den C-terminalen Bereich des Moleküls und die Substratbindetaschen der einzelnen Ketten mit gebundenen Liganden, Kette A (gelb), Kette B (türkis), Kette C (magenta). Das positiv geladene Arg-22 ist zusätzlich gepunktet dargestellt.

Zusätzlich zum Oberflächenpotential wurden die Liganden in den Substratbindetaschen als Stabmodelle dargestellt (Abbildung 3.35 B). Die Substratbindetasche ist in der Darstellung 
des elektronischen Oberflächenpotentials rot dargestellt, womit gezeigt wird, dass das aktive Zentrum von PpAOC1 aus negativen Aminosäureresten besteht. Die Carboxylgruppe der Liganden reicht weit aus dem Enzym heraus und ist in Richtung des positiv geladenen Arg-22 orientiert. Aufgrund der negativen Aminosäurereste im aktiven Zentrum ist eine inverse Substratbindung, bei welcher die Carboxylgruppe zuerst in das Enzym bindet, ausgeschlossen.

\subsubsection{Dreidimensionale Proteinstruktur von $P p A O C 2$ mit $12,13-E^{-O O D}{ }^{\triangle 9 Z \Delta 15 Z}$ im aktiven Zentrum}

In drei gesammelten Datensätzen von PpAOC2 befand sich das Vernolsäurederivat 12,13$\mathrm{EOD}^{\triangle 9 Z \Delta 15 Z}$ in den Substratbindetaschen der Enzyme. Im Folgenden wird die PpAOC2Struktur anhand der Struktur mit der höchsten Auflösung (1,85 A) beschrieben. In dieser Struktur befanden sich zudem in jeder der sechs Proteinketten $12,13-\mathrm{EOD}^{\triangle 9 Z \Delta 15 Z}$ im aktiven Zentrum des Enzyms.

Beim Vergleich der sechs PpAOC2-Monomere sind konformelle Unterschiede zwischen den Aminosäureresten, die das aktive Zentrum bilden, zu erkennen. Größere Konformationsänderungen im aktiven Zentrum sind zwischen den Tyrosinresten an Position 106 (PpAOC2 Tyr-106) und dem Phenylalaninrest an Position 137 (PpAOC2 Phe-137) sichtbar. Entsprechend der Betrachtung der PpAOC1-Struktur mit gebundenem Liganden 12,13-EOD ${ }^{\Delta 9 Z \Delta 15 Z}$ spielten auch der Glutamatrest an Position 18 (PpAOC2 Glu-18) sowie der Argininrest an Position 22 (PpAOC2 Arg-22) eine wichtige Rolle (3.4.6). Es befanden sich jeweils zwei oder drei Wassermoleküle im aktiven Zentrum von PpAOC2 (rot dargestellt). Die Farbe der einzelnen Ketten mit den jeweiligen Liganden richtet sich dabei nach den Farben in Abbildung 3.22. Da in der Struktur von PpAOC2 der Ligand 12,13-EOD ${ }^{\triangle 9 Z \Delta 15 Z}$ in zwei verschiedenen Bindemodi vorliegen, wird in Abbildung 3.36 anhand der Beispiele für Kette $\mathrm{C}$ und $\mathrm{E}$ die Lage des Substrates für beide Bindemodi und die dazugehörige Elektronendichte (2fofc-Mappe; Konturlevel, $\sigma=1,0$ ) gezeigt. 
(A)

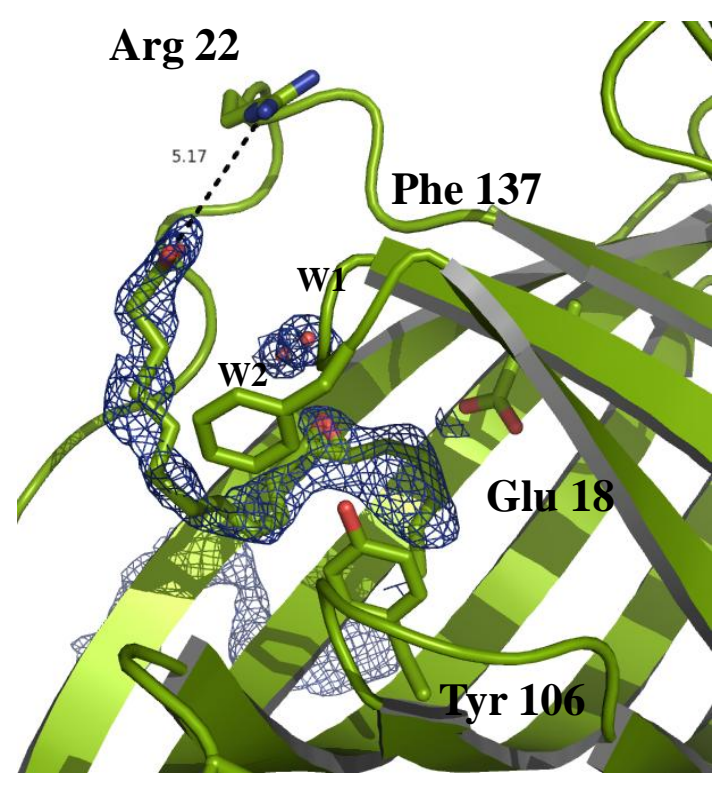

(B)

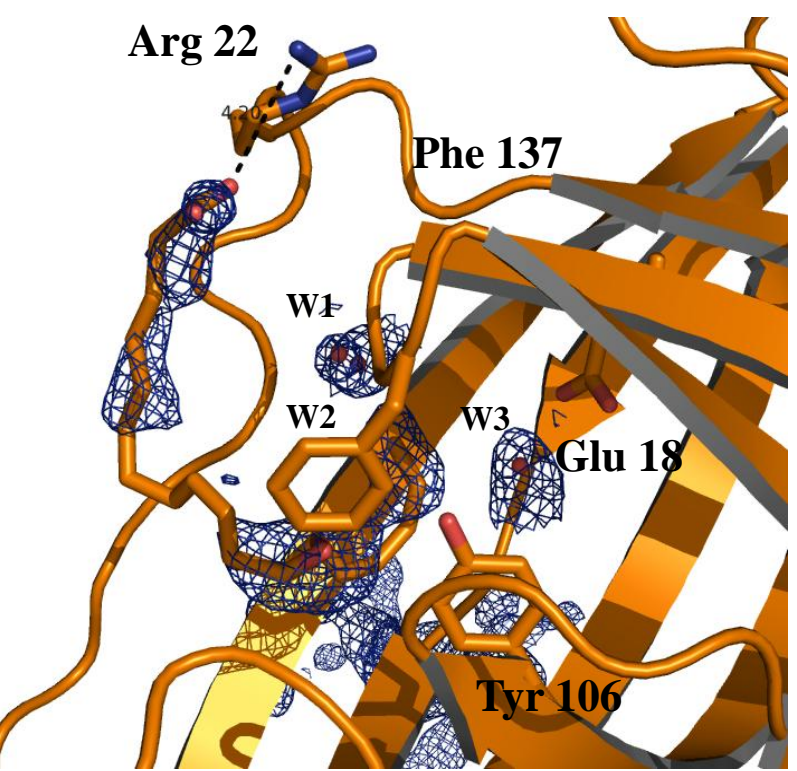

Abbildung 3.36: PpAOC2 Kette $\mathrm{C}$ und $\mathrm{E}$ mit Ligand 12,13-EOD ${ }^{\triangle 9 Z \triangle 15 Z}$ in Farbbanddarstellung. Anordnung des gebundenen Liganden 12,13-EOD ${ }^{\triangle 9 Z \Delta 15 Z}$ und der Aminosäurereste (Erläuterungen siehe Text) dargestellt als Stabmodelle. Zusätzlich ist für den Liganden und die Wassermoleküle (rot) die Elektronendichte der 2 fofc-Mappe bei $\sigma=1$ ist in blau gezeigt; Abstand zwischen der Carboxylgruppe des Liganden und dem Arg-22 in $\AA$ (gestrichelte Linie).

Wie bei PpAOC1 wird das Substratanalogon in der PpAOC2-Struktur mit dem Methylende in der Aushöhlung gebunden, welche von den acht antiparallelen $\beta$-Strängen eines Monomers gebildet werden. Interessanterweise liegt der Ligand in der Struktur von PpAOC2 in zwei verschiedenen Konformationen vor (Abbildung 3.36). In vier Ketten (A, C, D, F) war das Substrat ähnlich fest wie in der PpAOC1-Struktur (siehe 3.4.6) gebunden, während in den Ketten B und E der Ligand nur schwach gebunden im Enzym vorlag. Auch in der PpAOC2Struktur liegt die Allenoxidgruppe des Substratanalogons nicht wie erwartet in cis-Geometrie, sondern in trans-Geometrie vor.

Zum Vergleich der verschiedenen Bindemodi sind in Abbildung 3.37 die Liganden der Ketten A - F mit den genannten Aminosäureresten als Stabmodelle und den Wassermolekülen in zwei verschiedenen Orientierungen dargestellt, wobei Blick seitlich auf das Substrat gerichtet ist. Die jeweilige C15-Doppelbindung des Liganden ist zum Glu-18 und die Carboxylgruppe des Liganden ist zum Arg-22 orientiert. Die Ausnahmen bildeten der Ligand in Kette A, wo das Arg-22 vom Eingang der Bindetasche weggedreht ist und der Ligand in Kette F, dessen C15-Doppelbindung vom Glu-18 des Enzyms weg orientiert ist (Abbildung 3.37 F). Der Abstand zwischen der Carboxylgruppe des Liganden und dem Arg-22 beträgt zwischen 2,2 (Kette D) und 9,5 ̊ (Kette A) (Abbildung 3.37). 


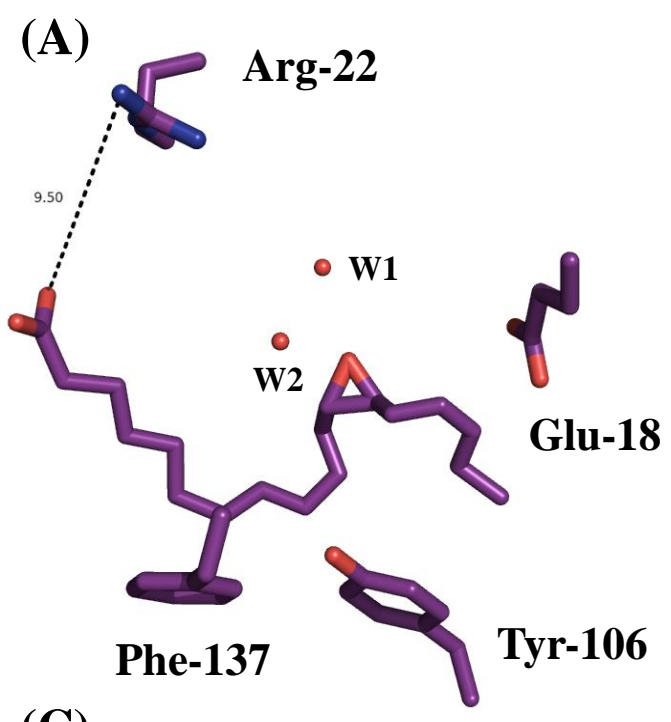

(C)
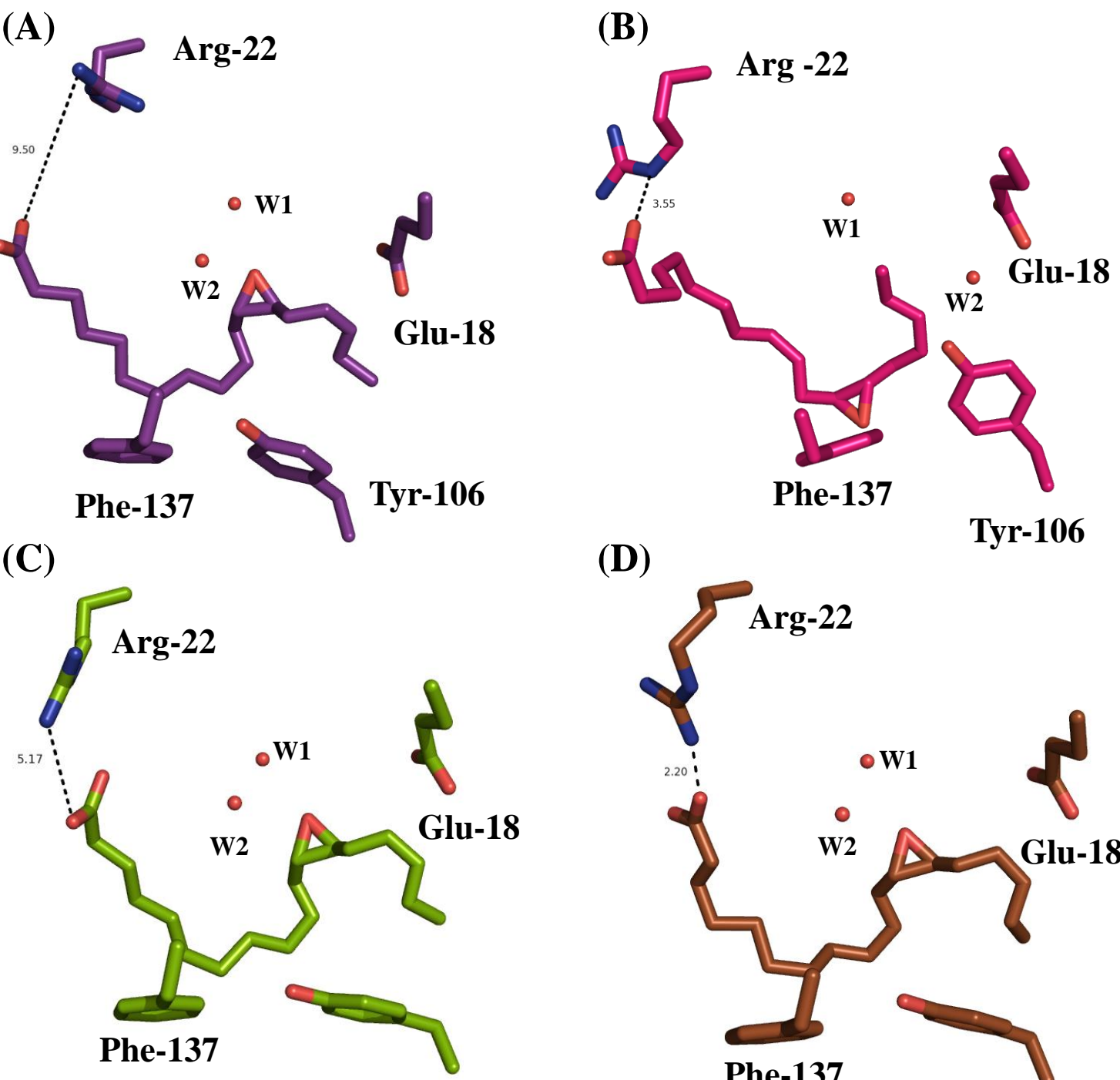

(D)

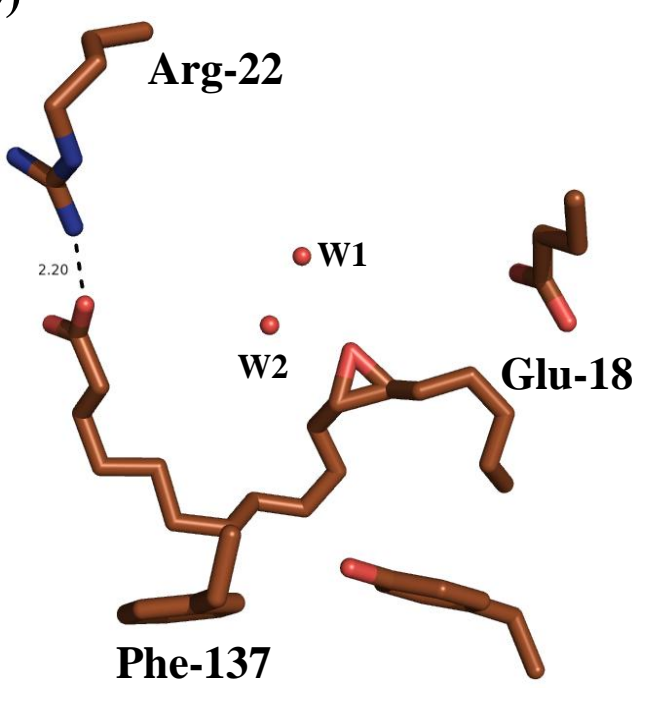

(E)

Tyr-106

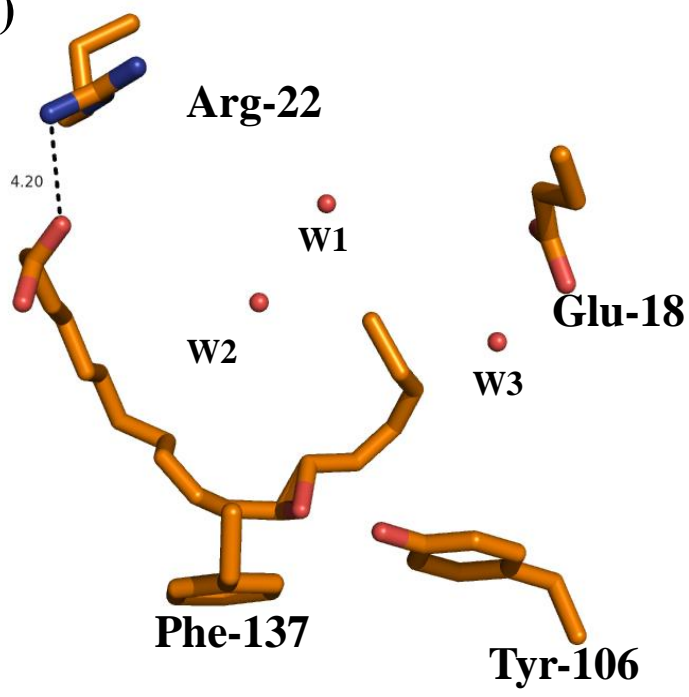

(F)

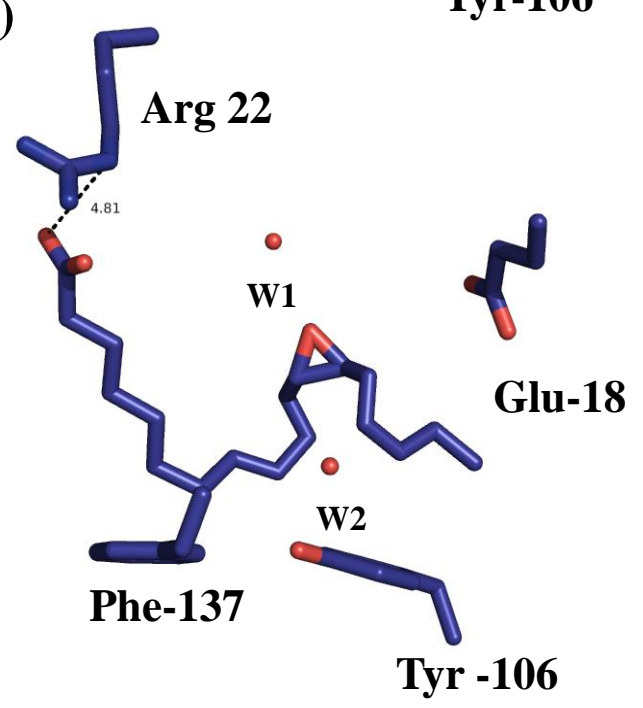

Abbildung 3.37: PpAOC2 Kette A - F mit Ligand 12,13-EOD ${ }^{\triangle 9 \mathrm{Z} \triangle 15 Z}$. Ligand 12,13-EOD ${ }^{\triangle 9 Z \triangle 15 Z}$ und die Aminosäurereste als Stabmodelle seitlich betrachtet. (A) Kette A (lila) (B) Kette B (magenta); (C) Kette C (grün); (D Kette D (braun); (E) Kette E (orange); (E) Kette F (blau). Wassermoleküle (rot); Abstand zwischen der Carboxylgruppe des Liganden und dem Arg-22 in Å (gestrichelte Linie). 
In den Ketten $\mathrm{B}$ und $\mathrm{E}$ weist der Ligand nur einen geringen Besetzungsgrad auf. Die jeweiligen C15-Doppelbindungen der Liganden sind zum Tyr-106 orientiert und der Abstand zum Glu-18 war im Vergleich zum festgebundenen Ligand größer. Die C9- und C15Doppelbindung, und die Allenoxidgruppe liegen im Vergleich $\mathrm{zu}$ den festgebundenen Liganden um etwa $180^{\circ}$ gedreht in der Substratbindetasche. Wie bei den festgebundenen Liganden ist die Carboxylgruppe der schwachgebundenen Liganden zum Arg-22 orientiert. er Abstand zwischen Carboxylgruppe des Liganden und dem Arg-22 beträgt jeweils 3,55 (Kette B) und 4,20 ̊ (Kette E) (Abbildung 3.37), was für die Ausbildung einer Salzbrücke zur Fixierung des Substrates am Enzym sprechen könnte. Aufgrund der Substratfixierung durch das Arg-22 und der Tatsache das die Liganden nicht so tief in die Substratbindetasche hinein reichten, war der Bereich zwischen dem $\mathrm{C} 1$ - und dem C8-Atom der schwachgebundenen Liganden stärker zusammengestaucht, als bei den festgebundenen Liganden, die wie in der PpAOC1-Struktur, gestreckt vorliegen (Abbildung 3.37).

Interessanterweise befinden sich in Kette E mit dem schwach gebunden Liganden drei Wassermoleküle im aktiven Zentrum, von denen das erste (W1) und das zweite (W2) wie in Kette A, C und D angeordnet sind. Das dritte Wassermolekül (W3) hingegen ist ähnlich wie das zweite Wasser (W2) in Kette B positioniert (Abbildung 3.37). Analog zu PpAOC1Struktur wurde ein Ligplot (Wallace et al., 1995) erstellt und die Aminosäurereste bestimmt, welche den Liganden und die Wassermoleküle im aktiven Zentrum über polare Kontakte koordinieren (Abbildung 3.38).

(A)

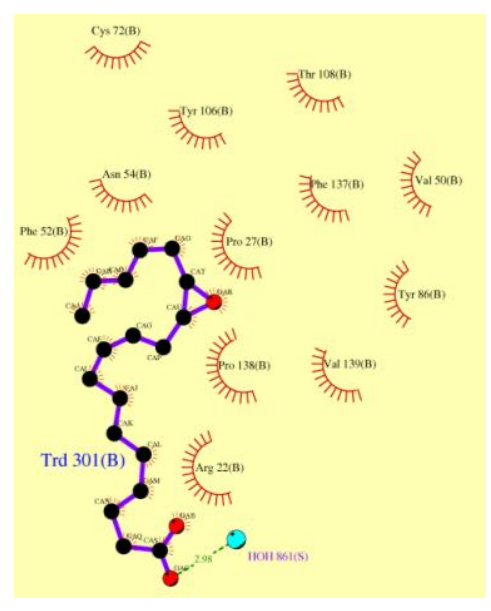

(B)

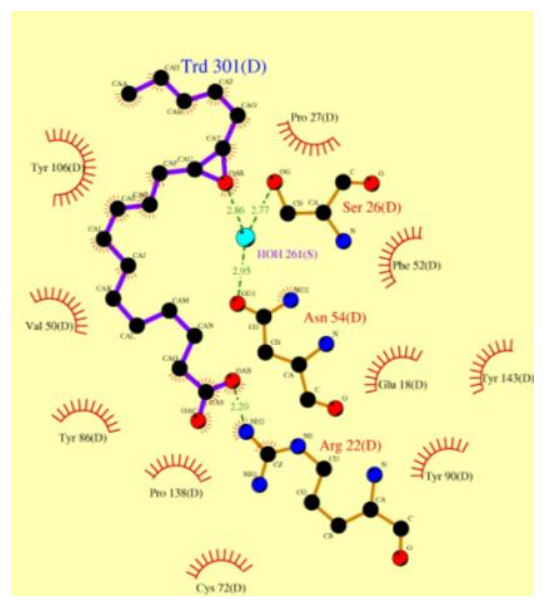

(C)

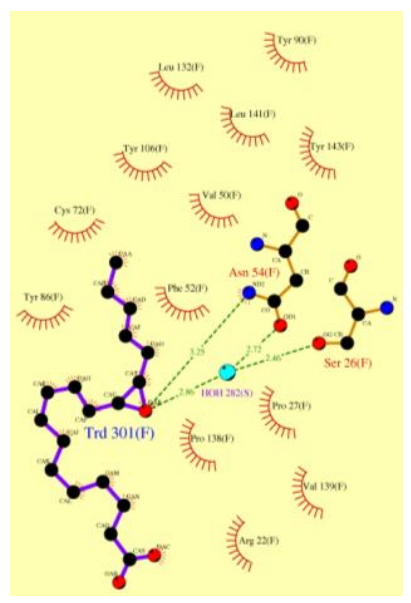

Abbildung 3.38: Darstellung polarer Kontakte im aktiven Zentrum von PpAOC2 mit gebundenem Ligand 12,13-EOD ${ }^{\Delta 9 Z \Delta 15 Z}$. (erzeugt mit Ligplot) Gezeigt sind Ligplot-Skizzen für drei PpAOC2-Ketten. Folgende Bindungen und Kontakte sind dargestellt: Ligandbindung (lila); Andere Bindung (braun); Wasserstoffbrückenbindung und ihre Länge (grün, gestrichelt); Aminosäurereste, involviert in hydrophobe 
Kontakte (rot, gestrichelt); Atome, involviert in polare Kontakte (schwarze Kreise mit rotgestricheltem Rand). (A) Kette B; (B) Kette D; (C) Kette F.

In Abbildung 3.38 sind die polaren Kontakte des Liganden 12,13-EOT ${ }^{\triangle 9 Z \Delta 15 Z}$ in der PpAOC2Struktur beispielhaft für die Ketten B, D und F dargestellt. Die Ligplot-Skizzen für die restlichen Ketten sind im Anhang aufgeführt (Abbildung 8.2).

In Abbildung 3.38 A ist die Ligplot-Skizze für den schwachen Bindemodus des Liganden in PpAOC2 beispielhaft anhand Kette B dargestellt. In Kette B sind 12 Aminosäurereste des Enzyms an molekularen Interaktionen mit dem Ligand beteiligt. Dabei handelte es sich entsprechend der PpAOC1-Struktur um die konservierten Reste Pro-27, Val-50, Phe-52, Cys72, Tyr-86, Tyr-90 und Tyr-106. Desweiteren interagiert das Arg-22 wahrscheinlich mit der Carboxylgruppe des Fettsäure-Liganden. Zusätzlich scheinen die Aminosäurereste Thr-108 und Pro-138, welche unter den AOC-Sequenzen konserviert sind, sowie Phe-137 und Val-139 an Interaktionen beteiligt zu sein. Hingegen interagiert das konservierte Glu-18 nicht mit dem Liganden. Interessanterweise wurden im schwachen Bindemodus von PpAOC2 keine Wasserstoffbrückenbindungen mit Wassermolekülen ausgebildet und das Asn-54, welches in den Ketten mit fest gebundenem Liganden eines der Wassermoleküle koordiniert (Abbildung 3.33) interagiert in Kette B und Kette E mit dem Liganden. Außerdem ist das Phe-137 an der Bindung der schwachgebunden Liganden beteiligt. Dieser Phenylalaninrest weist in der PpAOC1- und PpAOC2-Struktur konformelle Unterschiede zwischen den einzelnen Molekülketten auf. Phe-137 interagiert jedoch nicht mit den fest gebundenen Liganden in PpAOC1 und PpAOC2. In Kette E, mit ebenfalls schwach gebundenen Liganden, ist der Zustand der Ligandenbindung ähnlich wie in Kette B (nicht gezeigt). Mit der Ausnahme, dass die Aminosäurereste Pro-138 und Thr-108 nicht mit dem Liganden interagieren. Dafür scheint das Ile-29 an der kovalenten Bindung des Liganden beteiligt zu sein.

In Kette D mit festgebundenem Liganden (Abbildung 3.38 B) sind, zusätzlich zu den in PpAOC1 Kette A beobachten Interaktionspartnern, die konservierten Reste Pro-138 und Tyr143 an molekularen Interaktionen beteiligt. Das Arg-22 bildet mit seiner positiv geladenen Guanidingruppe eine Salzbrückenbindung zur negativ geladenen Carboxylgruppe des Liganden aus. Im Gegensatz zur PpAOC1-Struktur ist ein PpAOC2 nur ein Wassermolekül an der Koordination des festgebundenen Liganden beteiligt. Dieses Wasser wird in allen vier Ketten (A, C, D und F) von den Aminosäureresten Ser-26 und Asn-54 koordiniert. In Kette A und Kette C wird jeweils keine Salzbrücke vom Arg-22 zur Carboxylgruppe des Liganden gebildet (nicht gezeigt). Interessanterweise ist in Kette A keine Interaktion des Liganden mit dem Aminosäurerest Tyr-86 zu beobachten (nicht gezeigt). Zudem interagiert in Kette C das 
konservierte Val-50 nicht mit dem Liganden, dafür bildet Asn-20 eine Interaktion zum Liganden.

In Kette F (Abbildung 3.38 C) spielen die gleichen Aminosäurereste wie in Kette D eine Rolle bei molekularen Interaktionen mit dem Ligand. Auffällig war jedoch, dass es keine Interaktion des Liganden mit dem konservierten Glu-18 gibt, da die C15-Doppelbindung eine andere Orientierung hatte als in den anderen Ketten (Abbildung 3.37). Zusätzlich zu den für Kette D beschriebenen Aminosäureresten werden polare Kontakte des Liganden mit dem konservierten Aminosäureresten Leu-132, Val-139 und Leu-141 gebildet. Das Wassermolekül ist wie in Kette A, C, D von Ser-26 und Asn-54 koordiniert. In Tabelle 3.1 sind die molekularen Interaktionen der jeweiligen Aminosäureresten von PpAOC1 und PpAOC2 und dem Liganden aufgeführt.

Zusammenfassend lässt sich sagen, dass bei festgebundenem Liganden eher Aminosäurereste vom hinteren Teil des aktiven Zentrums mit dem Liganden interagieren. Hingegen interagieren im schwachen Bindemodus eher Aminosäurereste des vorderen Bereiches des aktiven Zentrums mit dem Liganden.

In Abbildung 3.39 ist ein Vergleich der einzelnen Ketten mit gebundenem Liganden in der gezeigt indem sie grafisch überlagert dargestellt sind. Die Ketten B - F wurden dazu über die Kette A gelagert. Die Lage der Carboxylgruppe der jeweiligen Liganden in Kette A - F hatte die gleiche Orientierung in Richtung des Arg-22, jedoch ist das Arg-22 zwischen den einzelnen Ketten flexibel angeordnet. Außer in Kette A und Kette C, in denen das Arg-22 mit jeweils 9,5 $\AA$ und 5,17 $\AA$ vom Substrat wegedreht ist, reicht der Abstand zwischen Carboxylgruppe der Liganden und Arg-22 zur Ausbildung einer Salzbrückenbindung über die das Substrat am Enzym fixiert werden könnte. 


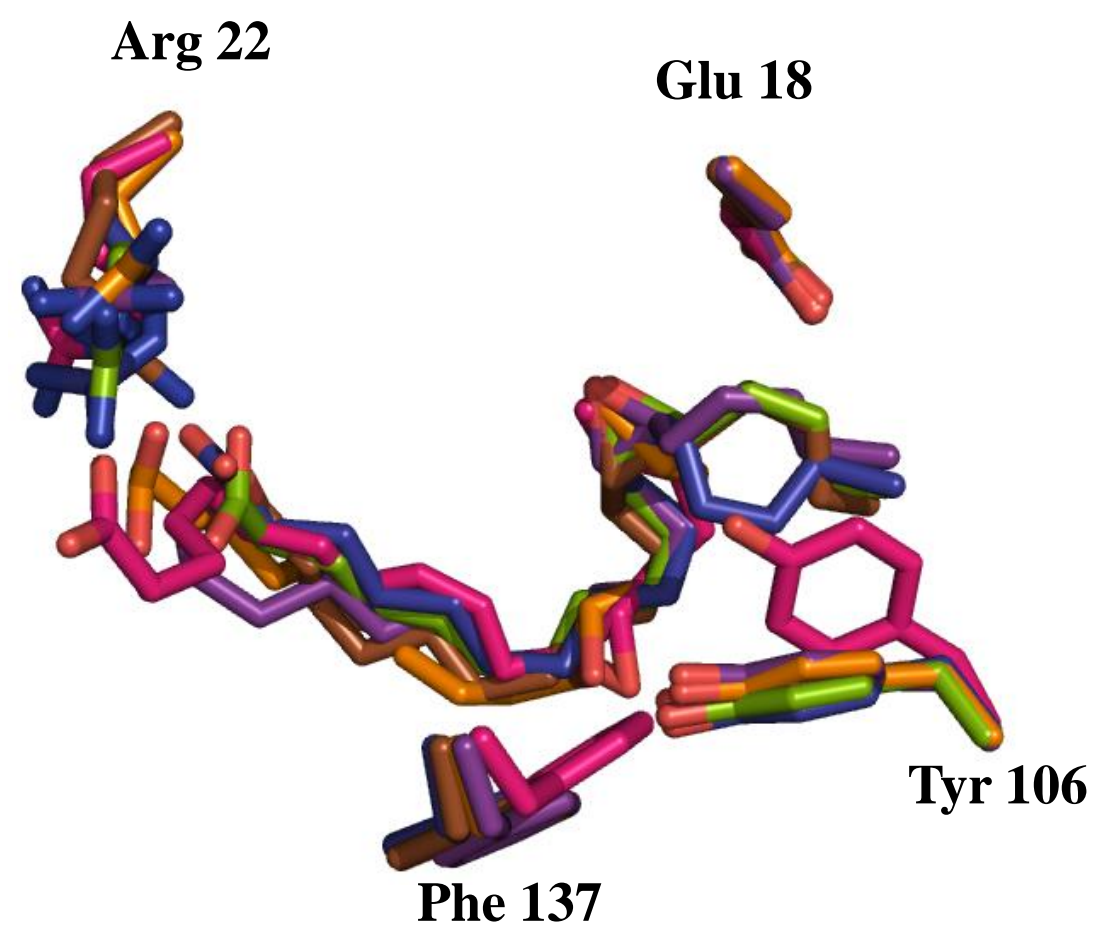

Abbildung 3.39: Grafische Überlagerung von PpAOC2 Kette A - F mit Ligand 12,13-EOD ${ }^{\triangle 9 Z \Delta 15 Z}$. Ligand 12,13-EOD ${ }^{\triangle 9 Z \triangle 15 Z}$ und die Aminosäurereste gezeigt als Stabmodelle. Kette A (lila); Kette B (magenta); Kette C (grün); Kette D (braun); Kette E (orange) Kette F (blau).

Das Glu-18 hat in allen Ketten dieselbe Konformation und war in den Ketten A, C und D in Richtung der C15-Doppelbindungen des jeweiligen Liganden orientiert. Die größten konformellen Unterschiede sind zwischen den Aminosäureresten Tyr-106 sowie Phe-137 der jeweiligen Kette zu erkennen. Während das Tyr-106 in den Ketten A, C-F die gleiche Konformation hatte, ist der aromatische Rest des Tyr-106 in Kette B um ca. $45^{\circ}$ in Richtung des Liganden orientiert. Das Phe-137 hatte in den Ketten A, C und E die gleiche Konformation. In Kette B war das Phe-137 leicht in Richtung Tyr-106 verschoben, während es in Kette D und F leicht in die entgegengesetzte Richtung verschoben ist.

In Abbildung 3.40 sind die Ketten mit den verschiedenen Bindemodi graphisch überlagert dargestellt, wobei in Abbildung 3.40 A die Ketten mit festgebundenen Liganden und in Abbildung 3.40 B die Ketten mit schwach gebundenen Liganden gezeigt sind. Die Abbildung 3.40 C zeigt eine grafische Überlagerung der Ketten, zwischen denen konformelle Unterschiede im Liganden und / oder den Aminosäureresten zu erkennen sind (Kette A, B, E und F). Da die Ketten A, C und D den gleichen Bindemodus und nahezu die gleiche Konformation der Aminosäurereste aufwiesen, ist dieser Bindemodus in Abbildung 3.40 C beispielhaft durch den Zustand in Kette A gezeigt. 
(A)

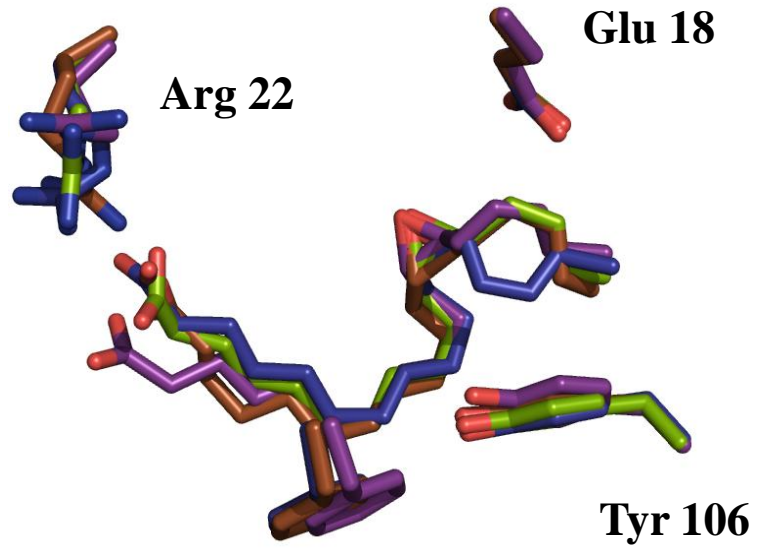

Phe 137
(B)

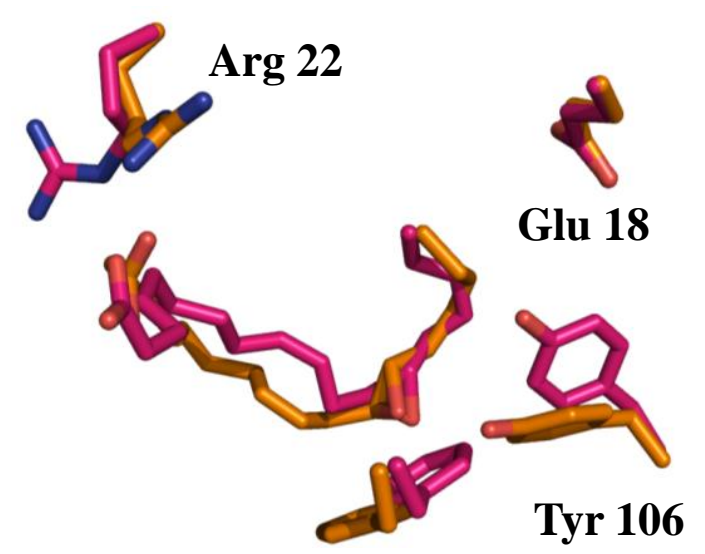

Phe 137

(C)

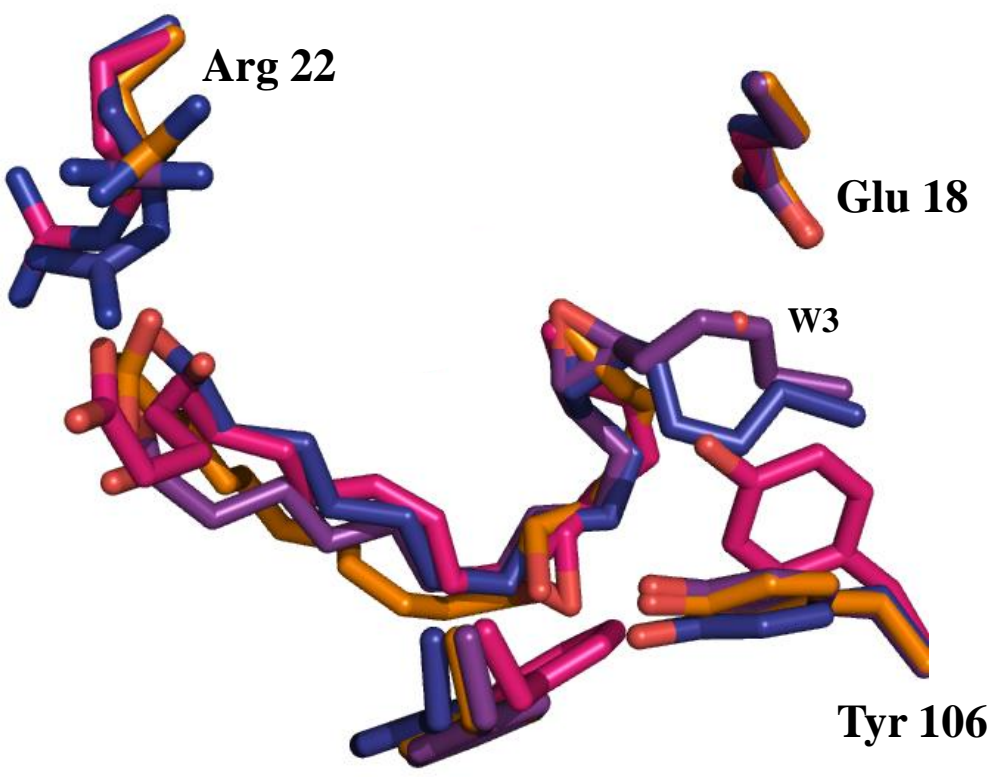

Phe 137

Abbildung 3.40: Graphische Überlagerung verschiedener PpAOC2-Ketten A - F mit Ligand 12,13EOD $^{\triangle 9 Z \Delta 15 Z}$. Anordnung des gebundenen Liganden $12,13-\mathrm{EOD}^{\triangle 9 Z \Delta 15 Z}$ und der Aminosäurereste gezeigt als Stabmodelle. Kette A (lila); Kette B (magenta); Kette C (grün); Kette D (braun); Kette E (orange) Kette F (blau). (A) Ketten mit fest gebundenem Liganden (B) Ketten mit schwach gebundenem Liganden (C) Ketten, mit Unterschieden zwischen den Aminosäureresten.

Es ist zu erkennen, dass die festgebunden Liganden in Kette A, C, D und F nahezu die gleiche Konformation haben. Den einzigen Unterschied bildet der Ligand in Kette F, welcher eine andere Konformation der C15-Doppelbindung hat. Im Gegensatz zu allen anderen Ketten, ist die C15-Doppelbindung des Liganden in Kette F vom Glu-18 weg und zum Tyr-106 orientiert (Abbildung 3.40 A). Ebenso sind die schwachgebunden Liganden in Kette B und E nahezu gleich im aktiven Zentrum angeordnet. Zwischen Kette B und C bestehen die einzigen 
Unterschiede in der Anordnung der Aminosäurereste zwischen dem Arg-22, Phe-137 und Tyr106. Interessanterweise interagieren diese Reste in beiden Ketten mit dem Liganden (Abbildung 3.38). In Abbildung 3.40 C sind die oben beschriebenen Unterschiede zwischen den Aminosäureresten und den Liganden der PpAOC2-Ketten zusammengefasst dargestellt.

\subsubsection{Oberflächenladung von PpAOC2 mit Ligand}

Wie für die PpAOC1-Struktur (3.4.6.1), wurde das elektrostatische Oberflächenpotential der PpAOC2-Struktur mit dem Programm Pymol errechnet. (Abbildung 3.41). Entsprechend der Darstellung für PpAOC1 bilden die N-terminale Enden der PpAOC2-Monomere einen positiv geladenen Bereich des Moleküls (Abbildung 3.35 A und B).

(A)

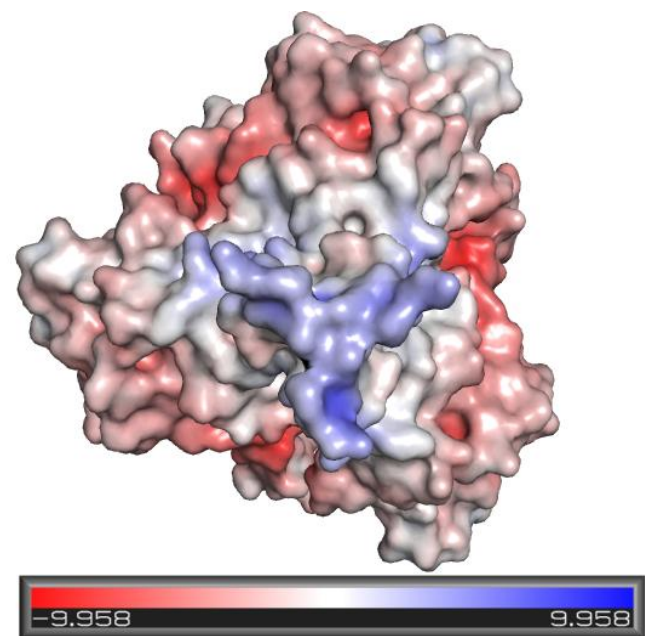

(B)

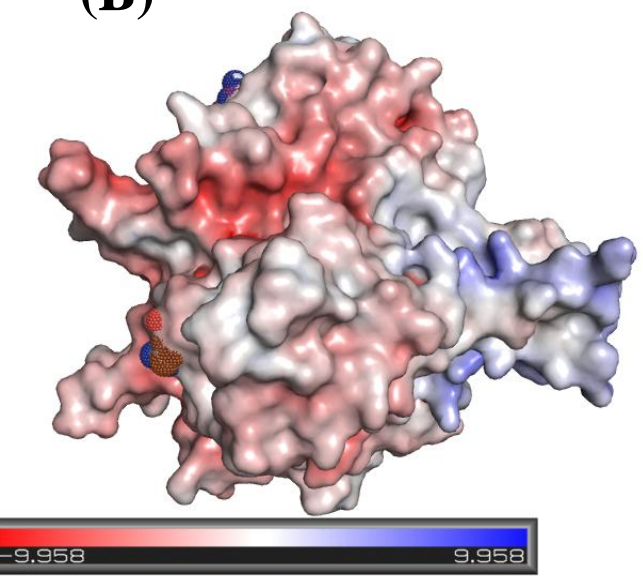

(C)

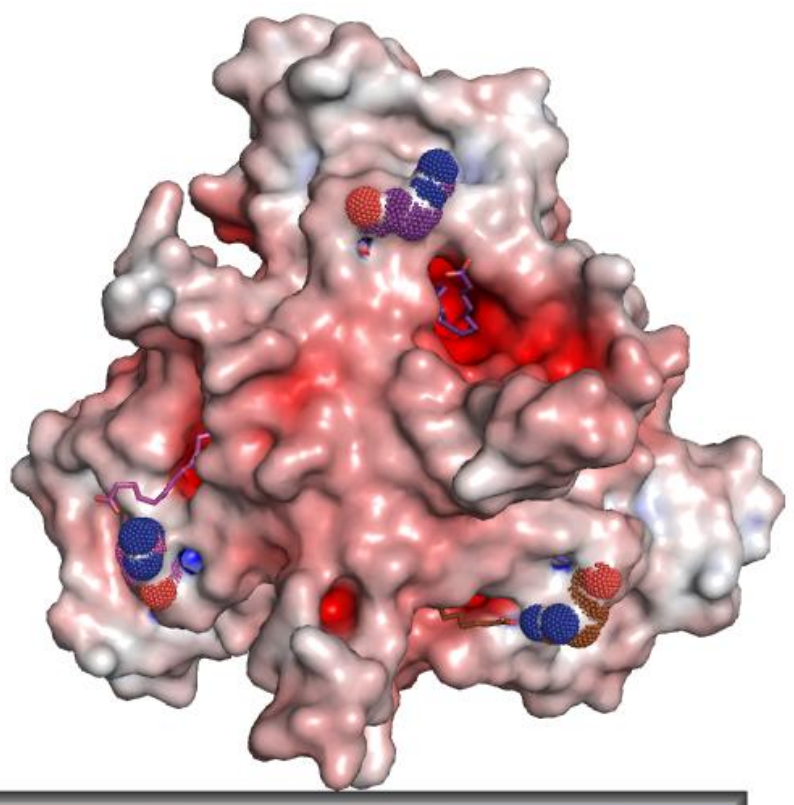

9.958

Abbildung 3.41: Oberflächendarstellung eines PpAOC2-Trimers. (erzeugt mit Pymol) Das elektrostatische Oberflächenpotential von PpAOC2 Kette A, B und D zeigt positive (blau), neutrale (weiß) und negative (rot) Bereiche des Moleküls. (A) Blick auf den N-terminalen Bereich (B) im Vgl. zu (A) um 90 nach links gedreht; 
Blick auf die Trimerachse (C) im Vgl zu (A) um $180^{\circ}$ nach links gedreht; Blick auf den C-terminalen Bereich des Moleküls und die Substratbindetaschen der einzelnen Ketten mit gebundenen Liganden, Kette A (lila), Kette B (magenta), Kette D (braun). Das positiv geladene Arg-22 ist zusätzlich gepunktet dargestellt.

Außerdem wurden in Abbildung 3.41 die Liganden in den Substratbindetaschen als Stabmodelle dargestellt. Anhand des elektronischen Oberflächenpotentials ist zu erkennen, dass die Substratbindetasche von PpAOC2 aus negativ geladenen Aminosäureresten besteht. Die Carboxylgruppe der Liganden reicht weit aus dem Enzym heraus und ist in Richtung des positiv geladenen Arg-22 orientiert. Aufgrund der negativ geladenen Aminosäurereste im aktiven Zentrum ist auch in $P p A O C 2$ eine inverse Substratbindung, mit der Carboxylgruppe nach vorne in das Enzym, ausgeschlossen.

Die Substratbindetasche von PpAOC1 uns PpAOC2 wird von negativ geladenen Aminosäureresten gebildet.

3.4.7.2 Vergleich der PpAOC2-Strukturmodelle mit und ohne Ligand 12,13-EOD ${ }^{\Delta 9 Z \Delta 15 Z}$ Es sind keine strukturellen Unterschiede zwischen der PpAOC2-Struktur ohne Ligand (ApoEnzym) und mit dem Ligand 12,13-EOD ${ }^{\triangle 9 Z \Delta 15 Z}$ besetzten PpAOC2-Struktur zu erkennen. Zum Vergleich der molekularen Unterschiede ist in Abbildung 3.42 beispielhaft die grafische Überlagerung der PpAOC2-Monomere von Kette A und B mit und ohne Ligand im aktiven Zentrum gezeigt.

(A)

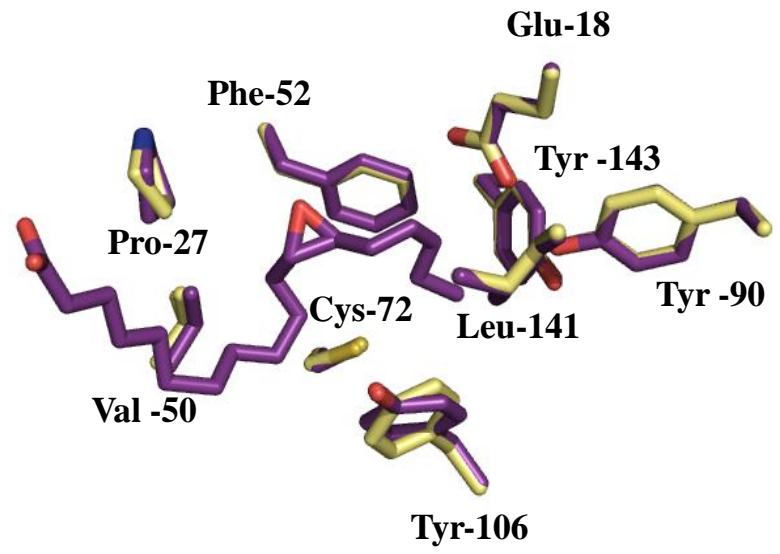

(B)

Arg-22

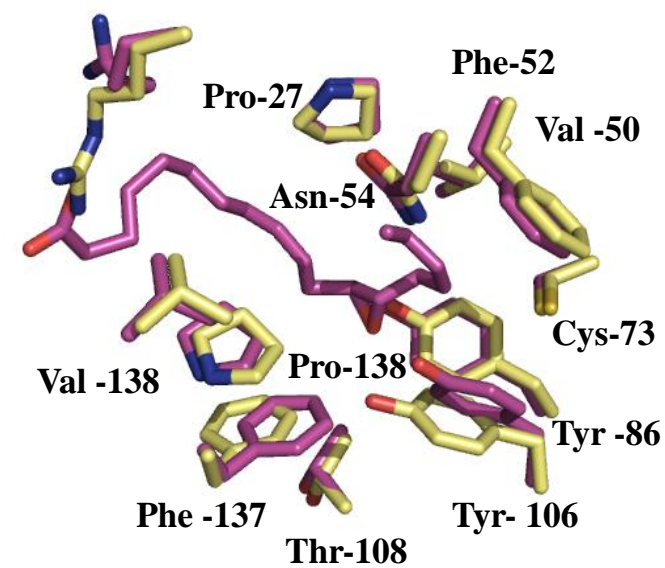

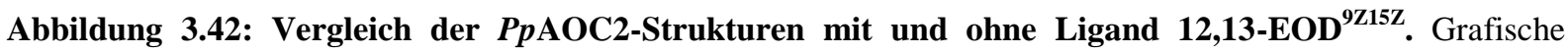
Überlagerung verschiedener $P p A O C 2$-Aminosäureste, von Ketten mit und ohne Ligand 12,13-EOD ${ }^{\triangle 9 Z \Delta 15 Z}$ als Stabmodelle. Es sind jeweils Aminosäurereste dargestellt, die an Ligandinteraktionen beteiligt sind (A) Kette A mit Ligand (lila) und Kette A ohne Ligand (gelb) (B) Kette B mit Ligand (magenta) und Kette B ohne Ligand (gelb). 
Wie in Abbildung $3.42 \mathrm{zu}$ erkennen ist, weisen die Aminosäurereste in Kette A, welche mit dem Liganden interagieren wenig konformelle Unterschiede auf. Eine leichte Veränderung ist am Tyr-106 zu erkennen, welches mit gebundenem Ligand leicht von diesem wegorientiert ist. In Kette B mit dem schwach gebundenen Liganden sind größere konformelle Unterschiede zwischen den Aminosäureresten Arg-22, Tyr-106 und Phe-137 zu beobachten.

\subsubsection{Vergleich der Proteinstrukturen von PpAOC1 und PpAOC2}

Zur abschließenden Betrachtung der PpAOC1- und PpAOC2-Strukturen ist in Abbildung

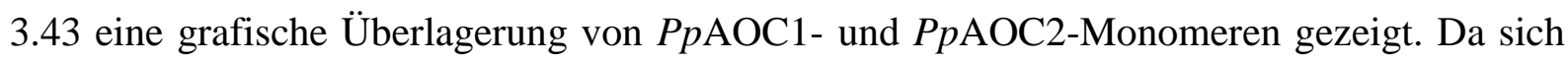
die einzelnen Ketten von PpAOC1 kaum unterscheiden wird der Zustand in PpAOC1 beispielhaft durch Kette A gezeigt. Für die PpAOC2-Struktur sind beispielhaft Kette B (magenta) und D (braun) gezeigt.

(A)

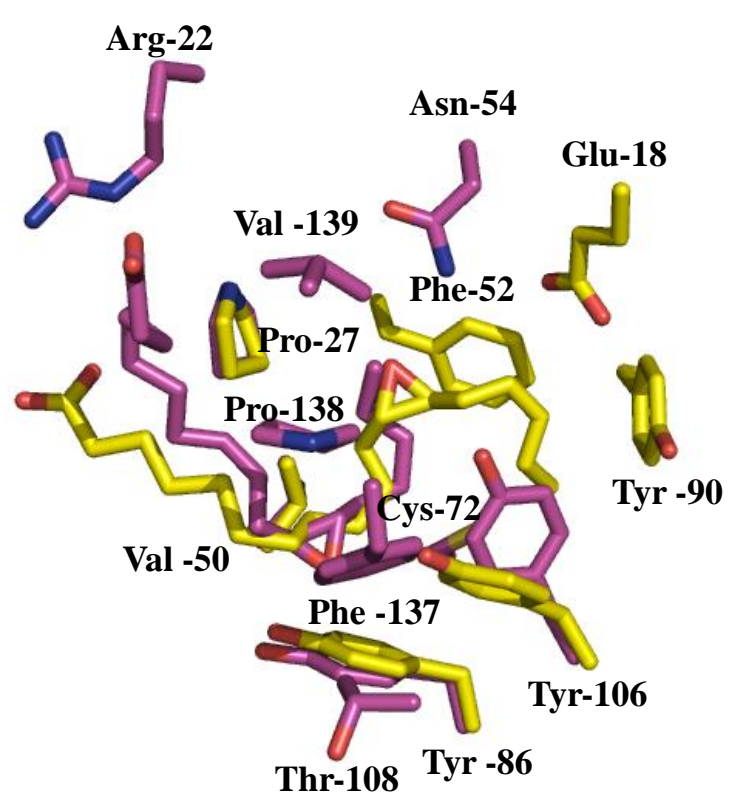

(B)

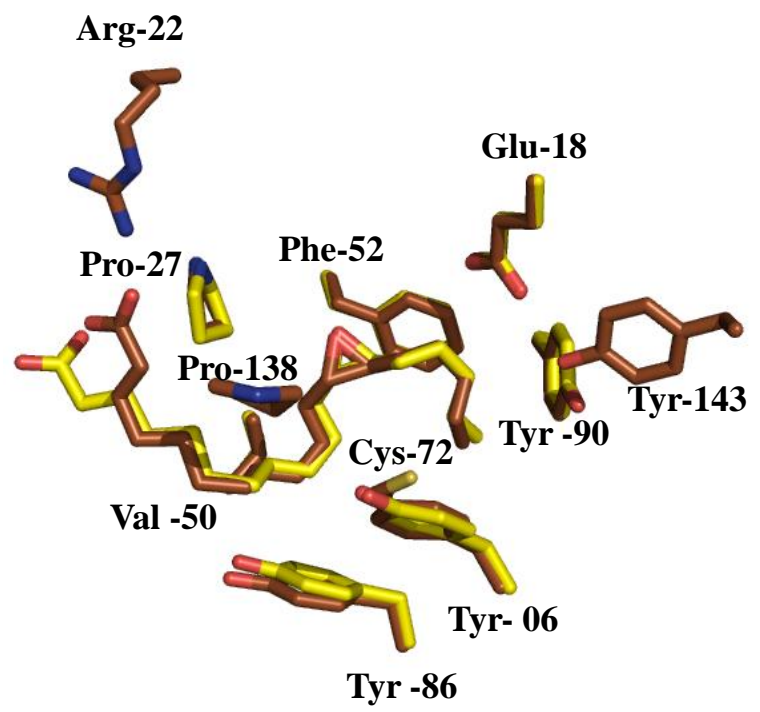

Abbildung 3.43: Vergleich verschiedener Aminosäureresten des aktiven Zentrums von PpAOC1 und $P p A O C 2$ mit gebundenem Liganden 12,13-EOD ${ }^{\Delta \mathrm{ZZ} \Delta 15 Z}$. Grafische Überlagerung von Aminosäureresten von PpAOC1- und PpAOC2-Ketten mit Ligand 12,13-EOD ${ }^{\triangle 9 Z \Delta 15 Z}$ als Stabmodelle. Es sind jeweils Aminosäurereste dargestellt, die an Ligandeninteraktionen beteiligt sind; Nummerierung basiert auf PpAOC2Aminosäuresequenz. (A) PpAOC1-Kette A (gelb) und PpAOC2-Kette B (magenta) (B) PpAOC1-Kette A (gelb) und $P p$ AOC2-Kette D (braun).

In Abbildung 3.43 $\mathrm{A}$ ist die grafische Überlagerung aller in Ligandenbindung involvierten Aminosäurereste aus PpAOC1-Kette A und PpAOC2-Kette B dargestellt. Es ist deutlich zu erkennen, dass in PpAOC2-Kette B im Vergleich zu PpAOC1-Kette A mehr Aminosäurereste des aktiven Zentrums mit dem Liganden $12,13-\mathrm{EOD}^{\triangle 9 Z \Delta 15 Z}$ interagierten. Vor allem im vorderen Bereich der Substratbindetasche wurde zusätzliche Reste wie Arg-22, Thr-108, Pro- 
138 und Val-139 beobachtet. Im Gegensatz dazu, interagierten in PpAOC1-Kette A die konservierten Aminosäurereste (Glu-18, Phe-52, Tyr-90) im hinteren Bereich der Substratbindetasche mit dem Liganden. Diese Reste interagieren jedoch nicht mit dem schwach gebundenen Ligand in PpAOC2-Kette B. Konformelle Unterschiede gibt es zwischen dem Aminosäurerest an Position PpAOC2 Tyr-107.

Die grafische Überlagerung von PpAOC1-Kette A und PpAOC2-Kette D ist in Abbildung 3.43 B gezeigt. In beiden Ketten ist der Ligand $12,13-\mathrm{EOD}^{\Delta 9 Z \Delta 15 Z}$ fest im aktiven Zentrum gebunden und somit sind auch keine großen konformellen Unterschiede zwischen den Aminosäureresten, die das aktive Zentrum bilden, zu erkennen. In PpAOC2-Kette D interagieren zusätzlich Arg-22, Pro-138 und Tyr-143 mit dem Liganden. In Tabelle 3.1 sind alle Aminosäurereste, die an Ligandeninteraktionen beteiligt sind zusammengefasst.

Tabelle 3.1: Aminosäurereste des aktiven Zentrums von PpAOC1 und PpAOC2. Es sind alle Aminosäurereste aufgeführt, die laut Ligplot-Analyse an polaren Interaktionen mit dem Liganden beteiligt sind. Aminosäurereste, die in mehr als fünf Ketten von PpAOC1 bzw. PpAOC2 mit dem Liganden interagieren (fett). Interagieren die fett gedruckten Aminosäurereste in einer Kette nicht mit dem Liganden, sind sie (eingeklammert) dargestellt.

\begin{tabular}{|c|c|c|}
\hline Monomer & $\begin{array}{l}\text { Aminosäurereste mit kovalenter } \\
\text { Ligandenbindung }\end{array}$ & $\begin{array}{l}\text { Aminosäurereste mit } \\
\text { Wasserkoordinierung }\end{array}$ \\
\hline $\begin{array}{l}\text { PpAOC1 } \\
\text { Kette A }\end{array}$ & $\begin{array}{l}\text { Glu-18, Val-51, Phe-53, Cys-73, Tyr-87, Tyr-91, } \\
\text { Tyr-107, (Pro-27, Tyr-143), }\end{array}$ & $\begin{array}{l}\text { W1: Ser-26, Asn-55 } \\
\text { W2: Asn-20, Pro-138 } \\
\text { W3: Pro-27 }\end{array}$ \\
\hline $\begin{array}{l}\text { PpAOC1 } \\
\text { Kette B }\end{array}$ & $\begin{array}{l}\text { Glu-18, Pro-27, Val-51, Phe-53, Cys-73, Tyr-87, } \\
\text { Tyr-91, Tyr-107, Leu-142, (Tyr-143), }\end{array}$ & $\begin{array}{l}\text { W 1: Ser-26, Asn-55 } \\
\text { W2: Asn-20, Pro-138 } \\
\text { W3: Phe-29 }\end{array}$ \\
\hline $\begin{array}{l}P p \mathrm{AOC} 2 \\
\text { Kette A }\end{array}$ & $\begin{array}{l}\text { Glu-18, Pro-27, Val-50, Phe-52,Cys-72, Tyr-90, } \\
\text { Tyr-106, Leu-141, Tyr-143, (Tyr-86) }\end{array}$ & W1: Ser-26, Asn-54 \\
\hline $\begin{array}{l}P p \mathrm{AOC} 2 \\
\text { Kette B }\end{array}$ & $\begin{array}{l}\text { Pro-27, Arg-22, Val-50, Phe-52, Asn-54, Cys-72, } \\
\text { Tyr-86, Tyr-90, Tyr-106, Phe-137, Pro-138, Val- } \\
\text { 19, Tyr-143 (Glu-18) }\end{array}$ & - \\
\hline $\begin{array}{l}P p \mathrm{AOC} 2 \\
\text { Kette C }\end{array}$ & $\begin{array}{l}\text { Glu-18, Asn-20, Pro-27, Phe-52,Cys-72, Tyr-86, } \\
\text { Tyr-90, Tyr-106, Pro-138, Tyr-143, (Val-50) }\end{array}$ & W1: Ser-26, Asn-54 \\
\hline $\begin{array}{l}P p A O C 2 \\
\text { Kette D }\end{array}$ & $\begin{array}{l}\text { Glu-18, Pro-27, Arg-22; Val-50, Phe-52, Cys-72, } \\
\text { Tyr-86, Tyr-90, Tyr-106, Pro-138, Tyr-143 }\end{array}$ & W1: Ser-26, Asn-54 \\
\hline $\begin{array}{l}P p \mathrm{AOC} 2 \\
\text { Kette E }\end{array}$ & $\begin{array}{l}\text { Pro-27, Arg-22, Ile-29, Val-50, Phe-52, Asn-54, } \\
\text { Cys-72, Tyr-86, Tyr-90, Tyr-106, Phe-137, Val- } \\
\text { 139, (Glu-18, Tyr-143) }\end{array}$ & - \\
\hline PpAOC2 & Arg-22, Pro-27, Val-50, Phe-52, Cys-72, Tyr-86, & W1: Ser-26, Asn-54 \\
\hline
\end{tabular}


Kette F Tyr-90, Tyr-106, Leu-132, Pro-138, Val-139,

Leu-141, Tyr-143, (Glu-18)

\subsubsection{Ortsgerichtete Mutagenese von PpAOC1 und PpAOC2}

Mithilfe der strukturellen Daten wurden Aminosäurereste, welche eventuell für die AOCReaktion verantwortlich sind gefunden. Einige dieser Aminosäurereste wurden durch ortsgerichtete Mutagenese ausgetauscht. Mit diesen Punktmutationen soll der Einfluss dieser Reste auf Bindung und Umwandlung des Allenoxid-Substrates untersucht werden.

Folgende Aminosäurereste wurden mittels Mutagenese-PCR (2.12.4) ausgetauscht.

Glutamat 18 Asparginsäure (E18D)

Glutamat $18 \quad$ Glutamin (E18Q)

Arginin $22 \quad$ Leucin (R22L)

Anschließend wurden pro Mutation drei unterschiedliche Klone für Aktivitätstests ausgewählt und das Substrat 13S-HPOTE durch diese im bereits beschriebenen gekoppelten Enzymtest umgesetzt (3.3). Die Produktspektren der AOC-Varianten wurden im Vergleich zum Wildform-Enzym durch HPLC/MS-Analysen untersucht (Abbildung 3.44).

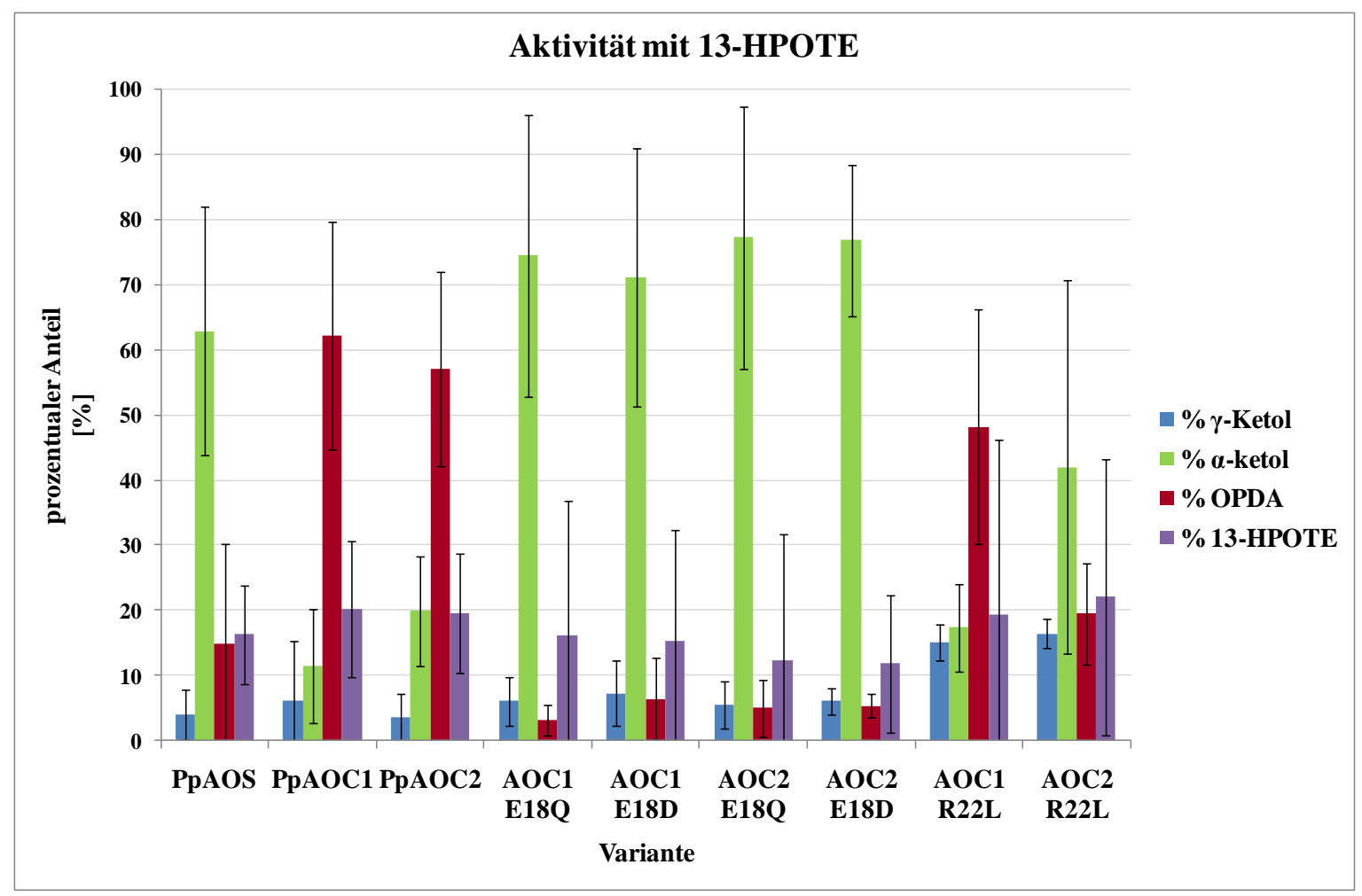

Abbildung 3.44: Reaktionsgemische enzymatischer Umsetzungen von 13S-HPOTE durch verschiedene PpAOC1 und PpAOC2 Varianten im Vergleich zu den Ausgangsenzymen. Produktspektrum der Umsetzung von 13S-HPOTE durch die AOC-Varianten im Vergleich zu den Ausgangsformen als relative Menge der Produkte in Prozent. Gekoppelte Umsetzungen von PpAOS1/PpAOC1 oder PpAOS1/PpAOC2. Prozentualer 
Anteil $\gamma$-Ketol (blau), $\alpha$-Ketol (grün), zyklischem Produkt (rot) und Substrat (violett). Gezeigt wird der Mittelwert aus vier unabhängigen Experimenten mit dazugehöriger Standardabweichung.

Die Abbildung 3.44 zeigt deutlich, dass beide Ausgangsenzyme das Substrat 13S-HPOTE zum zyklischen Produkt OPDA umwandeln. Dagegen wurde im Reaktionsgemisch der PpAOS1-Umsetzung von 13S-HPOTE ein deutlich geringerer OPDA-Anteil nachgewiesen. Darüber hinaus ist der Anteil an $\alpha$-Ketol im Reaktionsgemisch der PpAOS1-Umsetzung im Vergleich zur Umsetzung durch PpAOS1/PpAOC1 und PpAOS1/PpAOC2 deutlich größer.

In den Reaktionsgemischen der Umsetzungen der jeweiligen Glu-18 Variante (E18D/Q) ist dieser relative Anteil an zyklischem Produkt dagegen sehr gering. Jedoch wurde ein sehr großer relativer Anteil von $\alpha$-Ketol nachgewiesen. Damit weisen sowohl die PpAOC1- als auch die PpAOC2-Varianten des Aminosäurerestes Glu-18 keine OPDA-Aktivität auf. Mit Westernblot-Analyse (2.15.7) wurde festgestellt, dass der Verlust der Enzymaktivität in den Glu-18 Varianten nicht auf fehlende Genexpression zurückzuführen war (Abbildung 3.45).

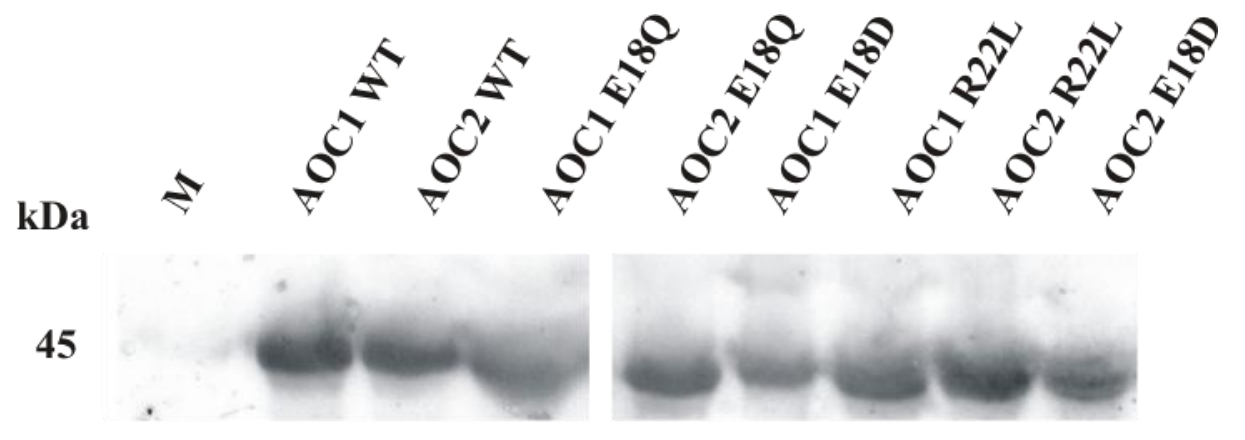

Abbildung 3.45: Western-Blot Analyse der AOC-Varianten und der Ausgangsformen. Gezeigt ist die Western-Blot Analyse verschiedener AOC-Varianten im Vergleich zu Wildform. Primärere Antikörper: antiGST-Antikörper; sekundärer Antikörper: Ziege-anti-GST-Antikörper. Es wurden jeweils $20 \mu \mathrm{g}$ Protein aufgetragen. $\mathrm{M}=$ Molekulargewichtsstandard.

Das Glutamat an Position 18 hat somit in PpAOC1 und PpAOC2 eine wichtige Funktion bei der Umsetzung des Allenoxides zum OPDA.

Die Untersuchung der Produktspektren der Arg-22 Varianten zeigte dagegen unterschiedliche Resultate. Hier zeigte sich ein höherer relativer Anteil an zyklischem Produkt in den Reaktionsgemischen der PpAOS/PpAOC1-R22L-Umsetzung im Vergleich zur PpAOS sowie PpAOS/PpAOC2-R22L-Umsetzung. Es ist anzumerken, dass der relative OPDA-Anteil im Reaktionsgemisch von PpAOS/PpAOC1-R22L-Umsetzung unter dem des Ausgangsenzyms blieb. Außerdem war der relative Anteil an $\alpha$-Ketol in den Reaktionsgemischen der PpAOS1/PpAOC2-R22L-Umsetzung im Vergleich zur PpAOS1-Umsetzung geringer.

Abschließend kann gesagt werden, dass das Arginin an Position 22 eine größere Bedeutung für die Enzymaktivität von $P p A O C 2$ als für die von $P p A O C 1$ hat. 


\section{DISKUSSION}

Im Rahmen der vorliegenden Dissertation wurden Enzyme des Oxylipinstoffwechsels in $P$. patens funktionell und strukturell charakterisiert. Dafür wurden die bifunktionelle PpLOX1 (Senger et al., 2005) und zwei kürzlich beschriebene AOCs (PpAOC1 und PpAOC2; M. Stumpe, Dissertation, 2006) ausgewählt. Mittels verschiedener biochemischer, bioinformatischer und physikalischer Methoden wurden die oben genannten Proteine bezüglich Funktion, Aktivität und Struktur charakterisiert. Zum einen erfolgte eine massenspektrometrische Analyse der Produktgemische nach Umsetzung verschiedener Substrate durch die Enzyme sowie einiger mutierten Varianten. Desweiteren wurden nach erfolgreicher Kristallisation von PpAOC1 und PpAOC2 die Röntgenkristallstrukturen beider Enzyme im Grundzustand sowie im Komplex mit Substratanalogen gelöst. Anhand dieser Strukturen kann eine Diskussion über Teilschritte des Reaktionsmechanismus von AOC erfolgen.

Der folgende Diskussionsteil der Dissertation gliedert sich in drei Teile. Zuerst werden die Arbeiten mit P $p$ LOX1 kurz erörtert, im zweiten Teil werden die Ergebnisse der Experimente zur Umsetzung verschiedener Hydroperoxy-Fettsäuren durch PpAOC1 und PpAOC2 verglichen. Basierend auf diesem Vergleich wird eine mögliche biologische Relevanz der resultierenden Phytoprostan-Produkte in $P$. patens diskutiert. Desweiteren werden im dritten Teil die Röntgenkristallstrukturen von PpAOC1 und PpAOC2 mit den bereits bekannten AOC-Strukturen aus A. thaliana (Hofmann et al., 2006) verglichen. Die Röntgenkristallstrukturen der Komplexe von Substratanalogen mit PpAOC1 und PpAOC2 sollen abschließend als Diskussionsgrundlage zum Reaktionsmechanismus beider Enzyme dienen.

\subsection{Produktprofile verschiedener PpLOX1-Varianten}

Senger et al., (2005) zeigten, dass PpLOX1 mehrfach-ungesättigte Fettsäuren mit einer Kettenlänge von $\mathrm{C}_{18}$ bis $\mathrm{C}_{22}$ oxidiert und somit ein breites Substratspektrum besitzt (3.1.2). Zudem ist es, im Gegensatz zu allen bis jetzt klonierten LOXen, ein bifunktionales Enzym, denn es besitzt zusätzlich zur Dioxygenase- und Peroxygenase- eine Lyase-Aktivität (Senger et al., 2005, Anterola et al., 2009). Ein Ziel dieser Arbeit war die Bestimmung der molekularen und strukturellen Ursachen der beschriebenen Bifunktionalität. 
Zunächst wurde zunächst ein Aminosäure-Sequenzvergleich (Abbildung 3.1) mit verschiedenen LOXen aus Blütenpflanzen inklusive der GmLOX3, deren Röntgenkristallstruktur bereits bekannt ist (Skrzypczak-Jankun et al., 2001) und der CspLOX2 aus dem Cyanobakterium Cyanothece sp. sowie der putativen LOX aus $C$. reinhardtii (CrLOX) erstellt. Neuere phylogenetische Analysen zeigten, dass PpLOX1 zwischen den pflanzlichen 13-LOXen und der putativen CrLOX gruppiert ist (Andreou et al., 2009b).

Um ein putatives Strukturmodell von $P p L O X 1 \mathrm{zu}$ errechnen, wurde eine bereits bekannte LOX-Struktur mit einer Sequenzhomologie von mindestens 40 \% benötigt (Saqi et al., 1998). Eine solche Übereinstimmung von $41 \%$ wurde zwischen PpLOX1 und GmLOX3 identifiziert. Somit konnte mit der bekannten GmLOX3 Struktur (1IK3.pdb) Modell für PpLOX1 errechnet werden (Abbildung 3.2). Da es bis heute noch keine Struktur von einer LOX gibt, die ein Substrat gebundenem hat, ist die Lage innerhalb des aktiven Zentrums noch nicht eindeutig geklärt. Trotzallem, bietet die Struktur von GmLOX3 mit dem gebundenen Produkt einen Vorschlag, wo das Substrat ungefähr binden könnte (Skrzypczak-Jankun et al., 2001). Es muss aber erwähnt werden, dass diese Struktur den Reaktionsmechanismus nicht erklären kann, da das Produkt im Vergleich zur erwarteten Produktorientierung von PpLOX1 invers gebunden ist (Youn et al., 2006).

Anhand dieses PpLOX1-Modells und des Aminosäure-Sequenzvergleiches wurden Aminosäurereste im putativen aktiven Zentrum gefunden, deren Funktionalität mittels Mutagenesestudien und durch Umsetzung verschiedener Fettsäuresubstrate bestimmt wurde. Dabei handelte es sich um zwei Arginin-Reste in der Nähe des postulierten Eingangs zur Substratbindetasche (Arg-345 und Arg-638) und ein Tyrosin-Rest im aktiven Zentrum (Tyr851). Liavonchanka \& Feussner (2006) zeigten anhand des Vergleiches verschiedener Modelle pflanzlicher 13-LOXen, dass sich z. B. in AtLOX4, GmLOX3 und CslbLOX ein positiv geladener Lysinrest (jeweils Lys-345, Lys-278 und Lys-298) am Eingang der Substratbindetasche befindet. In AtLOX4 ist dieser Bereich im Vergleich zur GmLOX3 und CslbLOX zusätzlich durch einen Arg- und Lys-Rest (Arg-343 und Lys-396) noch polarer. Arginin-Reste, die eine Rolle bei der Positionierung des Fettsäuresubstrates spielen könnten, wurden auch bei einer mit $1.85 \AA$ aufgelösten LOX-Struktur der Korallenart Plexaura homomalla identifiziert (Neau et al., 2009). Diese Arginin-, bzw. Lysin-Reste könnten mit dem positiv geladenen Stickstoff eine Salzbrücke zur negativ geladenen Carboxylgruppe des Fettsäuresubstrates ausbilden. Im Sequenzvergleich sind die Arginin-Reste in den pflanzlichen 13-LOXen jeweils durch das oben beschriebene Lysin an PpLOX1 Position Arg- 
345 und durch ungeladene Alanin-, bzw. Glyzin-Reste an Position PpLOX1 Arg-638 ausgetauscht. Damit wird für PpLOX1 ebenfalls ein polarer Bereich in der Nähe des Eingangs zur Substratbindetasche vermutet. In Enzymen aus Säugetieren, die ebenfalls $\mathrm{C}_{20^{-}}$ Fettsäuresubstrate umwandeln, wie die PGHS-1, wurde das Vorhandensein einer Salzbrücke zwischen einem Arg-Rest am Eingang zur Substratbindetasche und der Carboxylgruppe des Fettsäuresubstrates durch strukturelle Aufklärung von Enzym/Substrat-Komplexen bereits bestätigt (Malkowski et al., 2001, Malkowski et al., 2000). Auch für ein bakterielles Enzym wurde die Interaktion zwischen einem Argininrest und der Carboxylgruppe des Substrates LA bereits beobachtet (Liavonchanka \& Feussner, 2006).

Des Weiteren befindet sich im postulierten aktiven Zentrum des PpLOX1-Modells ein TyrRest (Tyr-851), der in den anderen LOXen durch ein Isoleucin besetzt ist. Es gibt verschiedene Studien, die die Beteiligung von Tyr-Reaktionen bei der Familie der MyelinPeroxidasen, zu der z. B. $\alpha$-DOX und PpoA gehören, belegen (Koeduka et al., 2002, Brodhun et al., 2009). Die Hydroxidgruppe an Tyr-Resten ist reaktiv und kann z. B. an RadikalUmlagerungen oder an der Delokalisierung von Ladungen im Enzym/Substrat-Komplex beteiligt sein. Da der Tyr-Rest an PpLOX1-Position 851 in den zum Vergleich herangezogenen LOXen nicht vorhanden ist, sondern von einem konservierten Isoleucin vertreten wird, wurde vermutet, dass Tyr-851 für die zusätzliche Lyase-Aktivität von PpLOX1 verantwortlich ist.

In der vorliegenden Arbeit wurden die beschriebenen Aminosäurereste aus PpLOX1 (Arg345, Arg-638 und Tyr-851) durch ortsgerichtete Mutagenese ausgetauscht. Die Enzymaktivität der erzeugten Varianten und des Ausgangsenzyms wurden mit verschiedenen Fettsäuresubstraten in Aktivitätstests statistisch miteinander verglichen (3.1.2). Die Analyse der Produktspektren nach Umsetzung mit AA und EPA durch die Arg-Einzelvarianten (R345L bzw. R638L) zeigten wenig bis keine signifikanten Unterschiede im Vergleich zur Ausgangsform (Abbildung 3.4 - Abbildung 3.6). Die R345L-Variante erzeugte mit den getesteten Fettsäuresubstraten relativ höhere Anteile des Lyaseproduktes 12-ODTE im Vergleich zur Ausgangsform, während die R638L-Variante im Vergleich zur Ausgangsform relativ kleinere Anteile an 12-ODTE bildete. Eine Mutagnese des entsprechenden Arg-403 aus der humanen 15-LOX zu Leucin, führte ebenfalls zu einer Enzym-Variante mit deutlich niedrigerer Aktivität. Dagegen führte der Austausch gegen einen Lysinrest zu einer, mit der Ausgangsform vergleichbar, aktiver Enzymvariante (Gan et al., 1996).

Die Doppelvarianten (R345L/R638L) hingegen, erzeugten mit Umsetzung von EPA im Vergleich zur Ausgangsform relativ kleinere Anteile der 12-ODTE und der Ketofettsäuren, 
und dafür relativ höhere Anteile an Hydroxy-Fettsäuren. Bei Umsetzung von AA durch die Doppelvarianten waren hingegen keine Unterschiede zwischen den Produktgemischen im Vergleich zur Ausgangsform erkennbar. Auffallend im Vergleich zur Ausgangsform und den Einzelvarianten, waren die durch die Doppelvarianten kleineren Mengen an erzeugten Reaktionsprodukten nach Umsetzung von AA und EPA. Das spricht entweder für eine geringere Proteinexpression der Doppelvarianten oder für eine geringere Enzymaktivität im Vergleich zur Ausgangsform und den Einzelvarianten. Aufgrund der kleineren Produktmengen könnte auch vermutet werden, dass die Arginine tatsächlich bei der Stabilisierung des Substrates am Enzym eine Rolle spielen. Im Fall der Einzelvarianten könnte wiederum das Vorhandensein eines Arg-Restes für die Stabilisierung der Carboxylgruppe des Fettsäuresubstrates noch ausreichend sein.

Die Tyr-851 Varianten (Y851F bzw. Y851I) zeigten unterschiedliche Ergebnisse für die Umsetzung mit verschiedenen Fettsäuresubstraten (AA, EPA, GLA). Überraschenderweise zeigte die Y851F-Variante im Vergleich zur Ausgangsform jeweils einen höheren relativen Anteil an 12-ODTE und relativ geringeren Anteil an Hydroxy-Fettsäuren. Hingegen war für die Y851I-Variante genau das Gegenteil zu beobachten. Der Austausch des Tyr-851 gegen ein Isoleucin spiegelte sich in verringerten Anteilen an 12-ODTE und der Ketofettsäuren in den Produktgemischen der Variante wider. Zudem war für die Y851I-Variante die Menge an Reaktionsprodukten im Vergleich zur Ausgangsform und der Y851F-Variante kleiner. Das könnte ebenfalls für geringere Enzymaktivität der Y851I-Variante sprechen.

Um Klarheit über die Bifunktionalität von $P p L O X 1$ zu erhalten, müssen kinetische Parameter zur Umsetzung verschiedener Fettsäuresubstrate untersucht werden. In der vorliegenden Arbeit wurde jeweils nur eine Endpunktbestimmung der Enzymreaktion gemessen. Es könnte z. B. sein, dass die Km-Werte einer Fettsäure-Umsetzung zwischen PpLOX1-Ausgangsform und den Varianten gleich sind, jedoch $\mathrm{V}_{\max }$ der einzelnen Reaktionen unterschiedlich ist. Dieses Verhalten wurde kürzlich für die Variante einer LOX aus Nostoc sp. beschrieben (Andreou et al., 2008). Mittels solcher kinetischer Analysen wäre eine langsamere oder schnellere Umsetzung der jeweiligen Substrate durch die Ausgangsform bzw. die Varianten bestimmbar. Für diese tiefergehenden kinetischen Messungen muss jedoch gereinigtes Enzym vorhanden sein. Im Rahmen dieser Doktorarbeit ist es nicht gelungen ein Reinigungsprotokoll für $P p L O X 1 \mathrm{zu}$ etablieren. Zusätzlich könnte gereinigtes $P p L O X 1-E n z y m$ für Kristallisationsexperimente mit Enzym/Substrat-Komplexen verwendet werden. Letztendlich lassen sich die molekularen Ursachen für funktionelle Eigenschaften eines Enzyms oft erst durch Kristallstrukturen erklären. 


\subsection{Umsetzung von verschiedenen Hydroperoxy-Fettsäuren durch $P p A O C 1$ und PpAOC2}

Im Rahmen dieser Doktorarbeit wurden für PpAOC1 und PpAOC2 Protokolle etabliert, die zur Reinigung beider Enzyme in hohen Konzentrationen und in elektrophoretisch reinem Zustand führten (3.2.2). Die gereinigten Enzyme PpAOS, PpAOC1 und PpAOC2 wurden für Aktivitätstest mit verschiedenen $\mathrm{C}_{20}$-Fettsäure-Hydroperoxiden verwendet. Dazu wurden sowohl 12-Hydroperoxy-Fettsäuren als auch 15-Hydroperoxy-Fettsäuren in einem gekoppelten Aktivitätstest verwendet (3.3).

Das Vorkommen und die Funktion von Zyklopentenonen und Zyklopentanonen als wichtige Oxylipine in Samenpflanzen ist bis heute Gegenstand vieler Studien (Blée, 2002, Thoma et al., 2003, Browse, 2009a, Browse, 2009b). Auch in Säugetieren sind Oxylipine ausgehend von AA, wie Prostaglandine und Leukotriene, ausführlich beschrieben worden (Funk, 2001). Da jedoch das derzeitige Wissen über diese Verbindungen in nicht-blühenden pflanzlichen Organismen noch gering ist (Andreou et al., 2009b), untersuchte M. Stumpe (Dissertation, 2006) die Bildung und mögliche Funktion von Zyklopentenonen, Zyklopentanonen und Phytoprostanen im Moos P. patens, welches als Modellorganismus für nicht-blühende Pflanzen etabliert ist (Frank et al., 2005). Es wird diskutiert, in welchem Maße sich der Metabolismus der Moose unabhängig von dem der Grünalgen und den höheren Blütenpflanzen entwickelt hat. Für die Oxylipin-Biosynthese ist vor allem zu beachten, dass Moose im Gegensatz zu höheren Pflanzen, zusätzlich zu den mehrfach ungesättigten $\mathrm{C}_{18^{-}}$ Fettsäuren, die langkettigen mehrfach ungesättigten $\mathrm{C}_{20}$-Fettsäuren, AA und EPA, besitzen.

M. Stumpe testete die Substratspezifität der PpAOS1 um mögliche Substrate für PpAOC1 und $P p A O C 2 \mathrm{zu}$ finden. Dafür wurden verschiedene Hydroperoxy-Fettsäuren, die in $P$. patens vorkommen, verwendet (M. Stumpe, Dissertation, 2006). Bis auf $11 S$-HPETE und $5 S$ HPETE wurden die getesteten Substrate von PpAOS in Allenoxide umgewandelt (Abbildung 4.1). 


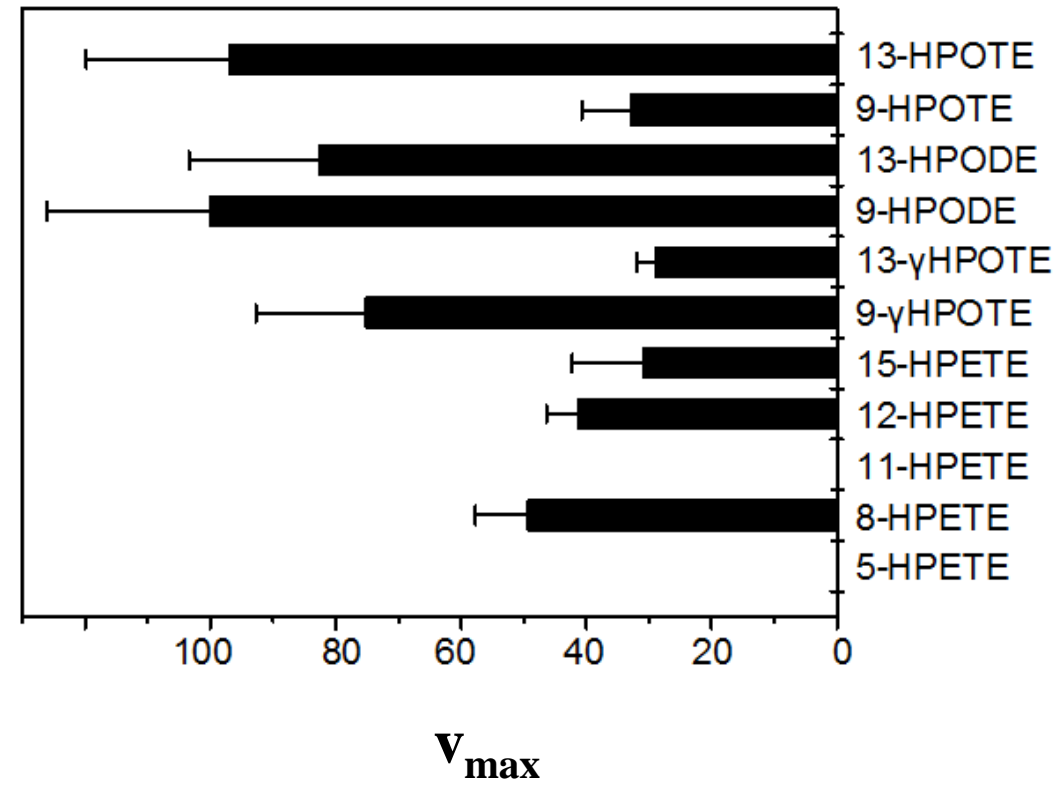

Abbildung 4.1: Aktivität von PpAOS. (modifiziert nach M. Stumpe, Dissertation, 2006). Gezeigt ist die prozentuale Geschwindigkeit $\mathrm{V}_{\max }$ der PpAOS1-Reaktion bezogen auf die Umsetzung von 13S-HPOTE.

Die AOS katalysiert zunächst die Wasserstoffabspaltung am 13S-HPOTE, wodurch das instabile Allenoxid 12,13-EOT ${ }^{\Delta 9 Z \Delta 11 \Delta 15 Z}$ gebildet wird (Vick \& Zimmerman, 1987a, Vick \& Zimmerman, 1987b). Aufgrund der sehr kurzen Halbwertszeit von Allenoxiden in wässriger Lösung [t $1 / 2 \leq 30 \mathrm{~s}$ bei $0{ }^{\circ} \mathrm{C}$ (Hamberg, 1988)], ist es notwendig AOC-Aktivität zusammen mit der vorangehenden AOS-Reaktion und dem jeweiligen Hydroperoxy-Fettsäuresubstrat in einem gekoppelten Aktivitätstest zu untersuchen (Ziegler et al., 1997). M. Stumpe (Dissertation, 2006) zeigten, dass PpAOS1/PpAOC1 und PpAOS1/PpAOC2 in der AOCtypischen Reaktion aus 13S-HPOTE das zyklische Produkt cis-(+)-OPDA als optisch reines Enatiomer bilden. Das zyklische Produkt der PpAOC2-Umsetzung von 12S-HPETE ist ein neues Phytoprostan, 5Z,8S,12S,15Z-11-Oxo-5,9,15-phytotriensäure (11-OPTA). Bis jetzt wurde keine AOC beschrieben, die diese Substratspezifität für 12S-HPETE aufweist.

Bemerkenswerterweise konnte Brash (1989) eine 11-OPTA ähnliche zyklische Verbindung im Produktgemisch bei Umsetzung von AA durch Extrakt aus $P$. homomalla beobachten. In $P$. homomalla wird AA durch ein $8 R$-LOX/AOS Fusionsprotein zu $8 R$-HPETE oxidiert, welches ebenfalls durch das Fusionsprotein zu einem instabilen Allenoxid umgewandelt wird. Dieses instabile Allenoxid hydrolisiert zu Ketolen und wird nichtenzymatisch in razemisches 5Z,14Z-9-Oxo-5,10,14-prostatriensäure zyklisiert (Brash, 1989). Möglicherweise handelt es sich bei dieser, auch als Preclavulon bezeichneten, Verbindung aus $P$. homomalla um eine Vorstufe der Prostaglandine, oder Clavulone (Andreou et al., 2009b). 
Über die Funktion von 11-OPTA in P. patens ist zum aktuellen Stand der Forschungen noch nichts bekannt. Die Arbeitsgruppe von (Oliver et al., 2009) beobachtete einen Anstieg des JAGehalts in P. patens nach Infektion mit zwei Pythium Spezies. Jedoch wurden diese Analysen nicht mittels zusätzlicher GC/MS-Messungen bestätigt, wie es in den Arbeiten von Wichard et al. (2005) und M. Stumpe. (Dissertation, 2006) gezeigt ist.

Rekombinant erzeugte Mischungen von PpAOS1/PpAOC1 und PpAOS1/PpAOC2 zeigten jeweils Aktivität mit den 15-Hydroperoxiden von EPA und ETA, jedoch nicht von AA (Abbildung 3.16). Darüber hinaus besaßen PpAOS1/PpAOC2, im Vergleich zu PpAOS1/PpAOC1, eine spezifische Enzymaktivität für die 12-Hydroperoxide von AA, EPA und DGLA (Abbildung 3.14). Es wurden zusätzlich zur 11-OPTA (M. Stumpe, Dissertation, 2006) bislang nicht beschriebene zyklische Verbindungen gebildet, deren Struktur durch Fragmentierung mittels ESI-MS/MS bestätigt wurde (Abbildung 3.15und Abbildung 3.17).

Bereits 1999 stellten Ziegler et al. (1999) die ersten Untersuchungen zur Substratspezifität von AOCs an. Ziegler und Mitarbeiter verwendeten dazu nativ gereinigte ZmAOC und StAOC in gekoppelten Aktivitätstests mit nativ gereinigter ZmAOS. In den Versuchen wurde beobachtet, dass ZmAOC und StAOC Allenoxide mit der Epoxydgruppe an Position n-6,7 und einer $\alpha, \beta, \gamma$-Doppelbindung an Position n-3, darunter auch die 15-Hydroperoxy-Fettsäuren von ETA und EPA in ein zyklisches Produkt umwandeln. Mit der Umsetzung von $12 S$ HPETE durch PpAOS1/PpAOC2 wurde erstmalig eine AOCs beschrieben, die Allenoxide mit der Epoxydgruppe an Position n-9,10 und der $\alpha, \beta, \gamma$-Doppelbindung an Position n- 6 als Substrat akzeptieren (M. Stumpe, Dissertation, 2006).

Es ist jedoch anzumerken, dass der Gehalt dieser identifizierten zyklischen Verbindungen, im Vergleich zu 11-OPTA, bislang nicht in vivo in P. patens nachgewiesen wurde. Solche in vivo Analysen sollten der nächste Schritt zum Verständnis der besonderen Produktbildung durch PpAOC2 in $P$. patens sein. Zudem könnten auch verschiedene Verwundungsexperimente, welche über die von Wichard et al. (2005) hinausgehen, neue Einblicke in den Oxylipinmetabolismus der $\mathrm{C}_{20}$-Verbindungen in P. patens gewähren.

Möglicherweise besitzen diese zyklischen $\mathrm{C}_{20}$-Verbindungen in $P$. patens eine ähnliche Aufgabe wie die nicht-enzymatisch gebildeten $\mathrm{C}_{18}$-Phytoprostane, wie Phytoprostan- $\mathrm{A}_{1}$, in Pflanzen (Thoma et al., 2003). Neuere Studien am Arabidopsis-Protenom zeigten den Einfluss von OPDA und Phytoprostan- $\mathrm{A}_{1}$ bei der Induzierung von klassischen Stressproteinen sowie von Enzymen, die mit dem zellulären Redox- und Entgiftungssystem verbunden sind (Dueckershoff et al., 2008). Zudem sind sich die zyklischen $\mathrm{C}_{18^{-}}$und $\mathrm{C}_{20^{-}}$-Verbindungen 12OPDA und 11-OPTA, durch die vorhandene $\alpha, \beta$-ungesättigte Carbonylgruppe strukturell sehr 
ähnlich. Verbindungen mit einer $\alpha, \beta$-ungesättigte Carbonylgruppe sind reaktive, elektrophile Moleküle (Reactive Electrophilic Species, RES) gegenüber zellulären Nukleophilen (Farmer et al., 2003). In Säugetieren wurde bereits die strukturelle Bedeutung der $\alpha, \beta$-ungesättigten Carbonylgruppe für die biologische Aktivität von Prostaglandinen, wie die Beeinflussung der Genexpression, bestimmt. Zudem wurde in Säugetieren gezeigt, dass Isoprostane und Prostaglandine (Strukturäquivalente zu Phytoprostan- $\mathrm{A}_{1}$ und dn-Phytoprostan- $\mathrm{J}_{1}$ ) kovalent an Thiolgruppen von Proteinen (z. B. Cystein) binden und somit die biologische Reaktionen steuern können (Milne et al., 2005). Es ist anzumerken, dass die Isoprostane und die Phytoprostane evolutionär alte biologisch aktive, oxidierte Lipide darstellen, deren strukturelles Wirkungsprinzip im Laufe der Evolution von Jasmonaten in Pflanzen und Prostaglandinen in Tieren übernommen worden ist (Müller, 2004).

Im folgenden Abschnitt wird die Bedeutung der zyklischen Verbindungen OPDA und 11OPTA in Abwesenheit von JA und ihren Derivaten in P. patens diskutiert.

\subsubsection{OPDA und Phytoprostane als Signalmolekül in $P$. patens?}

Obwohl sich die derzeitige Forschung hauptsächlich auf JA als Signal in Samenpflanzen richtet, wurde in vielen Experimenten bewiesen, dass OPDA ebenfalls ein eigenständiges Signalmolekül ist (Farmer et al., 2003, Taki et al., 2005, Müller et al., 2008). In Protonema und Gametophoren von $P$. patens wurden die endogenen Anteile von OPDA $(0,5 \mathrm{nmol} / \mathrm{g}$ Frischgewicht) und 11-OPTA (0,1 nmol/g Frischgewicht) bestimmt (M. Stumpe, Dissertation, 2006). Damit ähnelt der Anteil an OPDA in P. patens dem in Arabidopsis-Blättern (Stintzi et al., 2001, Müller et al., 2008). Im Jahr 2001 gelang es Stintzi et al. (2001) die Pflanzenabwehr in Arabidopsis ohne das OPR3 Transkript (opr3) und damit ohne JA und ihre Derivate zu untersuchen. Darüber hinaus wurde mit Untersuchungen an der opr3-Mutante bewiesen, dass JA essentiell für die Pollenreife und -freisetzung ist und die opr3-Pflanzen männlich steril sind (Stintzi \& Browse, 2000). Oxylipinprofile von mechanisch verwundeten Blättern der opr3-Mutanten zeigten zu Pflanzen ohne diese Mutation keine JA und veränderte Mengen an OPDA und dnOPDA. Darüber hinaus sind die Pflanzen mit opr3-Mutation wie die normalen Pflanzen resistent gegen Pathogenbefall. Diese Ergebnisse demonstrieren, dass in Abwesenheit von Jasmonaten der Schutz gegen Insekten oder Pilzpathogene und die COII abhängige Expression von Abwehrgenen durch OPDA und dnOPDA ersetzt werden kann (Abbildung 4.2).

Kürzlich wurde berichtet, dass nach Infektion mit zwei verschiedenen Pythium Spezies der endogene Gehalt an OPDA in P. patens nach $24 \mathrm{~h}$ stark ansteigt (Oliver et al., 2009). Zudem wurden Gene von LOXI (Accession-Nummer: BJ159508) Phenylalanin Ammonium Lyase 
(PAL, Accession-Nummer: BJ201257) und Chalkon Synthase (CHS, Accession-Nummer: BJ1922161) durch die Infektion hochreguliert. Bereits 2007 zeigten Ponce de Léon, dass diese Gene nach Infektion mit den Pflanzenpathogenen Botyris cinera und Erwinia carotovora (van Kan, 2006) hochreguliert wurden. Für Blütenpflanzen ist der Anstieg von LOX-, PAL- und CHS-Transkripten nach Pythium-Infektion bereits bestätigt (Vijayan et al., 1998, Bednarek et al., 2005, Adie et al., 2007). Somit konnte gezeigt werden, dass die Genexpression in P. patens nicht nur durch eine Vielzahl von abiotischem (Frank et al., 2005) sondern auch biotischem Stress reguliert wird.

M. Stumpe (Dissertation, 2006) untersuchte die Funktion von OPDA in P. patens mittels Mutanten in denen entweder das AOC1-, bzw. AOC2-Gen fehlte. Versuche eine $\triangle A O C 1 / \triangle A O C 2$-Mutante $\mathrm{zu}$ erzeugen scheiterten wahrscheinlich aufgrund $\mathrm{zu}$ niedriger Transformationseffizienzen für $P$. patens oder weil eine Doppelmutante letal ist. (M. Stumpe, Dissertation, 2006). Obwohl die Gametophyten der $\triangle A O C$-Mutanten keine Unterschiede zu den Ausgangspflanzen aufwiesen, zeigten sie eine stark reduzierte Sporophytenbildung, die meist nicht über das Tetrastadium hinausging. Insgesamt war die Anzahl der Sporen mehr als 10fach reduziert. Die verbliebenen Sporen entwickelten sich jedoch normal (M. Stumpe, Dissertation, 2006). Die beschriebenen Defekte wurden jedoch nur in einer Linie durch exogenes OPDA komplementiert (Bernd Faltin, Diplomarbeit) und der endogene OPDAGehalt war weder im Protonema noch in den Gametophoren der Mutanten reduziert (M. Stumpe, Dissertation, 2006).

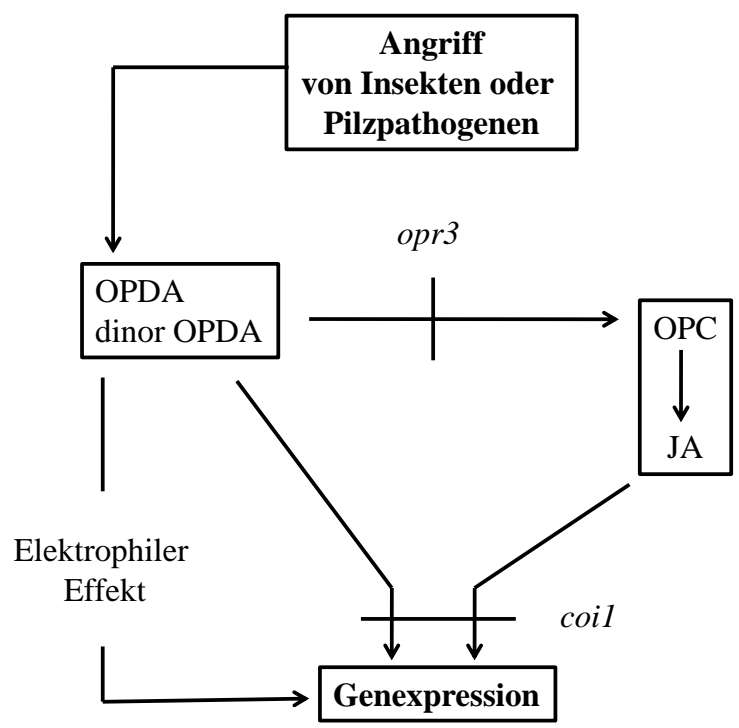

Abbildung 4.2: Modell über die Feinkontrolle der Genexpression durch Jasmonate in verwundeten oder erkrankten Arabidopsis-Blättern. (modifiziert nach Stintzi et al., 2001). Die Zyklopentenone OPDA und dnOPDA können Gene direkt über einen COI1-abhängigen Weg regulieren. Eine weitere Möglichkeit ist die Regulation über den gleichen COI1-abhängigen Weg nach Umwandlung in JA oder OPC. In diesem Fall, 
könnten sowohl OPDA als auch JA spezifische Gengruppen regulieren oder sie können zur Kontrolle dieser Gengruppe gemeinsam agieren. Ein anderer Weg der Regulation könnte durch die elektrophilen Eigenschaften von Zyklopentenonen gewährleistet sein.

Des Weiteren wurde beobachtet, dass OPDA in Blütenpflanzen Gene wie GST1, RNS1 und OPRl aktivieren kann (Reymond et al., 2000). Diese Gene werden bei Verwundung in COI-abhängiger Weise induziert, jedoch ist das direkte Signalmolekül für die Aktivierung dieser Gene nicht bekannt. Die Gene GST1, RNS1 und OPRI werden durch Verwundung jeweils in Kontroll- und opr3-defizienten Pflanzen induziert, können aber nicht durch exogenes JA aktiviert werden (Stintzi et al., 2001). Deshalb wird vermutet, dass die Expression dieser Gene von einem Stoffwechselweg abhängt, in welchem ein Effektor mit einer elektrophilen Gruppe involviert ist (Abbildung 4.2). Diese ist auch im Zyklopentenonrings von OPDA enthalten. In diesem Zusammenhang können $\alpha$, $\beta$-ungesättigte Ketogruppen an nukleophilen Michael-Additionen beteiligt sein, in denen Carbanionen an $\alpha, \beta$-ungesättigte Carbonylverbindungen angefügt werden. Diese Additionsreaktion an Proteinen oder dem Tripeptid Glutathion (GSH) könnte Veränderungen in Proteinaktivität oder dem zellulären Redoxzustand auslösen. Solche Veränderungen wiederum können die Genexpression zur Pathogenabwehr beeinflussen (Hayes \& McLellan, 1999). Die Ergebnisse von Stintzi et al., 2001 deuten auch auf einen neuen potenziellen Mechanismus zur wundinduzierten Expression von JA-unabhängigen Genen hin. Möglicherweise sind sowohl OPDA und dnOPDA, bzw. die abgeleiteten Derivate, „echte“ Regulatoren und erlauben somit den Zellen, je nach Veränderung ihres Anteils, in Entwicklung und bei Erkrankung eine feinabgestimmte Genexpression (Abbildung 4.2).

Vollenweider et al. (2000) beobachteten, dass weitere Moleküle mit elektrophilen Eigenschaften, wie Ketodiensäuren und Ketotriensäuren, als potenzielle Genregulatoren in verwundeten Pflanzengeweben fungieren, indem sie die GST-Expression erhöhen. Darüber hinaus beobachteten Wichard et al. (2005) in Verwundungsexperimenten an P. patens einen Anstieg der flüchtigen Verbindungen $2 E$-Nonenal und $2 E$-Oktenal, die ebenfalls reaktive Ketogruppen besitzen. Diese elektrophilen Verbindungen stammen, im Gegensatz zu Pflanzen nicht aus ALA, sondern aus einem AA-abhängigen Syntheseweg (Wichard et al., 2005, Senger et al., 2005). Es ist nicht auszuschließen, dass diese flüchtigen Verbindungen ebenfalls die Genexpression zur zellulären Entgiftung oder Pathogenabwehr in P. patens induzieren können. Almeras et al. (2003) zeigten in Versuchen an Arabidopsis-Blättern die zytotoxischen Eigenschaften u. a. von $2 E$-Nonenal, welches einen negativen Einfluss auf das Photosystem II zeigte, jedoch die untersuchten Abwehrgene nur in geringem Maß induzierte. 


\subsection{Die Kristallstrukturen von $P p A O C 1$ und $P p A O C 2$}

In dieser Arbeit gelang es die Röntgenkristallstrukturen für PpAOC1 und $P p A O C 2$ mit gebundenem Liganden 12,13-EOD ${ }^{\Delta 9 Z \Delta 15 Z}$ sowie eine ligandfreie PpAOC2-Struktur zu lösen. Die Datensätze für die $P p A O C 2-12,13-E^{2}{ }^{9 Z}$ und 11,12-EET waren zum derzeitigen Stand der Arbeiten nicht endgültig verfeinert um sie in eine präzise Analyse der Struktur einzubeziehen.

\subsubsection{Vergleich mit anderen AOC-Strukturen}

Momentan sind sechs Kristallstrukturen von zwei Arabidopsis-AOCs in der Proteindatenbank (www.pdb.org) deponiert. Dabei handelt es sich um eine AtAOC1-Struktur (1ZVC.pdb) und fünf AtAOC2-Strukturen, von denen vier Apo-Strukturen sind (1ZK8.pdb; 2BRJ.pdb; 2GIN.pdb; 2Q4I.pdb) und einer Struktur mit gebundenem Substratanalogon 12,13-EOD ${ }^{\Delta 9 Z}$ (2DIO.pdb). AtAOC1 und AtAOC2 sind sich strukturell nahezu identisch und unterscheiden sich nur in 10 Aminosäureresten wobei die meisten konservative Austausche sind (Hofmann et al., 2006). Aufgrund der hohen Ähnlichkeit von AtOC1 und AtAOC2 werden die PpAOC1und PpAOC2-Strukturen ausschließlich mit dem AtAOC2-Enyzm/Substrat-Komplex verglichen.

Die PpAOC1-Struktur mit 12,13-EOD ${ }^{\Delta 9 Z \Delta 15 Z}$ als gebundenem Liganden wurde bis zu einer Auflösung von 1,33 $\AA$ und kristallografischen R-Faktoren von $\mathrm{R}_{\text {work }}=14,80$ und $\mathrm{R}_{\text {free }}=18,17$ verfeinert. Damit lagen der Rfree und Rwork Wert mit einer Differenz von 3,37 auseinander. Zum Vergleich besitzt die bereits publizierte AtAOC2-Struktur mit gebundenen Liganden (2DIO.pdb; Hofmann et al., 2006) eine Auflösung von 1,7 $\AA$ mit kristallografischen RFaktoren von $\mathrm{R}_{\text {work }}=19,80$ und $\mathrm{R}_{\text {free }}=23,30$. Somit wurde für die hier präsentierte PpAOC1Struktur eine höhere Auflösung und niedrigere R-Faktoren erreicht.

Die Strukturen von PpAOC1, bzw. PpAOC2 werden im folgenden Abschnitt mit der AtAOC2-Struktur (2DIO.pdb) verglichen. Zum Vergleich von Homologien wichtiger Aminosäurereste ist in Abbildung 4.3 ein Aminosäure-Sequenzvergleich verschiedener AOCs gezeigt. Beim Vergleich der AOC-Sequenzen ist zu beachten, dass die PpAOC-Enzyme aufgrund der fehlenden CTS um ca. 70 Aminosäuren kürzer sind als die restlichen AOCs. Der Sequenzvergleich in Abbildung 4.3 beginnt jeweils mit dem ersten Methionin für PpAOC1 und $P p A O C 2$. 

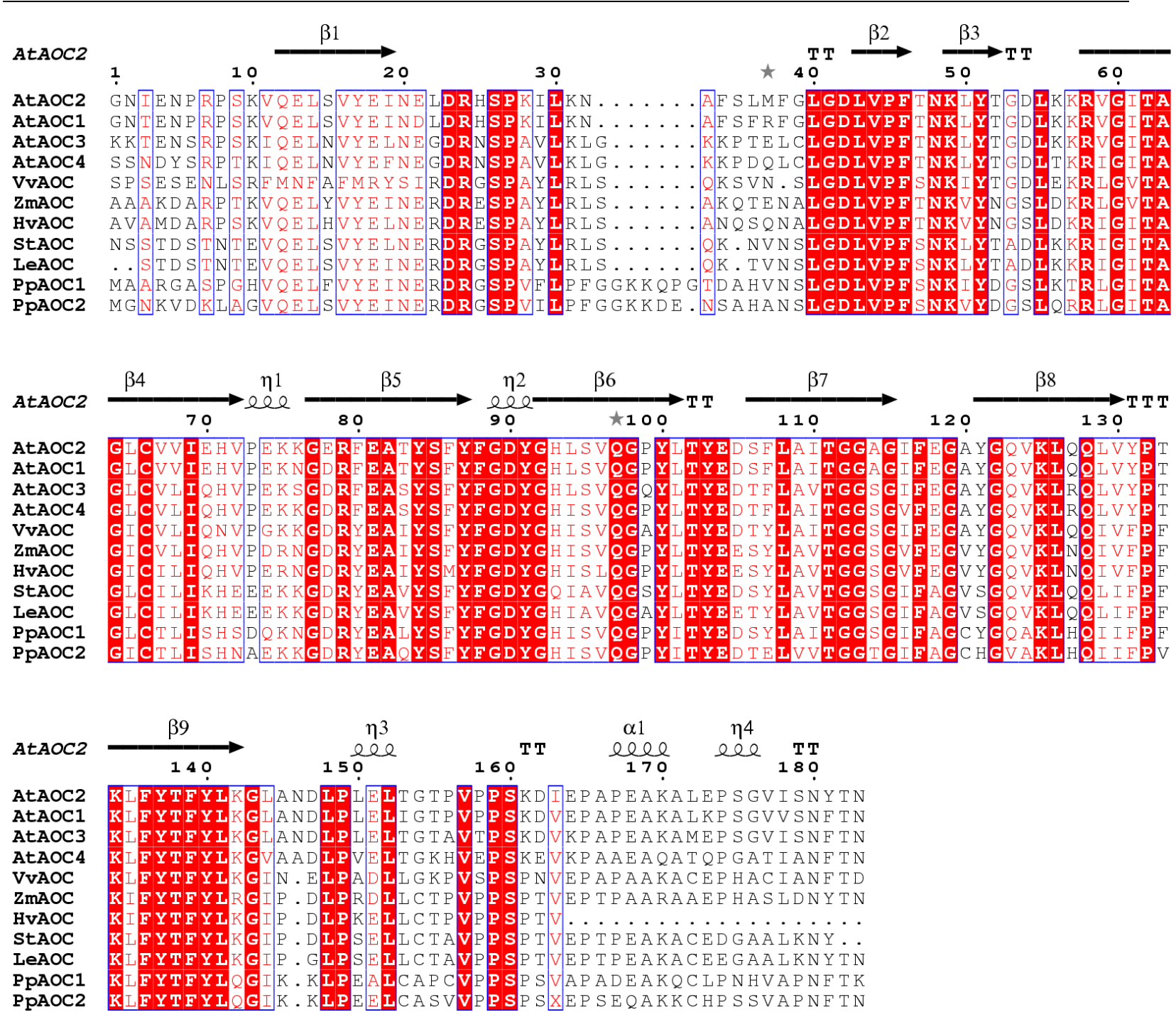

Abbildung 4.3: Sequenzvergleich verschiedener AOCs. [erstellt mit ESPript (Gouet et al., 1999)]. Sekundärstrukturelemente basieren auf der AtAOC2-Struktur (Hofmann et al., 2006; 2DIO.pdb). Nummerierung basierend auf PpAOC1-Sequenz ohne die Aminosäurereste 31-38. Die folgenden AOCs sind aufgeführt (Accession-Nummern sind eingeklammert): AtAOC2 (Q9LS02), AtAOC1 (Q9LS03), AtAOC3 (Q9LS01), AtAOC4 (Q93ZC5), PpAOC1 (Q8GS38), PpAOC2 (Q8H0N6) StAOC (Q8H1X5), LeAOC (Q9LEG5), Vitis vinifera [VvAOC (ABD64688)], ZmAOC (Q6RW09), HvAOC (Q711R0).

Da die pdb-Dateien der Kristallstrukturen von PpAOC1 und PpAOC2 noch nicht in der Proteindatenbank deponiert wurden, sind im AOC-Sequenzvergleich (Abbildung 4.3) die Sekundärstrukturelemente von AtAOC2 (2DIO.pdb) dargestellt. Auf AminosäureSequenzebene sind PpAOC1 und AtAOC2 zu 41,3\% identisch, weshalb die bereits veröffentlichte AtAOC2-Struktur (2DIO.pdb) zur Lösung der ersten PpAOC1-Struktur über molekularen Ersatz (MR) verwendet wurde. In Abbildung 4.4 ist die grafische Überlagerung eines PpAOC1- und AtAOC2-Monomers mit gebundenem Ligand 12,13-EOD ${ }^{\triangle 9 Z \Delta 15 Z}$ dargestellt. Dabei handelt es sich um PpAOC1 Kette A und AtAOC2 Kette B. Die grafische 
Überlagerung von $P p A O C 2$ und AtAOC1 in Farbbanddarstellung zeigte keine Unterschiede zur grafischen Überlagerung von PpAOC1 und AtAOC2 (nicht gezeigt).

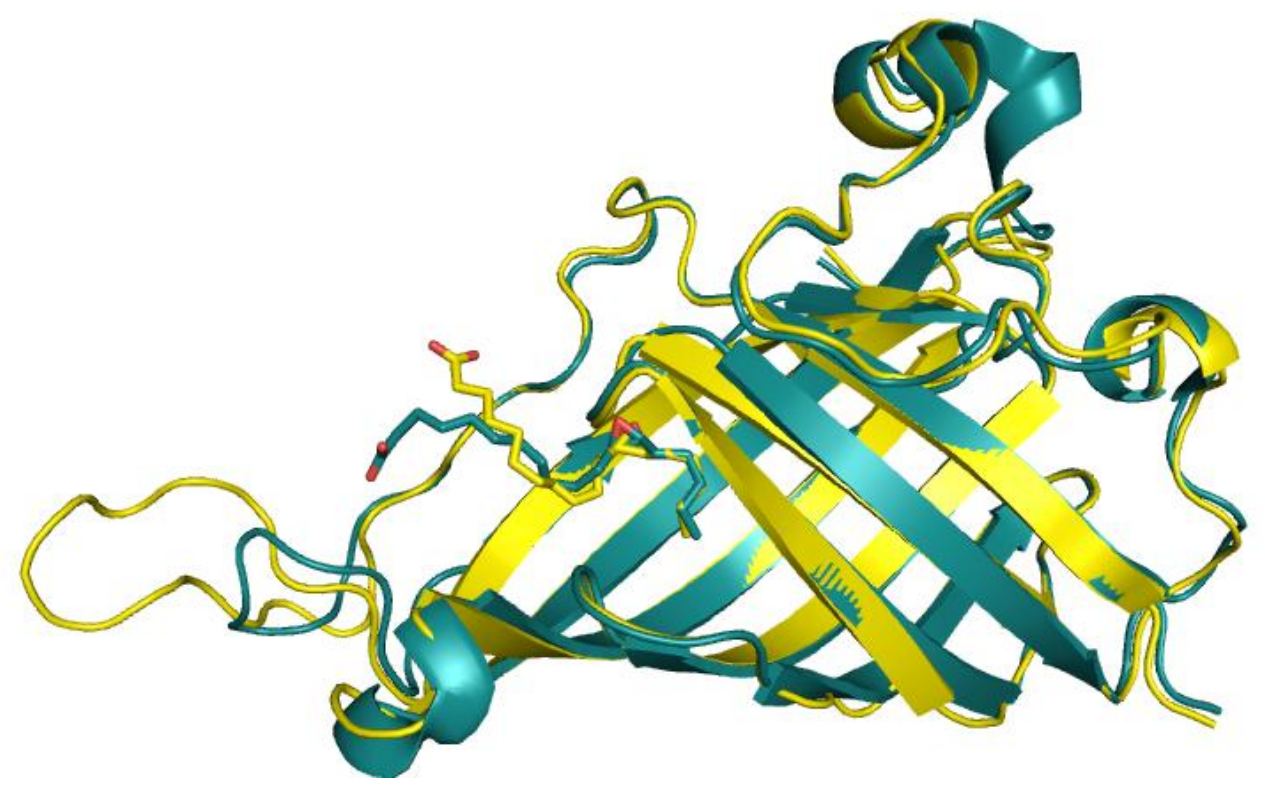

Abbildung 4.4: Grafische Überlagerung AtAOC2 und PpAOC1. Gezeigt ist die grafische Überlagerung einen PpAOC1-Monomers (Kette A; gelb) und des AtAOC2-Monomers (Kette B, grün) in Farbbanddarstellung mit gebundenem Liganden $12,12-\mathrm{EOD}^{\triangle 9 Z \Delta 15 Z}$ als Stabmodelle.

Es war zu erkennen, dass die Strukturen des PpAOC1-Monomers und AtAOC2-Monomers sehr gut überlagert sind. Die $\beta$-Faltblätter und die $\alpha$-helikalen Stränge am C-Terminus beider Strukturen zeigten eine sehr gute Übereinstimmung. Der einzige Unterschied bestand in der längeren Proteinschleife mit den Aminosäureresten PpAOC1 32-45, welche in AtAOC2 um sieben Aminosäurereste verkürzt vorliegt. Wie im Aminosäure-Sequenzvergleich zu erkennen war, scheint diese Schleifenerweiterung nur in den Strukturen von PpAOC1 und PpAOC2 vorhanden zu sein. Ob diese Erweiterung Einfluss auf die Funktionalität der Enzyme hat, wurde jedoch nicht geklärt. Dieser Bereich scheint in AOCs allgemein sehr variabel zu sein. Zudem wurden in den Strukturen von PpAOC1 und PpAOC2 hohe B-Faktoren für diesen Bereich erhalten (Abbildung 3.23 und Abbildung 3.26). Für einige Monomere (PpAOC2 Ketten B und E), war in dieser Region keine Elektronendichte definiert, was zusätzlich auf eine hohe Flexibilität dieser Proteinschleife hinweist. Darüber hinaus, waren im aktiven Zentrum von PpAOC1 zwei Wassermoleküle von vier Aminosäureresten (Ser-26 und Asn-55, bzw. Asn-20 und Pro-139) koordiniert, während in AtAOC2 ein Wassermolekül von vier Aminosäureresten (Asn-25, Ser-31, Pro-32 und Asn-53) gebunden ist. Dieses Wassermolekül befand sich ebenfalls in den restlichen oben beschriebenen AtAOC-Strukturen (Hofmann \& Pollmann, 2008). 
In den Strukturen von PpAOC1 und PpAOC2 ist die Allenoxidgruppe des Liganden in transKonformation gebunden. Das Substratanalogon, mit welchem die Kristalle inkubiert wurden, ist jedoch $( \pm)$-cis-12,13-EOD ${ }^{\Delta 9 Z \Delta 15 Z}$. Eine experimentelle Erklärung für die cis-/transIsomerisierung des Liganden in den Strukturen wurde bislang nicht gefunden. Eventuell könnte das Eindampfen des Substrates im $\mathrm{N}_{2}$-Strom zu einer cis-/trans-Isomerisierung geführt haben (I. Feußner, persönliche Mitteilung). Dieser Schritt war notwendig, um das Substratanalogon in gleichen Konzentrationen im Kristallisationspuffer aufzunehmen. Eine RP-HPLC-Analyse zur Trennung von cis- und trans-Allenoxiden der verwendeten Substratanaloga nach dem Eindampfen im $\mathrm{N}_{2}$-Strom ließ keine eindeutige Bestimmung der Konformation zu (durchgeführt von Dr. Cornelia Göbel, nicht dargestellt). Allerdings konnte für das Substratanalogon ohne vorheriges Eindampfen im $\mathrm{N}_{2}$-Strom eindeutig das Vorliegen der cis-Konformation nachgeweisen werden. Um zu klären, ob PpAOC1 und PpAOC2 eine cis $\mathrm{zu}$ trans-Isomerisierung des Substratanalogon katalysieren, müssten die gereinigten Enzyme mit dem $( \pm)$-cis-12,13-EOD ${ }^{\Delta 9 Z \Delta 15 Z}$ inkubiert werden. Eine anschließende RP-HPLC Trennung der cis- und trans-Allenoxide sollte Aufschluss über diese Theorie geben. Im Rahmen dieser Arbeit, wurden die Analysen jedoch nicht durchgeführt.

Einige Unterschiede wurden außerdem zwischen den Aminosäureresten, die das aktive Zentrum bilden, den Liganden binden und an der Koordinierung des Wassers beteiligt sind, beobachtet. Zum Vergleich des aktiven Zentrums von PpAOC1 und AtAOC2 ist in Abbildung 4.5 eine grafische Überlagerung der Aminosäurereste und der Liganden gezeigt. Es sind nahezu keine strukturellen und konformellen Unterschiede zwischen den Aminosäureresten, die in PpAOC1 und AtAOC2 das aktive Zentrum bilden zu erkennen. Im hinteren Bereich der Substratbindetasche interagieren ausschließlich konservierte Aminosäurereste ohne konformelle Unterschiede mit dem Liganden. Im vorderen Bereich der Substratbindetasche ist das Tyr-87 in PpAOC1 in AtAOC2 durch ein Phenylalanin (Phe-85) ersetzt. Wie dem Sequenzvergleich zu entnehmen ist, wird dieser Rest nur in AtAOC1-AtAOC4 von einem Phenylalanin bestimmt. In allen übrigen AOCs ist an dieser Position ein Tyrosinrest konserviert. Darüber hinaus befindet sich im vorderen Teil der AtAOC2-Struktur ein weiterer Phenylalaninrest (Phe-43), welcher in die Bindung des Liganden involviert ist (Hofmann et al., 2006). In AtAOC1 befindet sich an dieser Position ebenfalls ein Phenylalaninrest, und in AtAOC3 und AtAOC4 befindet sich ein Leucinrest. In allen übrigen AOCs, darunter auch beide $P$. patens Enzyme, befindet sich an dieser Position ein konservierter Asparaginrest. Dieses Asparagin, hat zu mindestens in PpAOC1 und PpAOC2, keinen Einfluss auf die Ligandenbindung (Abbildung 3.33 und Abbildung 3.38). Unterschiede im aktiven Zentrum von $P p A O C 1$ und PpAOC2 waren zudem bezüglich der Wasserkoordinierung zu erkennen 
(Abbildung 3.33 und Abbildung 3.38). Während in PpAOC1 vier Aminosäurereste (Asn-20, Ser-26, Asn-55 und Pro-139) zwei Wassermoleküle binden, sind in AtAOC2 vier Aminosäurereste (Asn-25, Ser-31, Pro-32 und Asn-53) an der Bindung eines Wassermoleküls beteiligt (Hofmann et al., 2006). Die Abbildung 4.5 zeigt grafisch übereinander gelagerte Aminosäurereste von PpAOC1 und AtAOC2, die jeweils an der Ligandenbindung beteiligt sind in. Dabei handelt es sich um die folgenden konservierten Reste in PpAOC1: Glu-18, Val51, Phe-53, Cys-72, Tyr-87, Tyr-91 und Tyr-107.

In Mutagenesestudien wurde die Bedeutung einiger dieser Aminosäurereste in AtAOC2 kürzlich eingehender untersucht (Schaller et al., 2008). Der Austausch des AtAOC2 Glu-23 (PpAOC1 Glu-18) in ein Alanin führte zum völligen Verlust der Enzymaktivität von AtAOC2. Mutagenesestudien dieser Arbeit, bestätigten die Bedeutung des Glutamtes an dieser Position für die Enzymaktivität von PpAOC1 und PpAOC2 (Abbildung 3.44). In den vorliegenden Studien zu PpAOC1 und PpAOC2 wurde das Glutamat an Position 18 jeweils sowohl durch Glutamin als auch Aspartat ausgetauscht. Beide Varianten von PpAOC1 und PpAOC2 zeigten einen völligen Verlust der Enzymaktivität (Abbildung 3.44). Durch den Austausch von Glutamat in Glutamin, wurde überprüft, ob die negativ geladene Gruppe des Glutamats für die enzymatische Reaktion entscheidend ist. Wie aus den Ergebnissen der Umsetzung von 13S-HPOTE durch die PpAOC1-, bzw. PpAOC2 E18Q-Varianten zu folgern ist, hat die negative Gruppe eine wichtige Funktion für die Umsetzung des Substrates. Ob durch die negativ geladene Gruppe am Aspartat die Enzymreaktion in PpAOC1 und PpAOC2 katalysiert werden könnte, sollte durch Austausch des Glutamats an Position 18 in Aspartat, geklärt werden. Es wurde gezeigt, dass die PpAOC1, bzw. PpAOC2 E18D-Varianten das Substrat 13S-HPOTE ebenfalls nicht umsetzten. Aus diesen Ergebnissen kann geschlussfolgert werden, dass der konservierte Glutamatrest und seine negative Gruppe im aktiven Zentrum von AOCs eine wichtige funktionelle Bedeutung für die Enzymreaktion hat, wie bereits von Schaller et al. (2008) beobachtet wurde. 


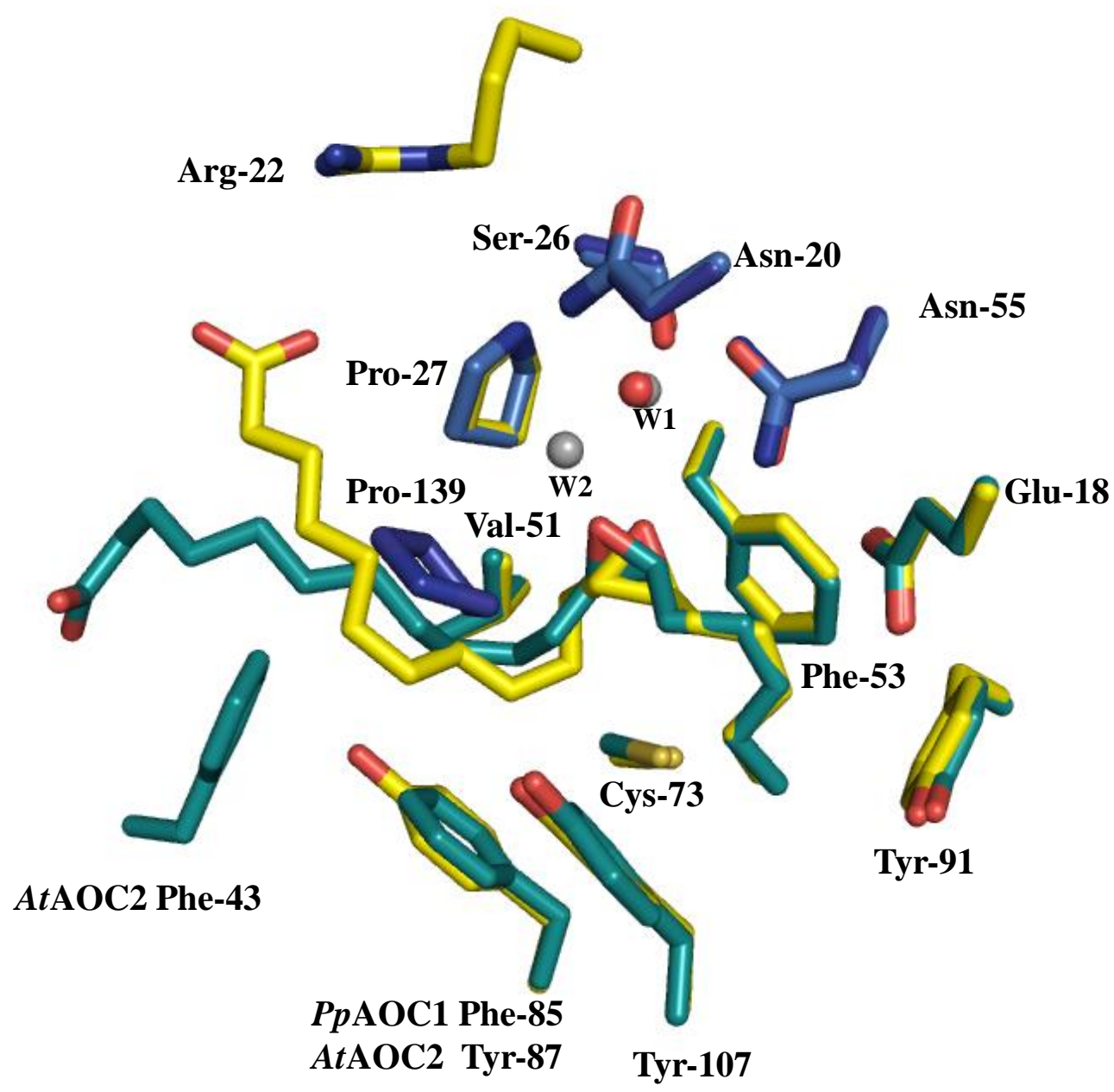

Abbildung 4.5: Aminosäurereste im aktiven Zentrum von PpAOC1 und AtAOC2: Grafische Überlagerung verschiedener Aminosäurereste von PpAOC1-Kette A (gelb) und AtAOC2-Kette B (grün) mit Ligand 12,13$\mathrm{EOD}^{\triangle 9 Z \Delta 15 Z}$. Anordnung des gebundenen Liganden $12,13-\mathrm{EOD}^{\triangle 9 Z \Delta 15 Z}$ und der Aminosäurereste gezeigt als Stabmodelle. Aminosäurereste, die jeweils Wasser koordinieren: PpAOC1 (blau); AtAOC2 (hellblau). Wenn nicht anders beschriftet, basiert die Nummerierung auf der PpAOC1-Sequenz.

Zudem zeigten die Arbeitsgruppe Schaller et al. (2008), dass ein Austausch des konservierten Val-49 (PpAOC1 Val-51) in Phenylalanin zur Erhöhung der relativen Enzymaktivität um $30 \%$ führte. Gleiche Ergebnisse wurden für den Austausch des konservierten Phe-51 (PpAOC1 Phe-53) in ein Tyrosin beobachtet. Diese Aminosäurereste interagieren in PpAOC1 und PpAOC2 ebenfalls mit dem Liganden, sowohl im schwachen als auch in festen gebundenen Zustand (Abbildung 3.38). Die untersuchten AtAOC2-Varianten (V49F und F53Y) zeigten zudem keinen Verlust der Stereoselektivität des Enzyms bei der OPDABildung. Möglicherweise können die Reste Tyrosin und Phenylalanin in den AtAOC2Varianten den Liganden noch stärker binden als die Ausgangsform. 
Unterschiede gibt es außerdem zwischen dem Aminosäurerest PpAOC1 Pro-27 und dem strukturäquivalenten AtAOC2 Pro-32. In PpAOC1 und PpAOC2 bildet der Prolinrest eine kovalente Bindung zum Liganden aus, hingegen koordiniert das Prolin in AtAOC2 das konservierte Wassermolekül. In Mutagenesestudien tauschten Schaller et al. (2008) das Pro32 gegen einen Valin aus, wodurch die relative Enzymaktivität der AtAOC2-Variante im Vergleich zur Ausgangsform um $40 \%$ niedriger war. Zusätzlich wurde von Schaller et al., (2008) ein vollständiger Verlust der relativen Stereoselektivität der AtAOC2 P32V Variante beobachtet. Diese Beobachtungen geben möglicherweise einen Hinweis auf die Funktionalität des Pro-32 für die Koordinierung des Wassermoleküls. In den Experimenten von Schaller et al. (2008) wurden auch die restlichen drei Aminosäurereste, die in AtAOC2 an der Bindung des Wassermoleküls beteiligt sind, ausgetauscht (jeweils N25L, S31A und N53L). Dabei zeigten die Varianten einen Verlust der relativen Enzymaktivität um jeweils 60 \%, $25 \%$ und $50 \%$ und einen Verlust der relativen Stereoselektivität um jeweils $30 \%, 20 \%$ und $10 \%$. Interessanterweise zeigte die AtAOC2-Doppelvariante S31A/N53L keinen Verlust ihrer relativen Enzymaktivität, bei einer Verringerung der relativen Stereoselektivität von $10 \%$ Schaller et al. (2008). Beide strukturäquivalenten Reste sind in PpAOC1 (Ser-26, Asn-55) und PpAOC2 (Ser-26, Asn-54) ebenfalls an der Koordination eines Wassermoleküls beteiligt. In PpAOC2 mit schwach gebundenem Liganden (Ketten B und E) ohne Wassermolekül im aktiven Zentrum koordiniert das strukturäquivalente Asn-55 zusätzlich den Liganden.

Jedoch scheinen nach Schaller et al. (2008) das Pro-32 und Asn-25 in AtAOC2 eine größere Bedeutung bei der Bindung des konservierten Wassers zu besitzen.

Wie oben beschrieben wurde in AtAOC2 eine Wechselwirkung zwischen dem Liganden und dem AtAOC2 Phe-43 beobachtet (Hofmann et al., 2006). Der Austausch des Phe-43 in ein Tyrosin von Schaller et al. (2008) hatte keinen Einfluss auf die relative Enzymaktivität von AtAOC2. Wie in Abbildung $4.5 \mathrm{zu}$ erkennen ist, ist der Ligand in AtAOC2 zum Phe-43 orientiert. Eine Vermutung ist, dass die aromatischen Aminosäurereste Phenylalanin und Tyrosin in AtAOC2 die Carboxylgruppe des Liganden 12,13-EOD stabilisieren können. Um diese Hypothese zu überprüfen, müsste der Phenylalaninrest gegen einen nicht-aromatischen Aminosäurerest ausgetauscht werden. Zudem befindet sich in AtAOC2 statt des positiv geladenen Argininrestes in PpAOC1 und PpAOC2 (Arg-21 bzw. Arg-22) ein Leucin (Leu27) am Eingang der Substratbindetasche. Schaller et al. (2008) zeigten, dass ein Austausch des Leucin 27 in ein Arginin die relative Enzymaktivität von AtAOC2 um $10 \%$ erhöhte, was durch optimalere Ligandenbindung über die Carboxylgruppe am Enzym erklärt werden könnte. Umgekehrt wurde in der vorliegenden Arbeit der strukturäquivalente Argininrest in 
PpAOC1 und PpAOC2 durch zielgerichtete Mutagenese in ein Leucin ausgetauscht (3.4.9). Die resultierenden Varianten zeigten unterschiedliche Ergebnisse für $P p A O C 1$ und $P p A O C 2$ (Abbildung 3.44). Während für PpAOC1 kein Einfluss auf die Enzymaktivität beobachtet wurde, zeigte die PpAOC2 R22L-Variante geringere Enzymaktivität im Vergleich zu Ausgangsform. In der Ligplot-Skizze (Abbildung 3.33 A) von PpAOC1-Kette A ist zu erkennen, dass der Prolinrest 27 ein Wassermolekül koordiniert, welches wiederum mit der Carboxylgruppe des Liganden wechselwirkt. In PpAOC1-Kette B hingegen (Abbildung 3.33 B), befindet sich ein aromatischer Phenylalaninrest (Phe-29) in der Nähe der Carboxylgruppe des Liganden. Dieses Phenylalanin koordiniert ebenfalls ein Wassermolekül, welches mit der Carboxylgruppe des Liganden wechselwirkt. Das könnte darauf hinweisen, dass die oben beschriebenen Reste Pro-27, bzw. Phe-29 indirekt über Wasserstoffbrücken die Carboxylgruppe des Liganden in PpAOC1 koordinieren.

Hofmann et al. 2006 postulierten den Einfluss des konservierten Aminosäurerestes Cys-73 auf die Enzymreaktion von AtAOC2. Schaller et al. (2008) tauschten das Cystein jeweils durch Leucin, Alanin und Tyrosin aus. Jedoch zeigte ausschließlich die C73Y-Variante einen völligen Verlust der Enzymaktivität. Dieser Einfluss könnte jedoch durch das größere Volumen und die besonderen chemischen Eigenschaften eines Tyrosinrestes im Vergleich zu Cystein bedingt sein. Bei Austausch des Cys-73 in Alanin oder Serin wurde normale Enzymaktivität der Varianten beobachtet. Aus diesen Ergebnissen lässt sich schlussfolgern, dass ein Cysteinrest an dieser Position in AOC-Enzymen nicht obligat ist.

Wie bereits oben erwähnt, befindet sich im aktiven Zentrum von PpAOC1, bzw. PpAOC2 ein Tyrosinrest anstelle des Phe-85 in AtAOC2. Schaller et al. (2008) tauschten das Phe-85 jeweils gegen Alanin und Leucin aus. Die Analyse der Leucin-Variante zeigte eine 20 \%igen Verlust und der Alanin-Variante einen 45 \%igen Verlust der Enzymaktivität. Jedoch war die relative Stereoselektivität der Varianten nur um jeweils $10 \%$ und $30 \%$ reduziert.

In der vorliegenden Arbeit wurden für PpAOC2 zwei verschiedene Bindemodi des Liganden beobachtet (Abbildung 3.40). Zwischen den Ketten mit festgebundenen Liganden und AtAOC2 Kette B wurden nur wenig strukturelle und konformelle Unterschiede beobachtet (nicht gezeigt). Zum Vergleich von AtAOC2 und dem schwachen Bindemodus in PpAOC2 ist in Abbildung 4.6 eine grafische Überlagerung von PpAOC2-Kette B und AtAOC2 Kette B gezeigt. Dargestellt sind jeweils Aminosäurereste des aktiven Zentrums, die an der Ligandenbindung beteiligt sind. 


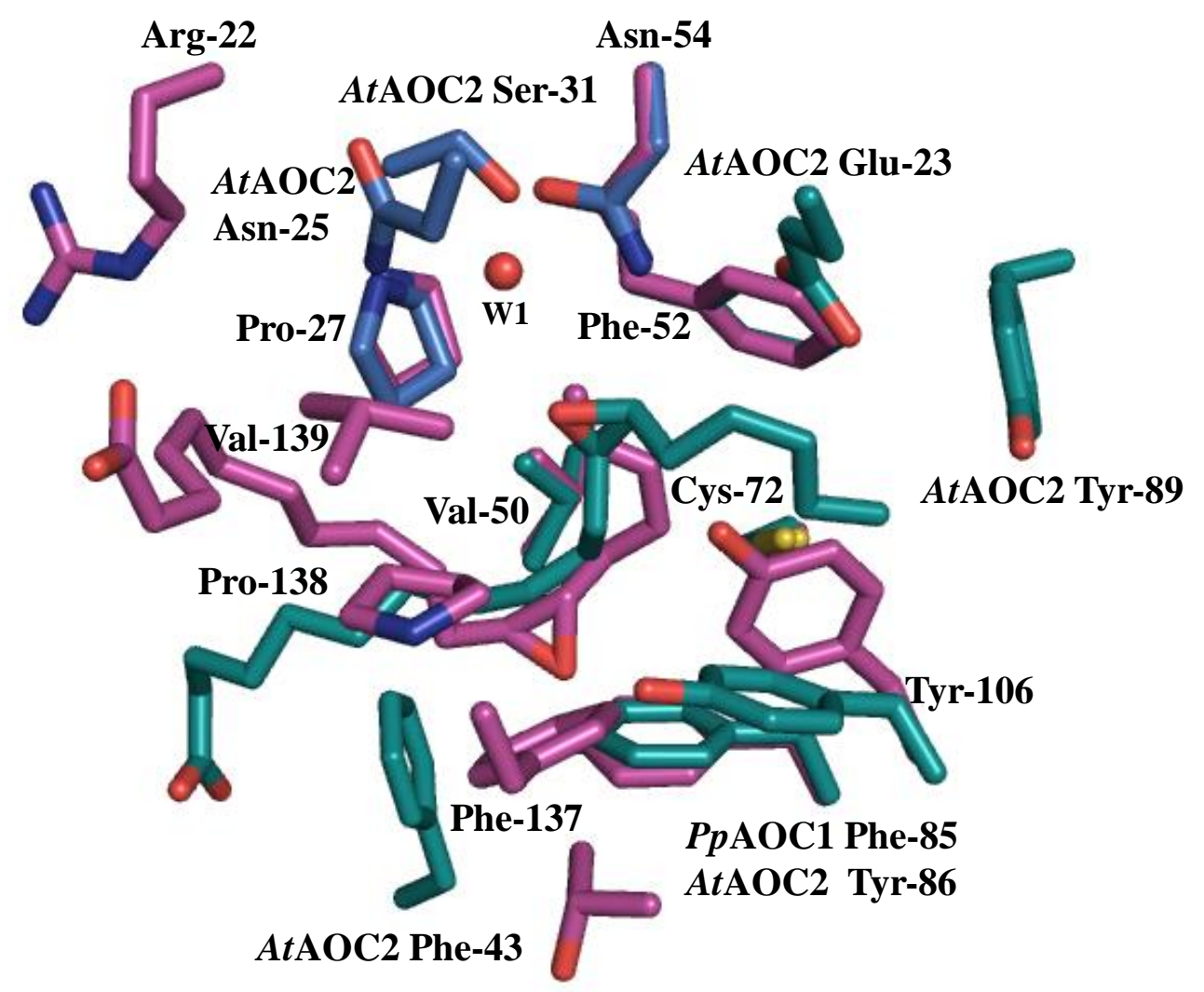

Thr-108

Abbildung 4.6: Aminosäurereste im aktiven Zentrum von PpAOC2 und AtAOC2. Grafische Überlagerung verschiedener Aminosäurereste von PpAOC2-Kette B (magenta) und AtAOC2-Kette B (grün) mit Ligand 12,13$\mathrm{EOD}^{\triangle 9 Z \Delta 15 Z}$. Anordnung des gebundenen Liganden $12,13-\mathrm{EOD}^{\triangle 9 Z \Delta 15 Z}$ und der Aminosäurereste gezeigt als Stabmodelle. Aminosäurereste, die in AtAOC2 das Wasser koordinieren (hellblau). Wenn nicht anders beschriftet, basiert die Nummerierung auf der $P p A O C 2$-Sequenz.

Wie beim Vergleich von PpAOC2 Kette B und PpAOC1 Kette A (Abbildung 3.43) ist zu erkennen, dass in PpAOC2 Kette B (magenta) im Vergleich zu AtAOC2-Kette B (grün) mehr Aminosäurereste des aktiven Zentrums mit dem Liganden $12,13-\mathrm{EOD}^{\triangle 9 Z \Delta 15 Z}$ interagieren. In PpAOC2 Kette B sind zusätzlich die Reste Arg-22, Pro-27, Thr-108, Phe-137, Pro-138, und Val-139 an der Bindung des Liganden beteiligt. Ähnliche Unterschiede wurden auch beim Vergleich der unterschiedlichen Bindemodi von PpAOC2 beobachtet (3.4.7). In AtAOC2 interagiert zusätzlich im vorderen Bereich der Substratbindetasche Phe-43 und im hinteren Bereich Glu-23 und Tyr-89 mit dem Liganden.

Das Strukturäquivalent zu PpAOC2 Val-139 ist in PpAOC1 und AtAOC2 jeweils von einem Threonin- oder Phenylalaninrest bestimmt. In den PpAOC2-Ketten mit festgebundenem Liganden ist zudem das Tyr-143 an der Bindung des Liganden beteiligt. Vielleicht spielen diese Reste bei der Koordinierung der $\mathrm{C}_{20}$-Allenoxide eine Rolle. Jedoch ist zum derzeitigen Stand der Arbeit der Datensatz mit 11,12-EET im aktiven Zentrum nicht endgültig verfeinert 
worden, weil die Elektronendichte für den mittleren Bereich des Liganden nicht eindeutig definiert ist (P. Neumann, persönliche Mitteilung). Erst durch die Analyse der Aminosäurereste im möglichen PpAOC2-11,12-EET Strukturmodell und zusätzliche Mutagenesestudien könnte diese Theorie bestätigt werden.

Somit kann geschlussfolgert werden, dass zwischen den festgebundenen Liganden in AtAOC2 und PpAOC1, bzw. PpAOC2 jeweils wenig strukturelle und konformelle Unterschiede bestehen. In AtAOC2 interagiert wahrscheinlich Phe-43 im vorderen Bereich der Substratbindetasche mit der Carboxylgruppe des Liganden. In PpAOC1 spielen die Aminosäurereste Pro-27 bzw. Phe-29 bei der Fixierung der Carboxylgruppe möglicherweise eine Rolle. Jedoch muss diese Hypothese durch Austausch von Pro-27 und/oder Phe-29 durch zielgerichtete Mutagenese in PpAOC1 bestätigt werden. In vier von sechs PpAOC2-Ketten ist das Arg-22 an der Fixierung der Carboxylgruppe des Liganden beteiligt. Durch zielgerichtete Mutagenese wurde diese Beobachtung zusätzlich gestützt. Der Einfluss der Strukturäquivalente der konservierten Reste Ser-26, Pro-27, Val-50, bzw. -51, Phe-52 bzw. 53, Asn-54 bzw. -55, Cys-72 bzw. -73 in PpAOC1, bzw. PpAOC2 wurden in AtAOC2 bereits untersucht (Schaller et al., 2008). Zusätzlich könnte durch Mutagenesestudien an PpAOC1 und PpAOC2 der Einfluss der Reste Ser-26 und Asn-54 bzw. Asn-55 auf die Wasserkoordinierung überprüft werden. Dabei sollten sowohl die Einzel- als auch Doppelvarianten analysiert werden. Für PpAOC1 wäre zudem interessant, die Bedeutung des zweiten Wassermoleküls für die Enzymaktivität durch zielgerichtete Mutagenese zu überprüfen. Dieses zweite Wassermolekül wird von Asn-20 und Pro-139 gebunden und ist nicht im aktiven Zentrum von AtAOC2 und PpAOC2 gebunden.

Darüber hinaus gibt es zwischen den untersuchten AOC-Enzymen jeweils größere konformelle Unterschiede zwischen den Aminosäureresten Tyr-106, bzw. Tyr-107 und Phe137, bzw. Phe-138. Da diese Reste in AtAOC2 von Schaller et al. (2008) nicht untersucht wurden, wäre die zielgerichtete Mutagenese in kleinere und/oder weniger polare Reste sehr sinnvoll. Vielleicht wird dadurch der postulierte AOC-Reaktionsmechanismus von Hofmann et al., (2006) weiter geklärt.

\subsubsection{Reaktionsmechanismus von AOCs}

Wie eingangs beschrieben (1.4.1), wurde ein Reaktionsmechanismus von AOC anhand der AtAOC2-Struktur und von Mutagenesestudien postuliert (Hofmann et al., 2006, Schaller et al., 2008). Nachdem das Substrat gebunden hat, wird das Epoxyd geöffnet und ein Pentadienyl-Kation gebildet. Die negative Ladung des AtAOC2 Glu-23 unterstützt die Delokalisation von $\pi$-Elektronen der C15-Doppelbindung in Richtung des Epoxydes, wodurch 
dessen Öffnung gefördert wird. Die Ringschlussreaktion erfolgt nach den Mechanismen der anchimeren Assistenz (oder auch Nachbargruppenbeteiligung) über das gebildete Carbokation, dessen Ladung zwischen C13 und C16 verteilt ist. Die Bildung des Oxyanions wird durch das konservierte Wassermolekül im aktiven Zentrum stabilisiert. Diese Möglichkeit der Zyklisierung von Allenoxiden über anchimere Assistenz der $\beta, \gamma$ Doppelbindung ( $\triangle \mathrm{C} 15)$ wurde bereits 1994 von Grechkin postuliert (Grechkin, 1994). Für den folgenden perizyklischen Ringschluss ist eine Konformationsänderung der C10 - C11 Bindung von cis zu trans Geometrie unter Bildung eines nicht-planaren, ringähnlichen Pentadienyl-Carbokations erforderlich. Ein Phenylalanin (AtAOC2 Phe-51) sowie ein Cysteinrest (AtAOC2 Cys-71) im aktiven Zentrum könnten diesen Vorgang stabilisieren. Dieser hypothetische Reaktionsmechanismus ermöglicht als letzten Schritt einen dipolaren perizyklischen Ringschluss, entsprechend den Woodward-Hoffmann Regeln. Dieser Reaktionsmechnismus lässt sich mit der vorliegenden Arbeit gesammelten Daten ebenfalls gut erklären. Mit den PpAOC1- und PpAOC2-Struktur- und Mutagensedaten, lässt sich der von Hofmann et al. (2006) postulierte AOC-Reaktionsmechnanismus zu mindestens nicht widerlegen. Es könnte nur vermutet werden, dass die von Hofmann et al. (2006) beschriebenen Aminosäurerste AtAOC2 Phe-51 und Cys-71 geringeren Einfluss auf den Mechanismus haben, wie die Studien von Schaller et al. (2008) zeigen. Dafür könnten andere Aminosäurereste, wie z. B. PpAOC2 Tyr-107, Phe-137, Pro-138 und Val-139 an der Stabilisierung der beschriebenen Übergangszustände beteiligt sein. Diese Hypothese muss jedoch durch Austausch der Reste überprüft werden. Zudem sollte die Funktion des zweiten Wassermoleküls in PpAOC1 näher untersucht werden.

Abschließend kann zusammengefasst werden, dass die Strukturdaten von PpAOC1 und PpAOC2 den Substratbindungsvorgang in AOCs erklären könnten. Bei Bindung des Substrates wird die Carboxylgruppe des Liganden entweder von einem aromatischen Aminosäurerest oder einem Arginin (Arg-22) fixiert. Zunächst bindet das Substrat mit der Allenoxidgruppe zum Phe-138, bzw. Phe-137. Die C15-Doppelbindung ist zum Tyr-107, bzw. 106 orientiert. Im nächsten Schritt orientiert sich die Allenoxidgruppe mit einer Drehung um ca. $180^{\circ}$ zum konservierten Wassermolekül. Die C15-Doppelbindung interagiert dann mit einem konservierten Glutamatrest (Glu-18).

In der veröffentlichten AtAOC2-Struktur war in nur einem Monomer der Ligand 12,13$\mathrm{EOT}^{\Delta 9 \mathrm{Z}}$ gebunden und es wurde nicht geklärt, ob auch tatsächlich immer ein oder mehrere Monomere eines AOC-Trimers von einem Liganden besetzt sind (Hofmann et al., 2006). In der asymmetrischen Einheit von PpAOC1 waren vier Trimere vorhanden, von denen drei 
Trimere jeweils ein nur ein Molekül 12,13-EOT ${ }^{\Delta 9 Z \Delta 15 Z}$ gebunden hatten (Kette A, Kette B und Kette G). In einem der Trimere waren jedoch zwei Liganden gebunden (Kette G und Kette H). In PpAOC2 hingegen, befanden sich zwei Trimere in der asymmetrischen Einheit, in denen jedes der sechs Monomere vom Ligand 12,13-EOT besetzt war. Dadurch kann geschlussfolgert werden, dass in P. patens mehr als ein Monomer des AOC-Trimers das Substrat bindet. Allerdings sollte angemerkt werden, dass Ergebnisse aus Kristallstrukturen nicht direkt auf die Situation eines Proteins in Lösung übertragen werden können. Insbesondere vor dem Hintergrund, dass die Inkubation mit den Substratanalogen über mehrere Stunden bis zu einem Tag verlief, könnte der Besetzungsgrad im Kristall artifiziell sein. 


\section{ZUSAMMENFASSUNG}

Im Rahmen der vorliegenden Dissertation wurden Enzyme des Oxylipinstoffwechsels in $P$. patens funktionell und strukturell charakterisiert. Dafür wurden die bifunktionelle PpLOX1 und zwei AOCs (PpAOC1 und PpAOC2) ausgewählt. Mittels verschiedener biochemischer, bioinformatischer und biophysikalischer Methoden wurden diese Enzyme bezüglich Funktion, Aktivität und Struktur charakterisiert. Desweiteren wurden nach erfolgreicher Kristallisation von PpAOC1 und PpAOC2 die hochaufgelösten Röntgenkristallstrukturen beider Enzyme im Grundzustand sowie im Komplex mit Substratanalogen gelöst. Für PpAOC2 wurden dabei zwei verschiedene Bindemodi des Liganden beobachtet.

Der Einfluß der Aminosäurereste Arg-345, Arg-638 und Tyr-851 auf den Reaktionsmechanismus von PpLOX1 wurde durch zielgerichtete Mutagenese und nachfolgende Analyse der Produktbildung durch die erhaltenen Varianten untersucht. Es wurden keine signifikanten Unterschiede bei der Umsetzung verschiedener Fettsäuren durch das Ausgangsenzym oder die Varianten R345L bzw. R638L gefunden. Dagegen zeigte die Doppelvariante R345L/R638L eine stark verringerte Menge an gebildeten Produkten. Demnach scheint zumindest das Vorliegen einer dieser beiden positiv geladenen Reste wichtig für die Umsetzung der Substrate zu sein. Möglicherweise wird die negativ geladene Carboxylatgruppe der jeweiligen Fettsäure durch elektrostatische Wechselwirkungen über Arg-345 oder Arg-638 gebunden. Die Variante Y851I bildete geringere Mengen von 12ODTE, Keto-Fettsäuren und auch weniger Produkt als das Ausgangsenzym. Demnach scheint auch dieser Rest an der Katalyse beteiligt zu sein. Da aber für die Variante Y851F sogar ein erhöhter Anteil an 12-ODTE gefunden wurde, scheint der voluminöse und hydrophobe aromatische Ring, und nicht die Hydroxyl-Gruppe des Tyrosin, wichtig zu sein.

Die gereinigten Enzyme PpAOC1 und PpAOC2 wurden für Aktivitätstest mit verschiedenen $\mathrm{C}_{20}$-Fettsäure-Hydroperoxiden verwendet. Beide Enzyme zeigten Aktivität gegenüber den 15Hydroperoxiden von EPA und ETA, jedoch nicht von AA. Darüber hinaus besitzt PpAOC2, aber nicht PpAOC1, Aktivität für die 12-Hydroperoxide welche sich von AA, EPA und DGLA ableiten. Es wurden zusätzlich zu 11-OPTA bislang nicht beschriebene zyklische Verbindungen gebildet, deren chemische Struktur durch Fragmentierung mittels ESI-MS/MS aufgeklärt wurde.

In den vorliegenden Studien zu PpAOC1 und PpAOC2 wurde das Glutamat an Position 18 jeweils durch Glutamin oder Aspartat ausgetauscht. Es wurde gezeigt, dass der konservierte Glutamatrest und seine negative Carboxylatgruppe in beiden Enzymen essenziell für die 
Katalyse ist. Dagegen wurde für die Variante R22L lediglich ein Einfluß auf die Aktivität in PpAOC2 gefunden.

Im aktiven Zentrum von PpAOC1 werden zwei Wassermoleküle von vier Aminosäureresten koordiniert, während in PpAOC2 ein Wassermolekül von zwei Aminosäureresten gebunden ist. Inwiefern diese Wassermoleküle an der Katalyse beteiligt sind, konnte bisher nicht eindeutig geklärt werden. 


\section{SUMMARY}

During the presented doctoral thesis enzymes of the oxylipin metabolism from P. patens have been purified \& described. Therefore, the bifunctional PpLOX1 \& two AOC enzymes (PpAOC1 \& PpAOC2) have been selected. Using different biochemical, bioinformatical \& biophysical approaches these enzymes were investigated regarding structure, function \& activity. High resolution X-ray structures of both, PpAOC1 \& PpAOC2, were obtained in the ground states of these enzymes as well as in complex with substrate analogue compounds. Two different modes of binding for such a ligand was found in the structure of PpAOC2.

The influence of Arg-345, Arg-638 \& Tyr-851 on the reaction mechanism of PpLOX1 was investigated by site directed mutagensis \& subsequent analysis of the product pattern of the respective variants using different fatty acid substrates. No distinct differences compared to the wildtype enzyme were found using the variants R345L \& R638L. However, the particular double mutant (R345L/R638L) showed a clear impairment resulting in significantly decreased amounts of reaction products. At least one of this positively charged residues might thus be important for binding of the substrate, maybe by an electrostatic interaction to the negatively charged carboxylate of the fatty acid. The variant Y851I produced less amounts of 12-ODTE $\&$ keto-fatty acids \& also a decreased amount of products indicating an involvement of this residue in catalysis. However, when Y851 is exchanged by phenylalanine an increase in the relative amount of 12-ODTE was observed. Thus, not the hydroxyl-group of tyrosine 851 but the huge hydrophobic \& aromatic system seems to be important.

The purified enzymes $P p A O C 1 \&$ PpAOC2 were applied for activity measurements using hydroperoxy-derivatives of $\mathrm{C}_{20}$-fatty acids. For both enzymes activity for turnover of the 15hydroperoxids derived from EPA \& ETA, but not from AA was detected. Furthermore, $P p A O C 2$ but not $P p A O C 1$ is able to convert the 12-hydroperoxides derived from AA, EPA \& DGLA. Additional to 11-OPTA, several hitherto undescribed cyclic compounds were formed $\&$ their chemical structure could be validated using ESI-MS/MS.

In $P p A O C 1 \& P p A O C 2$ the conserved glutamate 18 was exchanged by glutamine or aspartate. This residue is obviously essential for catalysis in both enzymes. For the variant R22L on the other hand only a catalytic impairment in PpAOC2, but not in PpAOC1 was found.

The X-ray-structures revealed the presence of coordinated water molecules in the active sites of both AOC enzymes. While in PpAOC1 two water molecules are organized by four amino 
acids, in PpAOC2 only one water molecule is bound by two residues. Whether these water molecules are involved in the reaction mechanism remains to be elucidated. 


\section{LITERATURVERZEICHNIS}

Adams, P.D., Afonine, P.V., Bunkoczi, G., Chen, V.B., Davis, I.W., Echols, N., Headd, J.J., Hung, L.W., Kapral, G.J., Grosse-Kunstleve, R.W., Mccoy, A.J., Moriarty, N.W., Oeffner, R., Read, R.J., Richardson, D.C., Richardson, J.S., Terwilliger, T.C. \& Zwart, P.H. PHENIX: a comprehensive Python-based system for macromolecular structure solution. Acta Crystallogr D Biol Crystallogr, 66: 213-21.

Adie, B., Chico, J., Rubio-Somoza, I. \& Solano, R. (2007). Modulation of Plant Defenses by Ethylene. Journal of Plant Growth Regulation, 26: 160-177.

Almeras, E., Stolz, S., Vollenweider, S., Reymond, P., Mene-Saffrane, L. \& Farmer, E.E. (2003). Reactive electrophile species activate defense gene expression in Arabidopsis. Plant J, 34: 205-16.

Andreou, A.-Z., Hornung, E., Kunze, S., Rosahl, S. \& Feussner, I. (2009a). On the substrate binding of linoleate 9-lipoxygenases. Lipids, 44: 207-215.

Andreou, A.-Z., Vanko, M., Bezakova, L. \& Feussner, I. (2008). Properties of a mini 9Rlipoxygenase from Nostoc sp. PCC 7120 \& its mutant forms. Phytochemistry, 69: $1832-1837$.

Andreou, A., Brodhun, F. \& Feussner, I. (2009b). Biosynthesis of oxylipins in non-mammals. Prog Lipid Res, 48: 148-170.

Andreou, A. \& Feussner, I. (2009). Lipoxygenases - Structure \& reaction mechanism. Phytochemistry, 70: 1504-1510.

Anterola, A., Göbel, C., Hornung, E., Sellhorn, G., Feussner, I. \& Grimes, H. (2009). Physcomitrella patens has lipoxygenases for both eicosanoid \& octadecanoid pathways. Phytochemistry, 70: 40-52.

Ausubel, F.M., Brent, R.E., Kingston, D.D., Seidmann, J.R., Smith, J.A. \& Struhl, K. (1993). Current Protocolls in Molecular Biology, New York: Green Publishing Associates \& John Wiley \& Sons Inc.

Axelrod, B., Cheesbrough, T.M. \& Laakso, S. (1981). Lipoxygenase from soybeans. Methods Enzymol, 71: 441-451.

Bednarek, P., Schneider, B., Svatos, A., Oldham, N.J. \& Hahlbrock, K. (2005). Structural complexity, differential response to infection, \& tissue specificity of indolic \& phenylpropanoid secondary metabolism in Arabidopsis roots. Plant Physiol, 138: 1058-70.

Belkner, J., Stender, H. \& Kühn, H. (1998). The rabbit 15-lipoxygenase preferentially oxygenates LDL cholesterol esters, \& this reaction does not require vitamin E. J Biol Chem, 273: 23225-23232.

Belkner, J., Wiesner, R., Kühn, H. \& Lankin, V.Z. (1991). The oxygenation of cholesterol esters by the reticulocyte lipoxygenase. FEBS Lett, 279: 110-114. 
Bell, E., Creelman, R.A. \& Mullet, J.E. (1995). A chloroplast lipoxygenase is required for wound-induced jasmonic acid accumulation in Arabidopsis. Proc Natl Acad Sci USA, 92: 8675-8679.

Berg, J., Tymoczko, J. \& Stryer, L. (2004). Biochemistry, New York: WH Freeman.

Berger, S., Weichert, H., Porzel, A., Wasternack, C., Kühn, H. \& Feussner, I. (2001). Enzymatic \& non-enzymatic lipid peroxidation in leaf development. Biochem Biophys Acta, 1533: 266-276.

Birkett, M.A., Campbell, C.A., Chamberlain, K., Guerrieri, E., Hick, A.J., Martin, J.L., Matthes, M., Napier, J.A., Pettersson, J., Pickett, J.A., Poppy, G.M., Pow, E.M., Pye, B.J., Smart, L.E., Wadhams, G.H., Wadhams, L.J. \& Woodcock, C.M. (2000). New roles for cis-jasmone as an insect semiochemical \& in plant defense. Proc Natl Acad Sci USA, 97: 9329-34.

Bisakowski, B., Perraud, X. \& Kermasha, S. (1997). Characterization of hydroperoxides \& carbonyl compounds obtained by lipoxygenase extracts of selected microorganisms. Biosci Biotechnol Biochem, 61: 1262-1269.

Blée, E. (2002). Impact of phyto-oxylipins in plant defense. Trends Plant Sci, 7: 315-322.

Bode, Julia (2005). Oxylipinprofil des Mooses Physcomitrella patens. Diplomarbeit, GeorgAugust-Universität, Göttingen

Boeglin, W., Itoh, A., Zheng, Y., Coffa, G., Howe, G. \& Brash, A. (2008). Investigation of substrate binding \& product stereochemistry issues in two linoleate 9-lipoxygenases. Lipids, 43: 979-987.

Borngräber, S., Kuban, R.J., Anton, M. \& Kühn, H. (1996). Phenylalanine 353 is a primary determinant for the positional specificity of mammalian 15-lipoxygenases. $J$ Mol Biol, 264: 1145-1153.

Boyington, J.C., Gaffney, B.J. \& Amzel, L.M. (1993). Structure of soybean lipoxygenase-I. Biochem Soc Trans, 21: 744-748.

Bradford, M.M. (1976). A rapid \& sensitive method for the quantitation of microgram quantities of proteins utilizing the principle of protein-dye binding. Anal Biochem, 72: 248-254.

Brash, A.R. (1989). Formation of an allene oxide from (8R)-8-hydroperoxyeicosatetraenoic acid in the coral Plexaura homomalla.J Am Chem Soc, 111: 1891-1892.

Brash, A.R. (1999). Lipoxygenases: Occurrence, functions, catalysis, \& acquisition of substrate. J Biol Chem, 274: 23679-23682.

Brash, A.R., Baertschi, S.W., Ingram, C.D. \& Harris, T.M. (1988). Isolation \& characterization of natural allene oxides: unstable intermediates in the metabolism of lipid hydroperoxides. Proc Natl Acad Sci USA, 85: 3382-3386. 
Brash, A.R., Boeglin, W.E., Chang, M.S. \& Shieh, B.-H. (1996). Purification \& molecular cloning of an $8 R$-lipoxygenase from the coral Plexaura homomalla reveal the related primary structures of $R$ - \& S-lipoxygenases. J Biol Chem, 271: 20949-20957.

Brodhun, F., Gobel, C., Hornung, E. \& Feussner, I. (2009). Identification of PpoA from Aspergillus nidulans as a fusion protein of a fatty acid heme dioxygenase/peroxidase \& a cytochrome P450. J Biol Chem, 284: 11792-11805.

Brodhun, F., Schneider, S., Gobel, C., Hornung, E. \& Feussner, I. PpoC from Aspergillus nidulans is a fusion protein with only one active haem. Biochem J, 425: 553-65.

Browner, M.F., Gillmor, S.A. \& Fletterick, R. (1998). Burying a charge. Nat Struct Biol, 5: 179.

Browse, J. (2005). Jasmonate: An oxylipin signal with many roles in plants. Vitam Hormones, $72: 431-456$.

Browse, J. (2009a). Jasmonate passes muster: A receptor \& targets for the defense hormone. Annu Rev Plant Biol: doi:10.1146/annurev.arplant.043008.092007.

Browse, J. (2009b). Jasmonate: Preventing the Maize Tassel from Getting in Touch with His Feminine Side. Sci Signal, 2: pe9-.

Brunger, A.T. (1997). Free R value: cross-validation in crystallography. Methods Enzymol, 277: 366-96.

Brunger, A.T., Adams, P.D. \& Rice, L.M. (1998). Recent developments for the efficient crystallographic refinement of macromolecular structures. Curr Opin Struct Biol, 8: 606-11.

Bullock, W.D., Fernandez, J.M. \& Hort, J.M.S. (1987). XL1-Blue: A high efficiency plasmid transformants recA Escherichia coli strain b-galactosidase selection. BioTechniques, 5: 376-378.

Castillo, M.C., Martinez, C., Buchala, A., Metraux, J.-P. \& Leon, J. (2004). Gene-Specific Involvement of $\beta$-Oxidation in Wound-Activated Responses in Arabidopsis. Plant Physiol, 135: 85-94.

Choi, J., Chon, J.K., Kim, S. \& Shin, W. (2008). Conformational flexibility in mammalian 15S-lipoxygenase: Reinterpretation of the crystallographic data. Proteins, 70: 102332.

Coffa, G. \& Brash, A.R. (2004). A single active site residue directs oxygenation stereospecificity in lipoxygenases: Stereocontrol is linked to the position of oxygenation. Proc Natl Acad Sci USA, 101: 15579-15584.

Coffa, G., Schneider, C. \& Brash, A.R. (2005). A comprehensive model of positional \& stereo control in lipoxygenases. Biochem Biophys Res Commun, 338: 87-92.

Conconi, A., Miquel, M., Browse, J.A. \& Ryan, C.A. (1996). Intracellular levels of free linolenic \& linoleic acids increase in tomato leaves in response to wounding. Plant Physiol, 111: 797-803. 
Cove, D., Bezanilla, M., Harries, P. \& Quatrano, R. (2006). MOSSES AS MODEL SYSTEMS FOR THE STUDY OF METABOLISM \& DEVELOPMENT. Annu Rev Plant Biol, 57: 497-520.

Creelman, R.A. \& Mullet, J.E. (1997). Biosynthesis \& action of jasmonates in plants. Ann Rev Plant Physiol Plant Mol Biol, 48: 355-381.

Crombie, L. \& Morgan, D.O. (1991). Synthesis of <14,14-H-2(2)>-Linolenic Acid \& Its Use to Confirm the Pathway to 12-Oxophytodienoic Acid (12-oxoPDA) in Plants - A Conspectus of the Epoxycarbonium Ion Derived Family of Metabolites from Linoleic \& Linolenic Acid Hydroperoxides. J Chem Soc-Perkin Trans I: 581-587.

Dembitsky, V.M. (1993). Lipids of bryophytes. Prog Lipid Res, 32: 281-356.

Dueckershoff, K., Mueller, S., Mueller, M.J. \& Reinders, J. (2008). Impact of cyclopentenone-oxylipins on the proteome of Arabidopsis thaliana. Biochim Biophys Acta, 1784: 1975-85.

Emsley, P. \& Cowtan, K. (2004). Coot: model-building tools for molecular graphics. Acta Crystallogr D Biol Crystallogr, 60: 2126-32.

Evans, P. (2006). Scaling \& assessment of data quality. Acta Crystallogr D Biol Crystallogr, 62: 72-82.

Farmer, E.E., Alméras, E. \& Krishnamurthy, V. (2003). Jasmonates \& related oxylipins in plant responses to pathogenesis \& herbivory. Curr Opin Plant Biol, 6: 372-378.

Farmer, E.E. \& Ryan, C.A. (1992). Octadecanoid precursors of jasmonic acid activate the synthesis of wound-inducible proteinase inhibitors. Plant Cell, 4: 129-134.

Feussner, I., Balkenhohl, T.J., Porzel, A., Kühn, H. \& Wasternack, C. (1997). Structural elucidation of oxygenated storage lipids in cucumber cotyledons - Implication of lipid body lipoxygenase in lipid mobilization during germination. J Biol Chem, 272: 2163521641.

Feussner, I., Balkenhohl, T.J., Porzel, A., Kühn, H. \& Wasternack, C. (1998). Structural elucidation of oxygenated triacylglycerols in cucumber \& sunflower cotyledons. IN Schreier, P., Herderich, M., Humpf, H.-U. \& Schwab, W. (Eds.) Natural Product Analysis. Braunschweig: Vieweg.

Feussner, I., Hause, B., Vörös, K., Parthier, B. \& Wasternack, C. (1995). Jasmonate-induced lipoxygenase forms are localized in chloroplasts of barley leaves (Hordeum vulgare cv Salome). Plant J, 7: 949-957.

Feussner, I. \& Kühn, H. (2000). Application of lipoxygenases \& related enzymes for the preparation of oxygenated lipids. IN Bornscheuer, U.T. (Ed.) Enzymes in Lipid Modification. Weinheim, Germany: Wiley-VCH.

Feussner, I. \& Wasternack, C. (2002). The lipoxygenase pathway. Annu Rev Plant Biol, 53: 275-297. 
Frank, W., Decker, E.L. \& Reski, R. (2005). Molecular tools to study Physcomitrella patens. Plant Biol, 7: 220-227.

Froehlich, J.E., Itoh, A. \& Howe, G.A. (2001). Tomato allene oxide synthase \& fatty acid hydroperoxide lyase, two cytochrome P450s involved in oxylipin metabolism, are targeted to different membranes of chloroplast envelope. Plant Physiol, 125: 306-317.

Fuller, M.A., Weichert, H., Fischer, A.M., Feussner, I. \& Grimes, H.D. (2001). Activity of soybean lipoxygenase isoforms against esterified fatty acids indicates functional specificity. Arch Biochem Biophys, 388: 146-154.

Funk, C.D. (2001). Prostaglandins \& leukotrienes: advances in eicosanoid biology. Science, 294: 1871-5.

Funk, C.D. \& Loll, P.J. (1997). A molecular dipstick? Nat Struct Biol, 4: 966-968.

Gan, Q.F., Browner, M.F., Sloane, D.L. \& Sigal, E. (1996). Defining the arachidonic acid binding site of human 15- lipoxygenase - molecular modeling \& mutagenesis. $J$ Biol Chem, 271: 25412-25418.

Gao, X., Stumpe, M., Feussner, I. \& Kolomiets, M. (2008). A novel plastidial lipoxygenase of maize (Zea mays) ZmLOX6 encodes for a fatty acid hydroperoxide lyase \& is uniquely regulated by phytohormones \& pathogen infection. Planta, 227: 491-503.

Gardner, H.W. (1991). Recent investigations into the lipoxygenase pathway of plants. Biochim Biophys Acta, 1084: 221-239.

Gerhardt, B., Fischer, K., Balkenhohl, T.J., Pohnert, G., Kühn, H., Wasternack, C. \& Feussner, I. (2005). Lipoxygenase-mediated metabolism of storage lipids in germinating sunflower cotyledons \& b-oxidation of $(9 Z, 11 E, 13 S)$-13-hydroxyoctadeca-9,11-dienoic acid by the cotyledonary glyoxysomes. Planta, 220: 919-930.

Gillmor, S.A., Villasenor, A., Fletterick, R., Sigal, E. \& Browner, M.F. (1998). The structure of mammalian 15-lipoxygenase reveals similarity to the lipases $\&$ the determinants of substrate specificity. Nat Struct Biol, 4: 1003-1009.

Glasgow, W.C., Harris, T.M. \& Brash, A.R. (1986). A short-chain aldehyde is a major lipoxygenase product in arachidonic acid-stimulated porcine leukocytes. $J$ Biol Chem, 261: 200-204.

Göbel, C., Feussner, I., Schmidt, A., Scheel, D., Sanchez-Serrano, J., Hamberg, M. \& Rosahl, S. (2001). Oxylipin profiling reveals the preferential stimulation of the 9-lipoxygenase pathway in elicitor-treated potato cells. J Biol Chem, 276: 6267-6273.

Grechkin, A. (1998). Recent developments in biochemistry of the plant lipoxygenase pathway. Prog Lipid Res, 37: 317-352.

Grimsley, N.H., Grimsley, J.M. \& Hartmann, E. (1981). Fatty acid composition of mutants of the moss Physcomitrella patens. Phytochemistry, 20: 1519-1524.

Hamberg, M. (1988). Biosynthesis of 12-oxo-10,15(Z)-phytodienoic acid: identification of an allene oxide cyclase. Biochem Biophys Res Comm, 156: 543-550. 
Hamberg, M. \& Fahlstadius, P. (1990). Allene oxide cyclase: a new enzyme in plant lipid metabolism. Arch Biochem Biophys, 276: 518-526.

Hamberg, M., Ponce De Leon, I., Rodriguez, M.J. \& Castresana, C. (2005). a-Dioxygenases. Biochem Biophys Res Commun, 338: 169-74.

Hamberg, M., Sanz, A. \& Castresana, C. (1999). a-oxidation of fatty acids in higher plants Identification of a pathogen-inducible oxygenase (PIOX) as an a-dioxygenase \& biosynthesis of 2-hydroperoxylinolenic acid. J Biol Chem, 274: 24503-24513.

Harms, K., Atzorn, R., Brash, A., Kühn, H., Wasternack, C., Willmitzer, L. \& Pena-Cortes, H. (1995). Expression of a flax allene oxide synthase cDNA leads to increased endogenous jasmonic acid (JA) levels in transgenic potato plants but not to a corresponding activation of JA- responding genes. Plant Cell, 7: 1645-1654.

Hayes, J.D. \& Mclellan, L.I. (1999). Glutathione \& glutathione-dependent enzymes represent a co-ordinately regulated defence against oxidative stress. Free Radic Res, 31: 273300 .

Hildebrand, D.F. (1996). Genetics of soybean lipoxygenases. IN Piazza, G.J. (Ed.) Lipoxygenase \& Lipoxygenase Pathway Enzymes. Champaign, Il: AOCS Press.

Hofmann, E. \& Pollmann, S. (2008). Molecular mechanism of enzymatic allene oxide cyclization in plants. Plant Physiol Biochem, 46: 302-8.

Hofmann, E., Zerbe, P. \& Schaller, F. (2006). The crystal structure of Arabidopsis thaliana allene oxide cyclase: Insights into the oxylipin cyclization reaction. Plant Cell, 18: 3201-17.

Holtman, W.L., Vredenbregt-Heistek, J.C., Schmitt, N.F. \& Feussner, I. (1997). Lipoxygenase-2 oxygenates storage lipids in embryos of germinating barley. Eur $J$ Biochem, 248: 452-458.

Hornung, E., Walther, M., Kühn, H. \& Feussner, I. (1999). Conversion of cucumber linoleate 13-lipoxygenase to a 9-lipoxygenating species by site-directed mutagenesis. Proc Natl Acad Sci USA, 96: 4192-4197.

Imbusch, R. \& Mueller, M.J. (2000). Formation of isoprostane $\mathrm{F}_{2}$-like compounds (phytoprostanes $\mathrm{F}_{1}$ ) from a-linolenic acid in plants. Free Radic Biol Med, 28: 720-6.

Inoue, H., Nojima, H. \& Okayama, H. (1990). High efficiency transformation of Escherichia coli with plasmids. Gene, 96: 23-28.

Kabsch, W. Xds. Acta Crystallogr D Biol Crystallogr, 66: 125-32.

Koch, T., Bandemer, K. \& Boland, W. (1997). Biosynthesis of cis-jasmone: A pathway for the inactivation \& the disposal of the plant stress hormone jasmonic acid to the gas phase? Helv Chim Acta, 80: 838-850.

Koeduka, T., Matsui, K., Akakabe, Y. \& Kajiwara, T. (2002). Catalytic properties of rice aoxygenase. A comparison with mammalian prostaglandin $\mathrm{H}$ synthases. $J$ Biol Chem, 277: 22648-55. 
Koljak, R., Boutaud, O., Shieh, B.H., Samel, N. \& Brash, A.R. (1997). Identification of a naturally occurring peroxidase-lipoxygenase fusion protein. Science, 277: 1994-1996.

Kühn, H., Saam, J., Eibach, S., Holzhütter, H.-G., Ivanov, I. \& Walther, M. (2005). Structural biology of mammalian lipoxygenases: Enzymatic consequences of targeted alterations of the protein structure. Biochem Biophys Res Commun, 338: 93-101.

Kühn, H., Schewe, T. \& Rapoport, S.M. (1986). The stereochemistry of the reactions of lipoxygenases \& their metabolites. Proposed nomenclature of lipoxygenases \& related enzymes. Adv Enzymol Relat Areas Mol Biol, 58: 273-311.

Kühn, H. \& Thiele, B.J. (1999). The diversity of the lipoxygenase family - Many sequence data but little information on biological significance. FEBS Lett, 449: 7-11.

Kühn, H., Wiesner, R., Rathmann, J. \& Schewe, T. (1991). Formation of ketodienoic fatty acids by the pure pea lipoxygenase-1. Eicosanoids, 4: 9-14.

Laemmli, U.K. (1970). Cleavage of structural proteins during the assembly of the head of bacteriophage T4. Nature, 227: 680-684.

Lang, I. \& Feussner, I. (2007). Oxylipin formation in Nostoc punctiforme (PCC73102). Phytochemistry, 68: 1120-1127.

Lang, I., Göbel, C., Porzel, A., Heilmann, I. \& Feussner, I. (2008). A lipoxygenase with linoleate diol synthase activity from Nostoc sp. PCC 7120. Biochem J, 410: 347-57.

Li, W., Liu, B., Yu, L., Feng, D., Wang, H. \& Wang, J. (2009). Phylogenetic analysis, structural evolution \& functional divergence of the 12-oxo-phytodienoate acid reductase gene family in plants. BMC Evolutionary Biology, 9: 90.

Liavonchanka, A. \& Feussner, I. (2006). Lipoxygenases: Occurrence, functions \& catalysis. $J$ Plant Physiol, 163: 348-357.

Lorenzo, O. \& Solano, R. (2005). Molecular players regulating the jasmonate signalling network. Curr Opin Plant Biol, 8: 532-40.

Maeda, H. \& Dellapenna, D. (2007). Tocopherol functions in photosynthetic organisms. Curr Opin Plant Biol, 10: 260-265.

Malkowski, M.G., Ginell, S.L., Smith, W.L. \& Garavito, R.M. (2000). The productive conformation of arachidonic acid bound to prostaglandin synthase. Science, 289: 1933-7.

Malkowski, M.G., Thuresson, E.D., Lakkides, K.M., Rieke, C.J., Micielli, R., Smith, W.L. \& Garavito, R.M. (2001). Structure of eicosapentaenoic \& linoleic acids in the cyclooxygenase site of prostaglandin endoperoxide H synthase-1. J Biol Chem, 276: 37547-55.

Matthews, B.W. (1968). Solvent content of protein crystals. J Mol Biol, 33: 491-7. 
Maucher, H., Stenzel, I., Miersch, O., Stein, N., Prasad, M., Zierold, U., Schweizer, P., Dorer, C., Hause, B. \& Wasternack, C. (2004). The allene oxide cyclase of barley (Hordeum vulgare L.)--cloning \& organ-specific expression. Phytochemistry, 65: 801-811.

Mccoy, A.J., Grosse-Kunstleve, R.W., Adams, P.D., Winn, M.D., Storoni, L.C. \& Read, R.J. (2007). Phaser crystallographic software. J Appl Crystallogr, 40: 658-674.

Milne, G.L., Musiek, E.S. \& Morrow, J.D. (2005). The cyclopentenone (A2/J2) isoprostanes-unique, highly reactive products of arachidonate peroxidation. Antioxid Redox Signal, 7: 210-20.

Minor, W., Steczko, J., Stec, B., Otwinowski, Z., Bolin, J.T., Walter, R. \& Axelrod, B. (1996). Crystal structure of soybean lipoxygenase L-1 at 1.4 A resolution. Biochemistry, 35: 10687-10701.

Mortimer, M., Jarving, R., Brash, A.R., Samel, N. \& Jarving, I. (2006). Identification \& characterization of an arachidonate 11R-lipoxygenase. Arch Biochem Biophys, 445: 147-155.

Mosblech, A., Feussner, I. \& Heilmann, I. (2009). Oxylipins: Structurally diverse metabolites from fatty acid oxidation. Plant Physiology \& Biochemistry, 47: 511-517.

Müller, M.J. (2004). Archetype signals in plants: the phytoprostanes. Curr Opin Plant Biol, 7: 441-8.

Müller, S., Hilbert, B., Dueckershoff, K., Roitsch, T., Krischke, M., Müller, M.J. \& Berger, S. (2008). General detoxification \& stress responses are mediated by oxidized lipids through TGA transcription factors in Arabidopsis. Plant Cell, 20: 768-785.

Murray, J.J. \& Brash, A.R. (1988). Rabbit reticulocyte lipoxygenase catalyzes specific 12(S) \& 15(S) oxygenation of arachidonoyl-phosphatidylcholine. Arch Biochem Biophys, 265: 514-532.

Murshudov, G.N., Vagin, A.A. \& Dodson, E.J. (1997). Refinement of macromolecular structures by the maximum-likelihood method. Acta Crystallogr D Biol Crystallogr, 53: $240-55$.

Narvaez-Vasquez, J., Florin-Christensen, J. \& Ryan, C.A. (1999). Positional specificity of a phospholipase A activity induced by wounding, systemin, \& oligosaccharide elicitors in tomato leaves. Plant Cell, 11:2249-2260.

Neau, D.B., Gilbert, N.C., Bartlett, S.G., Boeglin, W., Brash, A.R. \& Newcomer, M.E. (2009). The 1.85 A structure of an $8 R$-lipoxygenase suggests a general model for lipoxygenase product specificity. Biochemistry, 48: 7906-7915.

Noordermeer, M.A., Feussner, I., Kolbe, A., Veldink, G.A. \& Vliegenthart, J.F. (2000). Oxygenation of (3Z)-alkenals to 4-hydroxy-(2E)-alkenals in plant extracts: A nonenzymatic process. Biochem Biophys Res Commun, 277: 112-116.

Oliver, J., Castro, A., Gaggero, C., Cascón, T., Schmelz, E., Castresana, C. \& Ponce De León, I. (2009). Pythium infection activates conserved plant defense responses in mosses. Planta, 230: 569-579. 
Oliw, E.H. (2002). Plant \& fungal lipoxygenases. Prostaglandins \&Other Lipid Mediators, 68-69: 313-323.

Padilla, J.E. \& Yeates, T.O. (2003). A statistic for local intensity differences: robustness to anisotropy \& pseudo-centering \& utility for detecting twinning. Acta Crystallogr D Biol Crystallogr, 59: 1124-30.

Parchmann, S. \& Müller, M.J. (1998). Evidence for the formation of dinor isoprostanes $E_{1}$ from a-linolenic acid in plants. J Biol Chem, 273: 32650-32655.

Pohnert, G. (2002). Phospholipase $A_{2}$ activity triggers the wound-activated chemical defense in the diatom Thalassiosira rotula. Plant Physiol, 129: 103-11.

Porta, H. \& Rocha-Sosa, M. (2001). Lipoxygenase in bacteria: a horizontal transfer event? Microbiol, 147: 3199-3200.

Potterton, E., Briggs, P., Turkenburg, M. \& Dodson, E. (2003). A graphical user interface to the CCP4 program suite. Acta Crystallogr D Biol Crystallogr, 59: 1131-7.

Przybyla, D., Göbel, C., Imboden, A., Hamberg, M., Feussner, I. \& Apel, K. (2008). Enzymatic, but not non-enzymatic, ${ }^{1} \mathrm{O}_{2}$-mediated peroxidation of polyunsaturated fatty acids forms part of the EXECUTER1-dependent stress response program in the flu mutant of Arabidopsis thaliana. Plant J, 54: 236-248.

Ramachandran, G.N., Ramakrishnan, C. \& Sasisekharan, V. (1963). Stereochemistry of polypeptide chain configurations. J Mol Biol, 7: 95-9.

Rance, I., Fournier, J. \& Esquerre-Tugaye, M.T. (1998). The incompatible interaction between Phytophthora parasitica var. nicotianae race $0 \&$ tobacco is suppressed in transgenic plants expressing antisense lipoxygenase sequences. Proc Natl Acad Sci USA, 95: 6554-6559.

Rensing, S.A., Lang, D., Zimmer, A.D., Terry, A., Salamov, A., Shapiro, H., Nishiyama, T., Perroud, P.-F., Lindquist, E.A., Kamisugi, Y., Tanahashi, T., Sakakibara, K., Fujita, T., Oishi, K., Shin-I, T., Kuroki, Y., Toyoda, A., Suzuki, Y., Hashimoto, S.-I., Yamaguchi, K., Sugano, S., Kohara, Y., Fujiyama, A., Anterola, A., Aoki, S., Ashton, N., Barbazuk, W.B., Barker, E., Bennetzen, J.L., Blankenship, R., Cho, S.H., Dutcher, S.K., Estelle, M., Fawcett, J.A., Gundlach, H., Hanada, K., Heyl, A., Hicks, K.A., Hughes, J., Lohr, M., Mayer, K., Melkozernov, A., Murata, T., Nelson, D.R., Pils, B., Prigge, M., Reiss, B., Renner, T., Rombauts, S., Rushton, P.J., Sanderfoot, A., Schween, G., Shiu, S.-H., Stueber, K., Theodoulou, F.L., Tu, H., Van De Peer, Y., Verrier, P.J., Waters, E., Wood, A., Yang, L., Cove, D., Cuming, A.C., Hasebe, M., Lucas, S., Mishler, B.D., Reski, R., Grigoriev, I.V., Quatrano, R.S. \& Boore, J.L. (2008). The Physcomitrella genome reveals evolutionary insights into the conquest of land by plants. Science, 319: 64-69.

Reymond, P., Weber, H., Damond, M. \& Farmer, E.E. (2000). Differential gene expression in response to mechanical wounding \& insect feeding in Arabidopsis. Plant Cell, 12: 707-20. 
Saiki, R.K., Gelfand, D.H., Stoffel, S., Scharf, S.J., Higuchi, R., Horn, G.T., Mullis, K.B. \& Erlich, H.A. (1988). Primer-directed enzymatic amplification of DNA with a thermostable DNA polymerase. Science, 239: 487-91.

Sanger, F., Nicklen, S. \& Coulson, A.R. (1977)Proc Natl Acad Sci USA, 74: 5463-5467.

Saqi, M.A., Russell, R.B. \& Sternberg, M.J. (1998). Misleading local sequence alignments: implications for comparative protein modelling. Protein Eng, 11: 627-30.

Saravitz, D.M. \& Siedow, J.N. (1995). The lipoxygenase isozymes in soybean [Glycine max (L.) Merr.] leaves - changes during leaf development, after wounding, \& following reproductive sink removal. Plant Physiol, 107: 535-543.

Saravitz, D.M. \& Siedow, J.N. (1996). The differential expression of wound-inducible lipoxygenase genes in soybean leaves. Plant Physiol, 110: 287-299.

Schaller, F. (2001). Enzymes of the biosynthesis of octadecanoid-derived signalling molecules. J Exp Bot, 52: 11-23.

Schaller, F., Zerbe, P., Reinbothe, S., Reinbothe, C., Hofmann, E. \& Pollmann, S. (2008). The allene oxide cyclase family of Arabidopsis thaliana - localization \& cyclization. FEBS $J, 275: 2428-2441$.

Schilmiller, A.L. \& Howe, G.A. (2005). Systemic signaling in the wound response. Curr Opin Plant Biol, 8: 369-377.

Schneider, C., Pratt, D.A., Porter, N.A. \& Brash, A.R. (2007a). Control of oxygenation in lipoxygenase \& cyclooxygenase catalysis. Chemistry \& Biology, 14: 473-488.

Schneider, C., Yu, Z., Boeglin, W.E., Zheng, Y. \& Brash, A.R. (2007b). Enantiomeric separation of hydroxy \& hydroperoxy eicosanoids by chiral column chromatography. Methods Enzymol, 433: 145-57.

Schuttelkopf, A.W. \& Van Aalten, D.M. (2004). PRODRG: a tool for high-throughput crystallography of protein-ligand complexes. Acta Crystallogr D Biol Crystallogr, 60: 1355-63.

Senger, T., Wichard, T., Kunze, S., Göbel, C., Lerchl, J., Pohnert, G. \& Feussner, I. (2005). A multifunctional lipoxygenase with fatty acid hydroperoxide cleaving activity from the moss Physcomitrella patens. J Biol Chem, 280: 7588-7596.

Seo, H.S., Song, J.T., Cheong, J.J., Lee, Y.H., Lee, Y.W., Hwang, I., Lee, J.S. \& Choi, Y.D. (2001). Jasmonic acid carboxyl methyltransferase: a key enzyme for jasmonateregulated plant responses. Proc Natl Acad Sci USA, 98: 4788-93.

Shibata, D., Slusarenko, A., Casey, R., Hildebrand, D. \& Bell, E. (1994). Lipoxygenases. Plant Mol Biol Reporter, 12: S41-S42.

Shibata, D., Steczko, J., Dixon, J.E., Andrews, P.C., Hermodson, M. \& Axelrod, B. (1988). Primary structure of soybean lipoxygenase L-2. J Biol Chem, 263: 6816-6821. 
Shimizu, T., Radmark, O. \& Samuelsson, B. (1984). Enzyme with dual lipoxygenase activities catalyses leukotriene A4 synthesis from arachidonic acid. Proc Natl Acad Sci USA, 81: 689-693.

Siedow, J.N. (1991). Plant lipoxygenase - structure \& function. Ann Rev Plant Physiol Plant Mol Biol, 42: 145-188.

Skrzypczak-Jankun, E., Bross, R.A., Carroll, R.T., Dunham, W.R. \& Funk, M.O., Jr. (2001). Three-dimensional structure of a purple lipoxygenase. J Am Chem Soc, 123: 1081420 .

Sloane, D.L., Leung, R., Craik, C.S. \& Sigal, E. (1991). A primary determinant for lipoxygenase positional specificity. Nature, 354: 149-152.

Smith, W.L., Dewitt, D.L. \& Garavito, R.M. (2000). Cyclooxygenases: Structural, cellular, \& molecular biology. Annu Rev Biochem, 69: 145-182.

Song, W.-C. \& Brash, A.R. (1991). Purification of an allene oxide synthase \& identification of the enzyme as a cytochrome P-450. Sience, 253: 781-784.

Song, W.C., Funk, C.D. \& Brash, A.R. (1993). Molecular cloning of an allene oxide synthase - a cytochrome-P450 specialized for the metabolism of fatty acid hydroperoxides. Proc Natl Acad Sci USA, 90: 8519-8523.

Staswick, P.E. (1992). Jasmonate, Genes, \& Fragrant Signals. Plant Physiology, 99: 804-807.

Staswick, P.E., Su, W.P. \& Howell, S.H. (1992). Methyl Jasmonate Inhibition of Root Growth \& Induction of a Leaf Protein Are Decreased in an Arabidopsis-Thaliana Mutant. Proc Natl Acad Sci USA, 89: 6837-6840.

Staswick, P.E. \& Tiryaki, I. (2004). The oxylipin signal jasmonic acid is activated by an enzyme that conjugates it to isoleucine in Arabidopsis. Plant Cell, 16: 2117-2127.

Staswick, P.E., Tiryaki, I. \& Rowe, M.L. (2002). Jasmonate response locus JARl \& several related Arabidopsis genes encode enzymes of the firefly luciferase superfamily that show activity on jasmonic, salicylic, \& indole-3-acetic acids in an assay for adenylation. Plant Cell, 14: 1405-15.

Stelmach, B.A., Müller, A., Hennig, P., Gebhardt, S., Schubert-Zsilavecz, M. \& Weiler, E.W. (2001). A novel class of oxylipins, sn1-O-(12-Oxophytodienoyl)-sn2-O(hexadecatrienoyl)-monogalactosyl diglyceride, from Arabidopsis thaliana. J Biol Chem, 276: 12832-12838.

Stelmach, B.A., Muller, A., Hennig, P., Laudert, D., Andert, L. \& Weiler, E.W. (1998). Quantitation of the octadecanoid 12-oxo-phytodienoic acid, a signalling compound in plant mechanotransduction. Phytochemistry, 47: 539-546.

Stenzel, I., Hause, B., Maucher, H., Pitzschke, A., Miersch, O., Ziegler, J., Ryan, C.A. \& Wasternack, C. (2003a). Allene oxide cyclase dependence of the wound response \& vascular bundle-specific generation of jasmonates in tomato - amplification in wound signalling. Plant J, 33: 577-589. 
Stenzel, I., Hause, B., Miersch, O., Kurz, T., Maucher, H., Weichert, H., Ziegler, J., Feussner, I. \& Wasternack, C. (2003b). Jasmonate biosynthesis \& the allene oxide cyclase family of Arabidopsis thaliana. Plant Mol Biol, 51: 895-911.

Stintzi, A. \& Browse, J. (2000). The Arabidopsis male-sterile mutant, opr3, lacks the 12oxophytodienoic acid reductase required for jasmonate synthesis. Proc Natl Acad Sci USA, 97: 10625-30.

Stintzi, A., Weber, H., Reymond, P., Browse, J. \& Farmer, E.E. (2001). Plant defense in the absence of jasmonic acid: The role of cyclopentenones. Proc Natl Acad Sci USA, 98: $12837-42$.

Strassner, J., Schaller, F., Frick, U.B., Howe, G.A., Weiler, E.W., Amrhein, N., Macheroux, P. \& Schaller, A. (2002). Characterization \& cDNA-microarray expression analysis of 12-oxophytodienoate reductases reveals differential roles for octadecanoid biosynthesis in the local versus the systemic wound response. Plant J, 32: 585-601.

Stumpe, M., Bode, J., Göbel, C., Wichard, T., Schaaf, A., Frank, W., Frank, M., Reski, R., Pohnert, G. \& Feussner, I. (2006). Biosynthesis of C9-aldehydes in the moss Physcomitrella patens. Biochim Biophys Acta, 1761: 301-312.

Stumpe, M. \& Feussner, I. (2006). Formation of oxylipins by CYP74 enzymes. Phytochemistry Rev, 5: 347-357.

Stumpe, M. (2006). Charakterisierung und Funktion von CYP-74 Enzymen in pflanzlichen Organismen. Dissertation, Martin-Luther-Universität zu Halle-Wittenberg.

Stumpe, M., Kandzia, R., Göbel, C., Rosahl, S. \& Feussner, I. (2001). A pathogen-inducible divinyl ether synthase $(C Y P 74 D)$ from elicitor-treated potato suspension cells. FEBS Lett, 507: 371-376.

Stura, E.A., Chen, P., Wilmot, C.M., Arevalo, J.H. \& Wilson, I.A. (1992). Crystallization studies of glycosylated \& unglycosylated human recombinant interleukin-2. Proteins, 12: 24-30.

Su, C. \& Oliw, E.H. (1998). Manganese lipoxygenase - Purification \& characterization. J Biol Chem, 273: 13072-13079.

Taki, N., Sasaki-Sekimoto, Y., Obayashi, T., Kikuta, A., Kobayashi, K., Ainai, T., Yagi, K., Sakurai, N., Suzuki, H., Masuda, T., Takamiya, K.-I., Shibata, D., Kobayashi, Y. \& Ohta, H. (2005). 12-Oxo-phytodienoic acid triggers expression of a distinct set of genes \& plays a role in wound-induced gene expression in Arabidopsis. Plant Physiol, 139: $1268-1283$.

Thines, B., Katsir, L., Melotto, M., Niu, Y., Mandaokar, A., Liu, G., Nomura, K., He, S.Y., Howe, G.A. \& Browse, J. (2007). JAZ repressor proteins are targets of the SCFCOI1 complex during jasmonate signalling. Nature, 448: 661-665.

Thoma, I., Loeffler, C., Sinha, A.K., Gupta, M., Krischke, M., Steffan, B., Roitsch, T. \& Mueller, M.J. (2003). Cyclopentenone isoprostanes induced by reactive oxygen species trigger defense gene activation \& phytoalexin accumulation in plants. Plant $J$, 34: $363-75$. 
Van Kan, J.A. (2006). Licensed to kill: the lifestyle of a necrotrophic plant pathogen. Trends Plant Sci, 11: 247-53.

Veronesi, C., Rickauer, M., Fournier, J., Pouenat, M.L. \& Esquerre-Tugaye, M.T. (1996). Lipoxygenase gene expression in the tobacco-Phytophthora parasitica nicotianae interaction. Plant Physiol, 112: 997-1004.

Vick, B.A. \& Zimmerman, D.C. (1979). Distribution of a fatty acid cyclase enzyme system in plants. Plant Physiol, 64: 203-205.

Vick, B.A. \& Zimmerman, D.C. (1984). Biosynthesis of jasmonic acid by several plant species. Plant Physiol, 75: 458-461.

Vick, B.A. \& Zimmerman, D.C. (1987a). Oxidative systems for modification of fatty acids: the lipoxygenase pathway. IN Stumpf, P.K. \& Conn, E.E. (Eds.) The Biochemistry of Plants. London: Academic Press.

Vick, B.A. \& Zimmerman, D.C. (1987b). Pathways of fatty acid hydroperoxide metabolism in spinach leaf chloroplasts. Plant Physiol, 85: 1073-1078.

Vijayan, P., Shockey, J., Levesque, C.A., Cook, R.J. \& Browse, J. (1998). A role for jasmonate in pathogen defense of Arabidopsis. Proc Natl Acad Sci USA, 95: 72097214.

Vollenweider, S., Weber, H., Stolz, S., Chetelat, A. \& Farmer, E.E. (2000). Fatty acid ketodienes \& fatty acid ketotrienes: michael addition acceptors that accumulate in wounded \& diseased Arabidopsis leaves. Plant J, 24: 467-76.

Wallace, A.C., Laskowski, R.A. \& Thornton, J.M. (1995). LIGPLOT: a program to generate schematic diagrams of protein-ligand interactions. Protein Eng, 8: 127-34.

Wang, X., Li, W., Li, M. \& Welti, R. (2006). Profiling lipid changes in plant response to low temperatures. Physiol Plant, 126: 90-96.

Wasternack, C. (2007). Jasmonates: An update on biosynthesis, signal transduction \& action in plant stress response, growth \& development. Ann Bot, 100: 681-697.

Weber, H., Vick, B.A. \& Farmer, E.E. (1997). Dinor-oxo-phytodienoic acid: A new hexadecanoid signal in the jasmonate family. Proc Natl Acad Sci USA, 94: 1047310478.

Wichard, T., Göbel, C., Feussner, I. \& Pohnert, G. (2005). Unprecedented lipoxygenase/hydroperoxide lyase pathways in the moss Physcomitrella patens. Angew Chem Int Ed Engl, 44: 158-161.

Xue, H., Chen, X. \& Li, G. (2007). Involvement of phospholipid signaling in plant growth \& hormone effects. Curr Opin Plant Biol, 10: 483-489.

Yamamoto, S. (1992). Mammalian lipoxygenases - molecular structures \& functions. Biochim Biophys Acta, 1128: 117-131. 
Youn, B., Sellhorn, G.E., Mirchel, R.J., Gaffney, B.J., Grimes, H.D. \& Kang, C. (2006). Crystal structures of vegetative soybean lipoxygenase VLX-B \& VLX-D, \& comparisons with seed isoforms LOX-1 \& LOX-3. Proteins, 65: 1008-20.

Ziegler, J., Hamberg, M., Miersch, O. \& Parthier, B. (1997). Purification \& characterization of allene oxide cyclase from dry corn seeds. Plant Physiol, 114: 565-573.

Ziegler, J., Stenzel, I., Hause, B., Maucher, H., Hamberg, M., Grimm, R., Ganal, M. \& Wasternack, C. (2000). Molecular cloning of allene oxide cyclase. J Biol Chem, 275: 19132-8.

Ziegler, J., Wasternack, C. \& Hamberg, M. (1999). On the specificity of allene oxide cyclase. Lipids, 34: 1005-1015. 


\section{AnHang}

\subsection{Sequenzalignment verschiedener LOXen}
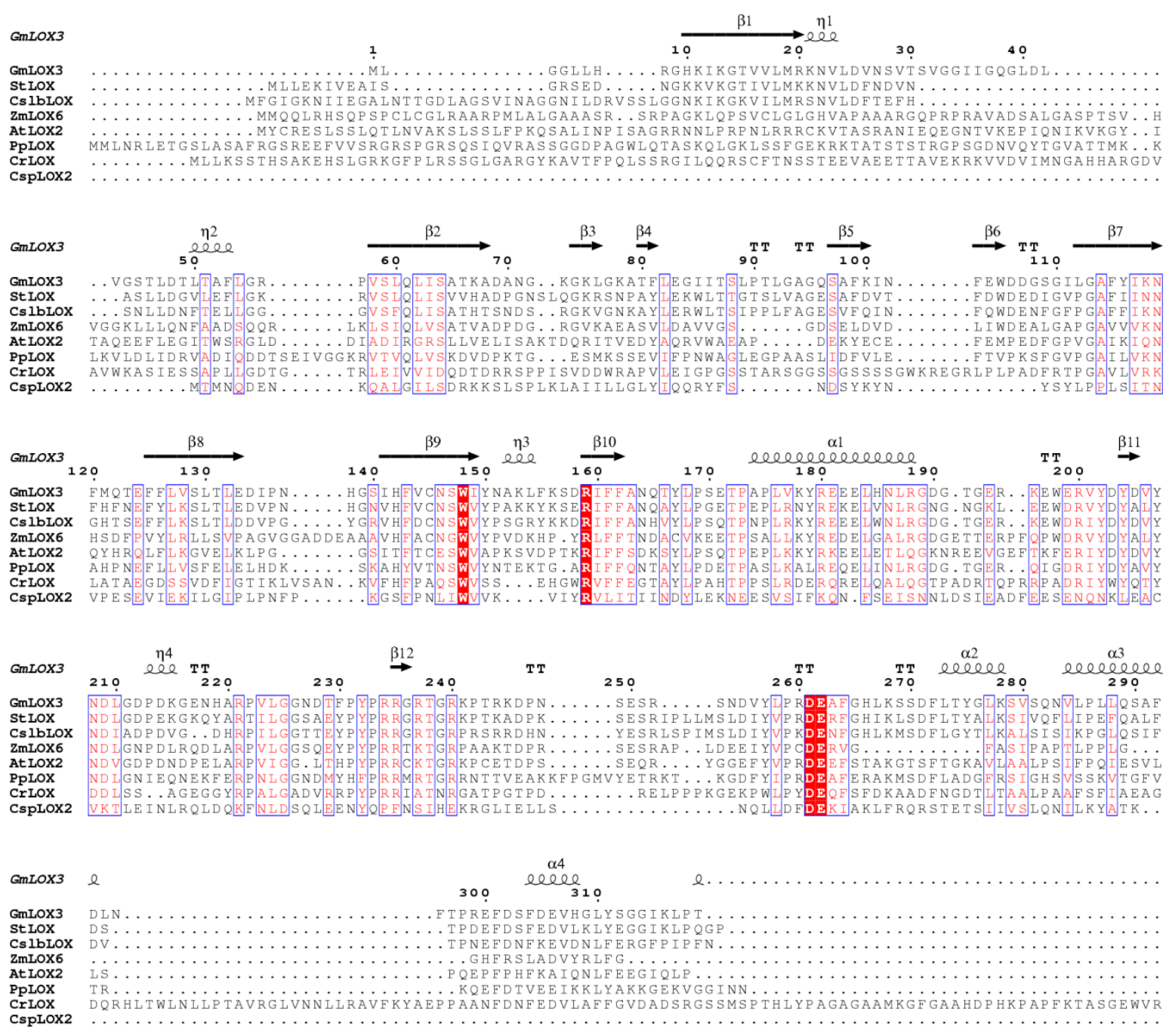

GmLox3

$\alpha 5$

GmLOX 3

CslbLoX

$\mathrm{zmLOX6}$

At LOX

CrIOX

Csplox2

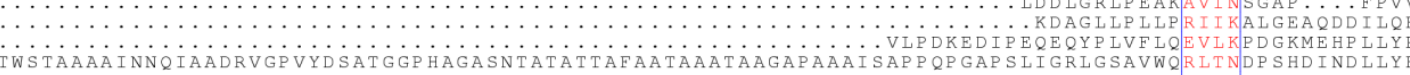

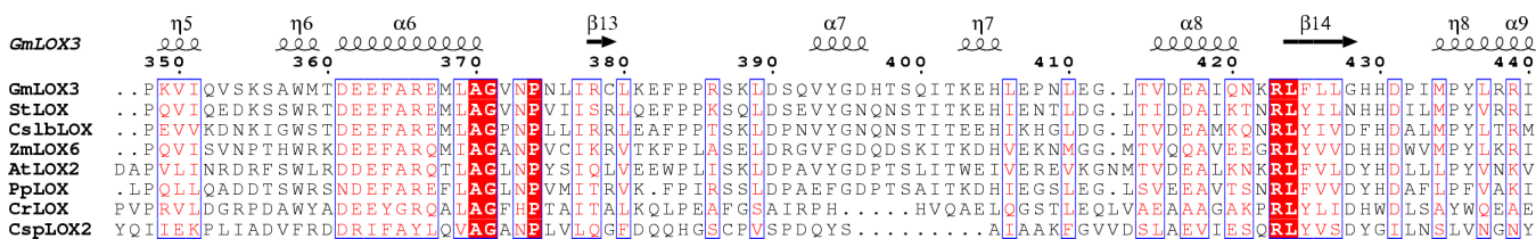



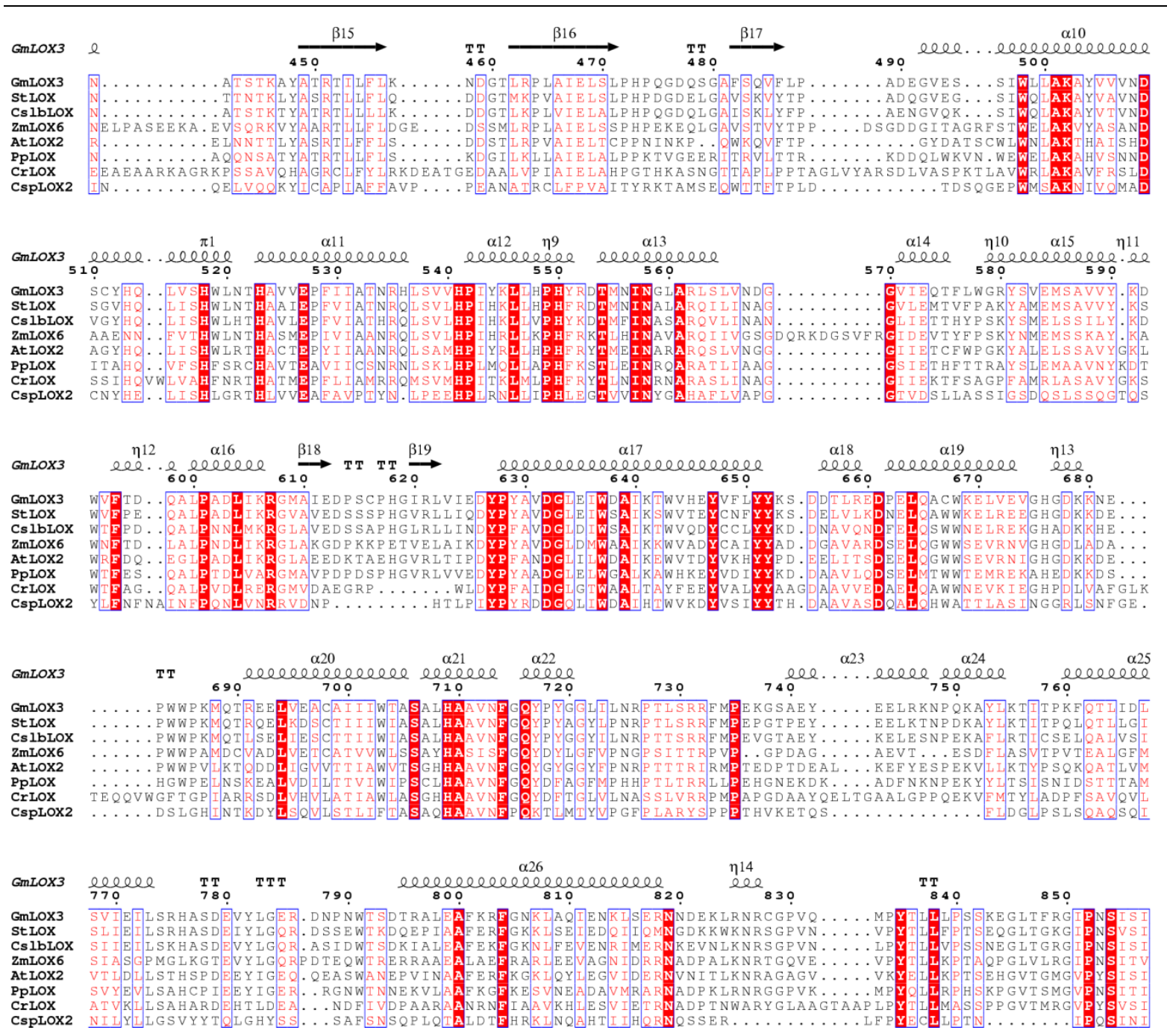

Abbildung 8.1: Aminosäure-Alignment verschiedener LOXen. [erstellt mit ESPript (Gouet et al., 1999)] Sekundärstrukturelemente und Nummerierung basierend auf der GmLOX3-Struktur (Skrzypczak-Jankun et al., 2001; 1IK3.pdb). Die folgenden LOXen sind aufgeführt (Accession-Nummern sind eingeklammert): GmLOX3 (P09186), StLOX (AAB31252), A. thaliana LOX3 (P38418), Cucumis sativus [(CsLOX; (CAA63483)], ZmLOX6 (NM_001112506), Cyanothece sp. [CspLOX; (YP_001804062)], Chlamydomonas reinhardtii [CrLOX (XP_0016908829] und PpLOX1 (CAE47464). 


\subsection{Datensammlung der $P p A O C 1-$ und $P p A O C 2-S t r u k t u r e n$}

Tabelle 8.1: Parameter für die Datensammlung von PpAOC1 und PpAOC2 Strukturen.

Messparameter und Statistiken der aufgenommenen Datensätze. Die Werte in den Klammern beziehen sich auf die äußerste Auflösungsschale. Rmerge $=\sum h k l \sum i|\mathrm{I} i(h k l)-\langle\operatorname{Ii}(h k l)\rangle| /\left(\sum h k l \sum i\right)\langle\operatorname{Ii}(h k l)\rangle$, wobei die Summe i über alle Einzelmessungen des Reflexes hkl einfach berechnet ist.

\begin{tabular}{lllllllll}
\hline Protein & AOC1 & AOC1 & AOC2 & AOC2 & AOC2 & AOC2 & AOC2 & AOC2 \\
Ligand & - & $12,13-$ & - & $12,13-$ & $12,13-$ & $12,13-$ & $12,13-$ & 11,12 \\
& & EOD- & & EOD- & EOD- & EOD- & EOD & EET \\
& & $9 Z, 15 Z$ & & $9 Z 15 Z-$ & $9 Z 15 Z$ & $9 Z 15 Z$ & $9 Z$ & $5 Z, 8 Z, 1$ \\
& & & I & II & III & & $4 Z$
\end{tabular}

\begin{tabular}{|c|c|c|c|c|c|c|c|c|}
\hline \multicolumn{9}{|c|}{ Datensammlung } \\
\hline \multirow[t]{4}{*}{ Datensatz } & AOC1- & $\mathrm{AOC} 1$ & AOC2- & EOD9Z & EOD9Z & EOD9Z1 & AOC2E & $\mathrm{AOC} 2 \mathrm{E}$ \\
\hline & APO & EOD- & APO & $15 Z \mathrm{I}$ & $15 \mathrm{Z}$ II & $5 Z$ III & OD & ET \\
\hline & & $9 Z, 15 Z$ & & & & & $9 Z$ & $5 Z, 8 Z, 1$ \\
\hline & & & & & & & & $4 Z$ \\
\hline Beamline & BESSY & BESSY & DESY & DESY & BESSY & DESY & BESSY & BESSY \\
\hline Wellenlänge (̊) & 0.91841 & 0.91891 & 0.8123 & 0.8123 & 0.9189 & 0.8123 & 0.9189 & 0.9189 \\
\hline Detektor (mm) & 140 & 140 & 150 & 150 & 140 & 150 & 140 & 140 \\
\hline Belichtungszeit pro & $1-3$ & $1-3$ & $10-20$ & $10-20$ & $1-3$ & $10-20$ & $1-3$ & $10-20$ \\
\hline \multicolumn{9}{|l|}{ Bild (sek) } \\
\hline$\Delta \mathbf{P h i}\left({ }^{\circ}\right)$ & 0.25 & 0.25 & 0.5 & 0.5 & 0.25 & 0.5 & 0.25 & 0.25 \\
\hline \multicolumn{9}{|c|}{ Integration und Skalierung } \\
\hline Auflösung (̊̊) & $30-1.32$ & $30-1.33$ & $30-1.95$ & $30-1.85$ & $30-2.25$ & $30-2.1$ & $30-2.00$ & $30-2.3$ \\
\hline Raumgruppe & $\mathrm{P} 1$ & $\mathrm{P} 1$ & $\mathrm{P} 2$ & $\mathrm{P} 2_{1}$ & $\mathrm{P} 2_{1}$ & $\mathrm{P} 2_{1}$ & $\mathrm{P} 2_{1}$ & $\mathrm{P} 22_{1}$ \\
\hline \multicolumn{9}{|c|}{ Einheitszelldimension } \\
\hline $\mathbf{a}(\AA)$ & 67.32 & 67.42 & 67.569 & 67.53 & 67.049 & 67.521 & 68.414 & 65.66 \\
\hline b $(\AA)$ & 67.43 & 67.513 & 115.40 & 114.11 & 115.350 & 114.813 & 115.57 & 115.62 \\
\hline c $(\AA)$ & 161.77 & 161.88 & 87.027 & 86.06 & 86.720 & 86.724 & 87.040 & 86.74 \\
\hline$\alpha\left(^{\circ}\right)$ & 84.614 & 84.364 & 90.0 & 90.0 & 90.0 & 90.0 & 90.00 & 90.00 \\
\hline$\beta\left({ }^{\circ}\right)$ & 79.316 & 79.153 & 91.577 & 91.875 & 91.446 & 91.653 & 92.40 & 90.20 \\
\hline$\gamma\left({ }^{\circ}\right)$ & 61.989 & 62.131 & 90.00 & 90.0 & 90.0 & 90.00 & 90.00 & 90.00 \\
\hline Beobachtete & $(125081)$ & 1140331 & 388903 & 431377 & 261908 & 290462 & 315327 & 142428 \\
\hline Reflexe (N) & 788831 & (186535) & $(54255)$ & $(64212)$ & (32374) & (37822) & 43808 & 17384 \\
\hline \multirow[t]{2}{*}{ Redundanz } & 1.69 & 2.19 & 4.02 & 3.9 & 4.45 & $3.8(3.83)$ & 3.47 & 2.68 \\
\hline & $(0.69)$ & (2.18) & $(4.02)$ & $(4.0)$ & $(4.42)$ & & $(3.54)$ & $(2.65)$ \\
\hline
\end{tabular}




\begin{tabular}{|c|c|c|c|c|c|c|c|c|}
\hline Vollständigkeit der & 80.6 & 91.3 & 99.7 & 99.6 & 94.1 & 99.2 & 99.6 & 92.49 \\
\hline Reflexe (\%) & $(69.4)$ & $(77.0)$ & (99.9) & $(99.4)$ & $(96.1)$ & $(99.0)$ & $(99.9)$ & $(95.7)$ \\
\hline Signal/Rauschverh & 15.34 & 14.62 & 20.14 & 11.89 & 10.03 & 8.2 & 9.42 & 9.29 \\
\hline ältnis $(I / \sigma)$ & $(1.89)$ & $(1.90)$ & $(2.68)$ & $(2.55)$ & $(2.79)$ & $(58.7)$ & $(2.55)$ & $(2.46)$ \\
\hline \multirow[t]{2}{*}{$\mathbf{R}_{\text {sym }}(\%)$} & $2.4(47.6)$ & $3.2(52.4)$ & 5.5 & 7.0 & 11.1 & 15.32 & 190 & 9.0 \\
\hline & & & $(60.99)$ & $(63.3)$ & $(60.5)$ & $(2.92)$ & $(64.1)$ & $(66.4)$ \\
\hline \multirow[t]{2}{*}{$\mathbf{R}_{\text {merge }}$} & $9.6(93.7)$ & 12.2 & 13.7 & & & & & \\
\hline & & (106.0) & $(75.5)$ & & & & & \\
\hline
\end{tabular}

\subsection{Verfeinerungsstatistiken der PpAOC1- und PpAOC2- Strukturen}

Tabelle 8.2: Verfeinerungsstatistiken der PpAOC1 und PpAOC2 Strukturen.

\begin{tabular}{|c|c|c|c|c|c|c|c|c|}
\hline Protein & AOC1 & AOC1 & AOC2 & $\mathrm{AOC2}$ & AOC2 & AOC2 & AOC2 & $\mathrm{AOC2}$ \\
\hline \multirow[t]{4}{*}{ Ligand } & - & $12,13-$ & - & $12,13-$ & $12,13-$ & $12,13-$ & $12,13-$ & $11,12-$ \\
\hline & & EOD- & & EOD- & EOD- & EOD- & EOD & EET \\
\hline & & $9 Z, 15 Z$ & & 9Z,15Z & $9 Z, 15 Z$ & $9 Z, 15 Z$ & $9 Z$ & $5 Z, 8 Z, 14 Z$ \\
\hline & & & & $\mathbf{I}$ & II & III & & \\
\hline \multicolumn{9}{|c|}{ Verfeinerung } \\
\hline Auflösung (̊̊) & 1.32 & 1.33 & 1.95 & 1.85 & 2.25 & 2.1 & 2.00 & \\
\hline $\mathbf{R}_{\text {work }}$ & 0.1574 & 0.148 & 0.2024 & 0.1978 & 0.1827 & 0.1709 & 0.1876 & \\
\hline $\mathbf{R}_{\text {free }}$ & 0.2039 & 0.1880 & 0.2375 & 0.2362 & 0.2334 & 0.2295 & 0.2387 & \\
\hline \multicolumn{9}{|c|}{ Standardabweichung } \\
\hline Bindungslängen (̊̊) & 0.005 & 0.009 & 0.004 & 0.008 & 0.009 & 0.013 & 0.02 & \\
\hline Bindungswinkel $\left({ }^{\circ}\right)$ & 0.966 & 1.357 & 0.830 & 1.395 & 1.809 & 2.093 & 1.944 & \\
\hline
\end{tabular}




\subsection{Ligplot-Skizzen}

(A)

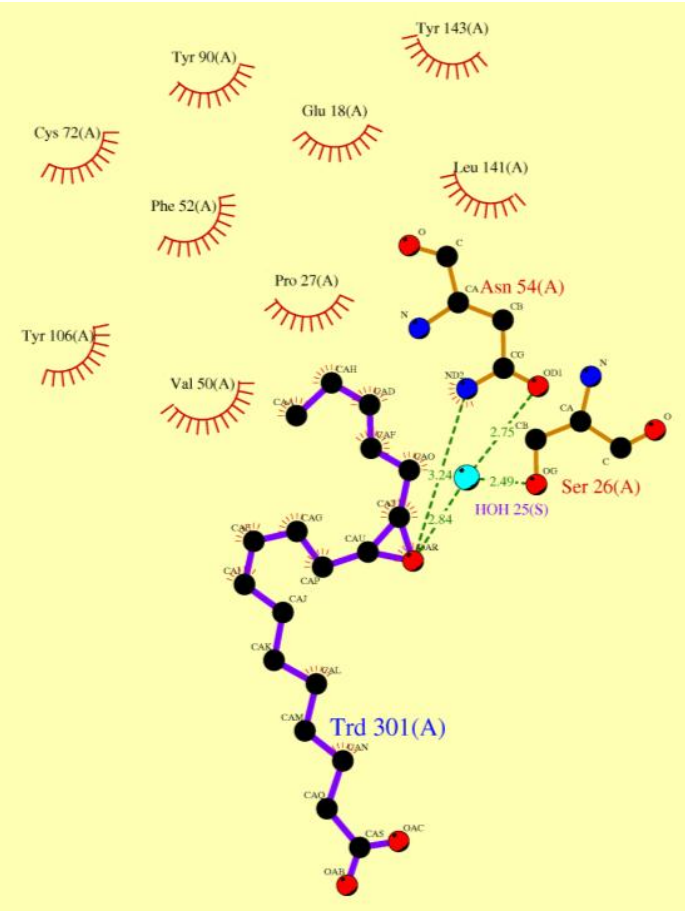

(B)

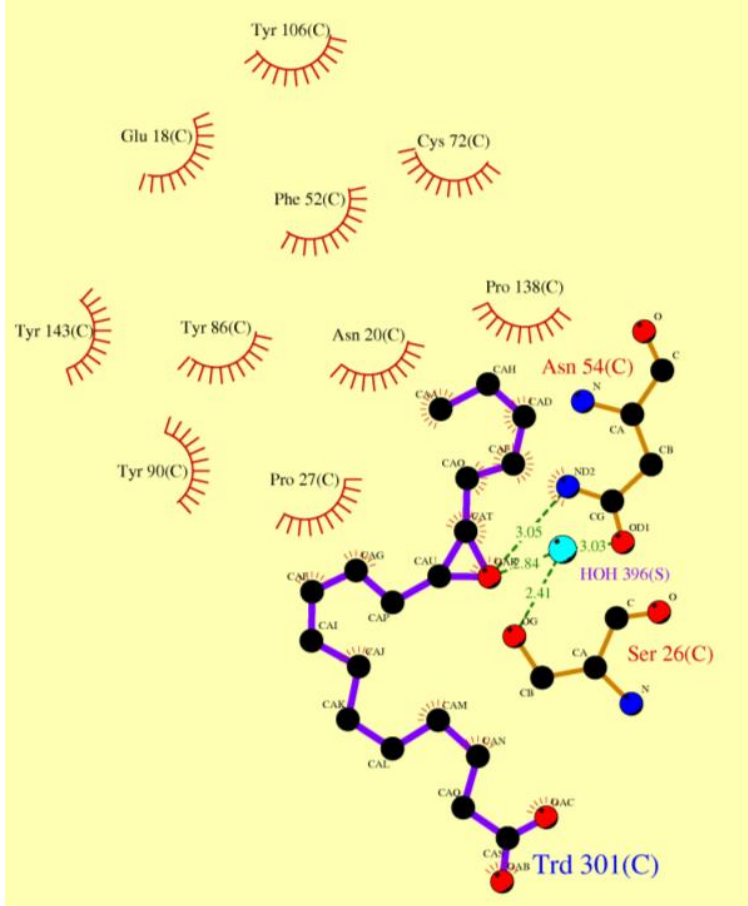

(C)

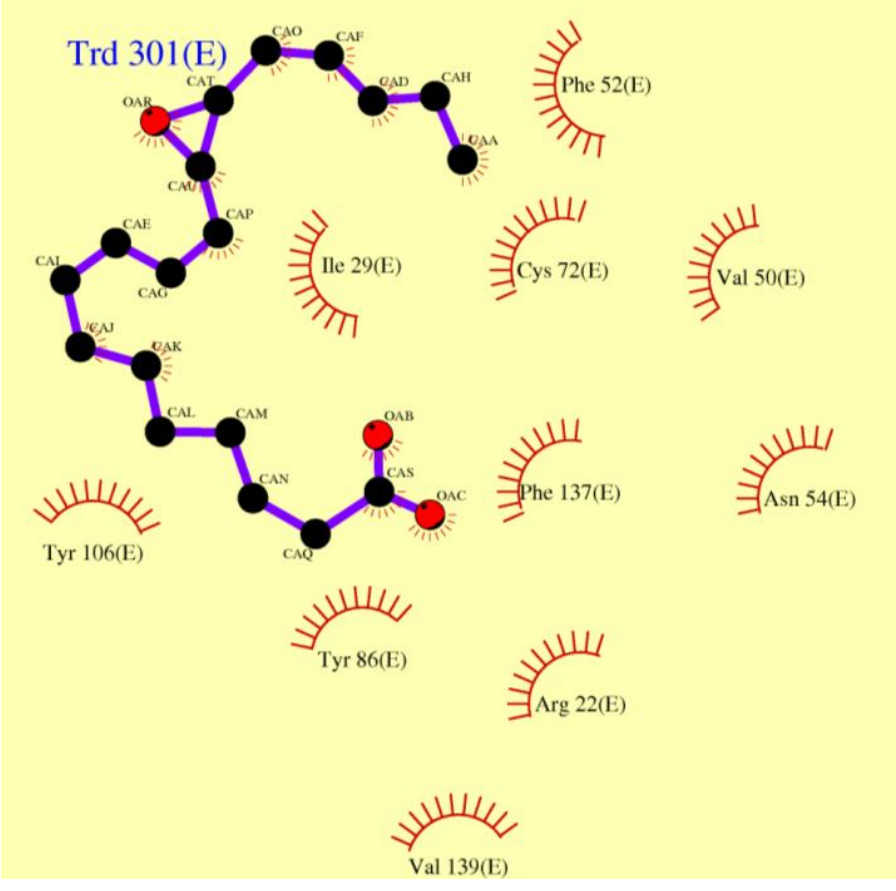

Abbildung 8.2: Darstellung polarer Kontakte im aktiven Zentrum von PpAOC2 mit gebundenem Ligand 12,13-EOD ${ }^{\Delta 9 Z \Delta 15 Z}$. (erzeugt mit Ligplot) Gezeigt sind Ligplot-Skizzen für drei PpAOC2-Ketten. Folgende Bindungen und Kontakte sind dargestellt: Ligandbindung (lila); Andere Bindung (braun); Wasserstoffbrückenbindung und ihre Länge (grün, gestrichelt); Aminosäurereste, involviert in hydrophobe Kontakte (rot, gestrichelt); Atome, involviert in polare Kontakte (schwarze Kreise mit rotgestricheltem Rand). (A) Kette A; (B) Kette C; (C) Kette E. 


\subsection{Abkürzungsverzeichnis}

$\begin{array}{ll}\AA & \text { Angström } \\ { }^{\circ} \mathrm{C} & \text { Grad Celsius } \\ \mathrm{A}_{260} \text { und } \mathrm{A}_{280} & \text { Absorption bei } 260 \text { bzw. } 280 \mathrm{~nm} \\ \text { Abb. } & \text { Abbildung } \\ \text { Ala } & \text { Alanin } \\ \text { Amp } & \text { Ampicilin } \\ \text { Apo } & \text { Apoenzym, Protein ohne Kofaktor(en) } \\ \text { Arg } & \text { Arginin } \\ \text { Asn } & \text { Asparagin } \\ \text { Asp } & \text { Asparaginsäure } \\ \text { Bd. } & \text { Band } \\ \text { bp } & \text { engl.: basepair (Basenpaar) } \\ \text { bzw. } & \text { beziehungsweise } \\ \text { ca. } & \text { circa } \\ \text { Cys } & \text { Cystein } \\ \text { d. h. } & \text { das heißt }\end{array}$

$\begin{array}{ll}\text { Da } & \text { Dalton } \\ \text { DNA } & \text { engl.: desoxyribonucleic acid (Desoxyribonukleinsäure) } \\ \text { engl. } & \text { englisch } \\ \text { et al. } & \text { et altera } \\ \text { Fa. } & \text { Firma } \\ \text { g } & \text { Gramm } \\ \text { Glu } & \text { Glutaminsäure } \\ \text { h } & \text { engl.: hour (Stunde) } \\ \text { His } & \text { Histidin } \\ \text { Hrsg. } & \text { Herausgeber } \\ \text { Ile } & \text { Isoleucin } \\ \text { J. } & \text { Journal }\end{array}$


$\mathrm{kb}$

1

$\lambda$

LB-Medium

Leu

Lys

$\mu \mathrm{m}$

$\mu \mathrm{mol}$

M

$\mathrm{ml}$

$\mathrm{mm}$

$\min$

obs

OD

p. A.

PCR

PEG

Phe

PMSF

Pro

RT

rpm

$\mathrm{s}$

SDS-PAGE

Ser

s. 0 .

s. u.

Suppl.

Tab.

TCA engl.: kilobasepair (Kilobasenpaare)

Liter

Wellenlänge

Luria-Bertani-Medium

Leucin

Lysin

Mikrometer

Mikromol

Molarität

Milliliter

Millimeter

Minute

beobachtet

Optische Dichte

pro analysi

engl.: polymerase chain reaction (Polymerase-Kettenreaktion)

Polyethylenglykol

Phenylalanin

Phenylmethylsulfonylfluorid

Prolin

Raumtemperatur

engl.: rotations per minute (Umdrehungen pro Minute)

Sekunde(n)

Natriumdodecylsulfat-Polyacrylamidgelelektrophorese

Serin

siehe oben

siehe unten

engl: supplement

Tabelle

Trichloressigsäure 
Tris

Thr

Tyr

u. a.

UV

$\mathrm{U}$

v. a.

Val

z. B.
Tris (hydroxymethyl)-aminomethan

Threonin

Tyrosin

unter anderem

ultraviolett

unit

vor allem

Valin

zum Beispiel 


\subsection{Abbildungsverzeichnis}

ABBILDUNG 1.1: SCHEMA DER OXYLIPIN-BIOSYNTHESE IN BLÜTENPFLANZEN................... 5

ABBILDUNG 1.2: $\quad$ DER JA-BIOSYNTHESEWEG IN PFLANZEN. .................................................. 9

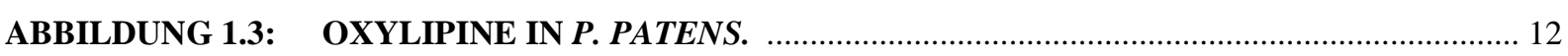

ABBILDUNG 1.4: DIE LOX-REAKTIONEN AM BEISPIEL DER LA. ............................................... 16

ABBILDUNG 1.5: RAUMSTRUKTUR VON ATAOC2 IN FARBBANDDARSTELLUNG (2DIO.PDB).

ABBILDUNG 1.6 HYPOTHETISCHER AOC-REAKTIONSMECHANISMUS. .................................... 23

ABBILDUNG 2.1: $\quad$ SOAKINGSUBSTANZEN FÜR PPAOC1 UND PPAOC2 ......................................... 53

ABBILDUNG 3.1: AUSSCHNITT AUS EINEM ALIGNMENT VERSCHIEDENER LOXEN. N. ........... 60 ABBILDUNG 3.2: ...DIE DREIDIMENSIONALE PROTEINSTRUKTUR DES PPLOX1-MODELLS IM ÜBERBLICK.

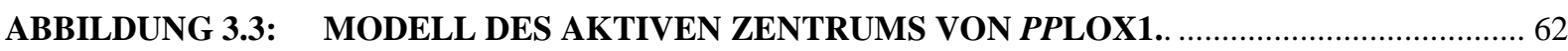
ABBILDUNG 3.4: ..............HPLC-ANALYSE DER UMSETZUNG VON AA DURCH VERSCHIEDENE

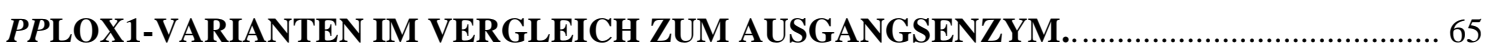
ABBILDUNG 3.5: ............HPLC-ANALYSE DER UMSETZUNG VON EPA DURCH VERSCHIEDENE PPLOX1-VARIANTEN IM VERGLEICH ZUM AUSGANGSENZYM..

ABBILDUNG 3.6: .......... HPLC-ANALYSE DER UMSETZUNG VON GLA DURCH VERSCHIEDENE

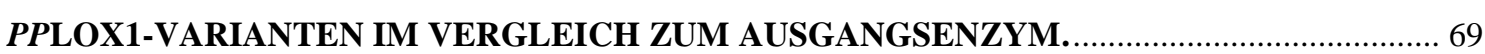

ABBILDUNG 3.7: ELUTIONSPROFILE DER AUFREINIGUNG VON PPAOC1. (A)............................ 72 ABBILDUNG 3.8: ELUTIONSPROFILE DER AUFREINIGUNG VON PPAOC2. (A) ……………......... 73 ABBILDUNG 3.9: SDS-PAGE DER REINIGUNG VON PPAOC1............................................................ 74 ABBILDUNG 3.10: SDS-PAGE DER REINIGUNG VON PPAOC2 .......................................................... 75 ABBILDUNG 3.11: REINIGUNGSSCHRITTE VON KO-EXPRIMIERTEN HIS-PPAOC1- UND GSTPPAOC2. 76 ABBILDUNG 3.12: SDS-PAGE DER KO-EXPRESSION VON PPAOC1 UND PPAOC2 …...................... 77 ABBILDUNG 3.13: SUBSTRATE ZUR CHARAKTERISIERUNG VON PPAOC1 UND PPAOC2....... 79 ABBILDUNG 3.14: REAKTIONSGEMISCHE ENZYMATISCHER UMSETZUNGEN VON 12HYDROPEROXY-FETTSÄUREN DURCH PPAOC1 UND PPAOC2. 80

ABBILDUNG 3.15: MS/MS-SPEKTREN DER ZYKLISCHEN PRODUKTE VON 12HYDROPEROXIDEN..

ABBILDUNG 3.16: REAKTIONSGEMISCHE ENZYMATISCHER UMSETZUNGEN VON 15HYDROPEROXY-FETTSÄUREN.

ABBILDUNG 3.17: MS/MS-SPEKTREN DER ZYKLISCHEN 15-PRODUKTE....................................... 84

ABBILDUNG 3.18: INITIALE KRISTALLISATIONSBEDINGUNGEN VON PPAOC1 ..................... 86

ABBILDUNG 3.19: VERSCHIEDENE PPAOC1-KRISTALLE ............................................................. 88

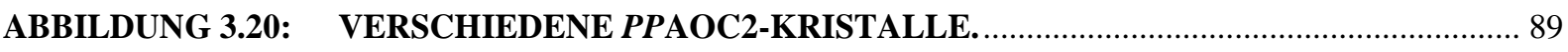

ABBILDUNG 3.21: DIE ASYMMETRISCHE EINHEIT DES PPAOC1-KRISTALLS MIT GEBUNDENEN LIGANDEN 12,13-EOD ${ }^{\Delta 9 Z \Delta 15 Z}$. 
ABBILDUNG 3.22: DIE ASYMMETRISCHE EINHEIT DER PPAOC2-KRISTALLE MIT

GEBUNDENEM LIGANDEN 12,13-EOD ${ }^{\Delta 9 Z \Delta 15 Z}$

ABBILDUNG 3.23: DIE ASYMMETRISCHE EINHEIT DES PPAOC1-KRISTALLS MIT DEN B-

FAKTOREN DER CA-ATOME.

ABBILDUNG 3.24: GRAPHISCHE ÜBERLAGERUNG DER 12 PPAOC1-MONOMERE EINER ASYMMETRISCHEN EINHEIT.

ABBILDUNG 3.25: RAMACHANDRAN-DIAGRAMM FÜR DIE PPAOC1-STRUKTUR MIT GEBUNDENEM LIGAND 12,13-EOD ${ }^{\triangle 9 Z \triangle 15 Z}$

ABBILDUNG 3.26: DIE ASYMMETRISCHE EINHEIT VON PPAOC2 MIT DEN B-FAKTOREN DER

CA-ATOME.

ABBILDUNG 3.27: GRAPHISCHE ÜBERLAGERUNG DER SECHS PPAOC2-MONOMERE EINER ASYMMETRISCHEN EINHEIT.

ABBILDUNG 3.28: RAMACHANDRAN-DIAGRAMM FÜR DIE PPAOC2-STRUKTUR MIT 12,13-

EOD $^{\triangle 9 Z \Delta 15 Z}$

ABBILDUNG 3.29: VERSCHIEDENE ANSICHTEN DES PPAOC1- UND PPAOC2-TRIMERS..... 101

ABBILDUNG 3.30: DAS PPAOC1- UND PPAOC2-MONOMER.

ABBILDUNG 3.31: GRAFISCHE ÜBERLAGERUNG DES PPAOC1- UND PPAOC2-MOLEKÜLS. . 102 ABBILDUNG 3.32: PPAOC1 KETTE B MIT LIGAND 12,13-EOD ${ }^{\triangle 9 Z \triangle 15 Z}$ IN

FARBBANDDARSTELLUNG.

ABBILDUNG 3.33: DARSTELLUNG POLARER KONTAKTE IM AKTIVEN ZENTRUM VON....... 105 ABBILDUNG 3.34: PPAOC1 KETTE A, B, C, G UND H MIT LIGAND 12,13-EOD ${ }^{\triangle 9 Z \Delta 15 Z}$ IM

ÜBERBLICK.

ABBILDUNG 3.35: OBERFLÄCHENDARSTELLUNG EINES PPAOC1-TRIMERS.

ABBILDUNG 3.36: PPAOC2 KETTE C UND E MIT LIGAND 12,13-EOD ${ }^{\triangle 9 Z \triangle 15 Z}$ IN

FARBBANDDARSTELLUNG.

ABBILDUNG 3.37: PPAOC2 KETTE A - F MIT LIGAND 12,13-EOD ${ }^{\triangle 9 Z \triangle 15 Z}$.

ABBILDUNG 3.38: DARSTELLUNG POLARER KONTAKTE IM AKTIVEN ZENTRUM VON PPAOC2 MIT GEBUNDENEM LIGAND 12,13-EOD ${ }^{\triangle 9 Z \Delta 15 Z}$..

ABBILDUNG 3.39: GRAFISCHE ÜBERLAGERUNG VON PPAOC2 KETTE A - F MIT LIGAND 12,13-EOD ${ }^{\triangle 9 Z \Delta 15 Z}$

ABBILDUNG 3.40: GRAPHISCHE ÜBERLAGERUNG VERSCHIEDENER PPAOC2-KETTEN A - F MIT LIGAND 12,13-EOD ${ }^{\triangle 9 \mathrm{Z} \triangle 15 \mathrm{Z}}$

ABBILDUNG 3.41: OBERFLÄCHENDARSTELLUNG EINES PPAOC2-TRIMERS. 117

ABBILDUNG 3.42: VERGLEICH DER PPAOC2-STRUKTUREN MIT UND OHNE LIGAND 12,13EOD $^{9 Z 15 Z}$

ABBILDUNG 3.43: VERGLEICH VERSCHIEDENER AMINOSÄURERESTEN DES AKTIVEN ZENTRUMS VON PPAOC1 UND PPAOC2 MIT GEBUNDENEM LIGANDEN 12,13-EOD ${ }^{\triangle 9 Z \triangle 15 Z}$

ABBILDUNG 3.44: REAKTIONSGEMISCHE ENZYMATISCHER UMSETZUNGEN VON 13SHPOTE DURCH VERSCHIEDENE PPAOC1 UND PPAOC2 VARIANTEN IM VERGLEICH ZU DEN AUSGANGSENZYMEN. 
ABBILDUNG 3.45: WESTERN-BLOT ANALYSE DER AOC-VARIANTEN UND DER

AUSGANGSFORMEN. 122

ABBILDUNG 4.1: $\quad$ AKTIVITÄT VON PPAOS. 128

ABBILDUNG 4.2: MODELL ÜBER DIE FEINKONTROLLE DER GENEXPRESSION DURCH

JASMONATE IN VERWUNDETEN ODER ERKRANKTEN ARABIDOPSIS-BLÄTTERN........ 131

ABBILDUNG 4.3: SEQUENZVERGLEICH VERSCHIEDENER AOCS........................................... 134

ABBILDUNG 4.4: GRAFISCHE ÜBERLAGERUNG ATAOC2 UND PPAOC1................................ 135

ABBILDUNG 4.5: AMINOSÄURERESTE IM AKTIVEN ZENTRUM VON PPAOC1 UND ATAOC2.

ABBILDUNG 4.6: AMINOSÄURERESTE IM AKTIVEN ZENTRUM VON PPAOC2 UND ATAOC2.

141

ABBILDUNG 8.1: AMINOSÄURE-ALIGNMENT VERSCHIEDENER LOXEN.. 164 ABBILDUNG 8.2: DARSTELLUNG POLARER KONTAKTE IM AKTIVEN ZENTRUM VON PPAOC2 MIT GEBUNDENEM LIGAND 12,13-EOD ${ }^{\triangle 9 Z \triangle 15 Z}$ 


\section{DANKSAgung}

Ich danke Prof. Dr. Ivo Feußner für die Betreuung dieser Doktorarbeit, sein Verständnis und die vielen anregenden Diskussionen.

Für die Übernahme des Koreferats danke ich Prof. Dr. Ralf Ficner (Abt. Molekulare Strukturbiologie, Georg-August-Universität, Göttingen). Danke, für die hervorragende Kooperation bezüglich der Kristallisationsexperimente, Datensammlung und -auswertung.

Ich danke Jens Brinkmann, Dr. Achim Dickmanns und v. a. Dr. Piotr Neumann (Abt. Molekulare Strukturbiologie, Georg-August-Universität Göttingen) für die großartige und hilfreiche Betreuung sowie der geduldigen Beantwortung meiner Fragen.

Dr. Cornelia Göbel danke ich für die Mithilfe bei den Lipidanalysen und deren Auswertung. Für die gemeinsame Zeit im Labor und die Betreuung der molekularbiologischen Arbeiten geht ein großer Dank an Dr. Ellen Hornung. Danke für die vielen Tipps und Tricks bei kniffligen Laborangelegenheiten, der großen Hilfsbereitschaft und die schöne Arbeitsatmosphäre.

Theres Riemekasten, Sabine Freitag und Pia Meyer danke ich für ihre großartige technische Assistenz und die Hilfe bei molekularen Arbeiten und bei der Lipidanalytik.

Allen Mitarbeitern der Abt. Biochemie danke ich für die kleinen und großen Hilfen im Laboralltag, den unzähligen amüsanten Mittagspausen, den leckeren Geburtstagsfrühstücken und dem lustigem Drumherum.

Den Mitarbeitern der Labore 1.303 und 1.304 gebührt besonderer Dank für die tolle Atmosphäre, die anregenden und konstruktiven Diskussionen, dem ungezwungen Miteinander, auch nach Laborschluss. Danke dafür an: Alexandra Andreou, Theres Riemekasten, Florian Brodhun, Ellen Hornung, Michael Stumpe, Julia Bode, Jan-Gerrit Carstjens, Elena Liavonchanka, Julia Scholz und Stefan Schneider.

Ich bedanke mich an dieser Stelle bei Dr. A. Mangholz für die ärztliche Betreuung, ihre aufbauenden Worte und offenen Ohren - danke liebe Frau Mangholz!

Ein dickes Dankeschön für die Hilfestellung beim Anfertigen der Doktorarbeit und die zahlreiche konstruktive und wichtige Kritik, geht an Cornelia Göbel, Ellen Hornung, Gert Weber, Imke Lang, Christian Thater, Dr. Alexandra Andreou, Amina Ibrahim, Stephanie Schell, Dr. Danilo Meyer, Stefan Lüdtke, Dr. Ingo Heilmann und natürlich Prof. Ivo Feußner. 
Für die unersetzliche Freundschaft geht mein fast größter Dank an Dajana, Katja, Steffi, Gert, Christian, Imke, Moni, Danilo und Stefan, der dazu ein großartiger Mitbewohner ist. Ohne Euch wäre Vieles schwer gewesen!

In Liebe danke ich meiner Oma Edeltraut Russow und meinen Eltern Hero und Hannelore Sauer, die mir soviel ermöglicht haben. Danke, dass ihr immer zu mir steht und mich in einem schönen zu Hause immer willkommen heißt. Bei euch kann ich immer sein wie ich bin und das bedeutet mir so viel!

Diese Arbeit widme ich in Liebe und Dankbarkeit meinen Eltern! 
Düstere-Eichen-Weg 30

37073 Göttingen

Tel. privat 0551-4886250

e-mail: ksauer@gwdg.de

\title{
LEBENSLAUF
}

\author{
29.01.1979 Geburtsdatum \\ Schwerin Geburtsort \\ ledig Familienstand
}

keine Kinder

\section{Studium}

Doktorandin am Albrecht-von-Haller Institut für

2005-2010

Pflanzenwissenschaften, Abteilung Biochemie der Pflanze

Studium der Biologie an der Georg-August Universität Göttingen

1998-2004

Abschluss: Diplom-Biologin

Diplomarbeit am Albrecht-von-Haller Institut für

10/2003-07/2004

Pflanzenwissenschaften, Abteilung Experimentelle Phykologie und Sammlung von Algenkulturen Göttingen

\section{Schulausbildung}

Schliemann Gymnasium, Schwerin

1991-1995

Friedrich Franz Gymnasium, Parchim

1995-1997

Göttingen, 7.6.2010 